\title{
Genetic Regulation Of The Elicitation Of Glyceollin Biosynthesis In Soybean
}

Md. Asraful Jahan

West Virginia University, mjahan@mix.wvu.edu

Follow this and additional works at: https://researchrepository.wvu.edu/etd

Part of the Agricultural Science Commons, Genetics Commons, Molecular Genetics Commons, Plant Breeding and Genetics Commons, and the Plant Pathology Commons

\section{Recommended Citation}

Jahan, Md. Asraful, "Genetic Regulation Of The Elicitation Of Glyceollin Biosynthesis In Soybean" (2019). Graduate Theses, Dissertations, and Problem Reports. 3782.

https://researchrepository.wvu.edu/etd/3782

This Dissertation is protected by copyright and/or related rights. It has been brought to you by the The Research Repository @ WVU with permission from the rights-holder(s). You are free to use this Dissertation in any way that is permitted by the copyright and related rights legislation that applies to your use. For other uses you must obtain permission from the rights-holder(s) directly, unless additional rights are indicated by a Creative Commons license in the record and/ or on the work itself. This Dissertation has been accepted for inclusion in WVU Graduate Theses, Dissertations, and Problem Reports collection by an authorized administrator of The Research Repository @ WVU.

For more information, please contact researchrepository@mail.wvu.edu. 


\title{
GENETIC REGULATION OF THE ELICITATION OF GLYCEOLLIN BIOSYNTHESIS IN SOYBEAN
}

\author{
Md. Asraful Jahan
}

Dissertation submitted to the

Davis College of Agriculture, Natural Resources and Design at West Virginia University in partial fulfillment of requirements for the degree of

\section{Doctor of Philosophy \\ in \\ Genetics and Developmental Biology}

\author{
Nikola Kovinich, Ph.D., Committee Chair \\ Daniel G. Panaccione, Ph.D. \\ Vagner A. Benedito, Ph.D. \\ Stephen P. DiFazio, Ph.D. \\ Jonathan R. Cumming, Ph.D.
}

Division of Plant and Soil Sciences

Morgantown, WV

2019

Key Words: Glyceollins; Isoflavonoids; NAC; MYB, Phytoalexin; Transcription factor, Bioproduction; P. sojae; Resistance; Soybean [Glycine max (L.) Merr.]

Copyright 2019 Md. Asraful Jahan 


\section{ABSTRACT \\ Genetic Regulation of the Elicitation of Glyceollin Biosynthesis in Soybean}

Md. Asraful Jahan

Glyceollin phytoalexins are the pathogen-elicited defense metabolites that belong to the isoflavonoid family of molecules of soybean (Glycine max L. Merr). Phytophthora root and stem rot of soybean caused by Phytophthora sojae is a destructive disease throughout the soybeangrowing regions worldwide causing devastating economic damages (globally \$1-2 billion and over \$250 million in the USA) every year. Engineering soybean plants that produce higher levels of glyceollins could confer resistance against this pathogen. Glyceollins also show anticancer and neuroprotective activities in mammals, therefore they are important for agriculture and medical research. Firstly, we were interested in understanding how biotic and chemical elicitors regulate glyceollin biosynthesis differently. We found that combining the biotic elicitor WGE (wall glucan elicitor) extracted for $P$. sojae and the chemical elicitor silver nitrate had an additive effect on the elicitation of glyceollins I. They elicited glyceollins by separate biosynthetic mechanisms. We treated soybean seedlings with a panel of abiotic stress conditions and found that acidic medium elicited the highest amount of glyceollins in root tissues of $1700 \mu \mathrm{g} \mathrm{gt}^{-1}$ (gram tissue, Fresh Weight). Then we focused on the identification of transcription factors (TFs) that regulate the biosynthesis of glyceollins in response to abiotic and biotic stress. Based on a comparative transcriptomics approach using RNA-seq, we chose to functionally characterize the NAC (NAM/ATAF1/CUC2) family TF GmNAC42-1, a homolog of the camalexin regulator $A N A C 042$ from Arabidopsis and an R2R3-MYB (myeloblastosis)-type TF GmMYB29A2, the homolog of the stilbene regulator $V v M Y B 14$ from grapevine. Overexpressing and RNAi silencing of GmNAC42-1 and GmMYB29A2 in WGE-elicited hairy roots resulted in significantly increased and decreased accumulation of glyceollin metabolites and biosynthesis gene transcripts such as glycinol 4-dimethylallyl transferase (G4DT) and isoflavone synthase2 (IFS2). The GmNAC42-1 and GmMYB29A2 proteins directly bound the promoters of glyceollin biosynthesis genes IFS2 and G4DT in the yeast one-hybrid (Y1H) system and localized to the nucleus when expressed with an N-terminal green fluorescent protein (GFP) tag. EMSA (Electrophoretic Mobility Shift Assay) confirmed that MYB29A2 protein binds glyceollin gene promoters. Overall, our findings indicate that $G m N A C 42-1$ and GmMYB29A2 are essential components of a glyceollin gene regulatory network (GRN) and could be used for the large-scale, economic bioproduction of glyceollins for therapeutic use and to enhance resistance against $P$. sojae. 


\title{
DEDICATION
}

\author{
Dedicated \\ to \\ My \\ Absolutely \\ Respectable \\ Mother and Father
}




\section{ACKNOWLEDGEMENT}

All praises belong to the Almighty ALLAH, the creator and sustainer of this world, who enabled the author to complete this task successfully.

I express my most humble indebtedness, profound sense of gratitude and sincere devotion to my teacher and Advisor Dr. Nikola Kovinich, Assistant Professor of Genetics of the Division of Plant and Soil Sciences, West Virginia University for his continuous encouragement, indefatigable patience and proper guidance and constant supervision throughout the course of the present study and preparation of this dissertation. I am indebted to Dr. Vagner Benedito, Division of Plant and Soil Sciences, West Virginia University for his encouragement and help. I would like to express my indebtedness to Dan Panaccione, Davis-Michael Professor of Plant and Soil Sciences for his special help and inspiration. I am also grateful to Dr. Steve DiFazio, Ph.D. and Dr. Jonathan R. Cumming, Ph.D, Department of Biology for their valuable suggestion and help sought for time to time during the tenure of the work.

All other faculty and staff of WVU specially Sven Verlinden, Dr. Mannon Gallegly, Sue Myers, Gail Sikorsky deserve special thanks for their benevolent inspiration and encouragement. Heartiest thanks to all of my friends whose inspiration helped him to complete this research work. I also extend heartiest thanks to Kelli Farrell for helping with chemical elicitors experiments, Brianna Harris for yeast one-hybrid experiments, Mathew Lowery for qRT-PCR, and Katie Coburn who provided all kinds of helps during my research. I am also grateful to Harrison Cline, Kristen Marrow and Maxwell Adams for helping with correcting grammar. Finally, I express my profound gratitude and indebtedness to West Virginia University, for providing me all the opportunities to complete my research work successfully.

The author 


\section{LIST OF ARTICLES}

Farrell KC†, Jahan MA†, Kovinich N (2017) Distinct Mechanisms of Biotic and Chemical Elicitors enable Additive Elicitation of the Anticancer Phytoalexin Glyceollin I. Molecules 22: 1261-1273 †These Authors contributed equally.

Jahan MA, Harris B, Lowery M, Coburn K, Infante AM, Percifield RJ, Ammer AG, Kovinich N (2019) The NAC family transcription factor GmNAC42-1 regulates biosynthesis of the anticancer and neuroprotective glyceollins in soybean. BMC genomics 20: 149

Jahan MA and Kovinich N (2019) Acidity stress for the systemic elicitation of glyceollin phytoalexins in soybean plants. Plant Signaling and Behavior.

https://doi.org/10.1080/15592324.2019.1604018

Jahan MA, Harris B, Lowery M, Infante AM, Percifield RJ, Kovinich N. Glyceollin transcription factor GmMYB29A2 is a regulator of soybean resistance to Phytophthora sojae.

(Under preparation) 


\section{CONTENTS}

\begin{tabular}{|c|c|c|}
\hline \multirow[t]{10}{*}{ CHAPTER } & DETAILS & Page No. \\
\hline & Abstract & ii \\
\hline & Dedication & iii \\
\hline & Acknowledgement & iv \\
\hline & List of Articles & $\mathrm{v}$ \\
\hline & Contents & vi \\
\hline & List of Figures & $\mathrm{x}$ \\
\hline & List of Tables & xii \\
\hline & List of Supplemental Figures & xiii \\
\hline & List of Supplemental Tables & xiv \\
\hline \multirow[t]{7}{*}{ CHAPTER 1} & INTRODUCTION & $1-18$ \\
\hline & Biosynthesis of Glyceollins & 4 \\
\hline & $\begin{array}{l}\text { Different elicitation pathways for chemical and biotic } \\
\text { elicitors }\end{array}$ & 6 \\
\hline & $\begin{array}{l}\text { Regulation of the Elicitation of Glyceollin biosynthesis } \\
\text { in Response to Abiotic Stresses }\end{array}$ & 7 \\
\hline & $\begin{array}{l}\text { Transcription Factors Regulate Elicitation of glyceollin } \\
\text { biosynthesis in Response to Biotic Stresses }\end{array}$ & 7 \\
\hline & Objectives & 10 \\
\hline & References & 11 \\
\hline \multirow[t]{7}{*}{ CHAPTER 2} & $\begin{array}{l}\text { Distinct Mechanisms of Biotic and Chemical Elicitors } \\
\text { Enable Additive Elicitation of the Anticancer } \\
\text { Phytoalexin Glyceollin I }\end{array}$ & $19-48$ \\
\hline & ABSTRACT & 20 \\
\hline & 1. INTRODUCTION & 21 \\
\hline & 2. RESULTS AND DISCUSSION & 22 \\
\hline & $\begin{array}{l}\text { 2.1. Imbibing Soybean Seeds Are the Most Abundant } \\
\text { Source of Glyceollin I }\end{array}$ & 22 \\
\hline & $\begin{array}{l}\text { 2.2. Wall Glucan Elicitors from P. sojae and Pythium } \\
\text { Elicit More Glyceollin I Than Rhizopus, Aspergillus, } \\
\text { and Fusarium Microspores at Standard Treatment } \\
\text { Concentrations }\end{array}$ & 23 \\
\hline & $\begin{array}{l}\text { 2.3. } \mathrm{AgNO}_{3} \text { Elicits More Glyceollin I Than } \mathrm{CuCl}_{2}, \mathrm{BTD} \text {, } \\
\mathrm{AVG} \text { and SA at Equivalent Treatment } \\
\text { Concentrations }\end{array}$ & 24 \\
\hline
\end{tabular}


2.4. $\mathrm{AgNO}_{3}$ and $\mathrm{P}$. sojae WGE Elicit Glyceollin I with Different Dynamics

2.5. P. sojae WGE and $\mathrm{AgNO}_{3}$ Elicit the Accumulation of Glyceollin I Mainly by Distinct Mechanisms

2.6. P. sojae WGE and not $\mathrm{AgNO}_{3}$ Induces Major Accumulation of Glyceollin Gene Transcripts

2.7. AgNO3 Inhibits the Degradation of Glyceollin I and Enhances the Specific Hydrolysis of 6"-OMalonyldaidzin

2.8. DISCUSSION

3. EXPERIMENTAL SECTION

3.1. Chemicals 28

3.2. Plant Growth and Elicitation 29

3.3. Isoflavonoid Analyses

3.4. UPLC-PDA-MS ${ }^{\mathrm{n}}$ 30

3.5. qRT-PCR 30

3.6. Degradation of Isoflavonoids 31

4. CONCLUSIONS

REFERENCES

\begin{tabular}{|c|c|c|}
\hline CHAPTER 3 & $\begin{array}{l}\text { The NAC Family Transcription Factor } G m N A C 42-1 \\
\text { Regulates Biosynthesis of the Anticancer and } \\
\text { Neuroprotective Glyceollins in Soybean }\end{array}$ & 49-90 \\
\hline & ABSTRACT & 50 \\
\hline & BACKGROUND & 51 \\
\hline & MATERIALS AND METHODS & 54 \\
\hline & Chemicals & 54 \\
\hline & Plant materials and growth conditions & 54 \\
\hline & Stress treatments & 54 \\
\hline & Isoflavonoid analysis & 55 \\
\hline & RNA extraction and qRT-PCR & 56 \\
\hline & RNA-seq & 56 \\
\hline & Cloning & 57 \\
\hline
\end{tabular}


Soybean hairy roots

Subcellular localization

Yeast one-hybrid

58

RESULTS

Novel abiotic stresses that regulate glyceollin biosynthesis

59

Acidity stress enhances and dehydration suppresses glyceollin biosynthesis

Acidity and dehydration stresses oppositely regulate all known glyceollin biosynthesis genes

Comparative transcriptomics identifies candidate transcription factors for the regulation of glyceollin biosynthesis

NAC42-type TFs are upregulated with glyceollins by abiotic and biotic elicitors

GmNAC42-1 regulates glyceollin biosynthesis in response to Phytophthora sojae WGE

GmNAC42-1 localizes to the nucleus and directly binds the promoters of glyceollin biosynthesis genes

DISCUSSION

GmNAC42-1 is required for full elicitation of glyceollin biosynthesis

GmNAC42-1 and a conserved phytoalexin elicitation pathway

Co-option of phytoalexin biosynthesis by NAC42

67

CONCLUSIONS

REFERENCES

\section{CHAPTER 4 Acidity stress for the systemic elicitation of glyceollin} phytoalexins in soybean plants 


\begin{tabular}{|c|c|c|}
\hline CHAPTER 5 & $\begin{array}{l}\text { Glyceollin transcription factor } G m M Y B 29 A 2 \text { is a } \\
\text { regulator of soybean resistance to Phytophthora sojae }\end{array}$ & 100-138 \\
\hline & ABSTRACT & 101 \\
\hline & INTRODUCTION & 102 \\
\hline & RESULTS & 104 \\
\hline & $\begin{array}{l}\text { Dynamics of glyceollin elicitation by Phytophthora sojae } \\
\text { WGE in soybean hairy roots and seeds }\end{array}$ & 104 \\
\hline & $\begin{array}{l}\text { Comparative transcriptomics identifies glyceollin TF } \\
\text { gene candidates }\end{array}$ & 105 \\
\hline & $\begin{array}{l}\text { Homologs GmMYB29A1 and GmMYB29A2 are } \\
\text { candidate regulators of WGE-elicited glyceollin } \\
\text { biosynthesis in soybean }\end{array}$ & 105 \\
\hline & $\begin{array}{l}\text { GmMYB29A2 is essential for the full elicitation of } \\
\text { glyceollin I }\end{array}$ & 107 \\
\hline & $\begin{array}{l}\text { GmMYB29A2 directly regulates the glyceollin } \\
\text { biosynthesis genes IFS2 and G4DT }\end{array}$ & 108 \\
\hline & GmMYB29A2 mediates resistance to race $1 P$. sojae & 108 \\
\hline & DISCUSSION & 109 \\
\hline & $\begin{array}{l}\text { GmMYB29A2 is essential for the elicitation of glyceollin } \\
\text { biosynthesis }\end{array}$ & 109 \\
\hline & $\begin{array}{l}\text { The role of GmMYB29A2 in regulating different } \\
\text { biosynthetic routes to glyceollin I }\end{array}$ & 110 \\
\hline & METHODS & 113 \\
\hline & Chemicals & 113 \\
\hline & Maintenance of Phytophthora sojae & 114 \\
\hline & Plant Materials and Elicitation & 114 \\
\hline & Isoflavonoid Analyses & 115 \\
\hline & RNA Extraction and qRT-PCR Analysis & 115 \\
\hline & RNA Sequencing and Analysis & 115 \\
\hline & Cloning & 116 \\
\hline & Hairy Root Transformation & 117 \\
\hline & Yeast One-hybrid & 118 \\
\hline & Electrophoretic Mobility Shift Assay & 118 \\
\hline & P. sojae Infection of Hairy Roots. & 119 \\
\hline & REFERENCES & 121 \\
\hline \multirow[t]{2}{*}{ CHAPTER 6} & DISCUSSION & 139 \\
\hline & REFERENCES & 141 \\
\hline
\end{tabular}




\section{LIST OF FIGURES}

\begin{tabular}{|c|c|c|}
\hline $\begin{array}{l}\text { Figure } \\
\text { No. }\end{array}$ & FIGURE TITLE & $\begin{array}{l}\text { PAGE } \\
\text { NO. }\end{array}$ \\
\hline & CHAPTER 1 & \\
\hline 1 & $\begin{array}{l}\text { The molecular convergence in abiotic and biotic stress } \\
\text { signaling pathways }\end{array}$ & 2 \\
\hline 2 & Biosynthesis of glyceollins in soybeans. & 4 \\
\hline 3 & $\begin{array}{l}\text { Proposed de novo and conversion model of glyceollin } \\
\text { biosynthesis. }\end{array}$ & 5 \\
\hline
\end{tabular}

\section{CHAPTER 2}

1 Glyceollin I biosynthetic pathway.

2 A Amounts of glyceollin I from soybean organs treated with (WGE) B UPLC-PDA chromatogram of isoflavonoids from imbibing seeds.

3 A Amounts of glyceollin I from soybean seeds treated with biotic elicitors for. B Treatment of seeds with chemical elicitors

Elicitation with $\mathrm{AgNO}_{3}$ and WGE separately and in combination.

5 Relative gene expression levels after elicitor treatment with elicitor measured by qRT-PCR

6 Degradation of externally supplied glyceollin I

42

\section{CHAPTER 3}

1 Soybean isoflavonoid biosynthetic pathway.

2 Phytoalexin and isoflavonoid content in response to abiotic stresses.

3 Time course of phytoalexin and isoflavonoid biosynthesis during acidity and dehydration stresses.

4 Comparative transcriptomics of seedlings treated with acidity stress or dehydration.

5 GmNAC42s expressions are induced with glyceollins in response to abiotic and biotic elicitors. 
6 Overexpression and silencing of GmNAC42-1 in soybean hairy roots.

Nuclear localization and DNA binding activities of

GmNAC42-1.

\section{CHAPTER 4}

1 Elicitation of glyceollins in soybean roots by $\mathrm{pH} 3.0$ medium

\section{CHAPTER 5}

1 Pathogen inducible and constitutive isoflavonoid biosynthesis pathways.

2 Glyceollin and daidzein-glycoside accumulations in W82 hairy roots and $\mathrm{H} 63$ seeds following treatment with $P$. sojae WGE.

3 Ontological characterization of TF genes upregulated by WGE with glyceollins.

$4 \quad$ Expressions and phylogeny of GmMYB29 genes.

5 Functional characterization of GmMYB29A2.

6 GmMYB29A2 binds glyceollin biosynthesis gene promoters.

7 Effects of RNAi silencing or overexpressing GmMYB29A2 on disease progression of race $1 P$. sojae in transgenic hairy roots. 


\section{LIST OF TABLES}

\begin{tabular}{|c|c|c|}
\hline $\begin{array}{l}\text { TABLE } \\
\text { NO. }\end{array}$ & TITLE & $\begin{array}{l}\text { PAGE } \\
\text { NO. }\end{array}$ \\
\hline & CHAPTER 3 & \\
\hline 1 & $\begin{array}{l}\text { Glyceollin biosynthesis genes upregulated by } \mathrm{pH} 3.0 \text { medium and } \\
\text { downregulated by dehydration. }\end{array}$ & 87 \\
\hline \multirow[t]{2}{*}{2} & $\begin{array}{l}\text { Select SAR genes upregulated by } \mathrm{pH} \quad 3.0 \text { medium and } \\
\text { downregulated by dehydration. }\end{array}$ & 88 \\
\hline & CHAPTER 5 & \\
\hline 1 & $\begin{array}{l}\text { Glyceollin biosynthesis genes upregulated by WGE in H63 seeds } \\
\text { and W82 hairy roots }\end{array}$ & 135 \\
\hline 2 & $\begin{array}{l}\text { The most highly upregulated TF genes by } P \text {. sojae WGE in } \mathrm{H} 63 \\
\text { germinating seeds and in W82 hairy roots }\end{array}$ & 136 \\
\hline
\end{tabular}




\section{LIST OF SUPPEMENTAL FIGURES}

\begin{tabular}{|ccc|}
$\begin{array}{c}\text { Figure } \\
\text { No. }\end{array}$ & \multicolumn{1}{c}{ SUPPLEMENTAL FIGURE TITLE } & PAGE \\
& CHAPTER 2 & NO. \\
\hline 1 & Supplementary Figure S1 & 43 \\
\hline 2 & Supplementary Figure S2 & 44 \\
\hline 3 & Supplementary Figure S3 & 45 \\
\hline & Supplementary Figure S4 & 46 \\
\hline 2 & CHAPTER 3 & 89 \\
\hline
\end{tabular}




\section{LIST OF SUPPEMENTAL TABLES}

\begin{tabular}{|c|c|c|}
\hline $\begin{array}{l}\text { Figure } \\
\text { No. }\end{array}$ & SUPPLEMENTAL TABLE TITLE & $\begin{array}{c}\text { PAGE } \\
\text { NO. }\end{array}$ \\
\hline \multicolumn{3}{|c|}{ CHAPTER 2} \\
\hline 1 & Supplementary Table S1 & 47 \\
\hline 2 & Supplementary Table S2 & 48 \\
\hline & Additional file 1: Table S1. & 90 \\
\hline \multicolumn{3}{|c|}{ CHAPTER 5} \\
\hline & Supplementary Table S4 & 48 \\
\hline 3 & Supplementary Table S5 & \\
\hline
\end{tabular}


LITERATURE REVIEW 


\section{Chapter One}

\section{Introduction}

Phytoalexins are low molecular mass secondary metabolites that have toxic antimicrobial and often antioxidative activities, that are biosynthesized de novo by plants at the site of infection following attack by pathogens (VanEtten et al., 1994, Ahuja et al., 2012). They are highly diverse among plant species. For example, these include the pterocarpan-type isoflavonoids the glyceollins in soybean, pisatin in garden pea, phaseolin in green bean, the phenylpropanoid compound resveratrol in grapevine, phenolics gossypol in cotton, terpenoids momilactones and phytocassanes in rice, 3-deoxyphytodienoic acids in maize, steroid glycoalkaloids in potato and the indole alkaloid camalexins in Arabidopsis (Cruickshank et al., 1960, Rathmell et al., 1971, Holl et al., 2013, Ginzberg et al., 2012, Ogawa et al., 2017, Ibraheem et al., 2015, Xu et al., 2004, Yamamura et al., 2015, Zheng et al., 2006). Phytoalexins are defense molecules that are biosynthesized in plant tissues in response to various pathogens like P. sojae, Plasmopara Viticola, Aspergillus sp. Fusarium sp., and specific inorganic chemical elicitors like the heavy metal AgNO3 and environmental stresses, like ultra violet (UV) irradiation.

Plants have evolved complex mechanisms to perceive external signals in order to survive under abiotic and biotic stress conditions. Transcription factors (TFs) and kinases can have common roles in both abiotic and biotic signal pathways (Fujita et al., 2006). TFs can be induced by reactive oxygen species (ROS) followed by biotic and abiotic stresses (Zheng et al., 2006, Saga et al., 2012). Recent studies also suggested that ROS signaling pathways and the phytohormone signaling pathways regulated by abscisic acid (ABA), salicylic acid (SA), jasmonic acid (JA) and ethylene (ET), can stimulate phytoalexin biosynthesis in response to abiotic and biotic stresses (Bostock et al., 2005; Lorenzoet al., 2005; Mauch-Maniet al., 2005). ROS signaling pathway is required for phytoalexin elicitation in response to abiotic and biotic stress conditions (Fujita et al., 2006). In response to abiotic and biotic stresses, plants express some common genes. The shared mechanisms in response to both individual and combined abiotic and biotic stresses include the production and detoxification of ROS, phytohormone signaling, calcium signaling and mitogen-activated protein kinase (MAPK) signaling pathway (Xiong et al., 2003; Atkinson et al., 2012; Suzuki et al., 2012, 2014; Rejeb et al., 2014). For instances, pathogens and heavy metal $\left(\mathrm{CuSO}_{4}\right)$ treatments trigger the expression of a significant number of overlapping genes and ROS signaling are common for both (Narusaka et al., 2004). 


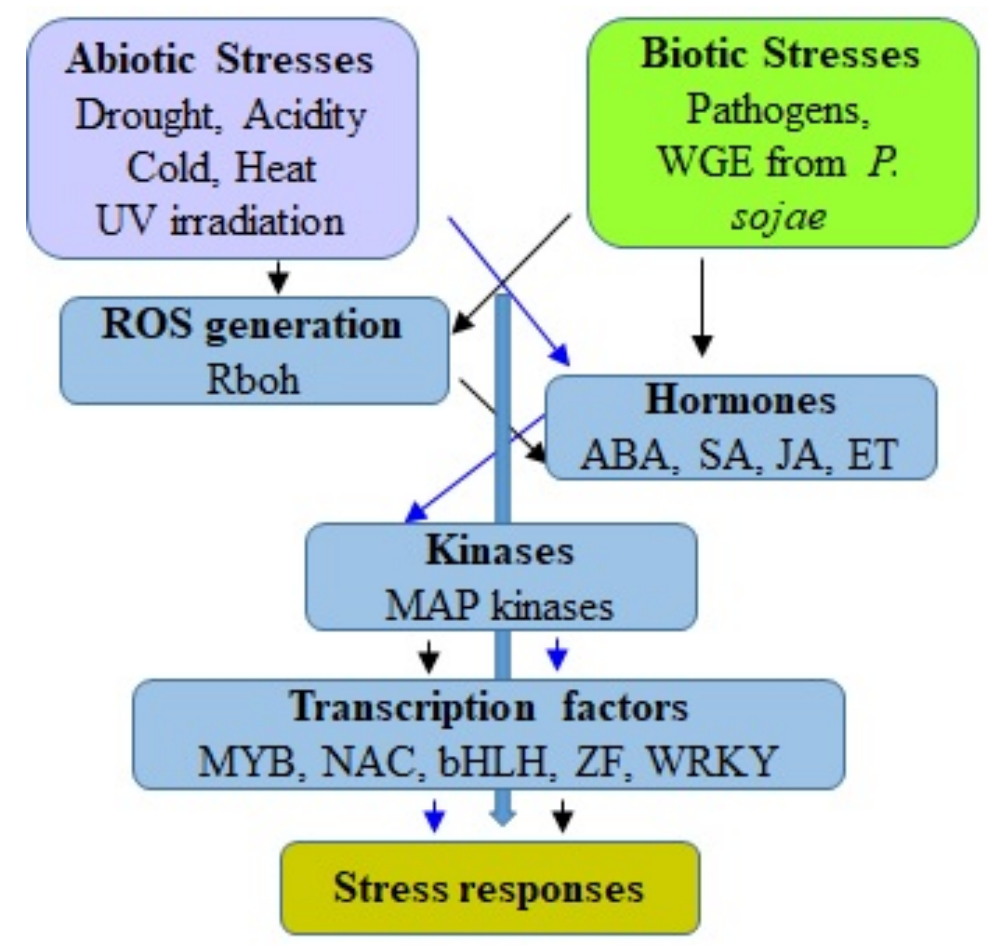

Figure 1. The molecular convergence in abiotic and biotic stress signaling pathways (adapted from Fujita et al., 2006).

Effectors are foreign molecules that can be recognized by specialized receptors located on plasma membrane and that stimulate chemical defense responses in plants. They are secreted from pathogens, such as PsAvh262 from P. sojae, AvrPto, AvrRpt2, and AvrRpm1 from bacterial pathogen Pseudomonas syringae and inhibit defense responses in plants elicited by PAMP (pathogen-associated molecular pattern) recognition (Jing et al., 2016, Hauck et al., 2003, Kim et al., 2005). $\beta$-glucans are PAMP elicitors that induce phytoalexins in plants (Ebel, 1986). $\beta$-glucans from oomycetes are the recognized by PAMP recognition receptors (PRRs) (Sharp et al., 1984).

Glyceollin are the major phytoalexins of soybean that confer resistance against pathogens. There are six different glyceollin isomers (glyceollin I-VI) and glyceofuran (Simons et al., 2011) but glyceollin I, II and III are the predominant and best characterized. Soybean is found to be the major source of the glyceollins in Leguminaceae family, however a few other legumes belonging to the Teramnus species are also reported to produce glyceollins (Keen et al., 1989). Glyceollins accumulate in soybeans in response to various pathogens, like $P$. sojae, or wall glucan elicitor (WGE), environmental factors such as wounding, freezing and UV radiation and 
inorganic chemical elicitors like, copper chloride, silver nitrate, mercuric chloride (Darvill and Albersheim 1984, Yoshikawa 1978, Reilly et al., 1980, Banks \& Dewick, 1983; Tilghman et al., 2010). However, the molecular mechanisms by which these diverse elicitors induce glyceollin accumulation in soybean are still not unknown. How the molecular pathways may differ for eliciting glyceollins by pathogens, chemical elicitors, and abiotic stresses. How the abiotic stresses affect the induction of glyceollins in soybean is still unknown.

$P$. sojae is a major soil-borne pathogen of soybean which causes damping-off in seedlings and roots and stem rot in mature plants. Economically it causes a devastating yield loss of \$1-2 billion globally each year and reached over \$250 million in USA in 2005 (Taylor 2007, Wrather et al., 2006). Downregulation of isoflavone biosynthesis genes in soybeans reduced the elicitation of glyceollins following $P$. sojae inoculation and the rapid accumulation of glyceollins during infection confers innate defense responses against $P$. sojae and Macrophomina phaseolina (Lygin et al., 2013). Glyceollins can serve as potential pharmaceuticals, natural antioxidants and nutraceuticals for human health. They have impressive antimicrobial, antinematode, anticancer, antiestrogenic, antiproliferative, and antitumor and neuroprotective activities (Kim et al., 2012, Bamji et al., 2017, Nwachukwa et al., 2013, Seo et al., 2018). Thus, enhancing glyceollin production in soybean could benefit both agriculture as well as pharmaceutical industries.

In this research thesis, overall, we are trying to understand the genetic regulation of the elicitation of glyceollin biosynthesis in soybeans. However, our first specific goal is to understand how abiotic stresses may differ from biotic stresses in regulating the biosynthesis of phytoalexins. The second goal is to identify the TFs that are involved in regulating the biosynthesis of glyceollins. The final objective is to identify the TFs that positively regulate glyceollin biosynthesis. Increased levels of glyceollins could enhance soybean's defense against phytophthora root and stem rot that negatively impacts soybean yields. 


\section{Biosynthesis of Glyceollins}

The glyceollin biosynthesis pathway includes the first three enzymatic steps of the general phenylpropanoid pathway which is catalyzed by three enzymes, namely phenylalanine ammonia lyase $(P A L)$, cinnamate 4-hydroxylase $(C 4 H)$, and 4-coumarate coenzyme A ligase (4CL) (Vogt 2010). The product p-coumaroyl-CoA is condensed with three molecules of malonyl-CoA to form isoliquiritigenin chalcone by a legume-specific enzyme chalcone reductase $(C H R)$. This reaction is recognized as the first step in isoflavonoid synthesis and branching away from flavonoid formation. Isoliquiritigenin chalcone gets converted into liquiritigenin by chalcone isomerase $(C H I)$. The key enzyme isoflavone synthase (IFSI/2) catalyzed the first committed step in isoflavonoid biosynthesis that converts liquiritigenin to daidzein. Other important enzymes for glyceollin biosynthesis are the isoflavone $2^{\prime}$ hydroxylase $\left(I 2^{\prime} H\right)$ and glycinol 4dimethylallyl transferase (G4DT) that catalyze the first committed steps to all glyceollins and glyceollin I, respectively.

\section{Biosynthesis of Glyceollins}

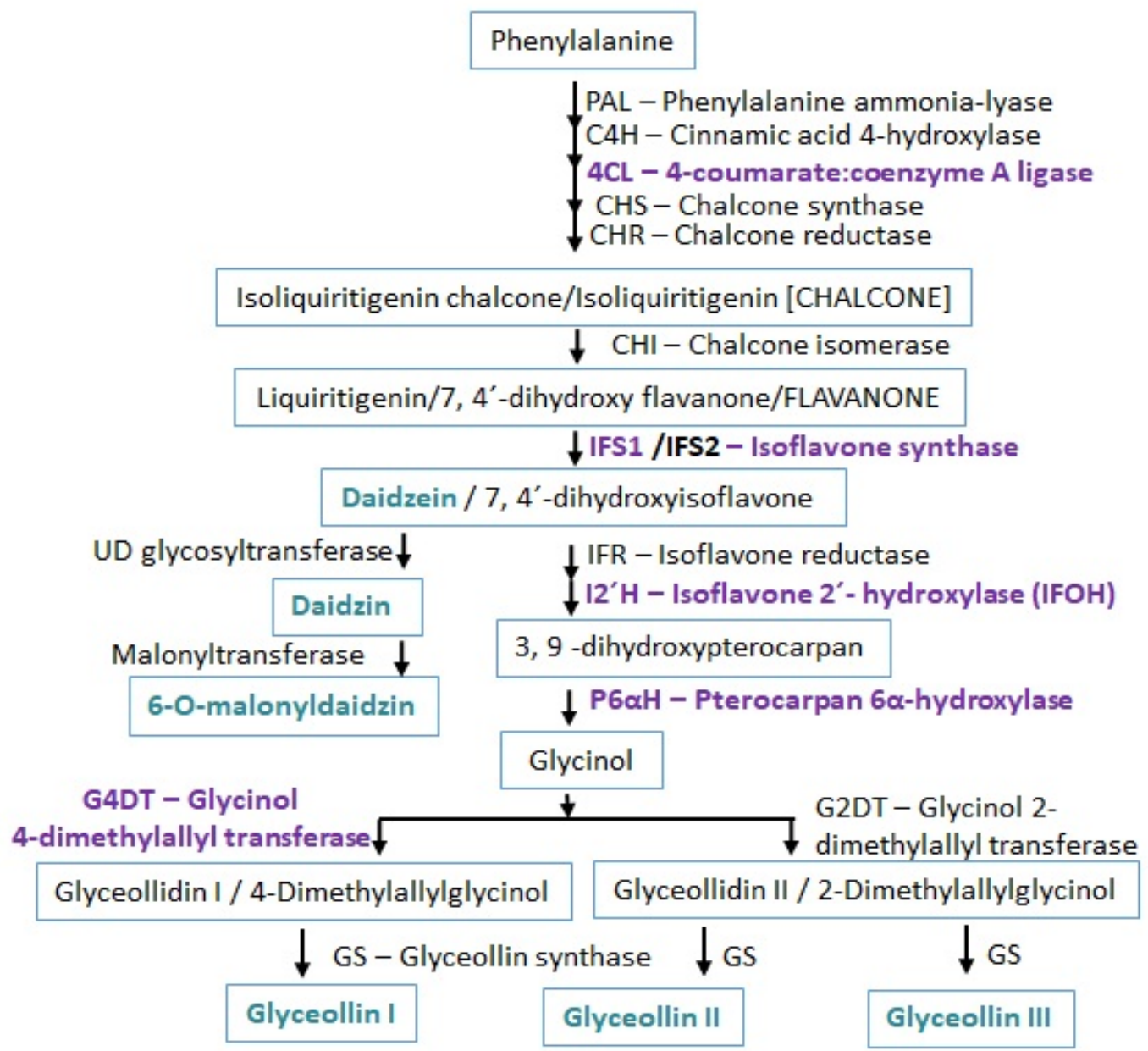

Figure 2: Biosynthesis of glyceollins in soybeans. Purple colored genes are found to be coinduced during induction of glyceollin biosynthesis 
We proposed that glyceollins can be biosynthesized through two biosynthetic pathways, through the general phenylpropanoid pathway called the 'de novo' biosynthetic pathway and the 'conversion pathway' where the glyceollins can be synthesized from the intermediate conjugates. In the de novo biosynthesis pathway, glyceollin biosynthesis begins with the deamination of phenyalanine by PAL. Genes for the general phenylpropanoid enzymes 4coumarate:coenzyme A ligase (4CL), isoflavonoid biosynthesis specific enzyme IFS1, G4DT, pterocarpan $6 \alpha$-hydroxylase $(P 6 \alpha H)$, and $I 2^{\prime} H$ were found to be co-induced with glyceollin metabolite accumulations (Akashi et. al., 2009, et. al., Schopfera et al., 1998, Akashi et. al., 1998, Jung et al., 2000 and Oliver Yu et. al., 2003).

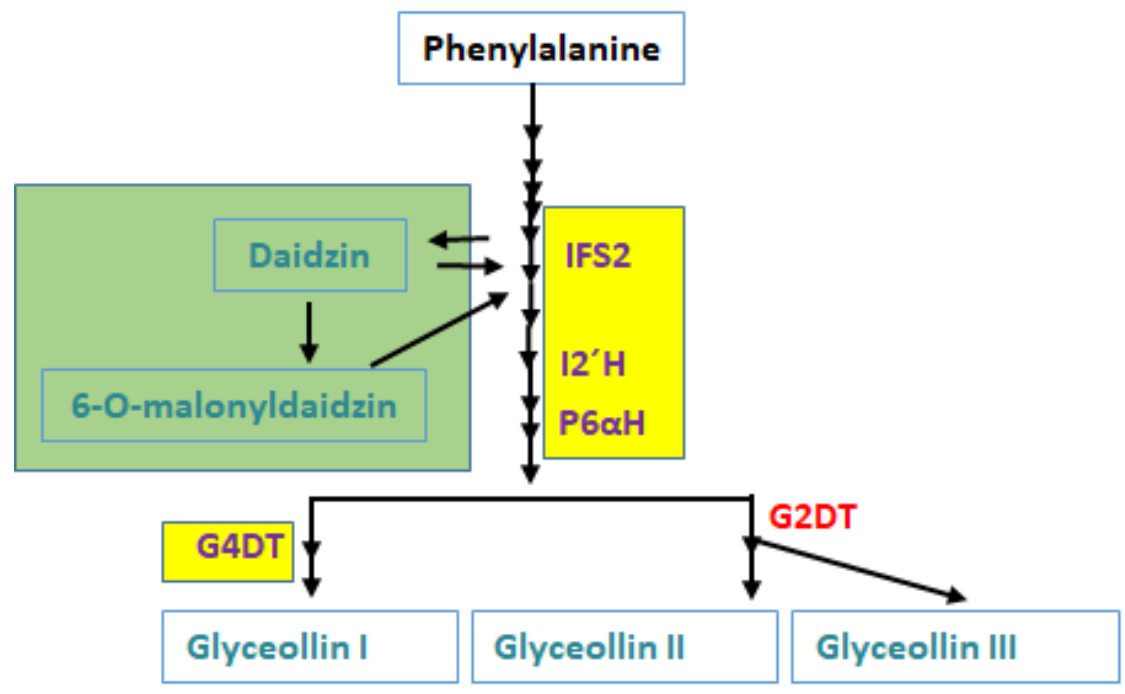

Figure 3. Proposed de novo and conversion pathways of glyceollin biosynthesis. In the de novo Model, yellow color shaded genes are found to be co-induced during elicitation of glyceollin biosynthesis. In conversion mechanism, TFs may induce glycosidase genes. Green color shade indicates glycosidases hydrolyzed the glucosyl conjugates daidzin and 6-O-malonyldaidzin and convert them to glyceollins.

According the conversion pathway, glucosyl conjugate daidzin and 6-O-malonyldaidzin can be converted to glyceollins by the enzymatic action of glycosidases. Glycosidases catalyze the hydrolysis of glycosidic bonds in the glucosyl conjugates. Daidzein is a key intermediate of glyceollin biosynthesis. The preexisting conjugates of daidzein (daidzin and 6-Omalonyldaidzin) are rapidly hydrolyzed in cotyledon tissues infected with $P$. sojae and a large quantity of free daidzein were found to liberated from those conjugates by the conversion pathway (Graham et al., 1990). 


\section{Different Elicitation Pathways for Chemical and Biotic Elicitors?}

Soybean has acquired effective defense systems over the course of evolution that secure its survival against a wide range of pathogens. The phytoalexins glyceollins provide a major defense against some devastating pathogens in soybeans. However, the regulation of elicitation of glyceollins in response to biotic and chemical stress is remain unknown. Phytoalexins in many plant species have been shown to be elicited by pathogen infection or by specific abiotic stresses. The biosynthesis of the phytoalexin camalexin is elicited by a variety of microorganisms, however, some abiotic elicitors like amino acid starvation, silver nitrate $\left(\mathrm{AgNO}_{3}\right)$ and $\mathrm{UV}$ are also found to strongly induce the camalexin biosynthesis in Arabidopsis (Glawischnig et al., 2004; Muller et al., 2015). Glyceollins are induced in soybean tissues in response to a wide range of inorganic chemicals, pathogens and environmental stimuli. These include ultraviolet light (Bridge and Klarman 1973), copper chloride, mercuric chloride and silver nitrate (Yoshikawa 1978), and P. sojae (Darvill and Albersheim 1984). Equal amounts of glyceollin I and III were found in soybean cotyledons treated with $\mathrm{CuCl}_{2}$ (Lyne et al., 1976). However, the biotic elicitors like, cell wall glucans (WGE) from P. sojae (Ayers et al., 1976b; Sharp et al., 1984) also can effectively induce glyceollins in the infected tissues of soybeans. The underlying molecular mechanisms of how chemical and biotic elicitors elicit glyceollin biosynthesis are not clearly understood and several questions remain to be answered. For example, which treatment and soybean tissue induces the highest amount of glyceollins.

To get the optimum bioproduction of glyceollins, selection of appropriate elicitor and the types of plant tissues is important. Different types of elicitors induce different levels of glyceollin I in soybean (Bhattacharyya et al., 1986). Harosoy 63 hypocotyls treated with P. sojae had detectable levels of glyceollin I after 8 hours of inoculation and the highest amount of glyceollins was found at 48 hours. By contrast, the nearly isogenic variety Harosoy only had detectable levels of glyceollin I after 12 hours. Harosoy 63 showed resistance to Race 1 P. sojae at all stages of seedling development but Harosoy showed susceptibility at the early stages (Bhattacharyya, et al., 1986b). On the other hand, when the hypocotyls were elicited with $\mathrm{AgNO}_{3}$, the levels of accumulation of glyceollin isomers were similar in both genotypes. These results indicated that that resistant variety Harosoy 63 and the susceptible variety Harosoy responded differently to biotic elicitors, but the same to chemical elicitors. 
These findings led us to hypothesized that the glyceollins could be elicited differently by biotic or chemical elicitors and that separate elicitation pathways might be involved in glyceollin biosynthesis.

\section{Regulation of the Elicitation of Glyceollin biosynthesis in Response to Abiotic}

\section{Stresses}

The gene regulatory networks (GRN) involved in the elicitation of glyceollins in response to abiotic and abiotic stresses and the molecular mechanisms behind these events are still unknown. Substantial progresses have been made in identifying the biosynthetic genes and enzymes involved and phytoalexin TFs in many plant species. However, the TFs involved in the regulation of glyceollin biosynthesis are still unknown. Abiotic stresses like UV irradiation, amino acid starvation, and chemical elicitors such as the oxidative stress-inducing herbicides acifluorfen, paraquat, chlorsulfuron, and the abiotic elicitor $\alpha$-amino butyric acid and heavy metal ions elicit camalexin biosynthesis in Arabidopsis and may do so as well in soybean (Zhao et al., 1998, Tierens et al., 2002).

\section{Transcription Factors Regulate Elicitation of Phytoalexin Biosynthesis in Response}

\section{to Biotic Stresses}

Some phytoalexins that rapidly accumulate at the site of infection play an important role in the plant defense (Dixon, 2001). Considering the number of genes in a phytoalexin biosynthetic pathway, it may be difficult to enhance their biosynthesis by only overexpressing a single biosynthesis gene. Some reports showed that the over-expression of PAL, C4H, 4CL, CHS or CHI did not lead to significant changes of isoflavonoid levels (Shirley et al. 1992; Jez et al., 2000; Jung et al., 2000; Yu and McGonigle 2005). Phytoalexins are biosynthesized by many complex inducible pathways. Overexpressing TFs can induce biosynthetic genes to boost the biosynthesis of phytoalexins. Therefore, the identification and the modification of the expression of TFs could be one of the potential approaches to engineering more glyceollin biosynthesis to enhance resistance in soybeans. TFs are the regulatory proteins that bind to specific regulatory elements in the promoters and regulate the transcription of the genes. TFs can act as molecular switches, which can activate or suppress the transcription of biosynthesis 
genes (Martin 1996; Dixon and Steele 1999; Butelli et al. 2008; Cutanda-Perez et al. 2009; Shelton et al. 2012). So, TF's have the potential to overcome problems associated with overexpressing a single structural gene in a metabolic pathway.

MYBs (myeloblastosis) are the proto-oncogene protein family of TFs which contain R2R3-type MYB domain in plants (Stracke et al., 2001). GmMYB39 is an R2R3 repeat containing MYB TF. It was found to regulate genes that affected the isoflavonoid biosynthesis in soybean. Overexpression of GmMYB39 in soybean hairy roots resulted in a significant decrease in the of transcript level of $P A L, C 4 H, C H S, 4 C L$, and $C H R$, which ultimately associated with reduction in isoflavonoid contents (Liu X. et al., 2013). The findings indicated that GmMYB39 played role as a negative regulator in isoflavonoid biosynthesis. Conversely, GmMYB29 was found to activate IFS2 and CHS8 gene promoters and enhance isoflavonoid biosynthesis (Chu et al., 2017). These results confirmed the role of MYB transcription factors in regulation of the isoflavonoid biosynthesis. So, there might be some positive regulators that induce glyceollin genes in soybeans.

Camalexin is an indole alkaloid synthesized from tryptophan and is the major phytoalexin in Arabidopsis thaliana. The biosynthesis of camalexin was induced by a variety of microorganisms, including Pseudomonas syringae, Alternaria brassicicola, and Botrytis cinerea (Eckardt 2011). Three MYB TFs MYB34, MYB51 and MYB122 were involved in the regulation of camalexin and glucosinolates biosynthesis in Arabidopsis. MYB51 and MYB122 were found to enhance camalexin inducing agent in the biosynthesis pathway (Frerigmann et al., 2015). However, these three MYBs did directly regulate the camalexin-specific biosynthesis genes located downstream of IAOx (indole-3-acetaldoxime) in camalexin biosynthesis pathway. The Arabidopsis TF WRKY33 was crucial for defense against the fungus Botrytis cinerea (Zheng et al., 2006). WRKY33 is a TF that induces camalexin in Arabidopsis in response to P. syringae, and binds directly to the promoter of the camalexin biosynthesis gene phytoalexin deficient 3 (PAD3) (Qiu et al., 2008). WRKY33 is essential for resistance to $B$. cinerea and it positively regulates JA and ET mediated defense responses while negatively regulate SA-mediated signaling (Zheng et al., 2006).

ANAC042 belongs to the NAM, ATAF1/2, and CUC2 (NAC) family of TF genes and has been identified using T-DNA insertion mutants (Saga et al., 2012). It was found to regulate camalexin biosynthesis in Arabidopsis in response to Alternaria brassicicola infection, bacterial flagellin (Flg22) or the herbicide acifluorfen. 
Momilactones and phytocassanes are the major diterpenoid phytoalexins induced in rice in response to pathogens. OsTGAPl is an elicitor-inducible basic leucine zipper (bZIP) TF, that was essential for the induction of biosynthesis of momilactone in rice and it also influenced the expression of a phytocassane biosynthetic gene and the MEP pathway gene, leading to the production of phytocassanes (Okada et al., 2009).

Plant stilbenes are phytoalexins that derived from phenylpropanoid pathway and accumulate in a wide range of plant species, including grapevine, cranberry, blueberry, etc. Two R2R3-MYBType TFs MYB14 and MYB15 in grapevine were identified to induce the stilbene biosynthetic pathway. These TFs were strongly coexpressed with stilbene synthases (STSs) genes in response to biotic and abiotic stresses and regulate stilbenes biosynthesis by directly binding the STSs gene promoters (Holl et al., 2013). The R2R3-MYB-type TFs in grapevine have been widely studied and two of them, $V v M Y B 14$ and $V v M Y B 15$ have been found to be co-induced with stilbene biosynthesis genes in response to UV-C irradiation, wounding and downy mildew infection. They were shown to activate the promoter of stilbene synthase genes (STS41 and STS29) using transient expression assays and stimulate the accumulation of stilbenes when ectopically expressed in $V$. vinifera Chardonnay hairy roots under the control of CaMV $35 \mathrm{~S}$ promoter (Holl et al., 2013). Higher levels of stilbene accumulation were found in grapevine cultivar Concord (Vitis labrusca) than in Cabernet Sauvignon (V. vinifera) in response to $\mathrm{Al}^{3+}$ and UV-C light radiation treatments (Bai et al., 2019). They demonstrated that two genotypes were different regarding the structure and function of the promoter of MYB14 following Nicotiana benthamiana heterologous expression system and treating with $\mathrm{Al}^{3+}$ and UV-C. They also reported that $\mathrm{Al}^{3+}$ - and $\mathrm{UV}-\mathrm{C}$-elicitated ROS (hydrogen peroxide, $\mathrm{H}_{2} \mathrm{O}_{2}$ ) are essential for the activity of promoter of MYB14. In sorghum, the elicitation of 3-deoxyanthocyanidin phytoalexins occurred at the site of primary infection in responds to the fungal pathogen Colletotrichum sublineolum. This required a MYB TF encoded by yellow seedl gene, an orthologue of the maize gene pericarp colorl (Ibraheem et al., 2015).

Recently, WRKY24 TF was also found to act as an activator that enhance the promoter activity of STS29 and regulate stilbenes biosynthesis in grapevine (Vitis vinifera) (Vannozzi et al., 2018). Diterpenoid phytoalexin factor (DPF) is a basic helix-loop-helix (bHLH)-type TF induced the accumulation of diterpenoid phytoalexins (DPs), momilactones and phytocassanes in rice in response to blast fungus Magnaporthe oryzae infection, copper chloride or UV light irradiation. Overexpression and RNAi silencing of $O S D P F$ in rice resulted in a significant 
increase and decrease of the expression of diterpenoid phytoalexins biosynthetic genes and the accumulation of momilactones and phytocassanes.

Thus, the previous studies reported that different families of TFs are involved in regulating phytoalexin biosynthetic pathways in different plant species. Several TFs also have been reported to regulate the isoflavonoid biosynthetic pathway in soybean. All these findings provoked us to raise a biological question of what TFs are involved in regulating glyceollin biosynthesis in soybean. Since common abiotic stresses elicited the biosynthesis of different phytoalexins in different plant species, we hypothesized that one or more of these TFs regulate the glyceollin biosynthesis pathway in response to abiotic elicitors in soybean.

\section{Objectives}

\section{Overall Goal:}

The overall goal of this proposed research project is to better understand the genetics and biochemistry for the induction of glyceollin biosynthesis.

\section{Specific aims:}

1. Determine whether separate regulatory pathways exist for chemical and biotic elicitors of glyceollins.

2. Determine the effect of abiotic stresses on the elicitation of glyceollins.

3. Identify the transcription factor(s) that regulate the biosynthesis of glyceollins. 


\section{References}

Ahuja I., Kissen R. and Bones AM., (2012) Phytoalexins in defense against pathogens. Trends in Plant Science. Vol. 17, Issue 2, February 2012, Pages 73-90

Akashi T., Aoki T., Ayabe S., (1998) Identification of a cytochrome P450 cDNA encoding (2S)flavanone 2-hydroxylase of licorice (Glycyrrhiza echinata L.; Fabaceae) which represents licodione synthase and flavone synthase II. FEBS Lett 431: 287-290

Akashi, T., Sasaki, K.; Aoki, T., Ayabe, S.-I., Yazaki, K. (2009) Molecular cloning and characterization of a cdna cDNA for pterocarpan 4-dimethylallyltransferase catalyzing the key prenylation step in the biosynthesis of glyceollin, a soybean phytoalexin. Plant Physiol. 149, 683-693.

Atkinson N.J., Urwin P.E., (2012) The interaction of plant biotic and abiotic stresses: from genes to the field. Journal of Experimental Botany, Volume 63, Issue 10, 13 June 2012, Pages $3523-3543$

Ayers, A.R., Ebel, J.; Valent, B., Albersheim, P. (1976) Host-pathogen interactions 10. Fractionation and biological-activity of an elicitor isolated from mycelial walls of phytophthoramegasperma var sojae. Plant Physiol. 1976, 57, 760-765.

Bai R., Luo Y., Wang L., Li J., Wu K., Zhao G., Duan D. (2019) A specific allele of MYB14 in grapevine correlates with high stilbene inducibility triggered by $\mathrm{Al}^{3+}$ and UV-C radiation. Plant Cell Reports (2019) 38:37-49

Bamji, S.F., Corbitt, C. (2017) Glyceollins: Soybean phytoalexins that exhibit a wide range of health-promoting effects. J. Funct. Foods, 34, 98-105.

Banks, S.W., \& Dewick, P. M. (1983) Biosynthesis of glyceollins I, II and III in soybean. Phytochemistry, 22, 2729-2733.

Bhattacharyya, M.; Ward, E. (1986) Expression of gene-specific and age-related resistance and the accumulation of glyceollin in soybean leaves infected with Phytophthora megasperma f. sp. glycinea. Physiol. Mol. Plant Path. 29, 105-113.

Bhattacharyya, M.; Ward, E. (1986) Resistance, susceptibility and accumulation of glyceollins I-III in soybean organs inoculated with Phytophthora megasperma f. sp. glycinea. Physiol. Mol. Plant Path. 29, 227-237.

Bostock RM (2005) Signal crosstalk and induced resistance: straddling the line between cost and benefit. Annu Rev Phytopathol. 43:545-580. 
Boué, S. M., Carter, C., Ehrlich, K. C., \& Cleveland, T. E. (2000). Induction of the soybean phytoalexins coumestrol and glyceollin by Aspergillus. Journal of Agricultural and Food Chemistry, 48, 2167-2172.

Bridge, M.A., and Klarman, W. L. (1973) Soybean phytoalexin, hydroxyphaseollin, induced by ultraviolet irradiation. Phytopathology 63:606-609.

Butelli E, Titta L, Giorgio M, Mock HP, Matros A, Peterek S, Schijlen EGWM, Hall RD, Bovy AG, Luo J, Martin C (2008) Enrichment of tomato fruit with health-promoting anthocyanins by expression of select transcription factors. Nat Biotechnol 26:1301-1308

Chu S., Wang J., Zhu Y., Liu S., Zhou X, Zhang H, et al., (2017) An R2R3-type MYB transcription factor, GmMYB29, regulate isoflavone biosynthesis in soybean, PLoS Genetics, 13(5):e1006770

Cruickshank, I.A.M. and Perrin, D.R. (1960) Isolation of a phytoalexin from Pisum sativum L. Nature 187: 799-800.

Cutanda-Perez MC, Ageorges A, Gomez C, Vialet S, Terrier N, Romieu C, Torregrosa L (2009) Ectopic expression of VlmybA1 in grapevine activates a narrow set of genes involved in anthocyanin synthesis and transport. Plant Mol Biol 69:633-648

Darvill, A.G., and Albersheim, P. (1984) Phytoalexins and their elicitorsA defense against microbial infection in plants. Annu. Rev. Plant Physiol. 35:243-275.

Dixon R.A., Steele C.L., (1999) Flavonoids and isoflavonoids - a gold mine for metabolic engineering. Trends Plant Sci 4:394-400

Dixon R.A. (2001) Natural products and plant disease resistance Nature, 411 pp. 843-847

Ebel, J. (1986) Phytoalexin synthesis: The biochemical analysis of the induction process. Annual Review of Phytopathology, 24,235-264.

Eckardt N.A., (2011) Induction of Phytoalexin Biosynthesis: WRKY33 Is a Target of MAPK Signaling April 2011.

Frerigmann H., Erich Glawischnig E. and Tamara Gigolashvili T. (2015) The role of MYB34, MYB51 and MYB122 in the regulation of camalexin biosynthesis in Arabidopsis thaliana. Front. Plant Sci. 6:654.

Fujita M., Fujita Y., Noutoshi Y., Takahashi F., Narusaka Y., Yamaguchi-Shinozaki K., Shinozaki K., (2006) Crosstalk between abiotic and biotic stress responses: a current view from 
the points of convergence in the stress signaling networks. Current Opinion in Plant Biology. Volume 9, Issue 4, August 2006, Pages 436-442

Ginzberg I., Thippeswamy M., Fogelman E., Demirel U., Mweetwa A.M., Tokuhisa J., Veilleux R.E. (2012) Induction of potato steroidal glycoalkaloid biosynthetic pathway by overexpression of cDNA encoding primary metabolism HMG-CoA reductase and squalene synthase. Planta 235:1341-1353.

Glawischnig, E., Hansen, B. G., Olsen, C. E., and Halkier, B. A. (2004) Camalexin is synthesized from indole-3-acetaldoxime, a key branching point between primary and secondary metabolism in Arabidopsis. Proc. Natl. Acad. Sci. U.S.A. 101:8245-8250.

Graham T., Kim J., Graham M. (1990) Role of constitutive isoflavone conjugates in the accumulation of glyceollin in soybean infected with Phytophthora megasperma. Mol PlantMicrobe Interact. 3:157-166

Hauck P., R. Thilmony, and He S. Y. (2003) "A Pseudomonas syringae type III effector suppresses cell wall-based extracellular defense in susceptible Arabidopsis plants," Proceedings of the National Academy of Sciences of the United States of America, vol. 100, no. 14, pp. $8577-8582$.

Höll J., Vannozzi A., Czemmel S., D'Onofrio C., Walker A.R., Rausch T., Lucchin M., Boss P.K., Dry I.B., Bogs J. (2013) The R2R3-MYB transcription factors MYB14 and MYB15 regulate stilbene biosynthesis in Vitis vinifera. Plant Cell. 25(10):4135-49.

Ibraheem F., Gaffoor I., Tan Q., Shyu C-R, Chopra S. (2015) A sorghum MYB transcription factor induces 3-deoxyanthocyanidins and enhances resistance against leaf blights in maize. Molecules. 20(2):2388-404.

Jeandet P., Clément C., Courot E. and Cordelier S. (2013) Modulation of Phytoalexin Biosynthesis in Engineered Plants for Disease Resistance. Int. J. Mol. Sci. 2013, 14, 1413614170

Jez, J. M., Bowman, M. E., Dixon, R. A., and Noel, J. P. (2000b). Structure and mechanism of the evolutionarily unique plant enzyme chalcone isomerase. Nat Struct Biol 7, 786-791.

Jing M., Guo B., Li H., Yang B., Wang H, Kong G, Zhao Y, Xu H, Wang Y, Tyler B. M., Wang Y et al., (2016) A Phytophthora sojae effector suppresses endoplasmic reticulum stressmediated immunity by stabilizing plant Binding immunoglobulin Proteins. Nature Communications volume 7, Article number: 11685 
Jung W., Yu O., Lau S.C., O’Keefe D.P., Odell J., Fader G., McGonigle B. (2000) Identification and expression of isoflavone synthase, the key enzyme for biosynthesis of isoflavones in legumes. Nat Biotechnol 18: 208-212;

Keen, N. T., Ingham, J. L., Hymowltz, T., Sims, J. J., \& Midland, S. (1989) The occurrence of glyceollins in plants related to Glycine $\max ($ L.) Merr. Biochemical Systematics and Ecology, 17, 395-398.

Kim H.J., Lim J.-S., Kim W.-K. and Kim J.-S (2012) Soyabean glyceollins: biological effects and relevance to human health. Proceedings of the Nutrition Society, 2012, 71, 166-174.

Kim M.G., L. da Cunha, A. J. McFall et al., (2005) "Two Pseudomonas syringae type III effectors inhibit RIN4-regulated basal defense in Arabidopsis," Cell, vol. 121, no. 5, pp. 749$759,2005$.

Liu X., Yuan L., Xu L., Xu Z., Huang Y., He X., Ma H., Yi J., Zhang D. (2013) Overexpression of GmMYB39 leads to an inhibition of the isoflavonoid biosynthesis in soybean (Glycine max. L). Plant Biotechnol Rep 7:445-455

Lorenzo O., Solano R. (2005) Molecular players regulating the jasmonate signaling network. Curr Opin Plant Biol, 8:532-540.

Lu M., Ying, S., Zhang D.F., Shi Y.S., Song Y. C., Wang T. Y., et al. (2012) A maize stressresponsive NAC transcription factor, ZmSNAC1, confers enhanced tolerance to dehydration in transgenic Arabidopsis. Plant Cell Rep. 31, 1701-1711.

Lygin A.V., Zernova O.V., Hill C.B., Kholina N.A., Widholm J.M., Hartman G.L., Lozovaya V.V. (2013) Glyceollin is an important component of soybean plant defense against Phytophthora sojae and Macrophomina phaseolina. Phytopathology. 103(10):984-94.

Lyne R.L., and Mulheirn L.J., (1976) New pterocarpinoid phytoalexins of soybean.J. Chem. Soc. Chem. Commun. 1976:497-498.

Martin C. (1996) Transcription factors and the manipulation of plant traits. Curr Opin Biotechnol 7:130-138

Mauch-Mani B., Mauch F (2005) The role of abscisic acid in plant-pathogen interactions. Curr Opin Plant Biol 8:409-414.

Muller T.M., Böttcher C., Robert Morbitzer R., Erich Glawischnig E., et al., (2015) TRANSCRIPTION ACTIVATOR-LIKE EFFECTOR NUCLEASE-Mediated Generation and 
Metabolic Analysis of Camalexin-Deficient cyp71a12 cyp71a13 Double Knockout Lines. Plant Physiol. 2015 Jul; 168(3): 849-858.

Narusaka Y., Narusaka M., Seki M., Umezawa T., Ishida J., Nakajima M., Enju A., Shinozaki K. (2004) Crosstalk in the responses to abiotic and biotic stresses in Arabidopsis: analysis of gene expression in cytochrome P450 gene superfamily by cDNA microarray. Plant Mol Biol. $55: 327-342$.

Nwachukwu I.D., Luciano F.B., Udenigwe C.C., (2013) The inducible soybean glyceollin phytoalexins with multifunctional health-promoting properties. Food Research International; 54:1208-16.

Ogawa S., Miyamoto K., Nemoto K., Sawasaki T., Yamane H., Nojiri H., Okada K. (2017) OsMYC2, an essential factor for JA-inductive sakuranetin production in rice, interacts with MYC2-like proteins that enhance its transactivation ability. Sci Rep. 7:40175.

Okada A., Okada K., Miyamoto K., Koga J., Shibuya N., Nojiri H., and Yamane H (2009) OsTGAP1, a bZIP Transcription Factor, Coordinately Regulates the Inductive Production of Diterpenoid Phytoalexins in Rice. J Biol Chem. 284(39): 26510-26518.

Qiu J.L., Fiil B.K., Petersen K., Nielsen H.B., Botanga C.J., Thorgrimsen S., Palma K., Suarez-Rodriguez M.C., Sandbech-Clausen S., Lichota J., (2008) Arabidopsis MAP kinase 4 regulates gene expression through transcription factor release in the nucleus. The EMBO Journal 27(16):2214-2221.

Rathmell W.G. and Bendall D.S., (1971) Phenolic compounds in relation to phytoalexin biosynthesis in hypocotyls of Phaseolus vulgaris. Physiological Plant Pathology, Volume 1, Issue 3, July 1971, Pages 351-362,

Reilly J.J., Klarman W.L. (1980) Thymine dimer and glyceollin accumulation in UV-irradiated soybean suspension cultures. Environmental and Experimental Botany 20(2):131-134.

Rejeb, I., Pastor, V., and Mauch-Mani, B. (2014) Plant responses to simultaneous biotic and abiotic stress: molecular mechanisms. Plants 3, 458-475.

Saga H., Ogawa T., Kai K., Suzuki H., Ogata Y., Sakurai N., Shibata D., Ohta D. (2012) Identification and characterization of ANAC042, a transcription factor family gene involved in the regulation of camalexin biosynthesis in Arabidopsis. Mol Plant Microbe In. 25(5):684-96. 
Schopfera C.R., Georg Kochsb G., Lottspeichc F., Ebela J., (1998) Molecular characterization and functional expression of dihydroxypterocarpan 6a-hydroxylase, an enzyme specific for pterocarpanoid phytoalexin biosynthesis in soybean (Glycine max L.). FEBS Lett. 432(3):182-6

Seo J.Y., Kim B.R., Oh J., Kim J.S. (2018). Soybean-Derived Phytoalexins Improve Cognitive Function through Activation of Nrf2/HO-1 Signaling Pathway. Int J Mol Sci. 16;19(1). pii: E268.

Sharp J.K., Valent B., Albersheim P. (1984) Purification and partial characterization of a betaglucan fragment that elicits phytoalexin accumulation in soybean. J. Biol. Chem. 259: 1131211320 .

Shelton D., Stranne M., Mikkelsen L., Pakseresht N., Welham T., Hiraka H., Tabata S., Sato S., Paquette S., Wang T.L., Martin C., Bailey P. (2012) Transcription factors of lotus: regulation of isoflavonoid biosynthesis requires coordinated changes in transcription factor activity. Plant Physiol 159:531-547

Shirley, B.W., Hanley, S., and Goodman, H. M. (1992) Effects of ionizing radiation on a plant genome: analysis of two Arabidopsis transparent testa mutations. Plant Cell 4, 333-347.

Simons, R., Vincken, J.P., Roidos, N., Bovee, T. F. H., van Iersel, M., Verbruggen, M.A., et al. (2011). Increasing soy isoflavonoid content and diversity by simultaneous malting and challenging by a fungus to modulate estrogenicity. Journal of Agricultural and Food Chemistry, $59,6748-6758$

Stracke R., Werber M., Weisshaar B. (October 2001) "The R2R3-MYB gene family in Arabidopsis thaliana". Curr. Opin. Plant Biol. 4 (5): 447-56.

Suzuki, N., Koussevitzky, S., Mittler, R. O. N., and Miller, G. A. D. (2012) ROS and redox signalling in the response of plants to abiotic stress. Plant Cell Environ. 35, 259-270.

Tierens, K.F.M.J. et al. (2002) Esa1, an Arabidopsis mutant with enhanced susceptibility to a range of necrotrophic fungal pathogens, shows a distorted induction of defense responses by reactive oxygen generating compounds. Plant J. 29, 131-140

Tilghman, S.L., Boué, S. M., \& Burow, M. E. (2010) Glyceollins, a novel class of antiestrogenic phytoalexins. Molecular and Cellular Pharmacology, 2, 155-160.

Tyler B.M. (2007) Phytophthora sojae: root rot pathogen of soybean and model oomycete. Mol Plant Pathol 8:1-8 
Van Etten H. D., Mansfield J. W., Bailey J. A., Farmer E. E. (1994) Two Classes of Plant Antibiotics: Phytoalexins versus "Phytoanticipins". Plant Cell 6, 1191-1192

Vannozzi A., Wong D.C.J., Höll J. et al (2018) Combinatorial regulation of stilbene synthase genes by WRKY and MYB transcription factors in grapevine (Vitis vinifera L.). Plant Cell Physiol 59:1043-1059

Vogt T. (2010) Phenylpropanoid biosynthesis. Mol Plant 3:2-20

Wong D.C.J., Schlechter R., Vannozzi A. et al., (2016) A systems-oriented analysis of the grapevine R2R3-MYB transcription factor family uncovers new insights into the regulation of stilbene accumulation. DNA Res 23:451-466

Wrather, J.A., and Koenning, S.R. (2006) Estimates of disease effects on soybean yields in the United States 2003 to 2005. J. Nematol. 38:173-180.

Xiong, L., and Yang, Y. (2003) Disease resistance and abiotic stress tolerance in rice are inversely modulated by an abscisic acid - inducible mitogen-activated protein kinase. Plant Cell 15, 745-759.

Xu Y-H, Wang J-W, Wang S, Wang J-Y, Chen X-Y. (2004) Characterization of GaWRKY1, a cotton transcription factor that regulates the sesquiterpene synthase gene $(+)-\delta$-cadinene synthase-a. Plant Physiol. 135(1):507-15.

Yamamura C., Mizutani E., Okada K., Nakagawa H., Fukushima S., Tanaka A., Maeda S., Kamakura T., Yamane H., Takatsuji H., et al., (2015) Diterpenoid Phytoalexin factor, a bHLH transcription factor, plays a central role in the biosynthesis of Diterpenoid Phytoalexins in Rice. Plant J. 84(6):1100-13.

Yoshikawa, M. (1978) Diverse modes of action of biotic and abiotic phytoalexin elicitors. Nature (London) 275:546-547.

$\mathrm{Yu}$ and McGonigle (2005) Metabolic Engineering of Isoflavone Biosynthesis. Advances in Agronomy. Volume 86, 2005, Pages 147-190

Yu O, Shi J, Hession AO, Maxwell CA, McGonigle B, Odell JT (2003) Metabolic engineering to increase isoflavone biosynthesis in soybean seed. Phytochemistry. 63(7):753-63.

Yu-Mei Lina, Shu-Lein Shiha, Wan-Chi Lin, Jia-Wei Wu, Ya-Ting Chen, Chi-Ying Hsieh, LiChing Guan, LuLin, Chiu-Ping Cheng (2014). Phytoalexin biosynthesis genes are regulated and 
involved in plant response to Ralstonia solanacearum infection. Plant Science. Volume 224, Pages 86-94.

Zhao, J.M. et al. (1998) Induction of Arabidopsis tryptophan pathway enzymes and camalexin by amino acid starvation, oxidative stress, and an abiotic elicitor. Plant Cell 10, 359-370

Zheng Z., Qamar S.A., Chen Z., Mengiste T. (2006) Arabidopsis WRKY33 transcription factor is required for resistance to necrotrophic fungal pathogens. Plant J 48 (4): 592-605 


\title{
Chapter Two
}

\section{Distinct Mechanisms of Biotic and Chemical Elicitors Enable Additive Elicitation of the Anticancer Phytoalexin Glyceollin I}

\author{
Kelli Farrell ${ }^{1, \dagger}$, Md Asraful Jahan ${ }^{2, \dagger}$, and Nik Kovinich ${ }^{2, *}$
}

${ }^{1}$ Department of Biology, West Virginia University, Morgantown, WV 26506, USA; kcfarrell@mix.wvu.edu

2 Division of Plant and Soil Sciences, West Virginia University, Morgantown, WV 26506, USA; mjahan@mix.wvu.edu

$\dagger$ These Authors contributed equally.

\section{* Corresponding author}

Nik Kovinich

Assistant Professor of Genetics, Division of Plant and Soil Sciences

Davis College of Agriculture, Natural Resources and Design

West Virginia University

1194 Evansdale Dr

Morgantown, WV 26506-6108

Tel.: +1-304-293-9240

E-mail: nikovinich@mail.wvu.edu

Farrell KC, Jahan MA, Kovinich N. Distinct mechanisms of biotic and chemical elicitors enable additive elicitation of the anticancer Phytoalexin Glyceollin I. Molecules. 2017;22(8):1261-73. 


\begin{abstract}
Phytoalexins are metabolites biosynthesized in plants in response to pathogen, environmental, and chemical stresses that often have potent bioactivities, rendering them promising for use as therapeutics or scaffolds for pharmaceutical development. Glyceollin I is an isoflavonoid phytoalexin from soybean that exhibits potent anticancer activities and is not economical to synthesize. Here, we tested a range of source tissues from soybean, in addition to chemical and biotic elicitors, to understand how to enhance the bioproduction of glyceollin I. Combining the inorganic chemical silver nitrate $\left(\mathrm{AgNO}_{3}\right)$ with the wall glucan elicitor (WGE) from the soybean pathogen Phytophthora sojae had an additive effect on the elicitation of soybean seeds, resulting in a yield of up to $745.1 \mu \mathrm{g} \mathrm{gt}^{-1}$ glyceollin I. The additive elicitation suggested that the biotic and chemical elicitors acted largely by separate mechanisms. WGE caused a major accumulation of phytoalexin gene transcripts, whereas $\mathrm{AgNO}_{3}$ inhibited and enhanced the degradation of glyceollin I and 6"-O-malonyldaidzin, respectively.
\end{abstract}

Keywords: bioproduction; phytoalexin; isoflavonoid; glyceollin; soybean [Glycine max (L.) Merr.] 


\section{INTRODUCTION}

Plants, like other organisms, have metabolic pathways that remain silent until activated by stresses. Phytoalexins are defense metabolites biosynthesized in response to pathogens, but which for unknown reasons also accumulate in response to specific environmental stresses and inorganic chemicals, such as heavy metals (Ahuja et al., 2012, Großkinsky et al., 2012, Jeandet et al., 2014). Much of what is known about phytoalexin elicitation mechanisms comes from studies of the glyceollins in soybean, camalexins in Arabidopsis, diterpenoids and flavonoids in rice, stilbenes in grapevine, alkaloids in California poppy, and the 3-deoxyanthocyanidins, terpenoids, and phytodienoic acids in maize. However, very few studies have attempted to distinguish the elicitation mechanisms of biotic and chemical elicitors.

Biotic elicitation begins when a microbial derived pathogen-associated molecular pattern (PAMP) or effector binds to a pattern recognition receptor at the plasma membrane of the plant cell. Mitogen-activated protein kinase (MAPK) or phospholipase signaling ultimately results in the expression of transcription factors (TFs) that directly activate the transcription of phytoalexin biosynthesis genes. MYB-, bHLH-, or WRKY-type TFs directly activate some or all of the phytoalexin biosynthesis genes in cotton, sorghum, rice, Arabidopsis, and grapevine (Ibraheem, et al., 2015; Xu et al., 2004; Yamamura et al., 2015). In soybean, no phytoalexin TF has been identified, but transcription of glyceollin biosynthesis genes was coordinately induced in response to the pathogen Phytophthora sojae (Akashi et al., 2009; Moy et al., 2004).

Heavy metals, such as silver nitrate $\left(\mathrm{AgNO}_{3}\right)$, have elicited chemically diverse phytoalexins in many plant species. The molecular target(s) of these heavy metals remain(s) unknown. $\mathrm{AgNO}_{3}$ was shown to inhibit developmental processes triggered by exogenous ethylene treatment, and thus has been considered a potent inhibitor of ethylene perception (Beyer et al., 1976). Some evidence has suggested that $\mathrm{AgNO}_{3}$ and pathogens elicit phytoalexins primarily by different mechanisms. The P. sojae-resistant soybean variety Harosoy 63 elicited glyceollins rapidly in response to race $1 P$. sojae, but the susceptible variety Harosoy did not, whereas both varieties responded similarly to $\mathrm{AgNO}_{3}$ (Bhattacharyya et al., 1986). Feeding $\mathrm{AgNO}_{3}$-elicited soybean cotyledons the radiolabeled intermediate phenylalanine did not result in radiolabeled glyceollins, but AgNO3 treatment reduced the degradation of radiolabeled glyceollins (Yoshikawa et al., 1978). 
Glyceollins are the major phytoalexins of the soybean. They belong to the pterocarpan subclass of isoflavonoids, which possesses great potential as scaffolds for pharmaceutical development (Selvam et al., 2017). Glyceollins are biosynthesized from the isoflavonoid daidzein, which can result from de novo biosynthesis beginning at phenylalanine, or possibly from the hydrolysis of preformed isoflavonoid-glycoside conjugates (Figure 1). Glyceollins have broad-spectrum antiproliferative or antitumor activities against human lung, breast, prostate, ovary, skin, and kidney cancers. Glyceollin I is the most potent, and directly antagonizes human estrogen receptor $\alpha(\mathrm{ER} \alpha)$ and $\mathrm{ER} \beta$ (Zimmermann et al., 2010). Glyceollin I also exhibits a rare ERindependent mode-of-action via a mechanism that is not yet fully understood (Rhodes et al., 2012). In light of the therapeutic potential of glyceollin I, studies have attempted to produce large-scale (gram) amounts by chemical synthesis or by the elicitation of soybean (Luniwal et al., 2011; Simons., et al 2011). However, the yield by chemical synthesis was up to $12 \%$, and required a highly concerted effort of specialists six months to complete, rendering it uneconomical for commercial production (Luniwal et al., 2011). Here, we aimed to identify which soybean tissues and treatments provide optimal glyceollin I bioproduction in vitro. Our study provides novel insight into how biotic and chemical elicitation pathways are distinct, and how this can be exploited to enhance the bioproduction of glyceollin I.

\section{RESULTS AND DISCUSSION}

\subsection{Imbibing Soybean Seeds Are the Most Abundant Source of Glyceollin I}

Prior studies have found that glyceollins were readily elicited up to the first-true-leaf stage of development, when they were essential for defense against P. sojae (Bhattacharyya et al., 1986; Bhattacharyya et al., 1986; Graham et al., 1996). They were also elicited in transgenic hairy roots and soybean seeds (Burow et al., 2001; Cheng et al., 2015; Lygin et al., 2013). Yet, no single study has compared different soybean tissues to determine which produces the most glyceollin I.

We compared the organs of seedlings at the first-true-leaf stage, imbibing seeds, and hairy roots. The samples were treated with the well-characterized wall glucan elicitor (WGE) isolated from the mycelium of $P$. sojae (Ayers et al., 1976). The organs of the seedlings and imbibing seeds were spot-treated on a wound of equivalent size with the same amount of WGE, and tissue of 
roughly the same mass encompassing the wound site was collected for the measurement of glyceollin I (see Methods).

The imbibing seeds produced the highest amount of glyceollin I: $421.7 \mu \mathrm{g}$ per gram fresh tissue $\left(\mathrm{gt}^{-1}\right)$ (Figure 2A). This amount was roughly sixfold greater than that of hairy roots and hypocotyls, and 16-fold greater than cotyledons and roots. The glyceollin I from the imbibing seeds represented a major peak at $283 \mathrm{~nm}$ absorbance (Figure 2B).

Since glyceollin I is costly to purify from other glyceollins (Van De Schans et al., 2016), we determined which tissue had the greatest purity of glyceollin I relative to the other glyceollins. The roots produced $85.9 \%$ glyceollin I (Supplementary Figure S1), but produced the lowest total amount with our elicitation parameters (Figure 2A). Since imbibing seeds produced the greatest total amounts of glyceollin I and exhibited the second greatest purity (68.5\%), we decided to focus on imbibing seeds to compare the biotic and chemical elicitation mechanisms of glyceollin I.

\subsection{Wall Glucan Elicitors from $P$. sojae and Pythium Elicit More Glyceollin I Than Rhizopus, Aspergillus, and Fusarium Microspores at Standard Treatment Concentrations}

A wide variety of fungal, nematode, and oomycete pathogens elicit glyceollins. The commonly studied microspore elicitors are from the Rhizopus and Aspergillus species, whereas WGE is most commonly from P. sojae (Aisyah et al., 2013; Boue et al., 2000; Simons et al., 2011). To compare the elicitation features of several biotic elicitors at typical treatment concentrations, we treated imbibing soybean seeds with $7 \times 10^{7} \mathrm{CFU} \mathrm{mL}^{-1}$ microspores from Aspergillus fumigatus, Rhizopus nigricans, and Fusarium tricinctum, or WGEs from P. sojae and Pythium at $20 \mathrm{mg} \mathrm{mL}^{-1}$.

WGE from $P$. sojae induced the highest amounts of glyceollin I (428.3 $\left.\mu \mathrm{g} \mathrm{gt}^{-1}\right)$, followed by Pythium (199.0 $\mathrm{g} \mathrm{gt}^{-1}$ ) (Figure 3A). Glyceollin I comprised more than $50 \%$ of the total glyceollin amounts elicited by P. sojae and Pythium, whereas it was less than $50 \%$ for the fungal microspore elicitors (Supplementary Figure S1). 


\section{3. $\mathrm{AgNO}_{3}$ Elicits More Glyceollin I Than $\mathrm{CuCl2}$, BTD, AVG, and SA at Equivalent Treatment Concentrations}

Chemical elicitors, such as heavy metals or inorganic compounds, that stimulate or inhibit components of the plant immune system can function as phytoalexin elicitors. We chose to compare under the same conditions as our biotic elicitors the elicitation potential of the heavy metals $\mathrm{AgNO}_{3}$ and $\mathrm{CuCl}_{2}$ and inorganic compounds that affect the immune system. The duration of elicitation for our experiments was initially set to $24 \mathrm{~h}$, since that is the duration typically reported in previous studies. Benzothiadiazole (BTD) stimulated the immune system by functioning as a mimic of the plant hormone salicylic acid (SA) (Bektas et al., 2014). Aminoethoxyvinyl glycine (AVG) inhibited the biosynthesis of ethylene (Paradies et al., 1980), and thus could be compared to the putative inhibitor of ethylene perception, $\mathrm{AgNO}_{3}$.

At $1 \mathrm{mM}$ treatment concentration, $\mathrm{AgNO}_{3}$ was the most potent and elicited $48.2 \mu \mathrm{g} \mathrm{gt}^{-1}$ glyceollin I (Figure 3B). That was eightfold more than AVG. BTD was the second most potent, eliciting $48.2 \mu \mathrm{g} \mathrm{gt}^{-1}$, which was 17 -fold more than SA. Only $\mathrm{AgNO}_{3}$ preferentially elicited glyceollin I (Supplementary Figure S1).

\section{4. $\mathrm{AgNO}_{3}$ and P. sojae WGE Elicit Glyceollin I with Different Dynamics}

Since $\mathrm{AgNO}_{3}$ and WGE from $P$. sojae were the most potent chemical and biotic elicitors at the treatment concentrations tested, we chose to investigate in more detail their mechanisms, beginning with elicitation dynamics. $\mathrm{AgNO}_{3}$ elicited the accumulation of glyceollin $\mathrm{I}$ in a biphasic fashion, with peaks at $24 \mathrm{~h}$ and $96 \mathrm{~h}$ after treatment (Supplementary Figure S2). By contrast, WGE reached a maximum at $24 \mathrm{~h}$ that was sustained. To distinguish effect of each elicitor from that of the wounding, we calculated the fold change in metabolite levels of each elicitor relative to the water control. WGE caused the greatest induction over the wounded control at $48 \mathrm{~h}$, whereas $\mathrm{AgNO}_{3}$ was at $72 \mathrm{~h}$ (Supplementary Figure S2).

\subsection{P. sojae WGE and $\mathrm{AgNO}_{3}$ Elicit the Accumulation of Glyceollin I Mainly by Distinct Mechanisms}

Since the elicitation dynamics were different for WGE compared to $\mathrm{AgNO}_{3}$, we anticipated that each elicitor functioned by a different mechanism. We tested this hypothesis by first identifying the optimal concentration of each elicitor required to elicit the maximum accumulation of glyceollin I, and then combined the elicitors at these maximum concentrations. The rationale 
was that the combined treatment would result in a greater accumulation of glyceollin I only if the elicitation mechanisms were different. To determine the maximum level of glyceollin I that WGE and $\mathrm{AgNO}_{3}$ can respectively elicit, we conducted dose response analyses. Germinating soybean seeds were treated with up to $10 \mathrm{mM} \mathrm{AgNO}_{3}$ and $60 \mathrm{mg} \mathrm{mL}^{-1}$ WGE.

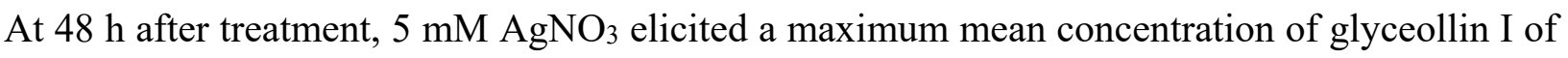
$202.5 \mu \mathrm{g} \mathrm{gt}^{-1}$ (Supplementary Figure S3). By contrast, $20 \mathrm{mg} \mathrm{mL}^{-1}$ WGE elicited more than double this amount, with a mean concentration of $449.8 \mu \mathrm{g} \mathrm{gt}^{-1}$. The combined treatment elicited a mean glyceollin I concentration of $635.8 \mu \mathrm{g} \mathrm{gt}^{-1}$ and a maximum of $745.1 \mu \mathrm{g} \mathrm{gt}^{-1}$ (Figure 4). This mean concentration was significantly greater than that observed for the single treatments, and was very close empirically to the sum of the individual elicitor treatments (640.0 $\left.\mu \mathrm{g} \mathrm{gt}^{-1}\right)$. This strongly suggests that $\mathrm{WGE}$ and $\mathrm{AgNO}_{3}$ function by distinct elicitation mechanisms.

The combined treatment also enhanced the purity of glyceollin I to $89.4 \%$ of the total glyceollins and to $34.6 \%$ of the total seed isoflavonoids (Supplementary Figures S1 and S4, respectively).

\section{6. $P$. sojae WGE and not $\mathrm{AgNO}_{3}$ Induces Major Accumulation of Glyceollin Gene Transcripts}

Since glyceollin biosynthesis genes were regulated at the level of transcription in response to $P$. sojae (Ward et al., 1989; Akashi et al., 2009; Moy et al., 2004), we determined whether the elicitors WGE and $\mathrm{AgNO}_{3}$ induced glyceollin biosynthesis at the mRNA level. We measured mRNA accumulation for genes spanning from general isoflavonoid to late-stage glyceollin I biosynthesis. The homologous genes IFS1 and IFS2 encode isoflavone synthase (IFS) enzymes that catalyze the first committed step in isoflavonoid biosynthesis (Figure 1). The enzyme isoflavone $2^{\prime}$-hydroxylase encoded by $I 2^{\prime} H$ and the glycinol 4-dimethylallyltransferase encoded by G4DT catalyze the first committed steps for the biosynthesis of all glyceollins and glyceollin I, respectively (Akashi et al., 2009; Liu et al., 2003).

WGE induced the accumulation of the mRNAs of all four genes compared to the solvent control at $48 \mathrm{~h}$ after elicitation (Figure $5 \mathrm{~A}$ ). By contrast, $\mathrm{AgNO}_{3}$ did not significantly induce any genes at this time point. Further, the combined treatment did not have elevated levels of mRNAs compared to the WGE treatment, and even exhibited a reduced expression of IFS1. These results 
suggest that $\mathrm{AgNO}_{3}$ did not elicit glyceollins by stimulating the accumulation of glyceollin biosynthesis gene mRNAs.

Since the elicitation of phytoalexins is a transient process subject to feedback mechanisms, we also tested whether $\mathrm{AgNO}_{3}$ elicited the accumulation of biosynthesis gene mRNAs more rapidly than WGE. To test this, we measured mRNA levels at $8 \mathrm{~h}$ after treatment, a time point that preceded the measurable accumulation of glyceollin I. Again, $\mathrm{AgNO}_{3}$ did not elicit the accumulation of any of the mRNAs (Figure 5B). Further, the combined treatment exhibited less expressions of IFS2 and G4DT compared to the WGE treatment, suggesting that the elevated levels of glyceollin I observed at $48 \mathrm{~h}$ were not due to regulation of biosynthesis at the mRNA level.

\subsection{AgNO3 Inhibits the Degradation of Glyceollin I and Enhances the Specific Hydrolysis of 6"-O-Malonyldaidzin}

Our gene expression measurements demonstrated that $\mathrm{AgNO}_{3}$ did not induce the expression of glyceollin biosynthesis genes. This suggested that $\mathrm{AgNO}_{3}$ acted via another mechanism to elicit glyceollin I in the soybean seed. Heavy metal elicitors have been suggested to elicit isoflavonoid phytoalexins by inhibiting their degradation or by increasing the rates of the hydrolysis of isoflavone conjugates to provide metabolic intermediates for phytoalexin biosynthesis (Yoshikawa et al., 1978; Naoumkina et al., 2007). To investigate whether $\mathrm{AgNO}_{3}$ inhibited the degradation of glyceollin I, we incubated dissected seeds in water or $5 \mathrm{mM} \mathrm{AgNO}$ for $2 \mathrm{~h}$, then transferred them to an extract containing partially purified glyceollin I.

The incubation of the dissected seed with 115 umol $\mathrm{mL}^{-1}$ of glyceollin I resulted in the degradation of $54.9 \mu \mathrm{mol} \mathrm{mL}-1$ (Figure 6A). The pretreatment of the seed with $\mathrm{AgNO}_{3}$ for $2 \mathrm{~h}$ did not cause a detectable induction of glyceollin I (not shown) and reduced this degradation by $25.7 \%$, rendering the final amount statistically equivalent to the initial extract. A similar inhibition of degradation was observed for the intermediate daidzein (Figure 6B). By contrast, $\mathrm{AgNO}_{3}$ accelerated the hydrolysis of the isoflavone conjugate $6 "-O$-malonyldaidzin (Figure 6C). The levels of daidzin were unchanged compared to the control (Figure 6D). $\mathrm{AgNO}_{3}$ did not affect the levels of any of the metabolites in the absence of the seed (not shown), indicating that the changes in metabolite levels were catalyzed by seed enzymes. During the course of the experiment, no de novo biosynthesis of glyceollin I was detected from seeds incubated in the 
absence of the glyceollin I extract (Figure 6A). In summary, these results show that $\mathrm{AgNO}_{3}$ acts by inhibiting the degradation of glyceollin I and by accelerating the hydrolysis of 6 "-Omalonyldaidzin, possibly to provide daidzein intermediates for glyceollin I biosynthesis.

\subsection{DISCUSSION}

Previous attempts were made to biosynthesize and synthesize glyceollin I on a preparative scale. The most effective approach yielded $12 \%$ glyceollin I, but its scale up to produce gram amounts required $\sim 6$ months and a highly concerted team effort of highly experienced chemists (Luniwal et al., 2011). A creative approach to biosynthesize prenylated isoflavonoids on a preparative scale involved the malting (as in the brewing industry) and simultaneous elicitation of $4.0 \mathrm{~kg}$ of germinating soybeans with the fungus Rhizopus microspores (Simons., et al 2011). This yielded up to $335 \mu \mathrm{g} \mathrm{gt}^{-1}$ glyceollin I in nine days. Thus, the overall yield from $4.0 \mathrm{~kg}$ of seeds could be $1.34 \mathrm{~g}$ in a fraction of the time needed for synthesis. Here, we demonstrated on an analytical scale that combining biotic and chemical elicitors resulted in an additive effect on the accumulation of glyceollin I, with $\mathrm{WGE}$ and $\mathrm{AgNO}_{3}$ eliciting almost double that amount (635.8 $\mu \mathrm{g} \mathrm{gt}^{-1}$ ) in $48 \mathrm{~h}$ (Figure 4). The approach was labor-intensive and could benefit from mechanization, but if amenable to direct scale up would yield almost double the amount $(2.54 \mathrm{~g})$ of glyceollin I from $4.0 \mathrm{~kg}$ of seeds in 2-3 days.

Several lines of evidence suggested that this occurred because the chemical and biotic elicitors functioned by distinct mechanisms. Firstly, $\mathrm{AgNO}_{3}$ and WGE elicited different patterns of glyceollin I accumulation over time (Supplementary Figure S2). Second, our gene expression experiments demonstrated that $\mathrm{AgNO}_{3}$ did not increase the accumulation of essential glyceollin genes, whereas WGE from $P$. sojae highly upregulated both the isoflavonoid and glyceollin genes (Figure 5). Finally, $\mathrm{AgNO}_{3}$ inhibited the degradation of glyceollin I (Figure 6), whereas WGE did not (Yoshikawa et al., 1978). These results suggested distinct genetic targets for enhancing biotic and chemical elicitation pathways by genetic engineering. Transcription factors (TFs) of the MYB, WRKY, and bHLH families directly activated the transcription of phytoalexin biosynthesis gene promoters, and thus their overexpression could be used to enhance the biotic elicitation pathway. Yet to our knowledge, TFs that activate specifically the heavy metal elicitation pathway have not been identified. 
$\mathrm{AgNO}_{3}$ was shown to be a potent inhibitor of ethylene perception (Beyer et al., 1976). Yet, even though we applied the ethylene biosynthesis inhibitor AVG at four times the concentration found to fully inhibit ethylene biosynthesis in soybean (Paradies et al., 1980), we observed 8.1fold less elicitation compared to $\mathrm{AgNO}_{3}$. This suggested that the mechanism-of-action of $\mathrm{AgNO}_{3}$ on glyceollin I was mostly distinct from the inhibition of ethylene biosynthesis. $\mathrm{AgNO}_{3}$ and several other heavy metals inhibited the degradation of glyceollins in soybean cotyledons, suggesting that heavy metal elicitors may target a glyceollin degrading enzyme or pathway (Yoshikawa et al., 1978). Our results confirmed this, but we also found that $\mathrm{AgNO}_{3}$ enhanced the degradation of the major isoflavone conjugate, 6"-O-malonyldaidzin, and reduced the consumption of daidzein (Figure 6). This suggested that $\mathrm{AgNO}_{3}$ acted by stimulating the expression or activity of an enzyme that catalyzed the hydrolysis of 6 "-O-malonyldaidzin to provide daidzein intermediates for the biosynthesis of glyceollin I, rather than by solely inhibiting glyceollin degradation. Future studies should address whether $\mathrm{AgNO}_{3}$ directly enhances the activity of a glycosidase that hydrolyzes 6' - $O$-malonyldaidzin, or whether $\mathrm{AgNO}_{3}$ stimulates the upregulation of the corresponding glycosidase gene(s). Our results suggest that overexpressing a glycosidase with specificity for 6 "-O-malonyldaidzin would enhance the heavy metal elicitation pathway. Glycosidase activities towards malonyl conjugates of daidzin and genistin were detected in the seed and root exudates of soybean (Graham et al., 1991). The jasmonic acid (JA)-inducible glycosidase G2 from Medicago truncatula has high specificity for daidzin (i.e., daidzein-7-O-glucoside) when expressed in yeast (Naoumkina et al., 2007), but 6"$O$-malonyldaidzin was not tested as a substrate. The significance of $\mathrm{AgNO}_{3}$ preferentially stimulating the degradation of $6 "$ - $O$-malonyldaidzin and not daidzin remains unclear. Studies may have to address the subcellular localization of these metabolites relative to the glycosidase(s) capable of hydrolyzing them to understand this mechanism.

\section{EXPERIMENTAL SECTION}

\subsection{Chemicals}

Stocks of the chemical elicitors $\mathrm{AgNO}_{3}$ (Sargent Welch, Buffalo, NY, USA), $\mathrm{CuCl}_{2}$, and 2,1,3benzothiadiazole were $5 \mathrm{M}$ in water. Salicylic acid was $5 \mathrm{M}$ in DMSO. Elicitors were purchased from Sigma. The glyceollin I synthetic standard was from Paul Erhardt (University of Toledo, Bancroft, MI, USA), daidzein from Cayman Chemical and daidzin, genistin (Ann Arbor, MI, 
USA), and genistein were from Indofine (Hillsborough, CA, USA). All UPLC solvents were LC-MS grade from Fisher (Hampton, FL, USA).

\subsection{Plant Growth and Elicitation}

Harosoy 63 seeds were sterilized in 70\% ethanol $0.2 \%$ triton $\mathrm{X}(v / v)$ for $5 \mathrm{~min}$, rinsed thrice with $95 \%$ ethanol, and imbibed in sterile water overnight. The imbibate was then discarded to remove growth inhibitors. For the elicitation of seeds, the seed coat was carefully removed to avoid damaging the embryo. The distal $2-3 \mathrm{~mm}$ of the cotyledons (the tips) were excised, and an incision was made through the axis of the central vein two thirds of the way towards the radical. Elicitor was applied to the wound, and the embryo was placed upright on its distal end on sterile wetted filter paper in a petri dish. For the elicitation of seedlings, sterilized seeds were transferred to water-soaked sterile vermiculite in beakers. The beakers were covered with a sterile cheese that had a circular hole cut into it to permit the passage of light. The cloth was covered with plastic wrap to ensure aseptic growth. The seed coats were carefully removed within 1-2 days. Seedlings were grown until the first-true-leaf stage ( $\sim 1$ week). For elicitation, a knotch $\sim 3 \mathrm{~mm}$ in diameter and 1-2 $\mathrm{mm}$ deep was cut into the central vein on the abaxial side of the cotyledon or into the hypocotyl, and roughly $250 \mathrm{mg}$ tissues (the weight of a seed) were harvested for the measurement of glyceollin I. Hairy root transformation with Agrobacterium rhizogenes strain K599 was done according to (Jacobs et al., 2015). The roots and hairy roots were elicited by cutting $\sim 250 \mathrm{mg}$ into $1 \mathrm{~cm}$ pieces and applying elicitor over the wounds. All seedling growth and elicitation treatments were done under $24 \mathrm{~h}$ cool white T5 fluorescent lights $\left(500 \mu \mathrm{E} \mathrm{m}^{-2} \mathrm{~s}^{-1}\right)$ at $24{ }^{\circ} \mathrm{C}$. The samples were treated with $50 \mu \mathrm{L}$ of elicitor for $48 \mathrm{~h}$ unless otherwise specified. The hairy roots and roots were treated for $24 \mathrm{~h}$. WGE was purified from race $1 P$. sojae according to (Ayers et al., 1976), with the exception that suction filtration was replaced by centrifugation at all steps.

\subsection{Isoflavonoid Analyses}

For the extraction of isoflavonoids, elicited seeds were pulverized for 3 min using $5 \mathrm{~mm}$ stainless steel grinding balls in a MM400 mixer mill (Retsch, Newtown, CT, USA) at frequency of $30 / \mathrm{s}$, then again following the addition of $80 \%$ ethanol $\left(1 \mu \mathrm{L} \mathrm{mg}^{-1}\right.$ fresh tissue). Seedling 
organs were ground using a mortar and pestle following freeze-drying, and were extracted similarly to seeds. The samples were centrifuged at $17,000 \times \mathrm{g}$ for $3 \mathrm{~min}$, clarified at $-20{ }^{\circ} \mathrm{C}$ overnight, then centrifuged again. The supernatant was filtered through a $0.2 \mu \mathrm{m}$, and $1 \mu \mathrm{L}$ was analyzed by UPLC-PDA-MS ${ }^{\mathrm{n}}$ adapted from (Aisyah et al., 2013). The quantity of each isoflavonoid was determined by comparison of the area under their peak at $283 \mathrm{~nm}$ absorbance in comparison to a standard curve of authentic standard. To estimate the amount of glyceollin I relative to all other seed isoflavonoids, unknown compounds and compounds for which we did not have standards were quantified in comparison a standard curve of daidzin.

\subsection{UPLC-PDA-MS}

UPLC-PDA-MS ${ }^{\mathrm{n}}$ was conducted using an Accela system (Thermo Scientific, San Jose, CA, USA) consisting of a 1250 pump, Open AS autosampler, and photodiode array (PDA) detector connected to a Q-Exactive-Oribitrap MS containing a HESI. Separations were achieved with an Acquity UPLC BEH shield RP18 column $(2.1 \mathrm{~mm}$ i.d. $\times 150 \mathrm{~mm}, 1.7 \mu \mathrm{m}$ particle size; Waters, Milford, MA, USA) with an Acquity UPLC BEH shield RP18 VanGuard precolumn (2.1 mm i.d. $\times 5 \mathrm{~mm}, 1.7 \mu \mathrm{m}$ particle size; Waters). The solvents, at a flow rate of $300 \mu \mathrm{L} / \mathrm{min}$, were water acidified with $0.1 \%(v / v)$ acetic acid, eluent A, and ACN acidified with $0.1 \%(v / v)$ acetic acid, eluent B. The temperature of the column oven was $35{ }^{\circ} \mathrm{C}$. The elution profile was as follows: $0-2 \mathrm{~min}$, from $10 \%$ to $25 \%(v / v) \mathrm{B}$; 2-9 $\mathrm{min}$, from $25 \%$ to $50 \% \mathrm{~B}$; $9-12 \mathrm{~min}, 50 \% \mathrm{~B}$; $12-17 \mathrm{~min}$, from $50 \%$ to $100 \% \mathrm{~B} ; 22-24 \mathrm{~min}, 100 \%$ to $10 \% \mathrm{~B}$; and $24-30 \mathrm{~min}, 10 \% \mathrm{~B}$. MS analysis was performed in Full MS/AIF mode in both positive and negative polarities. The Full MS properties were: Resolution 70,000, AGC target 3e6, Maximum IT $200 \mathrm{~ms}$, and Scan range 120-1200 m/z. AIF properties were: Resolution 70,000, AGC target 3e6, Maximum IT $200 \mathrm{ms,}$ NCE 35, and Scan range $80-1200 \mathrm{~m} / \mathrm{z}$. Nitrogen was used as sheath and auxiliary gas.

\section{5. qRT-PCR}

For the gene expression measurements, seeds were harvested into liquid nitrogen and lyophilized for at least 3 days. Tissues were ground to a fine powder using a mixer mill as indicated above. Total RNA was extracted using the Spectrum Plant Total RNA Kit (SigmaAldrich, St. Louis, MO, USA) following the manufacturer's protocol with the exception that 700 
$\mu \mathrm{L}$ lysis buffer was used per seed. RNA (500 ng) was treated with DNase I (Amplification grade, Invitrogen, Carlsbad, USA) to remove contaminating DNA. First-strand cDNA was synthesized using SuperScript II Reverse Transcriptase (Invitrogen). Parallel reactions were performed in the absence of Superscript II to test for genomic DNA contamination. Gene expressions from each cDNA sample were normalized to the endogenous reference PEPC16 (Ayers et al., 1976). The reactions $(5 \mu \mathrm{L})$ consisted of $1 \mu \mathrm{L}$ of first-strand cDNA (or untreated RNA) diluted $1 / 4$ to $1 / 10,250 \mathrm{nM}$ of forward and reverse primers, and $2.5 \mu \mathrm{L}$ of the iQ SYBR Green Supermix (BioRad, Hercules, CA, USA). qRT-PCR was performed on cDNA from four biological replicates or untreated RNA using a 7500 Realtime-PCR System (Applied Biosystems, Foster City, CA, USA). To verify the specificity of the qRT-PCR reactions, melting curves were determined subsequent to each reaction, and RT-PCR products for each primer set were fractionated on agarose gels. For the primer sequences, see Supplementary Table S2.

\subsection{Degradation of Isoflavonoids}

To obtain an extract that was concentrated in glyceollin I, or 6"-O-malonyldaidzin and daidzin, Harosoy 63 seeds $(\sim 500 \mathrm{~g})$ were elicited for $48 \mathrm{~h}$ with $20 \mathrm{mg} \mathrm{mL}^{-1} P$. sojae WGE, and the total isoflavonoids were extracted with $80 \%$ ethanol $\left(2 \mu \mathrm{L} \mathrm{mg}^{-1}\right.$ fresh tissue) using a Waring blender. Ethanol was removed by rotary evaporation and water by freeze-drying. The powder was reconstituted in $100 \mathrm{~mL}$ ethyl acetate and fractionated on $\sim 20$ preparative TLC plates according to (Kovinich et al., 2011). The top band $\left(R_{\mathrm{f}}=0.32\right)$ contained $\sim 60 \%$ of glyceollin $\mathrm{I}$ and minor amounts of glyceollin II, III, coumestrol, and genistein, and was extracted separately from the origin containing 39\% and 34\% 6"-O-malonyldaidzin and daidzin, respectively. The extracts were resuspended in deionized water to an absorbance of $0.5-0.6$ to be of physiologically relevant concentrations similar to that typically extracted from soybean seeds. The extract was sterilized by passage through nylon $(0.22 \mu \mathrm{m})$. To test whether the seeds catalyzed the degradation of metabolites, seed coats were removed from surface-sterilized seeds that were imbibed overnight in water. The seeds were cut in half through the radical to separate the two cotyledons, and each cotyledon was incised once from the distal tip along the adaxial plane to $\sim 3$ $\mathrm{mm}$ from the radical. In 24-well plates in the dark, dissected half-seeds were incubated in 600 $\mu \mathrm{L}$ of sterile $\mathrm{H}_{2} \mathrm{O}$ or $5 \mathrm{mM} \mathrm{AgNO}$ for $2 \mathrm{~h}$. These were then replaced with either extract enriched in glyceollin I, or 6"-O-malonyldaidzin and daidzin, or water, and incubated for $4 \mathrm{~h}$. The seeds were extracted with $80 \%$ ethanol $\left(1 \mu \mathrm{L} \mathrm{mg}^{-1}\right.$ fresh tissue) as indicated above. The liquid 
surrounding the seeds was extracted three times with an equal volume of ethyl acetate. The pooled extracts were evaporated to dryness with nitrogen gas and reconstituted with the extract from the corresponding seed. Isoflaonoids were quantified from the extract by UPLC-PDA-MS ${ }^{\mathrm{n}}$ as indicated above.

\section{CONCLUSIONS}

We have identified that combining the biotic elicitor WGE from $P$. sojae and the chemical elicitor $\mathrm{AgNO}_{3}$ stimulated the accumulation of the anticancer phytoalexin glyceollin $\mathrm{I}$ in an additive fashion, because they functioned by largely distinct elicitation mechanisms. WGE elicited a massive accumulation of biosynthesis gene mRNAs, and $\mathrm{AgNO}_{3}$ stimulated the hydrolysis of the isoflavone conjugate $6 "$-O-malonyldaidzin. Thus, our work suggests that overexpressing TFs that activate the transcription of phytoalexin biosynthesis genes and glycosidases that generate biosynthetic intermediates should be targets to genetically enhance biotic and chemical elicitation pathways, respectively. The combined elicitation approach represents an important discovery towards the economical bioproduction of glyceollin I and potentially other phytoalexins of medicinal or agricultural value.

Supplementary Materials: Supplementary materials are available online.

Acknowledgments: We thank Elroy Cober (AAFC, Ottawa) for kindly providing the Harosoy 63 seeds, Gustavo MacIntosh (Iowa State University) for the A. Rhizogenes, and Brett Tyler and Mannon Gallegly for the race 1 P. sojae. We thank Huiyuan Li for establishing the UPLC-PDAMS $^{\mathrm{n}}$ method, Maisha Huq for partially purifying the isoflavonoids, and Matt Kasson for identifying the fungal species isolated from soybean. This work was supported by WVU start-up funds to NK and is based upon work that is supported by the NIFA, USDA, and Hatch project under 1010200. 


\section{References}

1. Ahuja, I.; Kissen, R.; Bones, A.M. Phytoalexins in defense against pathogens. Trends Plant Sci. 2012, 17, 73-90.

2. Großkinsky, D.K.; van der Graaff, E.; Roitsch, T. Phytoalexin transgenics in crop protection-Fairy tale with a happy end? Plant Sci. 2012, 195, 54-70.

3. Jeandet, P.; Hébrard, C.; Deville, M.-A.; Cordelier, S.; Dorey, S.; Aziz, A.; Crouzet, J. Deciphering the role of phytoalexins in plant-microorganism interactions and human health. Molecules 2014, 19, 18033-18056.

4. Ibraheem, F.; Gaffoor, I.; Tan, Q.; Shyu, C.-R.; Chopra, S. A sorghum myb transcription factor induces 3-deoxyanthocyanidins and enhances resistance against leaf blights in maize. Molecules 2015, 20, 2388-2404.

5. Xu, Y.-H.; Wang, J.-W.; Wang, S.; Wang, J.-Y.; Chen, X.-Y. Characterization of gawrky1, a cotton transcription factor that regulates the sesquiterpene synthase gene $(+)-\delta$-cadinene synthase-a. Plant Physiol. 2004, 135, 507-515.

6. Yamamura, C.; Mizutani, E.; Okada, K.; Nakagawa, H.; Fukushima, S.; Tanaka, A.; Maeda, S.; Kamakura, T.; Yamane, H.; Takatsuji, H.; et al. Diterpenoid phytoalexin factor, a bHLH transcription factor, plays a central role in the biosynthesis of diterpenoid phytoalexins in rice. Plant J. 2015, 84, 1100-1113.

7. Akashi, T.; Sasaki, K.; Aoki, T.; Ayabe, S.-I.; Yazaki, K. Molecular cloning and characterization of a cdna for pterocarpan 4-dimethylallyltransferase catalyzing the key prenylation step in the biosynthesis of glyceollin, a soybean phytoalexin. Plant Physiol. 2009, 149, 683-693.

8. Moy, P.; Qutob, D.; Chapman, B.P.; Atkinson, I.; Gijzen, M. Patterns of gene expression upon infection of soybean plants by phytophthora sojae. Mol. Plant Microbe Interact. 2004, $17,1051-1062$.

9. Beyer, E.M. A potent inhibitor of ethylene action in plants. Plant Physiol. 1976, 58, 268271. 
10. Bhattacharyya, M.; Ward, E. Resistance, susceptibility and accumulation of glyceollins I-III in soybean organs inoculated with Phytophthora megasperma f. sp. glycinea. Physiol. Mol. Plant Path. 1986, 29, 227-237.

11. Yoshikawa, M. Diverse modes of action of biotic and abiotic phytoalexin elicitors. Nature 1978, 275, 546-547.

12. Selvam, C.; Jordan, B.C.; Prakash, S.; Mutisya, D.; Thilagavathi, R. Pterocarpan scaffold: A natural lead molecule with diverse pharmacological properties. Eur. J. Med. Chem. 2017, $128,219-236$.

13. Zimmermann, M.C.; Tilghman, S.L.; Boue, S.M.; Salvo, V.A.; Elliott, S.; Williams, K.Y.; Skripnikova, E.V.; Ashe, H.; Payton-Stewart, F.; Vanhoy-Rhodes, L.; et al. Glyceollin I, a novel antiestrogenic phytoalexin isolated from activated soy. J. Pharm. Exp. Ther. 2010, $332,35-45$.

14. Rhodes, L.V.; Tilghman, S.L.; Boue, S.M.; Wang, S.; Khalili, H.; Muir, S.E.; Bratton, M.R.; Zhang, Q.; Wang, G.; Burow, M.E. Glyceollins as novel targeted therapeutic for the treatment of triple-negative breast cancer. Oncol. Lett. 2012, 3, 163-171.

15. Luniwal, A.; Khupse, R.; Reese, M.; Liu, J.; El-Dakdouki, M.; Malik, N.; Fang, L.; Erhardt, P. Multigram synthesis of glyceollin I. Org. Process Res. Dev. 2011, 15, 1149-1162.

16. Simons, R.; Vincken, J.P.; Roidos, N.; Bovee, T.F.H.; van Iersel, M.; Verbruggen, M.A.; Gruppen, H. Increasing soy isoflavonoid content and diversity by simultaneous malting and challenging by a fungus to modulate estrogenicity. J. Agric. Food Chem. 2011, 59, 67486758.

17. Bhattacharyya, M.; Ward, E. Expression of gene-specific and age-related resistance and the accumulation of glyceollin in soybean leaves infected with Phytophthora megasperma f. sp. glycinea. Physiol. Mol. Plant Path. 1986, 29, 105-113.

18. Graham, T.L.; Graham, M.Y. Signaling in soybean phenylpropanoid responses (dissection of primary, secondary, and conditioning effects of light, wounding, and elicitor treatments). Plant Physiol. 1996, 110, 1123-1133. 
19. Burow, M.E.; Boue, S.M.; Collins-Burow, B.M.; Melnik, L.I.; Duong, B.N.; CarterWientjes, C.H.; Li, S.F.; Wiese, T.E.; Cleveland, T.E.; McLachlan, J.A. Phytochemical glyceollins, isolated from soy, mediate antihormonal effects through estrogen receptor alpha and beta. J. Clin. Endocr. Metable 2001, 86, 1750-1758.

20. Cheng, Q.; Li, N.; Dong, L.; Zhang, D.; Fan, S.; Jiang, L.; Wang, X.; Xu, P.; Zhang, S. Overexpression of soybean isoflavone reductase (gmifr) enhances resistance to phytophthora sojae in soybean. Front. Plant Sci. 2015, 6, 1024-1035.

21. Lygin, A.V.; Zernova, O.V.; Hill, C.B.; Kholina, N.A.; Widholm, J.M.; Hartman, G.L.; Lozovaya, V.V. Glyceollin is an important component of soybean plant defense against phytophthora sojae and macrophomina phaseolina. Phytopathology 2013, 103, 984-994.

22. Ayers, A.R.; Ebel, J.; Valent, B.; Albersheim, P. Host-pathogen interactions 10. Fractionation and biological-activity of an elicitor isolated from mycelial walls of phytophthora-megasperma var sojae. Plant Physiol. 1976, 57, 760-765.

23. Van De Schans, M.G.; Vincken, J.-P.; De Waard, P.; Hamers, A.R.; Bovee, T.F.; Gruppen, H. Glyceollins and dehydroglyceollins isolated from soybean act as serms and er subtypeselective phytoestrogens. J. Steroid Biochem. Mol. Biol. 2016, 156, 53-63.

24. Aisyah, S.; Gruppen, H.; Madzora, B.; Vincken, J.-P. Modulation of isoflavonoid composition of rhizopus oryzae elicited soybean (glycine max) seedlings by light and wounding. J. Agric. Food Chem. 2013, 61, 8657-8667.

25. Boue, S.M.; Carter, C.H.; Ehrlich, K.C.; Cleveland, T.E. Induction of the soybean phytoalexins coumestrol and glyceollin by aspergillus. J. Agric. Food Chem. 2000, 48, $2167-2172$.

26. Simons, R.; Vincken, J.P.; Bohin, M.C.; Kuijpers, T.F.M.; Verbruggen, M.A.; Gruppen, H. Identification of prenylated pterocarpans and other isoflavonoids in Rhizopus spp. Elicited soya bean seedlings by electrospray ionisation mass spectrometry. Rapid Commun. Mass Spectrom. 2011, 25, 55-65.

27. Bektas, Y.; Eulgem, T. Synthetic plant defense elicitors. Front. Plant Sci. 2014, 5, 1-17. 
28. Paradies, I.; Konze, J.R.; Elstner, E.F.; Paxton, J. Ethylene: Indicator but not inducer of phytoalexin synthesis in soybean. Plant Physiol. 1980, 66, 1106-1109.

29. Ward, E.W.; Cahill, D.M.; Bhattacharyya, M.K. Abscisic acid suppression of phenylalanine ammonia-lyase activity and mrna, and resistance of soybeans to Phytophthora megasperma f. sp. glycinea. Plant Physiol. 1989, 91, 23-27.

30. Liu, C.-J.; Huhman, D.; Sumner, L.W.; Dixon, R.A. Regiospecific hydroxylation of isoflavones by cytochrome p450 81e enzymes from medicago truncatula. Plant J. 2003, 36, $471-484$.

31. Naoumkina, M.; Farag, M.A.; Sumner, L.W.; Tang, Y.; Liu, C.-J.; Dixon, R.A. Different mechanisms for phytoalexin induction by pathogen and wound signals in medicago truncatula. Proc. Natl. Acad. Sci. USA 2007, 104, 17909-17915.

32. Graham, T.L. Flavonoid and isoflavonoid distribution in developing soybean seedling tissues and in seed and root exudates. Plant Physiol. 1991, 95, 594-603.

33. Jacobs, T.B.; LaFayette, P.R.; Schmitz, R.J.; Parrott, W.A. Targeted genome modifications in soybean with crispr/cas9. BMC Biotechnol. 2015, 15, 16-26.

34. Kovinich, N.; Saleem, A.; Arnason, J.T.; Miki, B. Combined analysis of transcriptome and metabolite data reveals extensive differences between black and brown nearly-isogenic soybean (glycine max) seed coats enabling the identification of pigment isogenes. BMC Genom. 2011, 12, 381-400.

35. Ayers, A.R.; Ebel, J.; Finelli, F.; Berger, N.; Albersheim, P. Host-pathogen interactions 9. Quantitative assays of elicitor activity and characterization of elicitor present in extracellular medium of cultures of phytophthora-mega-sperma var sojae. Plant Physiol. 1976, 57, 751-759. 


\section{Figures}

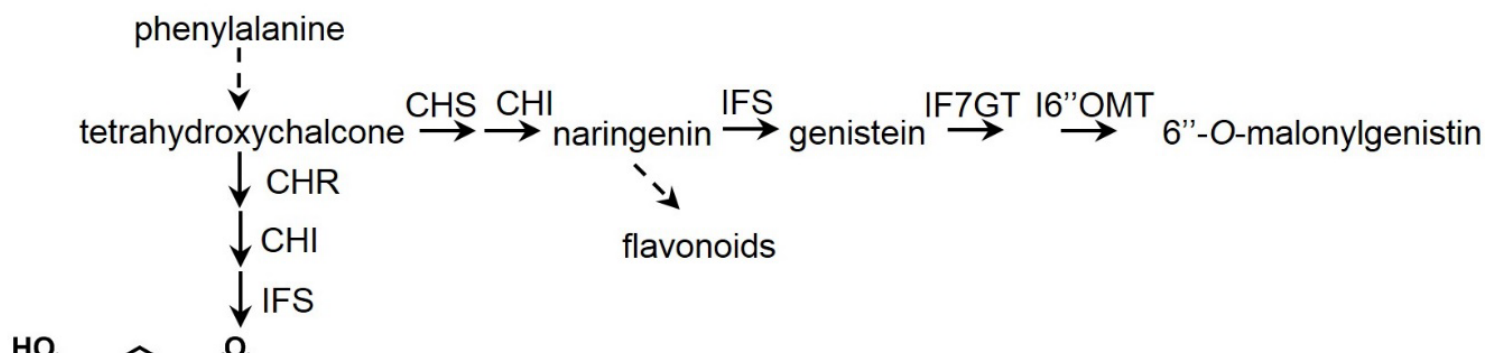<smiles>O=c1c(-c2ccco2)coc2cc(O)ccc12</smiles>

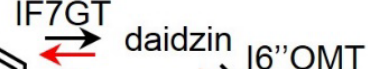

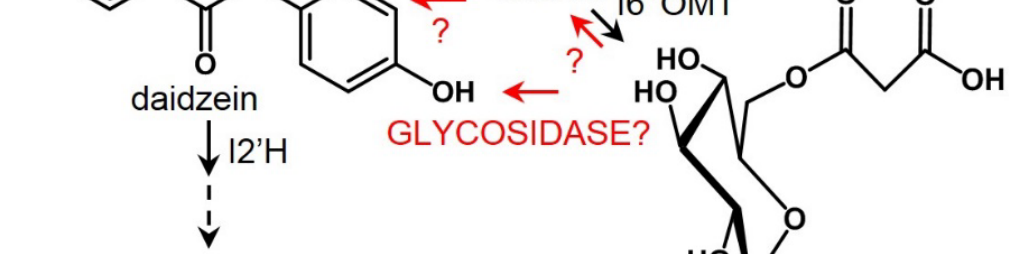

3,9-dihydroxypterocarpan

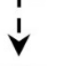

glycinol
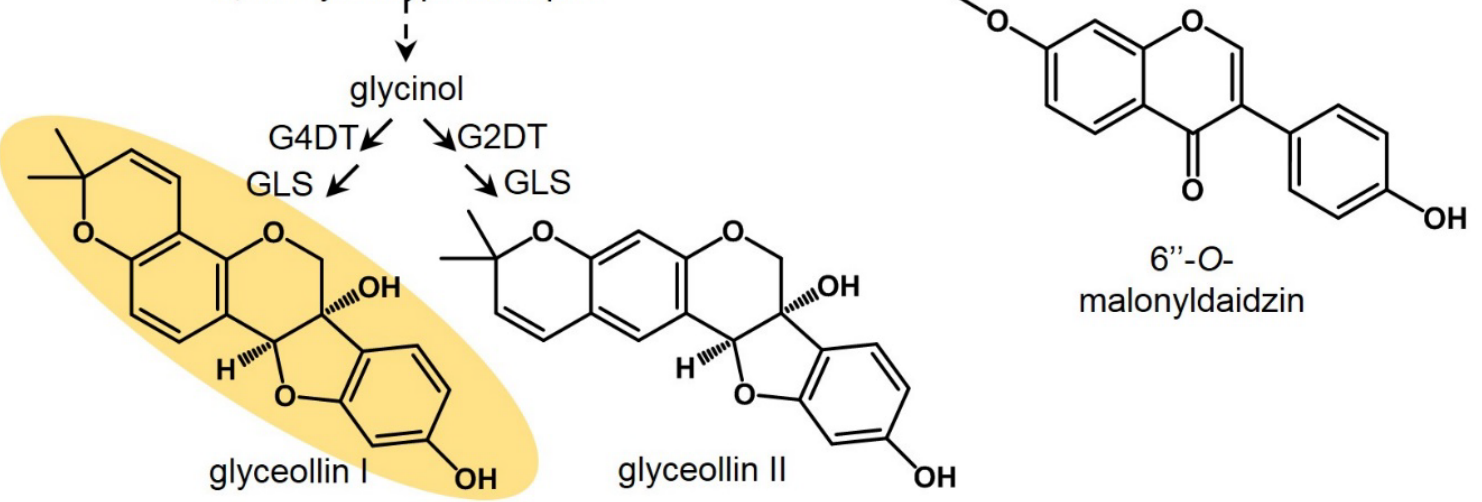

6"-O-

malonyldaidzin<smiles>C=C(C)C1Cc2cc3c(cc2O1)OC[C@]1(O)c2ccc(O)cc2O[C@H]31</smiles>

Figure 1. Glyceollin I biosynthetic pathway. In addition to de novo biosynthesis, the constitutively accumulating isoflavone conjugate 6 "-O-malonyldaidzin may be hydrolyzed to provide daidzein intermediates for glyceollin I biosynthesis. CHS, chalcone synthase; CHR, chalcone reductase; $\mathrm{CHI}$, chalcone isomerase; IFS, isoflavone synthase; I2'H, isoflavone 2'-hydroxylase; G4DT, glycinol 4-dimethylallyl transferase; G2DT, glycinol 2-dimethylallyl transferase; GLS, glyceollin synthase; UF7GT (UGT88E3) UDP-glucose:isoflavone-7-O-glucosyltransferase; I6"OMT (GmMT7) isoflavone-7-O-glucoside-6"-O-methyltransferase. 

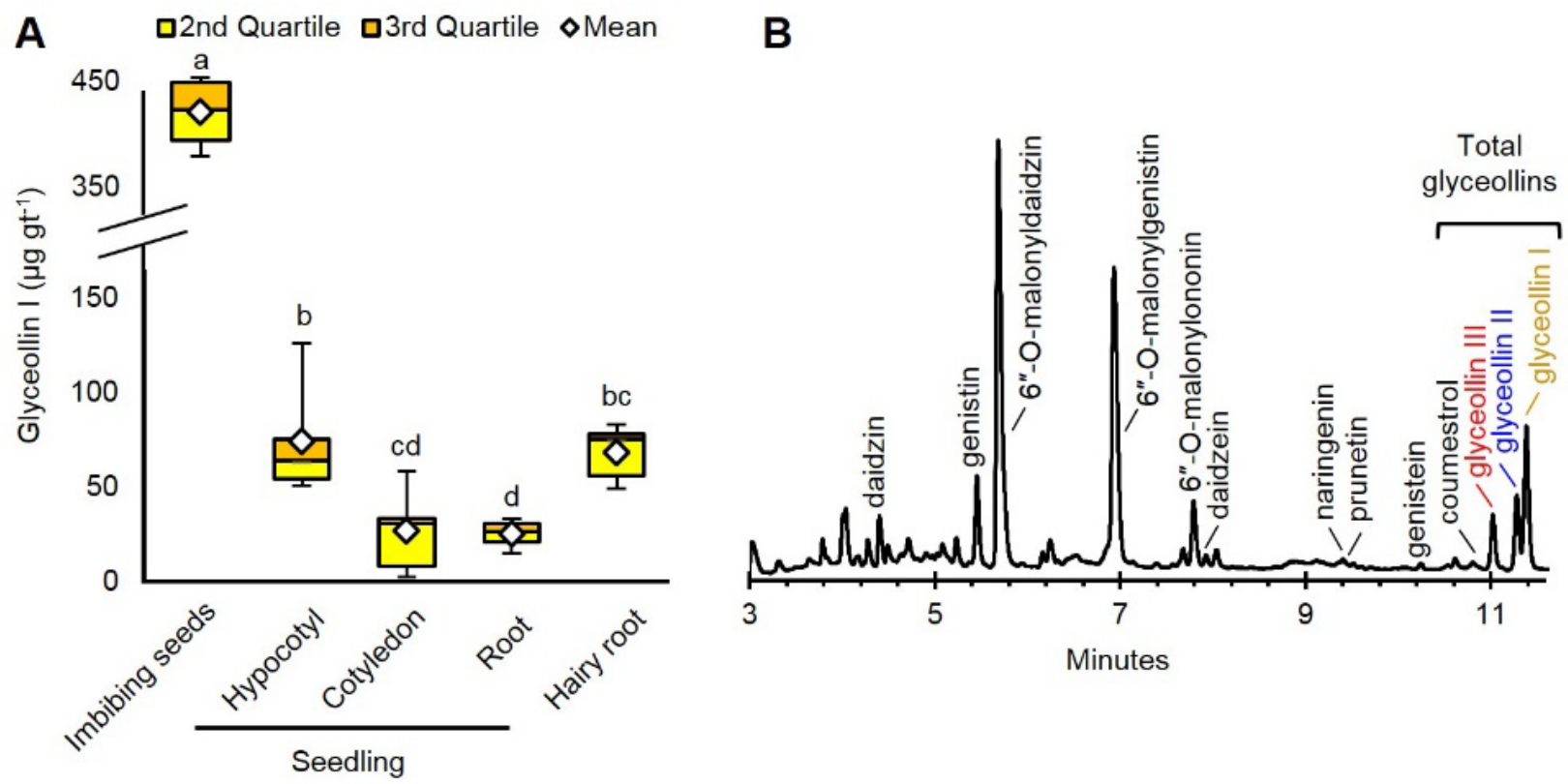

Figure 2. (A) Amounts of glyceollin I from soybean organs treated with wall glucan elicitor (WGE) from Phytophthora sojae. Two-way ANOVA, Tukey post hoc test $(p<$ 0.001); (B) UPLC-PDA chromatogram at $283 \mathrm{~nm}$ of isoflavonoids from imbibing seeds. Isoflavonoid identities were determined by UPLC-PDA-MS ${ }^{\mathrm{n}}$ retention time, fragmentation pattern, and absorbance features by comparison to standards (commercial or purified) and by comparison to the literature (Supplementary Table S1). Different letters show significant differences by ANOVA 

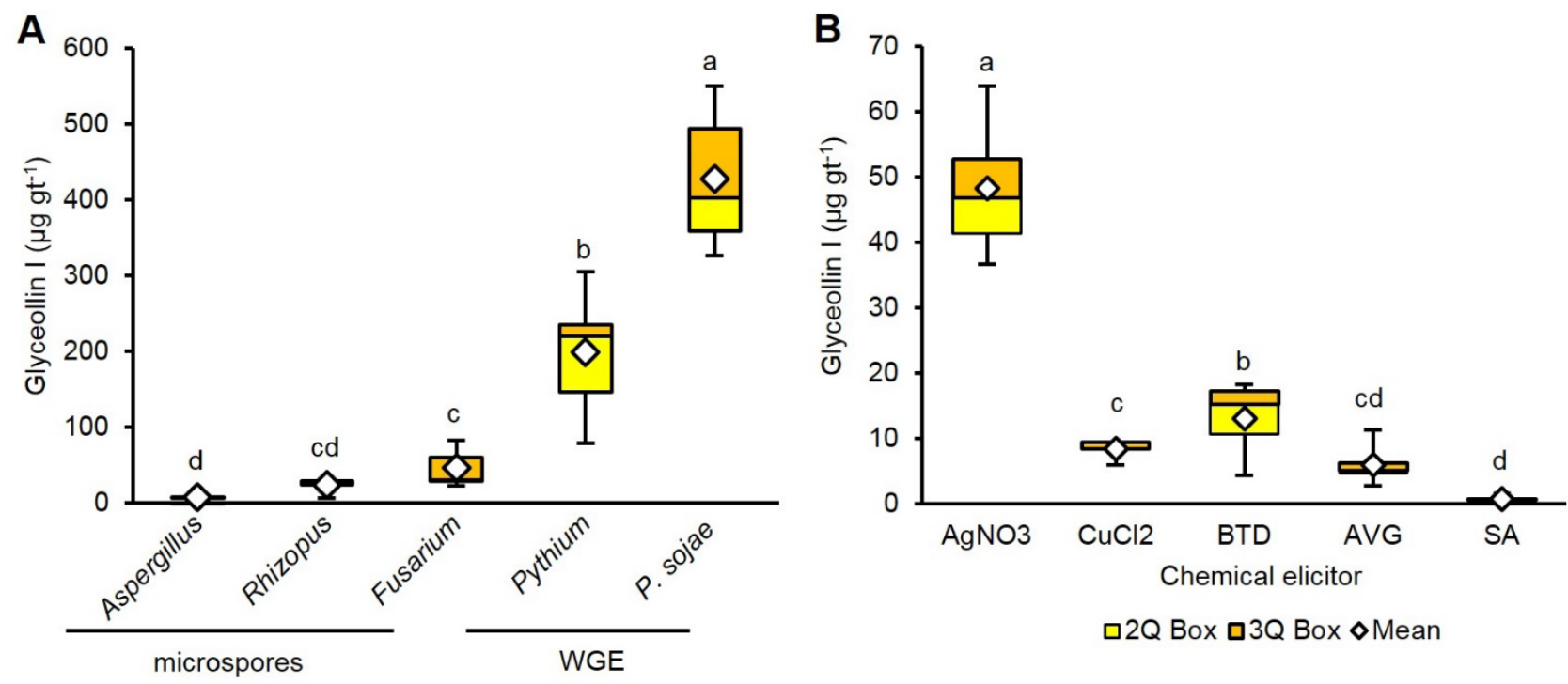

Figure 3. (A) Amounts of glyceollin I from soybean seeds treated with biotic elicitors for $24 \mathrm{~h}$. Two-way ANOVA, Tukey post hoc test $(p<0.001)$; (B) Treatment of seeds with chemical elicitors $\left(\mathrm{AgNO}_{3}\right)$, copper chloride $\left(\mathrm{CuCl}_{2}\right)$, benzothiadiazole (BTD), aminoethoxyvinyl glycine (AVG), and salicylic acid (SA) at $1 \mathrm{mM}$. Different letters show significant differences by ANOVA 


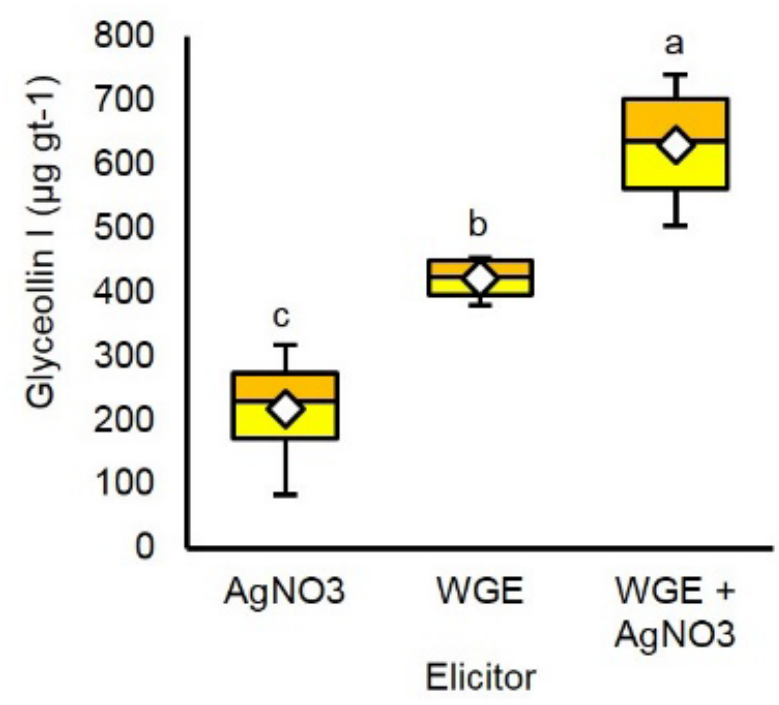

Figure 4. Elicitation with $\mathrm{AgNO}_{3}(5 \mathrm{mM})$ and WGE $\left(20 \mathrm{mg} \mathrm{mL}^{-1}\right)$ separately and in combination. Two-way ANOVA, Tukey post hoc test, $p<0.001$. Different letters show significant differences by ANOVA. 

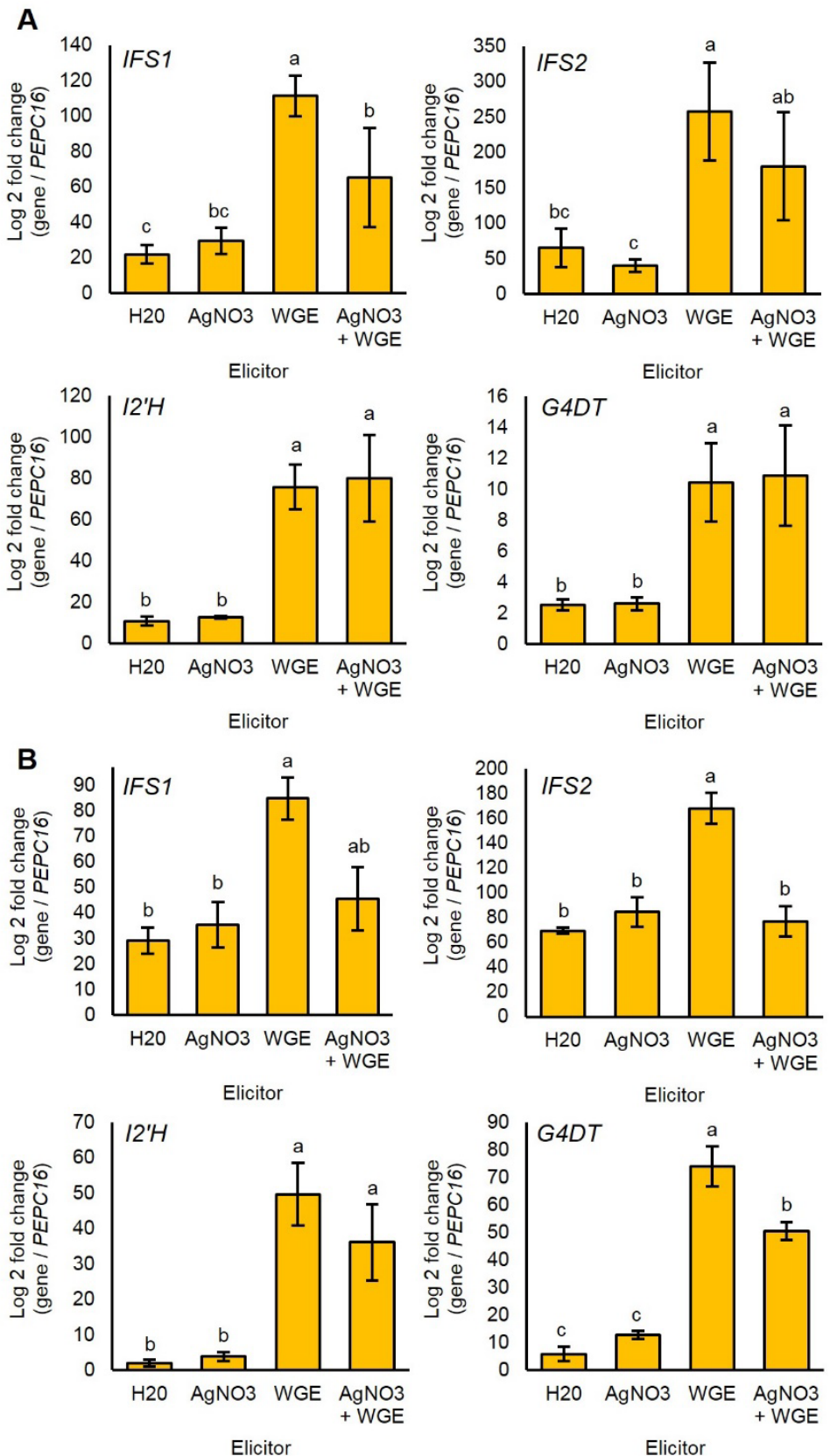

Figure 5. (A) Relative gene expression levels $48 \mathrm{~h}$ after elicitor treatment with elicitor measured by qRT-PCR; (B) Relative gene expression levels at $8 \mathrm{~h}$ after elicitor treatment. Expressions in each sample were measured relative to the endogenous reference gene PEPC16. Two-way ANOVA, Tukey post hoc test, $p<0.01$. Two independent experiments with four biological replicates were conducted with similar results. Different letters show significant differences by ANOVA 

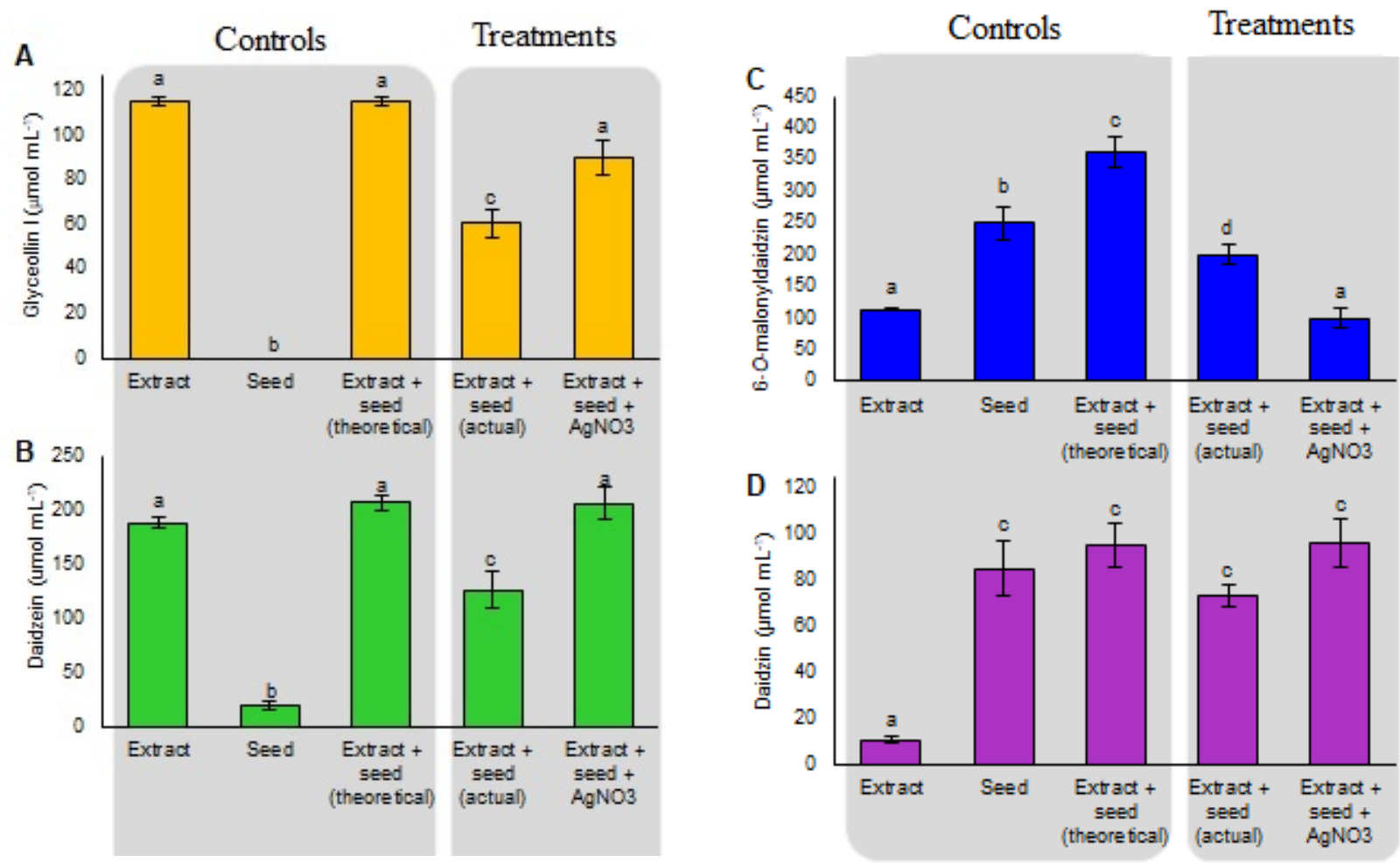

Figure 6. Degradation of externally supplied glyceollin I (A); daidzein (B); 6"-Omalonyldaidzin (C); and daidzin (D) by soybean seeds. Isoflavonoids were partially purified from an ethanolic extract of WGE-elicited soybean seeds, and were incubated with imbibed soybean seeds pretreated with $\mathrm{AgNO}_{3}$ or water to test for effects on metabolite degradation. Shown is the amount of metabolite from the initial partially purified ethanolic extract (Extract), the amount from imbibed seeds in incubated in water only (Seed), the theoretical amount from empirically adding the values from Extract and Seed (theoretical), the amount observed from incubating the seed in water for $2 \mathrm{~h}$ followed by metabolite extract for $4 \mathrm{~h}$ (actual), or from incubating the seed in 5 $\mathrm{mM} \mathrm{AgNO} 3$ for $2 \mathrm{~h}$ followed by metabolite extract for $4 \mathrm{~h}$ (Extract + seed $+\mathrm{AgNO}_{3}$ ). Two-way ANOVA, Tukey post hoc test $(p<0.001)$. The results represent four biological replicates. Different letters show significant differences by ANOVA 


\section{Supplementary Figures}
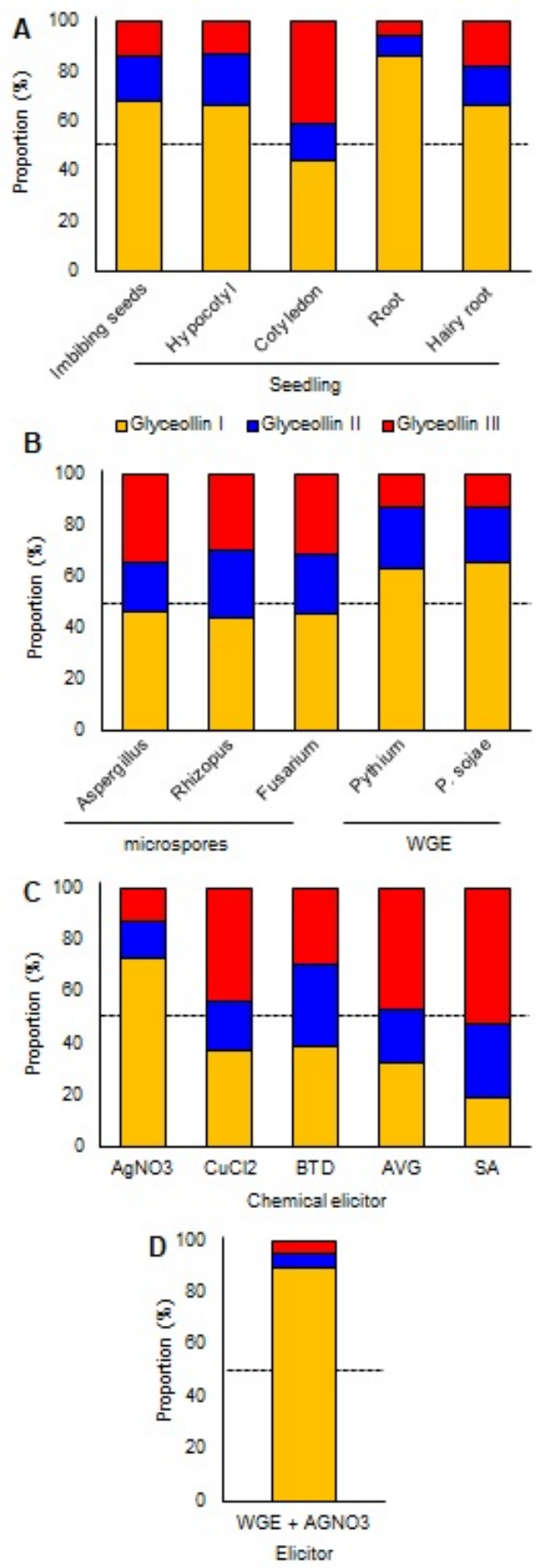

Supplementary Figure S1. Relative proportion of glyceollins from soybean organs treated with purified wall glucan elicitor (WGE) from $P$. sojae (A), from soybean seeds treated with biotic elicitors (B), chemical elicitors silver nitrate $\left(\mathrm{AgNO}_{3}\right)$, copper chloride $\left(\mathrm{CuCl}_{2}\right)$, benzothiadiazole (BTD), aminoethoxyvinyl glycine (AVG), and salicylic acid (SA) at $1 \mathrm{mM}(\mathrm{C})$, seeds with $\mathrm{AgNO}_{3}(5 \mathrm{mM})$ and WGE (20 $\left.\mathrm{mg} \mathrm{mL}^{-1}\right)(\mathrm{D})$. Dashed line demarcates 50\%. 

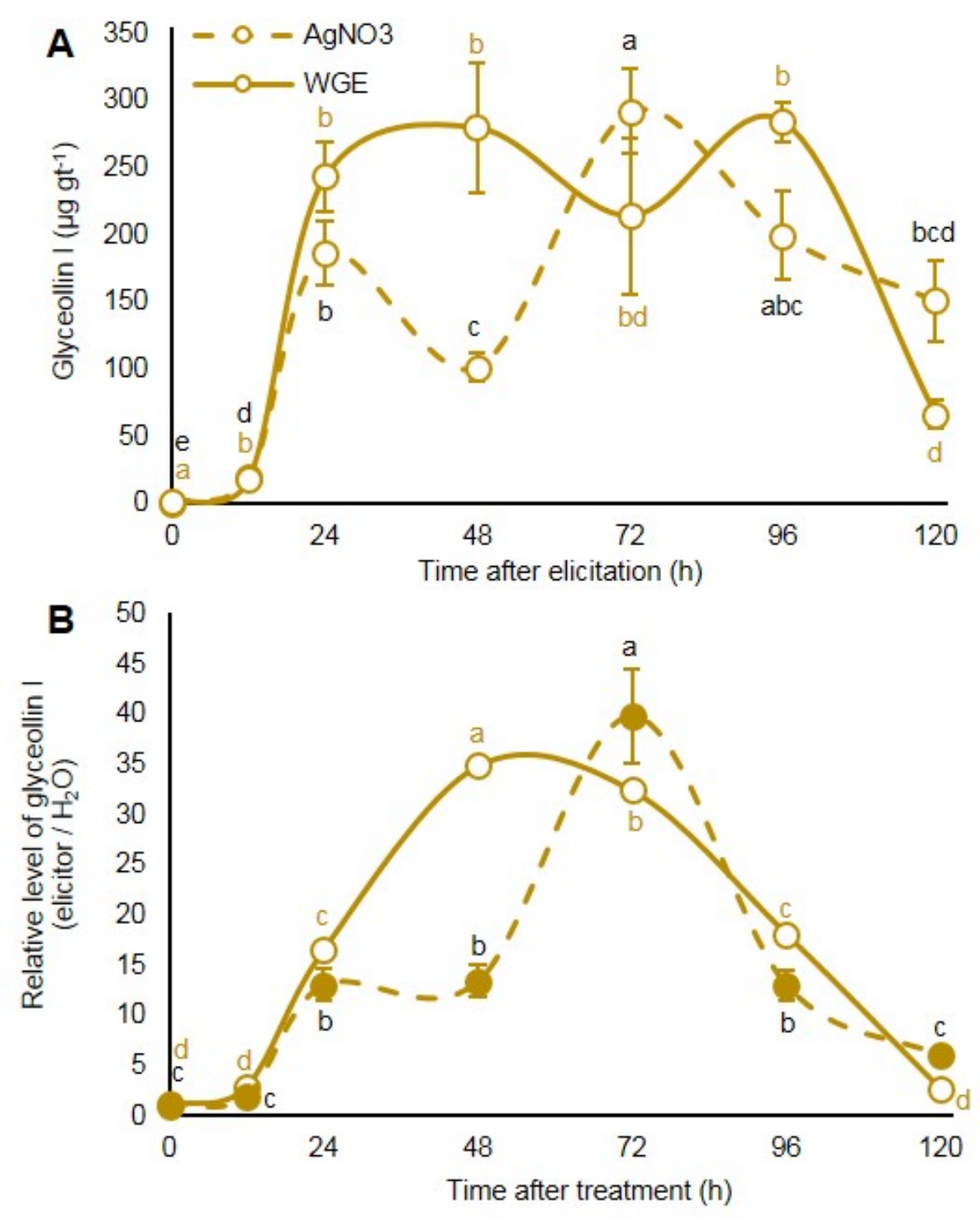

Supplementary Figure S2. (A) Glyceollin I accumulation dynamics after eliciting imbibed seeds with $5 \mathrm{mg} \mathrm{mL}-1 \mathrm{WGE}$ or $2.5 \mathrm{mM}$ AgNO3 for the indicated times. (B) Metabolite induction compared to the solvent control $(\mathrm{H} 2 \mathrm{O})$. Two-way ANOVA, Tukey post hoc test $(\mathrm{P}<0.001)$. 

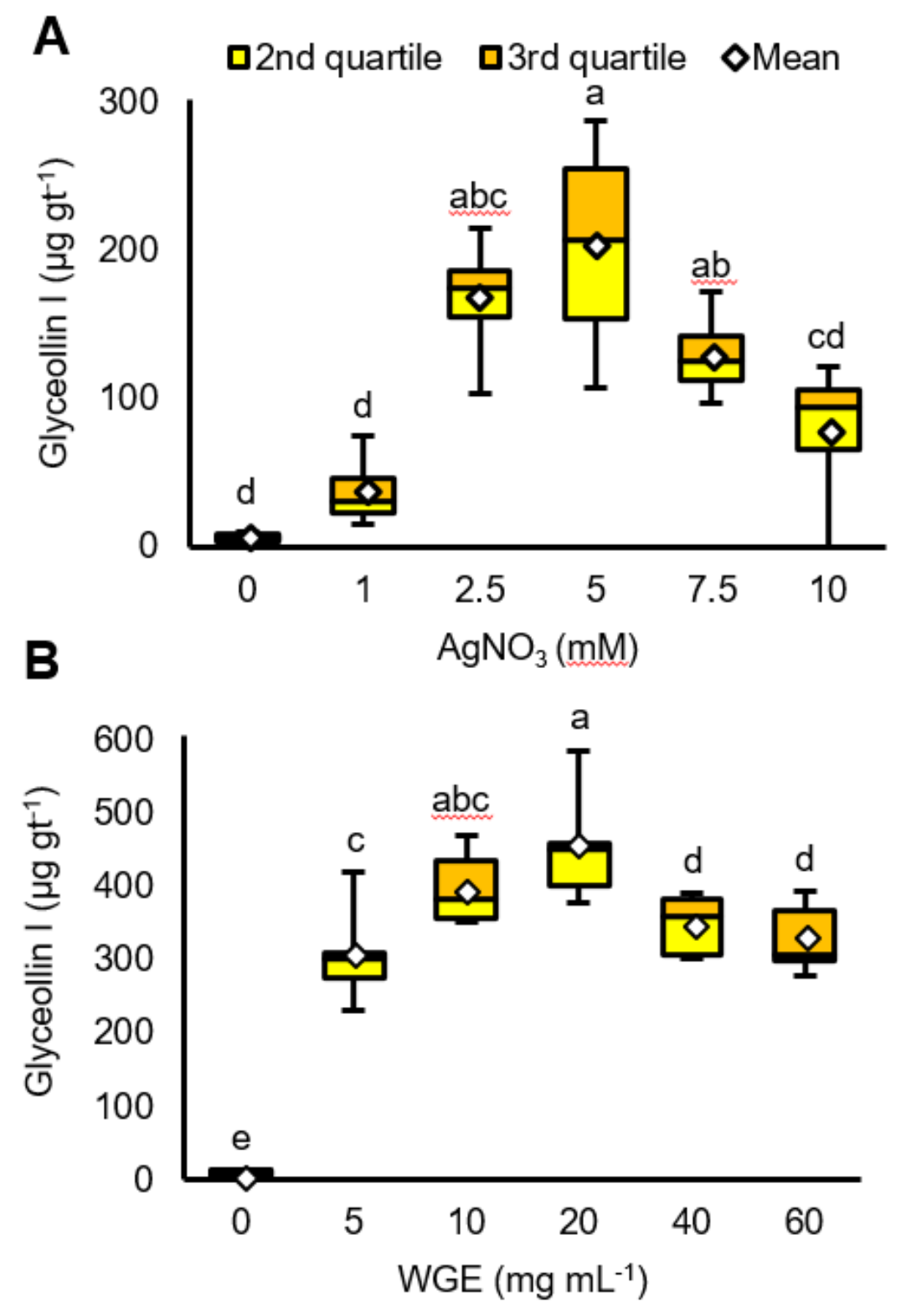

Supplementary Figure S3. (A) Glyceollin I concen-trations in imbibing soybean seeds elicited with different concentrations of AgNO3. (B) Elicitation with different concentrations of WGE. Two-way ANOVA, Tukey post hoc test, $\mathrm{P}<0.001$. 


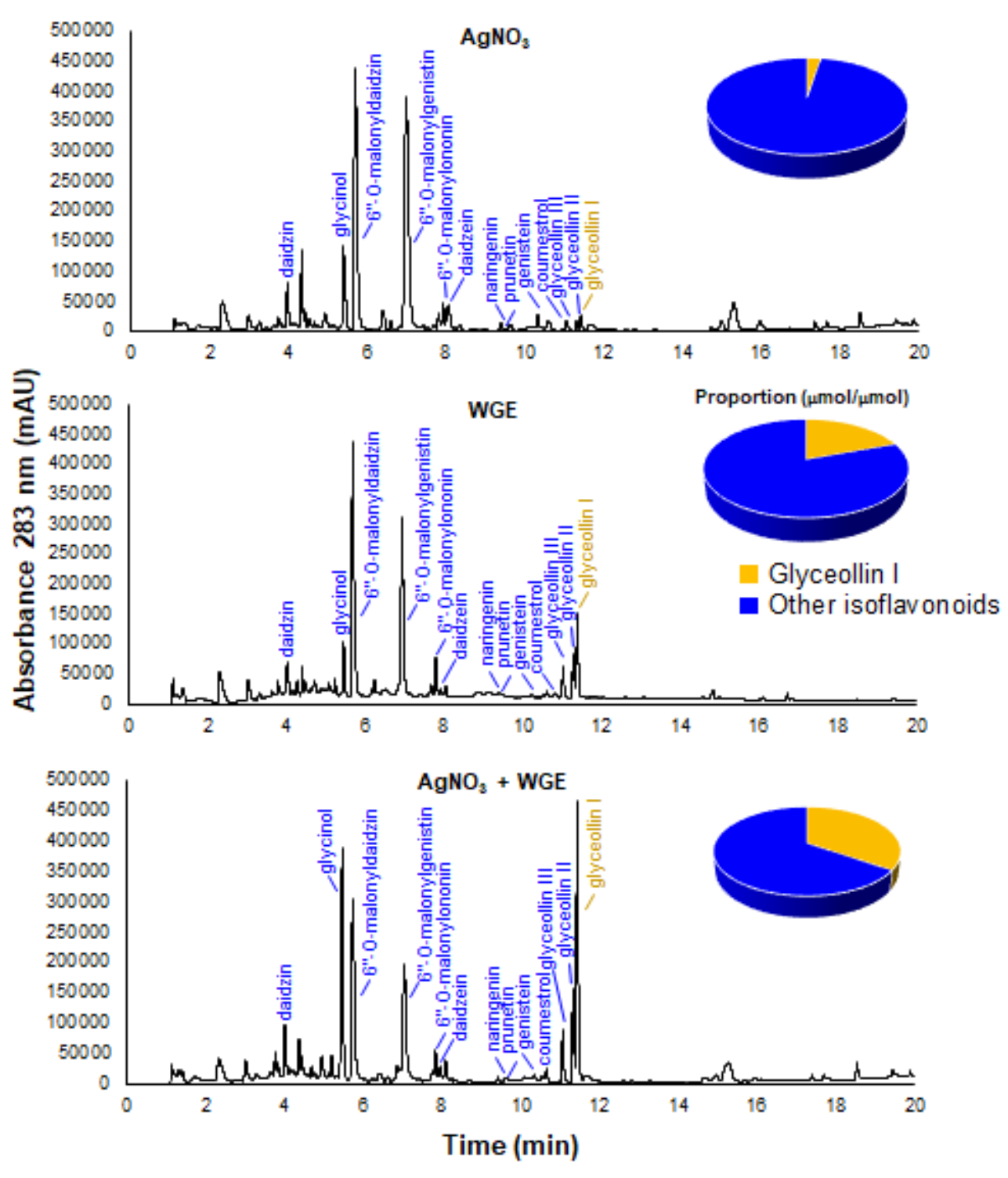

Supplementary Figure S4. Composition of glyceollin I relative to all other isoflavonoids in the seed ethanolic extract demonstated by UPLC-PDA and by pie chart. The amounts of all UPLC-PDA peaks that were not annotated were compounds for which we did not have standards and were quantified based on daidzin equivalents. 


\section{Supplementary Tables}

Supplementary Table S1. UPLC-PDA-MS ${ }^{\mathrm{n}}$ identifying features of isoflavonoids.

\begin{tabular}{|c|c|c|c|c|c|c|}
\hline Peak & $R_{t}(\min )$ & $\begin{array}{l}\lambda_{\max } \\
(\mathrm{nm}) \\
\end{array}$ & $\begin{array}{c}{[\mathrm{M}-} \\
\mathrm{H}]^{-}\end{array}$ & $\begin{array}{c}\text { MS/MS fragments } \\
(\mathrm{m} / \mathrm{z})\end{array}$ & $\begin{array}{c}{[\mathrm{M}+} \\
\mathrm{H}]^{+} \\
\end{array}$ & $\begin{array}{c}\text { MS/MS fragments }{ }^{+} \\
(\mathrm{m} / \mathrm{z})\end{array}$ \\
\hline daidzin $^{a}$ & 4.39 & 250 & 415.10 & $\begin{array}{c}253.05 \text { [daidzein - } \mathrm{H}^{-}\end{array}$ & 417.12 & $\begin{array}{c}255.06 \text { [daidzein + }^{+} \\
\mathrm{H}^{+}\end{array}$ \\
\hline glycinol $^{b}$ & 5.47 & 283 & 271.06 & 217 & 255.07 & $227.59,214.99$ \\
\hline genistin $^{a}$ & 5.48 & 260 & 431.10 & - & 433.11 & $\begin{array}{c}271.07 \text { [genistein }+ \\
\mathrm{H}^{+}, 255.07\end{array}$ \\
\hline $\begin{array}{l}6^{\prime \prime}-\mathrm{O}- \\
\text { malonyldaidzin }\end{array}$ & 5.80 & 251 & 501.10 & $\begin{array}{c}253.05 \text { [daidzein - } \\
\mathrm{H}^{-}\end{array}$ & 503.12 & $\begin{array}{c}255.06 \text { [daidzein + } \\
\mathrm{H}^{+}\end{array}$ \\
\hline $\begin{array}{l}6^{\prime \prime}-0- \\
\text { malonylgenistin }\end{array}$ & 7.01 & 260 & 517.10 & $\begin{array}{c}269.05 \text { [genistein - } \\
\text { H]- }\end{array}$ & 519.11 & $\begin{array}{c}271.06 \text { [genistein + } \\
\mathrm{H}^{+}\end{array}$ \\
\hline $\begin{array}{l}6^{\prime \prime}-\mathrm{O}- \\
\text { malonylononin }^{\mathrm{b}}\end{array}$ & 7.82 & 259 & 515.12 & $\begin{array}{c}253.05 \text { [daidzein - } \\
\mathrm{H}^{-} 267.07 \\
\text { [formononetin - H] }^{-}\end{array}$ & 517.13 & $\begin{array}{c}269.08 \\
{\text { [formononetin }+\mathrm{H}]^{+}}^{+}\end{array}$ \\
\hline daidzein $^{a}$ & 8.04 & 248 & 253.05 & 132.02 & 255.06 & 222.06 \\
\hline naringenin ${ }^{a}$ & 9.41 & 259 & 271.06 & 263.08 & 273.08 & 241.05 \\
\hline prunetin $^{a}$ & 9.90 & 258 & 283.06 & $\begin{array}{c}269.05 \text { [genistein - } \\
\text { H]- }\end{array}$ & 285.08 & - \\
\hline genistein $^{a}$ & 10.28 & 261 & 269.05 & 239.13 & 271.06 & 241.05 \\
\hline coumestrol $^{\mathrm{a}}$ & 10.90 & 342 & 267.03 & 253.09 & 269.04 & 236.05 \\
\hline glyceollin III ${ }^{b}$ & 11.10 & 289 & 337.11 & 319.10 & 339.12 & 321.11 \\
\hline glyceollin II & 11.30 & 283 & 337.11 & 319.10 & 339.12 & 321.11 \\
\hline glyceollin I ${ }^{a}$ & 11.48 & 283 & 337.11 & $255.07,319.10$ & 339.12 & 321.11 \\
\hline
\end{tabular}

aPeak identities were based on MS feature comparisons to authentic standards.

bIdentities based on MS feature comparisons to Aisyah et al. 2013 and Simons et al. 2014. 
Supplementary Table S2. Primers.

\begin{tabular}{lll}
\hline Gene & Primer & Sequence \\
\hline PEPC16 & qPCf & TGCAACTGATTCTTATGTTCCAA \\
PEPC16 & qPCr & GGCATCTTAACCACCTCACG \\
G4DT & qG4f & TGGCTTTCGGAGTTGGTATC \\
G4DT & qG4r & GAACAGCATTTCCCATACCC \\
IFS1 & qIF1f & CACTCAAACTCGGGATCACA \\
IFS1 & qIF1r & GACGCAAGTGCAGAAACAAA \\
IFS2 & qIF2f & GGAGAGGTTGTTGAGGGTGA \\
IFS2 & qIF2r & GACCCTTGATGTGGTCCTTG \\
I2'H & qI2f & CCATGCTTTTTGGTGGAACT \\
I2'H & qI2r & GCCTTCTTCAACACCTCTGG \\
\hline
\end{tabular}




\section{Chapter Three}

The NAC Family Transcription Factor GmNAC42-1 Regulates Biosynthesis of the Anticancer and Neuroprotective Glyceollins in Soybean

\section{Md Asraful Jahan', Brianna Harris², Matthew Lowery³, Katie Coburn², Aniello M. Infante $^{4}$, Ryan J. Percifield ${ }^{2}$, Amanda G. Ammer ${ }^{5}$, Nik Kovinich ${ }^{1 *}$}

${ }^{1}$ Division of Plant and Soil Sciences, ${ }^{2}$ Department of Biology, ${ }^{3}$ Department of Biochemistry, ${ }^{4}$ Department of Biostatistics, ${ }^{5}$ Microscope Imaging Facility, West Virginia University, Morgantown, West Virginia, 26506

\section{* Corresponding author}

Nik Kovinich

Assistant Professor of Genetics, Division of Plant and Soil Sciences

Davis College of Agriculture, Natural Resources and Design

West Virginia University

1194 Evansdale Dr

Morgantown, WV 26506-6108

Tel.: +1-304-293-9240

E-mail: nikovinich@mail.wvu.edu

Jahan MA, Harris B, Lowery M, Coburn K, Infante AM, Percifield RJ, Ammer AG, Kovinich N (2019). The NAC family transcription factor GmNAC42-1 regulates biosynthesis of the anticancer and neuroprotective glyceollins in soybean. BMC genomics 20: 149 


\section{ABSTRACT \\ Background}

Glyceollins are isoflavonoid-derived pathogen-inducible defense metabolites (phytoalexins) from soybean (Glycine max L. Merr) that have important roles in providing defense against pathogens. They also have impressive anticancer and neuroprotective activities in mammals. Despite their potential usefulness as therapeutics, glyceollins are not economical to synthesize and are biosynthesized only transiently and in low amounts in response to specific stresses. Engineering the regulation of glyceollin biosynthesis may be a promising approach to enhance their bioproduction, yet the transcription factors (TFs) that regulate their biosynthesis have remained elusive. To address this, we first aimed to identify novel abiotic stresses that enhance or suppress the elicitation of glyceollins and then used a comparative transcriptomics approach to search for TF gene candidates that may positively regulate glyceollin biosynthesis.

\section{Results}

Acidity stress ( $\mathrm{pH} 3.0$ medium) and dehydration exerted prolonged (week-long) inductive or suppressive effects on glyceollin biosynthesis, respectively. RNA-seq found that all known biosynthetic genes were oppositely regulated by acidity stress and dehydration, but known isoflavonoid TFs were not. Systemic acquired resistance (SAR) genes were highly enriched in the geneset. We chose to functionally characterize the NAC (NAM/ATAF1/2/CUC2)-family TF GmNAC42-1 that was annotated as an SAR gene and a homolog of the Arabidopsis thaliana (Arabidopsis) indole alkaloid phytoalexin regulator $A N A C 042$. Overexpressing and silencing GmNAC42-1 in elicited soybean hairy roots dramatically enhanced and suppressed the amounts of glyceollin metabolites and biosynthesis gene mRNAs, respectively. Yet, overexpressing GmNAC42-1 in non-elicited hairy roots failed to stimulate the expressions of all biosynthesis genes. Thus, GmNAC42-1 was necessary but not sufficient to activate all biosynthesis genes on its own, suggesting an important role in the glyceollin gene regulatory network (GRN). The GmNAC42-1 protein directly bound the promoters of biosynthesis genes IFS2 and G4DT in the yeast one-hybrid $(\mathrm{Y} 1 \mathrm{H})$ system.

\section{Conclusions}

Acidity stress is a novel elicitor and dehydration is a suppressor of glyceollin biosynthesis. The TF gene GmNAC42-1 is an essential positive regulator of glyceollin biosynthesis. Overexpressing GmNAC42-1 in hairy roots can be used to increase glyceollin yields $>10$-fold upon elicitation. Thus, manipulating the expressions of glyceollin TFs is an effective strategy for enhancing the bioproduction of glyceollins in soybean. 
Keywords: Phytoalexin, transcription factor, NAC, isoflavonoids, glyceollins

\section{BACKGROUND}

In 1939 K.O. Mueller et al. reported that metabolites that were elicited in potato upon inoculation with an incompatible race of Phytophthora infestans subsequently provided resistance to a compatible race (Müller et al., 1939). Since then, the pathogen-inducible defense metabolites that have been identified from numerous plant species have collectively been referred to as 'phytoalexins'. Some phytoalexins have essential roles in defending agricultural crops against major pathogens. A classic example is the glyceollins of soybean that provide resistance to the oomycete Phytophthora sojae (Graham et al., 2007; Lygin et al., 2013; Yoshikawa et al., 1978). For decades researchers have studied the genetic regulation of phytoalexin elicitation by pathogens. Efforts have recently focused on identifying the transcription factors (TFs) that activate phytoalexin biosynthesis, a goal that has been confounded by the myriad of plant responses that occur synchronously in response to pathogens. Phytoalexins are biosynthetically diverse among plant species and include the isoflavonoidderived glyceollins from soybean, the phenylpropanoid stilbenes from grapevine, the phenolic aldehyde gossypol from cotton, the terpenoid momilactones and phytocassanes from rice, and the indole alkaloid camalexin from Arabidopsis (Ibraheem et al., 2015; Ogawa et al., 2017; Saga et al., 2012; Xu et al., 2004; Yamamura et al., 2015; Zheng et al., 2006). Since the TFs that activate the biosynthesis of phytoalexins in different plant species belong to different gene families and/or are non-homologous, for decades an important question has remained whether phytoalexin TFs are as diverse as the biosynthetic pathways that they regulate. Yet, several excellent reviews highlight that phytoalexins share common abiotic elicitors (Ahuja et al., 2012; Großkinsky et al., 2012; Jeandet, 2015). This could suggest conserved regulatory pathways and TFs among plant species despite the biosynthetic heterogeneity of phytoalexins.

Highly conserved abiotic elicitors of phytoalexins include heavy metals, herbicides, and UV irradiation. UV elicits stilbene phytoalexins in grapevine, Cissus Antarctica, and Cannabis sativa (Marti et al., 2014), the flavonoid and diterpenoid phytoalexins in rice (Kato et al., 1993; Park et al., 2013), camalexin in Arabidopsis (Mert-Turk et al., 2003), and glyceollins in soybean (Reilly and Klarman, 1980). In rice, loss-of-function mutants of the JA biosynthesis gene allene oxide cyclase (aos) or jasmonic acid-amido synthetase (osjar1-2) resulted in an almost complete loss of sakuranetin elicitation in response to UV (Miyamoto et al., 2016). Yet, the diterpenoid phytoalexins of rice were not affected in JA biosynthesis mutants. Copper chloride $\left(\mathrm{CuCl}_{2}\right)$ 
elicitation of sakuranetin, momilactone, and diterpenoid phytoalexins in rice was dramatically reduced by JA biosynthesis inhibitors (Rakwal et al., 1996). The heavy metal silver nitrate $\left(\mathrm{AgNO}_{3}\right)$ elicited glyceollin accumulation in soybean by reducing its degradation and by enhancing the hydrolysis of isoflavone-glycoside conjugates that compete with glyceollins for the common biosynthetic intermediate daidzein (Farrell et al., 2017). $\mathrm{AgNO}_{3}$ was shown to antagonize many plant development processes by inhibiting ethylene perception (Beyer, 1976). Yet, glyceollin elicitation by $\mathrm{AgNO}_{3}$ was largely independent of ethylene signaling (Farrell et al., 2017). Herbicides such as acifluorfen elicit at least in part via the reactive oxygen species (ROS) signaling pathway(s). The ups 1 loss-of-function mutant of Arabidopsis defective in ROS signaling had reduced camalexin levels in response acifluorfen (Park et al., 2002). ups 1 also had reduced camalexin levels in response to Pseudomonas syringae and $P$. syringae pv maculicola (Psm), suggesting a shared biotic and abiotic elicitation pathway. In soybean, treatments with JA, ethylene, $P$. sojae WGE, or hydroxyl radical (a ROS) were highly effective at priming glyceollin biosynthesis in cells distal to the point of treatment, whereas SA was not (Epperlein et al., 1986; Park et al., 2002).

In contrast to the abiotic stresses and signaling molecules that have conserved roles in eliciting phytoalexins in response to abiotic stresses, the TFs found to regulate phytoalexin biosynthesis have varied widely among plant species. GaWRKY1 activated gossypol biosynthesis in cotton (Xu et al., 2004). GaWRKY1 transcripts were induced by methyl jasmonate (MeJA) and Verticillium dahlia but not by $\mathrm{SA}$ or $\mathrm{H}_{2} \mathrm{O}_{2}$. GaWRKY1 transcripts were co-expressed both spatially and temporally with gossypol biosynthesis genes and GaWRKY1 was able to directly bind the promoter of $(+)-\delta$-cadinene synthase $(C A D l)$ in the $\mathrm{Y} 1 \mathrm{H}$ system. Another WRKYfamily TF, namely AtWRKY33, was identified from Arabidopsis to directly bind and activate the promoter of the camalexin biosynthesis gene PAD3 (Qiu et al., 2008). WRKY33 transcripts were induced by the ROS-inducing herbicide paraquat, SA, and necrotrophic fungal pathogens (Zheng et al., 2006). GaWRKY1 and AtWRKY33 were not homologous since the proteins they encode had more than 20 other proteins that were more similar by reciprocal BLASTPs.

The R2R3-type MYB TF genes $V v M Y B 14$ and $V v M Y B 15$ from grapevine were co-induced with stilbene biosynthesis genes in response to UV irradiation, wounding, and the pathogen Plasmopara viticola (Höll et al., 2013). The proteins directly bound the promoter of STILBENE SYNTHASE (STS) in transient gene reporter assays using grapevine suspension cells and induced the accumulation of stilbenes when overexpressed in grapevine hairy roots (Höll et al., 2013). Homologs of $V v M Y B 14$ and $V v M Y B 15$ in Arabidopsis did not regulate camalexin biosynthesis but rather cold tolerance and defense-induced lignification, respectively (Chen et al., 2013; 
Chezem et al., 2017). Double and triple mutants of the Arabidopsis R2R3 MYBs AtMYB34, $A t M Y B 51$, and $A t M Y B 122$ had reduced camalexin levels upon elicitation with $\mathrm{UV}, \mathrm{AgNO}_{3}$, and a PAMP isolated from Pythium aphanidermatum (PaNie) (Frerigmann et al., 2015). However, these three MYBs were unable to bind camalexin biosynthesis gene promoters and feeding the triple mutant plant with a biosynthetic intermediate restored camalexin accumulation, suggesting that AtMYB34, AtMYB51, and AtMYB122 did not regulate camalexin biosynthesis directly but rather an upstream process in the elicitation pathway (Frerigmann et al., 2015). The constitutive overexpression of the sorghum R2R3 MYB gene yellow seed $(y 1)$ in maize resulted in the ectopic accumulation of 3-deoxyanthocyanidins in vegetative tissues only upon challenge with Colletotrichum graminicola (Ibraheem et al., 2015). VvMYB15 and VvMYB14 were not homologs of $y 1$ since reciprocal BLASTp's revealed 5 - 20 proteins that were more similar.

RNAi silencing of the bHLH-family TF gene OsMYC2 from rice almost completely eliminated the elicitation of sakuranetin in response to JA treatment (Ogawa et al., 2017). OsMYC2 directly activated the promoter of a sakuranetin biosynthesis gene by transient transactivation assays in rice leaves (Ogawa et al., 2017). Transcripts of another bHLH TF gene from rice, namely $O S D P F$, were inducible in rice leaves by $\mathrm{UV}, \mathrm{CuCl}_{2}$ and blast infection (Yamamura et al., 2015). OsDPF directly activated the promoters of phytocassane and momilactone biosynthesis genes by transient transactivation assays in rice leaves. Overexpressing OsDPF resulted in increased expression of all diterpenoid biosynthetic genes and the accumulation of momilactones and phytocassanes, whereas decreased levels were observed in RNAi knock-down lines. Two homologous JA-inducible bHLHs, TSAR1 and TSAR2, were identified to directly activate triterpene saponin biosynthesis genes in Medicago truncatula (Yamamura et al., 2015). TSAR1 and TSAR2 were not among the top 20 most similar proteins compared to OsDPF or OsMYC2, and OsDPF was only the $10^{\text {th }}$ most similar to OsMYC2.

A NAC-type TF gene, AtANAC042, was identified from Arabidopsis by T-DNA insertion mutagenesis to have reduced levels of camalexin biosynthesis gene expressions and metabolites when elicited with the ROS-inducing herbicide acifluorofen, bacterial flagellin, or $A$. brassicicola (Saga et al., 2012). Bacterial flagellin stimulated the accumulation of AtANAC042 transcripts at the elongation zone of the root (the site of camalexin biosynthesis), and the induction was abolished in the presence of either MeJA, a general kinase inhibitor (K252a), or a $\mathrm{Ca}^{2+}$-chelator (BAPTA).

Collectively, these studies have demonstrated that phytoalexin biosynthetic pathways are regulated by disparate, non-homologous TFs in different plant species, raising the question of whether any TF has a conserved role in regulating the biosynthesis of phytoalexins in plants. 
Here, we used a comparative transcriptomics approach on soybean that was exposed to novel abiotic stresses and identified a conserved phytoalexin regulator.

\section{MATERIALS AND METHODS}

\section{Chemicals}

(-)-Glyceollin I was from Dr. Paul Erhardt (University of Toledo). Soybean isoflavonoid standards were purified and characterized according to (Farrell et al., 2017). Isoflavone standards were from Extrasynthese (France). Solvents were LC-MS grade (Fisher).

\section{Plant materials and growth conditions}

Soybean seeds were obtained from the USDA-GRIN soybean germplasm collection and from Elroy Cober (Agriculture and Agri-Food Canada). Harosoy 63 seeds (16 per batch) were sterilized in $30 \mathrm{~mL}$ of $70 \%$ ethanol, $0.2 \%$ triton $\mathrm{X}(\mathrm{v} / \mathrm{v})$ for $5 \mathrm{~min}$ on a mixer wheel, rinsed thrice with sterile water, and imbibed overnight. The imbibate was then discarded to remove growth inhibitors and seeds were transferred to water soaked sterile vermiculite ( $250 \mathrm{~mL}$ in volume) in $500 \mathrm{~mL}$ beakers. The beaker tops were covered with ring-shaped sterile cheese cloth and covered with plastic wrap to ensure aseptic growth. The cheese cloth permitted passage of air between plastic wrap and the beaker top and the ring shape permitted the passage of light from above the beaker. Seedlings were grown at $22{ }^{\circ} \mathrm{C}$ under a $16 \mathrm{~h}$ photoperiod using cool white T5 fluorescent lights $\left(500 \mu \mathrm{E} \mathrm{m}^{-2} \mathrm{~s}^{-1}\right)$. At the first trifoliate leaf stage ( $\sim 8$ day old $)$, seedling roots were gently rinsed with sterile water to remove vermiculite and were transferred to stress treatments.

\section{Stress treatments}

For all stress treatments, the roots of five seedlings were wrapped together in a germination paper (Sartorius AG, Göttingen, Germany) saturated with half-strength Murashige and Skoog (MS) medium ( $\mathrm{pH} 5.8$ ) containing vitamins and 1\% (w/v) sucrose unless indicated otherwise. The wrapped seedlings were transferred to a $100 \mathrm{~mL}$ beaker containing $50 \mathrm{~mL}$ of the above medium for the control, cold, heat, wounding and UV-C treatments. Each of the $100 \mathrm{~mL}$ beakers were then placed inside a sterile $500 \mathrm{~mL}$ beaker and the $500 \mathrm{~mL}$ beaker tops were again covered with a ring-shape cut of sterile cheese cloth overlaid with plastic wrap. The volume of the medium in the basin of the $100 \mathrm{~mL}$ beaker was maintained daily for all treatments, with the exception of the dehydration treatment. For dehydration, the medium-saturated germination paper was allowed to dry gradually in the $100 \mathrm{~mL}$ beaker containing no medium. All seedlings were grown under the temperature and lighting conditions listed above unless otherwise 
indicated. For heat and cold treatments, the $500 \mathrm{~mL}$ beakers were transferred to 37 and $15{ }^{\circ} \mathrm{C}$, respectively. For high carbon stress, the growth medium in the $100 \mathrm{~mL}$ beaker was replaced with $3 \%$ sucrose in water. For flooding, control medium was maintained up to the level of the hypocotyl-root junction throughout the $9 \mathrm{~d}$ treatment. For phosphate deprivation (-P), halfstrength MS medium ( $\mathrm{pH}$ 5.8) that lacked phosphate was used (Caisson Labs, Smithfield, UT). For UV-C treatment, seedlings in beakers were exposed to a $30 \mathrm{~W}$ g30t8 germicidal light (Philips, NV) every day for $1 \mathrm{~h}$. For acidity stress, seedlings were transferred half-strength MS medium pH 3.0 (acidified with $\mathrm{HCl}$ ).

After $9 \mathrm{~d}$ of treatment (unless indicated otherwise), the five seedlings per treatment were unwrapped and separated, flash-frozen in liquid nitrogen, lyophilized to dryness, and individually ground to a fine powder and stored at $-80^{\circ} \mathrm{C}$ for metabolite and RNA extractions. The stored tissue powder was lyophilized again for $1 \mathrm{~h}$ prior to weighing.

For hairy root experiments, only secondary roots that grew to $3-6 \mathrm{~cm}$ on selection media were considered transgenic and were used for WGE treatments. Roots were cut into 1-cm pieces then overlaid with sterile water (mock) or wall glucan elicitor (WGE) that was extracted from $P$. sojae according to (Farrell et al., 2017). For RNA extraction, $100 \mathrm{mg}$ of fresh tissue was harvested on ice and freeze dried prior to storage at $-80{ }^{\circ} \mathrm{C}$. For metabolite analyses, fresh hairy root tissues $(\sim 100 \mathrm{mg})$ were extracted immediately upon harvesting without lyophilization.

\section{Isoflavonoid analysis}

For analysis of seedlings, lyophilized tissue powder $(12 \mathrm{mg})$ was extracted with $80 \%$ ethanol (10 $\mu \mathrm{L} \mathrm{mg}{ }^{-1}$ dry tissue) and isoflavonoid identifications were done by UPLC-PDA-MS ${ }^{\mathrm{n}}$ as indicated in (Farrell et al., 2017). Four seedlings per treatment were individually extracted for metabolite analysis. Metabolite analyses of $\mathrm{pH} 3.0$ medium, dehydration stress, and control treatments were confirmed by three independent experiments.

Hairy roots were extracted with $80 \%$ ethanol $\left(1 \mu \mathrm{L} \mathrm{mg}^{-1}\right.$ fresh weight, FW) as described (Farrell et al., 2017). For all hairy root experiments, five biological replicates were analyzed per treatment. Two independent transformation experiments were analyzed per DNA construct. Absolute amounts of isoflavonoids were determined by comparison of the UPLC-PDA peak areas to a concentration curve of purified or authentic standards as described in (Farrell et al., 2017). 


\section{RNA extraction and $q R T-P C R$}

Total RNA was isolated from lyophilized tissue powder using the Spectrum Plant Total RNA Kit (Sigma-Aldrich, St. Louis, MO, USA) as described (Farrell et al., 2017). Total RNA (500 ng) was treated with DNase I (Amplification grade, Invitrogen, Carlsbad, CA, USA) to remove genomic DNA and cDNA was synthesized using SuperScript II Reverse Transcriptase (Invitrogen). cDNA templates were diluted 4-fold with water and qRT-PCR was conducted as described (Farrell et al., 2017). All qRT-PCR experiments included four biological replicates and two technical replicates. Primers used in this study are listed in Additional file 1: Table S1.

\section{RNA-seq}

Total RNA was extracted from the powder of individual seedlings as described above. Three individual seedlings per stress treatment and their respective controls were used to make a total of 12 libraries for RNA-seq analysis. RNA samples were sent to the Genomics Core Facility of West Virginia University for library preparation. The quality of each RNA sample was determined using an RNA Nano 6000 Chip and an Agilent 2100 Bioanalyzer (Santa Clara, CA). RNA samples with an Integrity Number (RIN) greater than 8.0 were used to prepare the libraries. Following quantification of RNA using a Qubit fluorometer, libraries were constructed from 750ng using the mRNA stranded library prep kit (KAPA Biosystems) as per manufacturer's protocol with nine cycles of PCR. The completed cDNA libraries were quantified using a Qubit and pooled in equimolar ratios prior to sequencing at the Marshall University Genomics Core. The 100 bp paired-end reads were generated using a HiSeq1500 system (Illumina). Eight libraries were sequenced per lane in high-output mode.

Data filtering was carried out to eliminate adapter sequences and/or low-quality reads. The quality of raw reads was determined using FastQC software (http://www.bioinformatics.babraham.ac.uk/projects/fastqc/) and clean reads were then mapped/aligned to Glycine max reference genome (Gmax_275_V2.0.fa, https://phytozome.jgi.doe.gov/pz/portal.html) using STAR RNA-seq aligner (Dobin et al., 2013) with default mode based on the current gene annotation. Only the paired mapped reads were considered for further analyses. Reads were quantified using using featureCounts (Liao et al., 2013). Differentially expressed genes (DEGs) were identified using a Negative Binomial Distribution in DESeq2 (Anders and Huber, 2010). Multiple hypothesis correction was conducted with Benjamini Hochberg procedure to get an adjusted $\mathrm{P}$ value at 0.05 which 
decrease the false discovery rate (FDR). Principle component analysis, heatmap and clustering of the samples were done to check the robustness of the analysis. For the identification of gene homologs, genes were considered to be homologous if their predicted protein sequences were the best matches in reciprocal BLASTPs.

\section{Cloning}

The GmNAC42-1 ORF was PCR amplified from the cDNA of Harosoy63 seedlings treated with pH 3.0 medium (9 dat) by the attB Adapter PCR protocol (Invitrogen, Carlsbad, CA) using Phusion polymerase (Thermo Fisher Scientific) and primers (Additional file 1: Table S1). The amplicon was cloned into the donor vector pDONR221 using BP Clonase II (Invitrogen, Carlsbad, CA) and following sequencing was LR recombined downstream of GFP in the pGWB6 vector to assay subcellular localization and downstream of the GAL4 activation domain in the pDEST-GADT7 vector for Y1H. For silencing, a 227-bp region of exon 2 of GmNAC42-1 was amplified from cDNA and BP cloned into pDONR221, which after sequencing was LR subcloned into the RNAi vector pANDA35HK. Hairpin integrations were confirmed by sequencing.

\section{Soybean hairy roots}

Transgenic soybean hairy roots were produced according to (Jacobs et al., 2015) with some modifications. Relatively large Williams 82 soybean seeds without cracks were surface sterilized with $70 \%$ isopropyl alcohol (v/v) for $30 \mathrm{sec}$ and $10 \%$ commercial bleach $(6.0 \%(\mathrm{v} / \mathrm{v})$ sodium hypochlorite) for $5 \mathrm{~min}$ with gentle agitation, then rinsed three times in sterile MilliQfiltered water (EMD Millipore, MA). Seeds were transferred to germination paper saturated with germination and co-cultivation (GC) medium (half-strength MS salts (Caisson Labs, UT), 1\% sucrose, $\mathrm{pH}$ 5.8, and MS vitamins) in a sterile Petri dish and germinated for $3 \mathrm{~d}$ in the dark, then transferred to cool white $\mathrm{T} 5$ fluorescent lights $\left(100 \mu \mathrm{E} \mathrm{s}^{-1} \mathrm{~m}^{2}\right)$ at $24{ }^{\circ} \mathrm{C}$, a condition that was used for all subsequent soybean transformation steps.

Following pre-culture on LB-agar plates containing $50 \mathrm{mg} \mathrm{L}^{-1}$ kanamycin and hygromycin, Agrobacterium rhizogenes strain K599 containing the empty vector or construct DNA were resuspended to an OD600 of 0.5-0.8 in phosphate buffer $\left(0.01 \mathrm{M} \mathrm{Na}_{2} \mathrm{HPO}_{4}, 0.15 \mathrm{M} \mathrm{NaCl}, \mathrm{pH}\right.$ 7.5) containing $100 \mu \mathrm{M}$ acetosyringone. Cotyledons were gently twisted off of 6-7 d old seedlings. The apical meristem and hypocotyl was excised and several $1 \mathrm{~mm}$-deep cuts were made across the adaxial surface of the cotyledon with a scalpel previously dipped in the 
Agrobacterium solution. Twenty-four to 36 cotyledons were inoculated per DNA. Cotyledons were placed adaxial-side-down on germination paper saturated with GC medium containing 100 $\mu \mathrm{M}$ acetosyringone and co-cultivated for $3 \mathrm{~d}$ at $22^{\circ} \mathrm{C}$ under low light $\left(65 \mu \mathrm{E} \mathrm{s}^{-1} \mathrm{~m}^{2}\right)$ on a $16 \mathrm{~h}$ photoperiod. Cotyledons were then cultured adaxial-side-up on hairy root growth (HRG) medium (half strength MS salts, 3\% sucrose (w/v) (pH5.8) with gelzan $\left(2.4 \mathrm{~g} \mathrm{~L}^{-1}\right.$; SigmaAldrich, MO), MS vitamins $\left(2.5 \mathrm{~mL} \mathrm{~L}^{-1}\right)$ and timentin $\left(500 \mathrm{mg} \mathrm{L}^{-1}\right)$. Fourteen to $21 \mathrm{~d}$ later, transgenic primary roots with $2-3 \mathrm{~cm}$ secondary roots were transferred to and selected on HRG containing $50 \mathrm{mg} \mathrm{L}^{-1}$ kanamycin and hygromycin. Only secondary roots that grew to $3-6 \mathrm{~cm}$ were considered transgenic and were used for treatments. All hairy root experiments were conducted two times independently, representative results are shown.

\section{Subcellular localization}

Soybean hairy roots transformed with $n G F P-p G W B 6$ or $n G F P-N A C 42-1-p G W B 6$ were harvested and stained with propidium iodide according to the manufacturer's instructions (Sigma-Aldrich, St. Louis, MO, USA). Three-to-four roots per genotype per two independent transformation events were analyzed and a representative result is shown. Confocal images were acquired using a Nikon A1R Si confocal laser with N-SIM-E, a TiE inverted research microscope, and NIS Elements software. Imaging was performed using an Apo oil 60× objective, plus $1.5 \times$ optical zoom, and $6 \times$ digital zoom. Excitation and emission spectra were $488 \mathrm{~nm}$ and 500-550 nm for GFP and $488 \mathrm{~nm}$ and 570-620 nm for propidium iodide, respectively.

\section{Yeast one-hybrid}

G4DT and IFS2 promoter regions 1 and 2 flanked by attL4 and attR1 recombination sites (Additional file 2: Table S2) were synthesized by Genscript (Piscataway, NJ) and recombined into the destination vector pMW\#2 (Addgene, Cambridge, MA) using LR clonase (Invitrogen, Carlsbad, CA). Clones were selected by colony PCR then sequenced. Constructs were linearized by digestion with AflII (Thermo Scientific, Waltham, MA) prior to transformation into yeast strain YM4271 (MATa, ura3-52, his3-200, lys2-801, ade2-101, ade5, trp1-901, leu2-3, 112, tyr1-501, gal4D, gal80D, ade5::hisG) and were selected by growth in dropout medium lacking histidine (SD-His). Bait strains containing genomic integrations were confirmed by colony PCR using a pair of promoter- and genome-specific primers (Additional file 1: Table S1). Bait strains were transformed with pDEST-GADT7 (ABRC, Columbus, OH) or with GmNAC42-1-pDESTGADT7 and transformants were selected on media lacking histidine and leucine (SD-His-Leu) 
then confirmed by colony PCR. Autoactivation was tested for and positive DNA-protein interactions were determined by growth in SD-His-Leu medium containing increasing concentrations $(5,10,20,40$ and $60 \mathrm{mM})$ of 3-amino-1,2,4-triazole (3-AT; Fisher Scientific, Hampton, NH), as previously described (Yang et al., 2016a). Three biological replicates are shown, results were confirmed by two independent experiments.

\section{RESULTS}

\section{Novel abiotic stresses that regulate glyceollin biosynthesis}

To gain insight into how abiotic stresses regulate glyceollin biosynthesis in soybean we first searched for a control growth condition that would allow us to measure the inductive and suppressive effects of abiotic stress treatments on glyceollin biosynthesis. We grew soybean seedlings under two light intensities, 10 and $500 \mu \mathrm{mol} \mathrm{m}^{-2} \mathrm{~s}^{-1}$, which we refer to here as low and high light, respectively. We also compared seedlings grown on soil to those grown in liquid halfstrength Murashige and Skoog (MS) medium that can be readily manipulated to provide nutrient and chemical stresses (see Methods). In addition to glyceollins, we also measured the levels of two key biosynthetic intermediates, two additional phytoalexins that have potent anti-pathogenic and/or medicinal activities, and two constitutively biosynthesized isoflavone-glycoside conjugates known to compete with glyceollins for biosynthetic intermediates. Specifically, we measured the levels of glyceollin I, glyceollin II, glyceollin III, and phaseol that are biosynthesized from the intermediate daidzein, and $\beta_{\text {prenyl }}$ genistein that is biosynthesized from genistein (Fig. 1). We also measured the levels of an unknown metabolite that exhibited UV absorbance properties similar to isoflavonoids but did not represent any of the 57 (iso)flavonoid standards that we have in our library.

The MS medium high light condition was the only condition that elicited measurable amounts of all phytoalexins (Fig. 2a). The MS low light condition had greater amounts of glyceollins I and

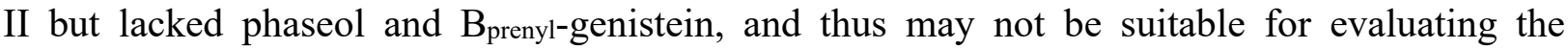
specificity of the effects of abiotic stresses on the glyceollin pathway. Glyceollins were absent or in trace amounts in seedlings grown on soil, either under the high or low light conditions. Based on these results, we selected the MS medium high light as the control condition to evaluate the effects of abiotic stresses on glyceollin biosynthesis.

Seedlings were transferred to eight abiotic stress conditions and the amounts of total phytoalexins were enhanced significantly by $\mathrm{pH} 3.0$ medium, UV-C, and dehydration compared to the control (ANOVA, Tukey post hoc test, $P<0.01$ ) (Fig. 2b). pH 3.0 medium stimulated the greatest increase, having 22.7-fold greater amounts of total phytoalexins compared to the control 
and significantly greater amounts compared to all other treatments. UPLC-PDA chromatograms revealed major increases in the levels of glyceollins for $\mathrm{pH} 3.0$ medium, and major reductions in the amounts of 6-O-malonyldaidzin for dehydration and $\mathrm{pH} 3.0$ medium that were not observe for the UV-C treatment (Fig. 2c). pH 3.0 medium and dehydration predominantly caused increases in the amounts of glyceollin III and glyceollin II (Fig. 2d). Overall, pH 3.0 medium had the greatest increase in glyceollin amounts, with glyceollin III becoming $25 \%$ of the total measured isoflavonoid content.

\section{Acidity stress enhances and dehydration suppresses glyceollin biosynthesis}

Pathogens generally elicit maximum glyceollin biosynthesis within 24-48 h of inoculation, then the levels rapidly decline (Bhattacharyya and Ward, 1986; Yoshikawa et al., 1978). To understand the dynamics of the regulation of glyceollin biosynthesis by $\mathrm{pH} 3.0$ medium and dehydration, we measured metabolite levels at regular intervals up to 9 dat.

Following the transfer of seedlings to the control condition, we observed a gradual accumulation of glyceollins and phaseol peaking at 6 dat (Fig. 3a). In contrast, $\beta$ prenyl-genistein rapidly decreased up to 3 dat then remained constant thereafter. Two elicitation patterns distinguished pH 3.0 medium from the control. Glyceollin III and phaseol exhibited sharp increases from 6 dat to 9 dat, whereas glyceollins I and II exhibited delayed and prolonged accumulation (Fig. 3a). Elicitation of these daidzein-derived phytoalexins was accompanied by decreases in daidzein and its glycosyl-conjugates, namely daidzin and 6-O-malonyldaidzin. Genistein and derived isoflavonoids were not increased by $\mathrm{pH} 3.0$ medium. In sharp contrast, dehydration caused a sustained suppression of all daidzein-derived isoflavonoids over the $9 \mathrm{~d}$ period with up to a 106.8-fold suppression of glyceollin I at 6 dat (Fig. 3a). This major suppressive effect was not observed for genistein-derived metabolites.

To determine whether $\mathrm{pH} 3.0$ medium and dehydration stresses regulated glyceollin biosynthesis gene transcripts, we measured the expression of key biosynthetic genes by quantitative reverse transcriptase-polymerase chain reaction (qRT-PCR). Specifically, we measured the expressions of isoflavone synthase 1 (IFS1) and IFS2, isogenes for the biosynthesis of isoflavones (Fig. 1). We also measured the expressions of isoflavone 2'-hydroxylase $\left(I 2^{\prime} H\right)$ and glycinol 4dimethylallyltransferase (G4DT), genes for the biosynthesis of all daidzein-derived phytoalexins and glyceollin I, respectively (Akashi et al., 2005; Akashi et al., 2009).

pH 3.0 medium upregulated all gene transcripts at 9 dat. The levels ranged from 4.4- to 20.7fold greater than the control for $I 2^{\prime} H$ and $I F S 2$, respectively (Fig. 3b). By contrast, dehydration 
stress had reduced levels of all gene transcripts at 6 dat, ranging from 2.2- to 11.7-fold less than the control for IFS2 and $I 2^{\prime} H$, respectively.

\section{Acidity and dehydration stresses oppositely regulate all known glyceollin biosynthesis genes}

To investigate whether $\mathrm{pH} 3.0$ medium and dehydration oppositely regulated all known glyceollin biosynthesis genes, we conducted RNA-seq comparing genes upregulated by $\mathrm{pH} 3.0$ medium to those downregulated by dehydration.

pH 3.0 medium upregulated 3242 and dehydration downregulated 9129 genes more than 2-fold, respectively $(P<0.05)$ (Additional file 3: Table S3 and Additional file 4: Table S4). By comparing the two gene lists, we found that 1058 genes were in common (Fig. 4a \& Additional file 5: Table S5). All 27 known glyceollin biosynthesis genes spanning from phenylalanine ammonia lyase $(P A L)$ to the glycinol:dimethylallyl diphosphate (DMAPP) transferases G4DT and G2DT (Akashi et al., 2009; Yoneyama et al., 2016) were upregulated by pH 3.0 medium and downregulated by dehydration, respectively (Table 1). Since DMAPP is derived from either the cytosolic mevalonate pathway or the plastidic methylerythritol phosphate (MEP) pathway, we checked our lists for these genes. $\mathrm{pH} 3.0$ and dehydration stresses oppositely regulated genes for all steps of the MEP pathway up to DMAPP formation, whereas no mevalonate genes were differentially regulated (Table 1).

Since our RNA-seq analyses found that $\mathrm{pH} 3.0$ medium and dehydration regulated glyceollin biosynthesis at the level of transcription, we hypothesized that $\mathrm{TF}$ genes required for the activation of those biosynthesis genes would also be present in our geneset. Yet, all previously identified isoflavonoid TF genes were not found. Those absent included TF genes identified by QTL mapping of isoflavonoid amounts, namely GmMYBJ3 (Glyma.06g193600) or GmMYB29 (Glyma20g35180) (Chu et al., 2017; Zhao et al., 2017). Also absent were TFs that activated the biosynthesis of chalcone synthase-derived isoflavonoids during seed development, namely GmMYB176 (Glyma.05G032200) and GmCYP1 (Glyma.11G098700) (Mainali et al., 2017; Yi et al., 2010). 


\section{Comparative transcriptomics identifies candidate transcription factors for the regulation of glyceollin biosynthesis}

To better understand the pathways that were oppositely regulated by acidity and dehydration stresses, we analyzed the ontologies of the 1058 oppositely regulated genes (Fig. 4a). Signal transduction was the most common category of ontology (31.4\% of genes, Fig. 4b). When the signal transduction category was broken down into ontologies, the greatest proportion (28.3\%) were annotated as systemic acquired resistance (SAR) (Fig. 4c). SAR is a component of the plant immune system whereby tissues distant from a pathogen infection site become primed (sensitized) to more rapidly activate resistance responses the second time the plant encounters the pathogen. Gene ontology (GO) enrichment analysis indicated that SAR genes were significantly enriched $\left(P<1.0^{-10}\right)$ and included those involved of salicylic acid (SA)-dependent and independent signaling pathways, in addition to jasmonic acid (JA) and ethylene signaling pathways (GO:0009627, GO:0009862, GO:0009864, GO:0009871, and GO:0010112). The SAR genes included homologs of AGD2-LIKE DEFENSE RESPONSE PROTEIN 1 (ALD1) and FLAVIN-DEPENDENT-MONOOXYGENASE1 (FMO1) that were indispensable for SAR in Arabidopsis (Table 2) (Mishina and Zeier, 2006; Návarová et al., 2012; Song et al., 2004). ALD1 encodes an enzyme that synthesizes the non-protein amino acid pipecolic acid (Pip) from Lys upon pathogen attack (Song et al., 2004). FMO1 converts Pip to N-hydroxypipecolic acid (NHP) (Hartmann et al., 2018) and is needed for Pip to orchestrate priming of pathogen responses by SA-dependent and independent pathways (Bernsdorff et al., 2016). The SAR genes also included homologs of signaling and TF genes that had roles in regulating the elicitation of the indole alkaloid phytoalexin camalexin in Arabidopsis. PHYTOALEXIN DEFICIENT4 (PAD4) is a lipase-like gene required for SA-dependent elicitation of camalexin in response to microbial pathogens (Ferrari et al., 2003). SIGMA FACTOR BINDING PROTEIN 1 (SIB1) encodes a TF that activates the expression of AtWRKY33, a direct regulator of camalexin biosynthesis genes (Lai et al., 2011). However, homologs of AtWRKY33 (namely Glyma.02G232600 and Glyma.14G200200) were not found in our gene set nor were they significantly upregulated by pH 3.0 medium alone.

Among the putative soybean SAR genes were three homologs of the NAC [no apical meristem (NAM), Arabidopsis transcription activation factor [ATAF1/2] and cup-shaped cotyledon (CUC2)] family gene $A N A C 042 / A t J U B 1$. ANAC042/AtJUB1 regulates camalexin biosynthesis in Arabidopsis in response to the ROS-inducing herbicide acifluorofen, Alternaria brassicicola, and bacterial flagellin (Flg22) (Saga et al., 2012). 


\section{NAC42-type TFs are upregulated with glyceollins by abiotic and biotic elicitors}

We conducted qRT-PCR to gain insight into whether the NAC42-type TFs that were identified by our transcriptomics analysis may be involved in regulating glyceollin biosynthesis. qRT-PCR confirmed that the three GmNAC42s were upregulated by $\mathrm{pH} 3.0$ medium and downregulated by dehydration (Fig. 5a-5b).

The predicted GmNAC42 proteins were $68.5 \%$ - 85.8\% similar to each other and $54.3 \%-56.7 \%$ similar to ANAC042/JUB1 with GmNAC42-1 being the most similar (Additional file 6: Table S6). The N-terminal halves of these proteins contained the conserved NAM domain (pfam02365) putatively involved in dimerization and binding DNA (Additional file 7: Figure $\mathrm{S} 1)$. The N-terminal halves of the GmNAC42s were highly similar to ANAC042/JUB1 (76.2\% 83.3\%), whereas the C-terminal halves putatively involved in protein-protein interactions were highly divergent $(30.5 \%-34.9 \%$ similarity) (Additional file 6: Table S6). A phylogenetic analysis of the predicted GmNAC42 proteins with characterized NACs revealed that the GmNAC42s were most closely related to VvNAC42_5 (Fig. 5c). VvNAC42_5 is an SAindependent powdery mildew responsive gene from grapevine (Vitis vinifera) (Toth et al., 2016). Also in this cluster were proteins that positively regulate drought stress responses, namely S1JUB1 and DINAC1 (Thirumalaikumar et al., 2017; Yang et al., 2016b). To probe further whether GmNAC42s may be positive regulators of glyceollins, we assessed whether their gene expressions were upregulated by the wall glucan elicitor (WGE) from P. sojae. Treatment of soybean hairy roots with WGE resulted in maximum accumulation of glyceollins at $24 \mathrm{~h}$ after treatment (Fig. 5d). qRT-PCR found that all three GmNAC42s were upregulated 9.6- to 14.4fold at this time with the glyceollin biosynthesis gene G4DT (Fig. 5e). GmNAC42-1 was the most highly upregulated.

\section{GmNAC42-1 regulates glyceollin biosynthesis in response to Phytophthora sojae WGE}

We chose to investigate the function of GmNAC42-1 since it is the soybean homolog of $A N A C 042$, an indole alkaloid phytoalexin regulator from Arabidopsis, and since its gene expressions coincided with the elicitation of glyceollin biosynthesis. If GmNAC42-1 positively regulates glyceollin biosynthesis, silencing its gene expressions in elicited tissues should reduce the accumulation of glyceollin metabolites and biosynthesis gene transcripts. Conversely, overexpressing GmNAC42-1 should increase the accumulation of glyceollins and their biosynthesis gene transcripts. To test, we produced soybean hairy roots harboring an RNA interference (RNAi) construct that encoded a hairpin dsRNA identical to a 227 bp region of 
exon 2 of GmNAC42-1 and roots that overexpressed the GmNAC42-1 open reading frame (ORF) via the constitutive cauliflower mosaic virus promoter (p35S).

A 2.0-fold silencing of GmNAC42-1 decreased the accumulations of glyceollin biosynthesis gene transcripts IFS1, IFS2, and G4DT 1.8- to 2.4-fold (Fig. 6a). Off-target silencing of GmNAC42-2 was observed but not for GmNAC42-3. The overexpression of GmNAC42-1 upregulated IFS1, IFS2, and G4DT from 2.1- to 8.3-fold in roots treated with WGE or mock $\left(\mathrm{H}_{2} \mathrm{O}\right)$ (Fig. 6b-6c).

RNAi silencing of WGE-elicited roots decreased the amounts of glyceollin I, II and III 4.0-, 2.8and 3.2-fold, respectively (Fig. 6d). It also caused 2.0-fold decreases in the amounts of 6-Omalonyldaidzin and daidzin (Fig. 6d), consistent with decreased expressions of IFS2 (Fig. 6a). Overexpressing GmNAC42-1 in WGE-elicited roots resulted in 10.8-, 4.9-, and 3.0-fold increases in the amounts of glyceollin I, genistein, and glyceollin II, respectively (Fig. 6e). It also caused a 1.6-to 2.7-fold reduction in the amounts of daidzin and 6-O-malonyldaidzin, consistent with upregulating G4DT (Fig. 6b). In the absence of WGE treatment, the overexpression of GmNAC42-1 alone was not sufficient to stimulate glyceollin accumulation, reflecting its inability to upregulate all glyceollin-specific biosynthesis genes when overexpressed. However, it did result in a 2.4 -fold reduction in the amounts of $6-O$ malonyldaidzin (Farrell et al., 2017).

\section{GmNAC42-1 localizes to the nucleus and directly binds the promoters of glyceollin}

\section{biosynthesis genes}

To determine whether the subcellular localization of the GmNAC42-1 protein was consistent with its putative role as a TF, we cloned its ORF downstream of an N-terminal GFP tag and expressed the translational fusion in soybean hairy roots using the constitutively active CaMV35S promoter (p35S) (Odell et al., 1985). nGFP-GmNAC42-1 localized to the nucleus as shown by co-localization with propidium iodide fluorescence (red arrowheads, Fig. 7a - 7c). By contrast, GFP expressed by the empty vector localized to the cytosol and other extra-nuclear compartments (Fig. 7d-7f).

To test whether the GmNAC42-1 protein could directly bind the promoters of glyceollin biosynthesis genes, the ORF was also cloned downstream of the GAL4 activation domain and expressed in yeast harboring several 500 bp segments of IFS2 or G4DT promoters (Fig. $7 \mathrm{~g}$ ). GmNAC42-1 weakly activated the G4DT promoter segment closest the transcription start site (G4DTprol) that had one predicted NAC binding element (T/ATTGACT/C), failed to activate 
the segment that lacked the element (G4DTpro1), and strongly activated both IFS2 promoter segments that each had several elements (Fig. 7h).

\section{DISCUSSION}

\section{GmNAC42-1 is required for full elicitation of glyceollin biosynthesis}

In this study, we found that transcripts of the NAC-family TF gene GmNAC42-1 were upregulated with glyceollin biosynthesis genes and metabolites when soybean tissues were elicited by acidity stress or the biotic elicitor WGE from $P$. sojae. They were also downregulated with glyceollin biosynthesis genes and metabolites by dehydration stress. The overexpression and silencing of GmNAC42-1 in WGE-treated hairy roots enhanced and suppressed, respectively, the expressions of the isoflavone biosynthetic genes IFS1 and IFS2, the glyceollinspecific gene $G 4 D T$, and the accumulation of glyceollin metabolites. Since G4DT is specifically involved in glyceollin biosynthesis, the results suggest that GmNAC42-1 is a regulator of glyceollin elicitation and not the biosynthesis of constitutively accumulating isoflavone conjugates. However, overexpressing or silencing GmNAC42-1 did not affect the expression levels of $I 2$ ' $H$, one of the key genes required for glyceollin biosynthesis (Akashi et al., 1998). Further, overexpression of GmNAC42-1 in the absence of WGE did not result in the accumulation of glyceollins. Thus, our results showed that GmNAC42-1 is required for the full elicitation of glyceollin biosynthesis in response to $P$. sojae WGE, but is not sufficient to upregulate all glyceollin biosynthesis genes.

The nGFP-GmNAC42-1 fusion protein localized to the nucleus in the absence of an elicitor treatment and thus did not rely on elicitor treatment for nuclear localization as observed for the phytoalexin TF AtWRKY33 or the NAC-family TFs StNTP1 and StNTP2 (Mao et al., 2011; McLellan et al., 2013). Since GmNAC42-1 is essential for full elicitation of glyceollins, we suggest that GmNAC42-1 acts in concert with at least one other TF to coordinately activate all glyceollin biosynthetic genes. Further, by upregulating some but not all glyceollin genes, GmNAC42-1 could also function in SAR to prime soybean tissues distal to an inoculation site for subsequent rapid/high-level elicitation (Park et al., 2002; Graham et al., 1991; Subramanian et al., 2005). A subsequent direct inoculation of the primed tissues would activate the expressions or activity of one or more additional TFs that upregulates $I 2^{\prime} H$ and other glyceollin biosynthesis genes that are not regulated by GmNAC42-1 alone. In that case, overexpressing GmNAC42-1 could serve as an alternative to spraying the lactofen-containing herbicide Cobra that primes glyceollin biosynthesis to increase resistance against pathogens such as white mold, the causal agent of sclerotinia stem rot, without adversely effecting yield (Dann et al., 1999; 
Landini et al., 2003). Future experiments should test whether overexpressing GmNAC42-1 in soybean plants primes glyceollin biosynthesis without adverse effects on yield as well. Since the rapidity of glyceollin elicitation is a major factor that distinguishes resistant to P. sojae (Rps) soybean genotypes from nearly-isogenic susceptible genotypes genotypes (Graham et al., 1990; Keen, 1975; Klarman and Gerdemann, 1963; Yoshikawa and Masago, 1982), experiments should also test whether overexpressing GmNAC42-1 enhances the rapidity of glyceollin elicitation in response to compatible $\underline{P}$. sojae (Rps) genotypes.

\section{GmNAC42-1 and a conserved phytoalexin elicitation pathway}

The regulation of phytoalexins by pathogens and specific abiotic stresses suggests that elicitation is highly complex and may require multiple signaling pathways. This study in soybean identified acidity stress ( $\mathrm{pH} 3.0$ medium) and dehydration as novel regulators of phytoalexin biosynthesis. Transcriptome analysis found that the genes upregulated by acidity stress and downregulated by dehydration were reminiscent of pathogen responses, with SAR genes being highly overrepresented. The SAR genes included homologs of Arabidopsis ALD1 and FMO1 that synthesize the systemic signaling molecules Pip and its derivative Nhydroxypipecolic acid (NHP) to orchestrate priming of pathogen responses (Bernsdorff et al., 2016, Hartmann et al., 2018), and the lipase-like and TF Arabidopsis genes PAD4 and ANAC042 that regulate the biosynthesis of camalexin in Arabidopsis (Ferrari et al., 2003; Saga et al., 2012). Here, we found that GmNAC42-1 is the soybean homolog of $A N A C 042$ and is required for full elicitation of glyceollins. The results suggest a conserved phytoalexin elicitation pathway for phenylpropanoid-derived glyceollins in soybean and indole alkaloid-derived camalexin in Arabidopsis that requires NAC42 TFs. Further, our investigation of Lager's transcriptome dataset (Lager et al., 2010) demonstrated that $A N A C 042$ and its target camalexin genes (namely CYP71A12, CYP71A13 and CYP71B15/PAD3) (Saga et al., 2012) were upregulated by longterm acidity stress, suggesting that NAC42-dependent induction of phytoalexins may be a conserved response to acidity stress.

More insight into the NAC42 pathway could be drawn from the fact that glyceollin biosynthesis was elicited by the treatment of soybean cotyledons with hydroxyl radical (a ROS) (Epperlein et al., 1986) and camalexin elicitation by the ROS-inducing herbicide acifluorofen required ANAC042 (Saga et al., 2012). The ROS-inducing herbicide lactofen systemically primes glyceollin biosynthesis (Landini et al., 2003). ROS accumulation is stimulated by various phytoalexin elicitors such as pathogens, heavy metals, and UV irradiation (Ma et al., 2015; Mewis et al., 2012; Vishwakarma et al., 2017). Further, the acidification of growth media from 
pH 5.0 to 4.5 stimulated ROS production in seedlings of barley and Scots pine (Ivanov et al., 2013; Song et al., 2011) and in MS medium containing Plantago shoots (Martins et al., 2013). Further, genes that positively regulate ROS (GO:2000377 and GO:2000379) were overrepresented in the soybean and Arabidopsis transcriptome responses to long-term acidity stress. Thus, the NAC42 pathway may be a conserved ROS signaling pathway responsible for phytoalexin elicitation in response to various abiotic and biotic elicitors. It is tempting to speculate that major TFs that regulate acidity and dehydration responses may regulate GmNAC42-1 since the stresses oppositely regulate GmNAC42-1 transcripts. STOP1 is a zinc finger TF that is a major regulator of protective responses to acidity stress (Sawaki et al., 2009; Luchi et al., 2007). STOP1 also stimulates ROS production (Mora-Macias et al., 2017). Yet, STOP1 homologs were not found in the soybean transcriptome response to long-term acidity stress (9 dat), and ANAC042 was not downregulated in an Arabidopsis stopl mutant at 1 dat (Sawaki et al., 2009). This could infer that NAC42 induction of phytoalexins is downstream of ROS signaling and not directly regulated by STOP1. ABA is a major regulator of dehydration responses in part through the activity of ABA-responsive element (ABRE)-binding TFs (Uno et al., 2000). Our transcriptome dataset shows that dehydration is a powerful negative regulator of glyceollin biosynthesis and $G m N A C 42-1$, raising the possibility that both are negatively regulated by $\mathrm{ABA}$. We found that ABREs were present in the promoter regions $(\sim 1000 \mathrm{bp}$ upstream of the transcription start site) of several glyceollin biosynthesis genes, but no ABREs were observed in the GmNAC42-1 promoter (data not shown). Thus, dehydration may regulate glyceollin biosynthesis at multiple levels.

\section{Co-option of phytoalexin biosynthesis by NAC42}

Phytoalexin TF genes of the NAC, MYB, bHLH, and WRKY families have been identified from Arabidopsis, rice, cotton, maize and grapevine (Ibraheem et al., 2015; Ogawa et al., 2017; Saga et al., 2012; Xu et al., 2004; Yamamura et al., 2015; Zheng et al., 2006). Yet none of these TF genes were homologous among plant species. The phytoalexins elicited in these species were biosynthetically diverse and included indole alkaloids, momilactones and phytocassanes, terpenoid aldehydes, deoxyanthocyanidins, and stilbenoids, respectively. Thus, it has remained a question whether any phytoalexin TFs are conserved in plants or whether they are as diverse as the biosynthetic pathways that they regulate. Here, we found that GmNAC42-1 is required for the full activation of glyceollin biosynthesis in soybean. Its homolog $A N A C 042$ is needed for the full elicitation of camalexin biosynthesis in Arabidopsis (Saga et al., 2012). Glyceollins are isoflavonoid derivatives derived from phenylalanine, whereas camalexin is an indole alkaloid 
biosynthesized from tryptophan. It is possible that NAC42 TFs regulate genes in the shikimate pathway that produces phenylalanine and tryptophan. Yet, our overexpression and silencing experiments demonstrated that GmNAC42-1 regulated isoflavonoid- and glyceollin-specific biosynthetic genes through the direct binding of their promoters. While our promoter sequence analyses identified the putative NAC-binding element T/ATTGACT/C within $1 \mathrm{~kb}$ of the translation start sites of the camalexin-specific biosynthetic genes CYP71A12 and CYP71A13 that were regulated at the mRNA level by ANAC042 (Saga et al., 2012), the DREB2A element that was suggested to be the target of ANAC042/JUB1 (Wu et al., 2012) was not found in those regions nor within glyceollin biosynthetic gene promoters. If NAC42 TFs indeed bind the element T/ATTGACT/C element in glyceollin- and camalexin-specific biosynthetic genes, this would suggest that phytoalexin biosynthesis pathways were co-opted into stress-inducible regulation by NAC42 TFs. Our future work will focus on characterizing the recognition elements and DNA binding domains of GmNAC42-1 and ANAC042 that are required to activate phytoalexin biosynthesis.

\section{CONCLUSIONS}

GmNAC42-1 is essential for the full elicitation of glyceollins in soybean. It's overexpression in elicited soybean hairy roots enhanced the biosynthesis of glyceollins more than 10-fold. Thus, bioengineering the expressions of GmNAC42-1 may be a promising venue for bioproducing glyceollins for medicinal use or for enhance soybean resistance to the economically destructive pathogen $P$. sojae. GmNAC42-1 is the first identified conserved regulator of phytoalexin biosynthesis and is a homolog of the indole alkaloid phytoalexin regulator ANAC042 from Arabidopsis. Possible implications are that NAC42-type TF genes could be used in a wide variety of crop plants to enhance the bioproduction of medicinal metabolites or for improving crop resistance to pathogens.

\section{Abbreviations}

3-AT: 3-amino-1,2,4-triazole; ABRC: Arabidopsis Biological Resource Center; ABRE: ABAresponsive element; AgNO3: silver nitrate; ALD1: AGD2-LIKE DEFENSE RESPONSE PROTEIN 1; aos: allene oxide cyclase; ATAF1/2: Arabidopsis transcription activation factor; CAD1: $(+)$ - $\delta$-cadinene synthase; CUC2: cup-shaped cotyledon; $\mathrm{CuCl2:} \mathrm{Copper} \mathrm{chloride;}$ DMAPP: dimethylallyl diphosphate; DW: dry weight; FDR: false discovery rate; FMO1: FLAVIN-DEPENDENT-MONOOXYGENASE1; FW: fresh weight; G4DT: glycinol:4dimethylallyl diphosphate transferase; G4DTpro1: G4DT gene promoter segment1; GC: 
germination and co-cultivation; GRN: gene regulatory network; HRG: hairy root growth; MeJA: methyl jasmonate; MEP: methylerythritol phosphate; MS: Murashige and Skoog; NAC: NAM/ATAF1/2/CUC2; NAM: no apical meristem; nGFP: N-terminal GFP tag; NHP: Nhydroxypipecolic acid; osjar1-2: Oryza sativa jasmonic acid-amido synthetase; PAD4: PHYTOALEXIN DEFICIENT4; PAL: phenylalanine ammonia lyase; PaNie; Pythium aphanidermatum; Pip: pipecolic acid; qRT-PCR: quantitative reverse transcriptase-polymerase chain reaction; RIN: RNA Integrity Number; RNAi: RNA interference; RNA-seq: RNA sequencing; ROS: reactive oxygen species; Rps: resistant to P. sojae; SAR: systemic acquired resistance; SD-His: synthetic dropout medium lacking histidine; SIB1: SIGMA FACTOR BINDING PROTEIN 1; STS: STILBENE SYNTHASE; TF: transcription factor; WGE: wall glucan elicitor; Y1H: yeast one-hybrid

\section{Declarations}

\section{Ethics approval and consent to participate}

Not applicable.

\section{Consent for publication}

No applicable.

\section{Availability of data and material}

All RNA-seq data are available in the Gene Expression Omnibus

(http://www.ncbi.nlm.nih.gov/geo) under the series accession GSE112584.

\section{Competing interests}

The authors declare that they have no competing interests.

\section{Funding}

This work was supported by WVU start-up funds to NK and was based upon work that is supported by the USDA National Institute of Food and Agriculture, Hatch, accession number 1010200, and the West Virginia Agricultural and Forestry Experiment Station project WVA00687.

\section{Acknowledgements}

We would like to acknowledge the WVU Genomics Core Facility, Morgantown WV for support provided to help make this publication possible. We thank Gustavo MacIntosh and Jessica Hohenstein (Iowa State University) for Agrobacterium rhizogenes strain K599, Wayne Parrott 
and Tim Chappell (University of Georgia) for the soybean hairy root transformation protocol, Brett Tyler (Oregon State University) for race 1 P. sojae, Erich Grotewold (University of Michigan) for the yeast YM4271, Tsuyoshi Nakagawa (Shimane University) for the pGWB2 vector, the ABRC (Columbus, OH) for pDEST-GADT7, and Hiroyuki Tsuji (Yokohama City University) and the late Ko Shimamoto for pANDA35HK. We acknowledge use of the WVU Shared Research Facilities UPLC-PDA-MS ${ }^{\mathrm{n}}$. Imaging experiments were performed at the West Virginia University Microscope Imaging Facility, which has been supported by the WVU Cancer Institute and NIH grants P20RR016440 and P30RR032138, P30GM103488 and U54GM104942 for the Nikon A1R/N SIM-E.

\section{Additional files}

Additional file 1: Table S1. Sequences of primers used in the experiments.

Additional file 2: Table S2. Sequences of promoters used in yeast one-hybrid experiments.

Additional file 3: Table S3. Genes upregulated by pH 3.0 medium compared to control at 9 dat in Harosoy 63 soybean seedlings.

Additional file 4: Table S4. Genes downregulated by dehydration in Harosoy 63 soybean seedlings compared to the control at 6 days after treatment.

Additional file 5: Table S5. Genes upregulated by $\mathrm{pH} 3.0$ medium compared to control at 9 dat and downregulated by dehydration compared to control at 6 dat in Harosoy 63 soybean seedlings.

Additional file 6: Table S6. Amino acid similarities of NAC42 proteins from soybean, Arabidopsis and grapevine. Full-length proteins (N-terminal and C-terminal halves).

Additional file 7: Figure S1. Amino acid alignment of NAC42 proteins from soybean, Arabidopsis and grapevine. 


\section{References}

1. Müller KO, Meyer G, Klinkowski M: Physiologisch-genetische Untersuchungen über die Resistenz der Kartoffel gegenüber Phytophthora infestans. Naturwissenschaften 1939, 27(46):765-768.

2. Graham TL, Graham MY, Subramanian S, Yu O: RNAi silencing of genes for elicitation or biosynthesis of 5-deoxyisoflavonoids suppresses race-specific resistance and hypersensitive cell death in Phytophthora sojae infected tissues. Plant physiology 2007, 144(2):728-740.

3. Lygin AV, Zernova OV, Hill CB, Kholina NA, Widholm JM, Hartman GL, Lozovaya VV: Glyceollin is an Important Component of Soybean Plant Defense Against Phytophthora sojae and Macrophomina phaseolina. Phytopathology 2013, 103(10):984994.

4. Yoshikawa M, Yamauchi K, Masago H: Glyceollin: its role in restricting fungal growth in resistant soybean hypocotyls infected with Phytophthora megasperma var. sojae. Physiological Plant Pathology 1978, 12(1):73-82.

5. Ibraheem F, Gaffoor I, Tan Q, Shyu C-R, Chopra S: A sorghum MYB transcription factor induces 3-deoxyanthocyanidins and enhances resistance against leaf blights in maize. Molecules 2015, 20(2):2388-2404.

6. Ogawa S, Miyamoto K, Nemoto K, Sawasaki T, Yamane H, Nojiri H, Okada K: OsMYC2, an essential factor for JA-inductive sakuranetin production in rice, interacts with MYC2-like proteins that enhance its transactivation ability. Scientific Reports 2017, $7: 40175$.

7. Saga H, Ogawa T, Kai K, Suzuki H, Ogata Y, Sakurai N, Shibata D, Ohta D: Identification and characterization of ANAC042, a transcription factor family gene involved in the regulation of camalexin biosynthesis in Arabidopsis. Mol Plant Microbe In 2012, 25(5):684-696.

8. Xu Y-H, Wang J-W, Wang S, Wang J-Y, Chen X-Y: Characterization of GaWRKY1, a cotton transcription factor that regulates the sesquiterpene synthase gene $(+)$ - $\delta$-cadinene synthase-A. Plant physiology 2004, 135(1):507-515. 
9. Yamamura C, Mizutani E, Okada K, Nakagawa H, Fukushima S, Tanaka A, Maeda S, Kamakura T, Yamane H, Takatsuji H et al: Diterpenoid Phytoalexin Factor, a bHLH Transcription Factor, Plays a Central Role in the Biosynthesis of Diterpenoid Phytoalexins in Rice. The Plant journal : for cell and molecular biology 2015.

10. Zheng Z, Qamar SA, Chen Z, Mengiste T: Arabidopsis WRKY33 transcription factor is required for resistance to necrotrophic fungal pathogens. The Plant Journal 2006, 48(4):592-605.

11. Ahuja I, Kissen R, Bones AM: Phytoalexins in defense against pathogens. Trends in plant science 2012, 17(2):73-90.

12. Großkinsky DK, van der Graaff E, Roitsch T: Phytoalexin transgenics in crop protection-Fairy tale with a happy end? Plant science 2012, 195:54-70.

13. Jeandet P: Phytoalexins: current progress and future prospects. In.: Multidisciplinary Digital Publishing Institute; 2015.

14. Marti G, Schnee S, Andrey Y, Simoes-Pires C, Carrupt P-A, Wolfender J-L, Gindro K: Study of leaf metabolome modifications induced by UV-C radiations in representative Vitis, Cissus and Cannabis species by LC-MS based metabolomics and antioxidant assays. Molecules 2014, 19(9):14004-14021.

15. Park HL, Lee S-W, Jung K-H, Hahn T-R, Cho M-H: Transcriptomic analysis of UVtreated rice leaves reveals UV-induced phytoalexin biosynthetic pathways and their regulatory networks in rice. Phytochemistry 2013, 96:57-71.

16. Kato H, Kodama O, Akatsuka T: Oryzalexin E, a diterpene phytoalexin from UVirradiated rice leaves. Phytochemistry 1993, 33(1):79-81.

17. Mert-Turk F, Bennett MH, Mansfield JW, Holub EB: Quantification of camalexin in several accessions ofArabidopsis thaliana following inductions withPeronospora parasitica and UV-B irradiation. Phytoparasitica 2003, 31(1):81-89.

18. Reilly JJ, Klarman WL: Thymine dimer and glyceollin accumulation in UV-irradiated soybean suspension cultures. Environmental and Experimental Botany 1980, 20(2):131134. 
19. Miyamoto K, Enda I, Okada T, Sato Y, Watanabe K, Sakazawa T, Yumoto E, Shibata K, Asahina M, Iino M: Jasmonoyl-L-isoleucine is required for the production of a flavonoid phytoalexin but not diterpenoid phytoalexins in ultraviolet-irradiated rice leaves. Bioscience, biotechnology, and biochemistry 2016, 80(10):1934-1938.

20. Rakwal R, Tamogami S, Kodama O: Role of jasmonic acid as a signaling molecule in copper chloride-elicited rice phytoalexin production. Bioscience, biotechnology, and biochemistry 1996, 60(6):1046-1048.

21. Farrell KC, Jahan MA, Kovinich N: Distinct Mechanisms of Biotic and Chemical Elicitors enable Additive Elicitation of the Anticancer Phytoalexin Glyceollin I. Molecules 2017, 22(8):1261-1273.

22. Beyer EM: A potent inhibitor of ethylene action in plants. Plant physiology 1976, 58(3):268-271.

23. Park D, Landini S, Graham M, Graham T: Induced distal defence potentiation against Phytophthora sojae in soybean. Physiological and molecular plant pathology 2002, 60(6):293-310.

24. Epperlein M, Noronha-Dutra A, Strange R: Involvement of the hydroxyl radical in the abiotic elicitation of phytoalexins in legumes. Physiological and molecular plant pathology 1986, 28(1):67-77.

25. Qiu JL, Fiil BK, Petersen K, Nielsen HB, Botanga CJ, Thorgrimsen S, Palma K, Suarez-Rodriguez MC, Sandbech-Clausen S, Lichota J: Arabidopsis MAP kinase 4 regulates gene expression through transcription factor release in the nucleus. The EMBO Journal 2008, 27(16):2214-2221.

26. Höll J, Vannozzi A, Czemmel S, D'Onofrio C, Walker AR, Rausch T, Lucchin M, Boss PK, Dry IB, Bogs J: The R2R3-MYB transcription factors MYB14 and MYB15 regulate stilbene biosynthesis in Vitis vinifera. The Plant Cell 2013, 25(10):4135-4149.

27. Chen Y, Chen Z, Kang J, Kang D, Gu H, Qin G: AtMYB14 regulates cold tolerance in Arabidopsis. Plant molecular biology reporter 2013, 31(1):87-97. 
28. Chezem WR, Memon A, Li F-S, Weng J-K, Clay NK: SG2-type R2R3-MYB transcription factor MYB15 controls defense-induced lignification and basal immunity in Arabidopsis. The Plant Cell 2017:tpc. 00954.02016.

29. Frerigmann H, Glawischnig E, Gigolashvili T: The role of MYB34, MYB51 and MYB122 in the regulation of camalexin biosynthesis in Arabidopsis thaliana. Frontiers in plant science 2015, 6 .

30. Dobin A, Davis CA, Schlesinger F, Drenkow J, Zaleski C, Jha S, Batut P, Chaisson M, Gingeras TR: STAR: ultrafast universal RNA-seq aligner. Bioinformatics 2013, 29(1):15-21.

31. Liao Y, Smyth GK, Shi W: featureCounts: an efficient general purpose program for assigning sequence reads to genomic features. Bioinformatics 2013, 30(7):923-930.

32. Anders S, Huber W: Differential expression analysis for sequence count data. Genome biology 2010, 11(10):R106.

33. Jacobs TB, LaFayette PR, Schmitz RJ, Parrott WA: Targeted genome modifications in soybean with CRISPR/Cas9. BMC biotechnology 2015, 15(1):16.

34. Yang F, Ouma W, Li W, Doseff A, Grotewold E: Establishing the architecture of plant gene regulatory networks. In: Methods in enzymology. vol. 576: Elsevier; 2016: 251-304.

35. Bhattacharyya M, Ward E: Resistance, susceptibility and accumulation of glyceollins IIII in soybean organs inoculated with Phytophthora megasperma f. sp. glycinea. Physiological and molecular plant pathology 1986, 29(2):227-237.

36. Akashi T, Aoki T, Ayabe S-i: Molecular and biochemical characterization of 2hydroxyisoflavanone dehydratase. Involvement of carboxylesterase-like proteins in leguminous isoflavone biosynthesis. Plant physiology 2005, 137(3):882-891.

37. Akashi T, Sasaki K, Aoki T, Ayabe S-i, Yazaki K: Molecular cloning and characterization of a cDNA for pterocarpan 4-dimethylallyltransferase catalyzing the key prenylation step in the biosynthesis of glyceollin, a soybean phytoalexin. Plant physiology 2009, 149(2):683-693. 
38. Yoneyama K, Akashi T, Aoki T: Molecular Characterization of Soybean Pterocarpan 2Dimethylallyltransferase in Glyceollin Biosynthesis: Local Gene and Whole-Genome Duplications of Prenyltransferase Genes Led to the Structural Diversity of Soybean Prenylated Isoflavonoids. Plant and Cell Physiology 2016, 57(12):2497-2509.

39. Chu S, Wang J, Zhu Y, Liu S, Zhou X, Zhang H, Wang C-e, Yang W, Tian Z, Cheng H: An R2R3-type MYB transcription factor, GmMYB29, regulates isoflavone biosynthesis in soybean. PLoS Genetics 2017, 13(5):e1006770.

40. Zhao M, Wang T, Wu P, Guo W, Su L, Wang Y, Liu Y, Yan F, Wang Q: Isolation and characterization of GmMYBJ3, an R2R3-MYB transcription factor that affects isoflavonoids biosynthesis in soybean. Plos One 2017, 12(6):e0179990.

41. Yi J, Derynck MR, Li X, Telmer P, Marsolais F, Dhaubhadel S: A single-repeat MYB transcription factor, GmMYB176, regulates CHS8 gene expression and affects isoflavonoid biosynthesis in soybean. The Plant Journal 2010, 62(6):1019-1034.

42. Mainali HR, Vadivel AKA, Li X, Gijzen M, Dhaubhadel S: Soybean cyclophilin GmCYP1 interacts with an isoflavonoid regulator GmMYB176. Scientific Reports 2017, $7: 39550$.

43. Mishina TE, Zeier J: The Arabidopsis flavin-dependent monooxygenase FMO1 is an essential component of biologically induced systemic acquired resistance. Plant physiology 2006, 141(4):1666-1675.

44. Návarová H, Bernsdorff F, Döring A-C, Zeier J: Pipecolic acid, an endogenous mediator of defense amplification and priming, is a critical regulator of inducible plant immunity. The Plant Cell 2012, 24(12):5123-5141.

45. Song JT, Lu H, Greenberg JT: Divergent roles in Arabidopsis thaliana development and defense of two homologous genes, aberrant growth and death2 and AGD2-LIKE DEFENSE RESPONSE PROTEIN1, encoding novel aminotransferases. The Plant Cell 2004, 16(2):353-366.

46. Hartmann M, Zeier T, Bernsdorff F, Reichel-Deland V, Kim D, Hohmann M, Scholten N, Schuck S, Bräutigam A, Hölzel T: Flavin monooxygenase-generated N- 
hydroxypipecolic acid is a critical element of plant systemic immunity. Cell 2018, 173(2):456-469. e416.

47. Bernsdorff F, Döring A-C, Gruner K, Schuck S, Bräutigam A, Zeier J: Pipecolic acid orchestrates plant systemic acquired resistance and defense priming via salicylic aciddependent and-independent pathways. The Plant Cell 2016, 28(1):102-129.

48. Ferrari S, Plotnikova JM, De Lorenzo G, Ausubel FM: Arabidopsis local resistance to Botrytis cinerea involves salicylic acid and camalexin and requires EDS4 and PAD2, but not SID2, EDS5 or PAD4. The Plant Journal 2003, 35(2):193-205.

49. Lai Z, Li Y, Wang F, Cheng Y, Fan B, Yu J-Q, Chen Z: Arabidopsis sigma factor binding proteins are activators of the WRKY33 transcription factor in plant defense. The Plant Cell 2011, 23(10):3824-3841.

50. Toth Z, Winterhagen P, Kalapos B, Su Y, Kovacs L, Kiss E: Expression of a grapevine NAC transcription factor gene is induced in response to Powdery Mildew colonization in Salicylic Acid-independent manner. Scientific Reports 2016, 6:30825.

51. Thirumalaikumar VP, Devkar V, Mehterov N, Ali S, Ozgur R, Turkan I, Mueller-Roeber B, Balazadeh S: NAC transcription factor JUNGBRUNNEN1 enhances drought tolerance in tomato. Plant biotechnology journal 2017.

52. Yang Y, Zhu K, Wu J, Liu L, Sun G, He Y, Chen F, Yu D: Identification and characterization of a novel NAC. Plant Cell Rep 2016, 35(8):1783-1798.

53. Odell JT, Nagy F, Chua N-H: Identification of DNA sequences required for activity of the cauliflower mosaic virus 35S promoter. Nature 1985, 313(6005):810.

54. Akashi T, Aoki T, Ayabe S-i: CYP81E1, a Cytochrome P450 cDNA of Licorice (Glycyrrhiza echinataL.), Encodes Isoflavone 2'-Hydroxylase. Biochemical and biophysical research communications 1998, 251(1):67-70.

55. Mao G, Meng X, Liu Y, Zheng Z, Chen Z, Zhang S: Phosphorylation of a WRKY transcription factor by two pathogen-responsive MAPKs drives phytoalexin biosynthesis in Arabidopsis. The Plant Cell 2011, 23(4):1639-1653. 
56. McLellan H, Boevink PC, Armstrong MR, Pritchard L, Gomez S, Morales J, Whisson SC, Beynon JL, Birch PR: An RxLR effector from Phytophthora infestans prevents relocalisation of two plant NAC transcription factors from the endoplasmic reticulum to the nucleus. PLoS pathogens 2013, 9(10):e1003670.

57. Graham T, Graham M: Glyceollin elicitors induce major but distinctly different shifts in isoflavonoid metabolism in proximal and distal soybean cell populations. Mol Plant Microbe Interact 1991, 4:60-68.

58. Subramanian S, Graham MY, Yu O, Graham TL: RNA interference of soybean isoflavone synthase genes leads to silencing in tissues distal to the transformation site and to enhanced susceptibility to Phytophthora sojae. Plant Physiol 2005, 137(4):13451353.

59. Landini S, Graham MY, Graham TL: Lactofen induces isoflavone accumulation and glyceollin elicitation competency in soybean. Phytochemistry 2003, 62(6):865-874.

60. Dann E, Diers B, Hammerschmidt R: Suppression of Sclerotinia stem rot of soybean by lactofen herbicide treatment. Phytopathology 1999, 89(7):598-602.

61. Graham T, Kim J, Graham M: Role of constitutive isoflavone conjugates in the accumulation of glyceollin in soybean infected with Phytophthora megasperma. Mol Plant Microbe Interact 1990, 3:157-166.

62. Keen N: Specific elicitors of plant phytoalexin production: detenninants of race specificity in pathogens? Science 1975, 187(4171):74-75.

63. Klarman WL, Gerdemann JW: Resistance of soybeans to three Phytophthora species due to the production of a phytoalexin. Phytopathology 1963, 53:1317-1320.

64. Yoshikawa M, Masago H: Biochemical mechanism of glyceollin accumulation in soybean. Plant infection: the physiological and biochemical basis/edited by Yasuji Asada[et al] 1982.

65. Lager I, Andréasson O, Dunbar TL, Andreasson E, Escobar MA, Rasmusson AG: Changes in external $\mathrm{pH}$ rapidly alter plant gene expression and modulate auxin and elicitor responses. Plant, cell \& environment 2010, 33(9):1513-1528. 
66. Ma Z, Song T, Zhu L, Ye W, Wang Y, Shao Y, Dong S, Zhang Z, Dou D, Zheng X: A Phytophthora sojae glycoside hydrolase 12 protein is a major virulence factor during soybean infection and is recognized as a PAMP. The Plant Cell 2015, 27(7):2057-2072.

67. Vishwakarma K, Upadhyay N, Singh J, Liu S, Singh VP, Prasad SM, Chauhan DK, Tripathi DK, Sharma S: Differential Phytotoxic Impact of Plant Mediated Silver Nanoparticles (AgNPs) and Silver Nitrate (AgNO3) on Brassica sp. Frontiers in plant science 2017, 8:1501.

68. Mewis I, Schreiner M, Nguyen CN, Krumbein A, Ulrichs C, Lohse M, Zrenner R: UV-B irradiation changes specifically the secondary metabolite profile in broccoli sprouts: induced signaling overlaps with defense response to biotic stressors. Plant and Cell Physiology 2012, 53(9):1546-1560.

69. Song H, Xu X, Wang H, Tao Y: Protein carbonylation in barley seedling roots caused by aluminum and proton toxicity is suppressed by salicylic acid. Russian journal of plant physiology 2011, 58(4):653-659.

70. Ivanov YV, Savochkin YV, Kuznetsov VV: Effect of mineral composition and medium $\mathrm{pH}$ on Scots pine tolerance to toxic effect of zinc ions. Russian journal of plant physiology 2013, 60(2):260-269.

71. Martins N, Gonçalves S, Romano A: Metabolism and aluminum accumulation in Plantago almogravensis and P. algarbiensis in response to low $\mathrm{pH}$ and aluminum stress. Biologia plantarum 2013, 57(2):325-331.

72. Sawaki Y, Iuchi S, Kobayashi Y, Kobayashi Y, Ikka T, Sakurai N, Fujita M, Shinozaki K, Shibata D, Kobayashi M: STOP1 regulates multiple genes that protect Arabidopsis from proton and aluminum toxicities. Plant physiology 2009, 150(1):281-294.

73. Iuchi S, Koyama H, Iuchi A, Kobayashi Y, Kitabayashi S, Kobayashi Y, Ikka T, Hirayama T, Shinozaki K, Kobayashi M: Zinc finger protein STOP1 is critical for proton tolerance in Arabidopsis and coregulates a key gene in aluminum tolerance. Proceedings of the National Academy of Sciences 2007, 104(23):9900-9905.

74. Mora-Macías J, Ojeda-Rivera JO, Gutiérrez-Alanís D, Yong-Villalobos L, OropezaAburto A, Raya-González J, Jiménez-Domínguez G, Chávez-Calvillo G, Rellán-Álvarez 
R, Herrera-Estrella L: Malate-dependent Fe accumulation is a critical checkpoint in the root developmental response to low phosphate. Proceedings of the National Academy of Sciences 2017, 114(17):E3563-E3572.

75. Uno Y, Furihata T, Abe H, Yoshida R, Shinozaki K, Yamaguchi-Shinozaki K: Arabidopsis basic leucine zipper transcription factors involved in an abscisic aciddependent signal transduction pathway under drought and high-salinity conditions. Proceedings of the National Academy of Sciences 2000, 97(21):11632-11637.

76. Wu A, Allu AD, Garapati P, Siddiqui H, Dortay H, Zanor M-I, Asensi-Fabado MA, Munné-Bosch S, Antonio C, Tohge T: JUNGBRUNNEN1, a reactive oxygen speciesresponsive NAC transcription factor, regulates longevity in Arabidopsis. The Plant Cell 2012:tpc. 111.090894. 


\section{Figures}

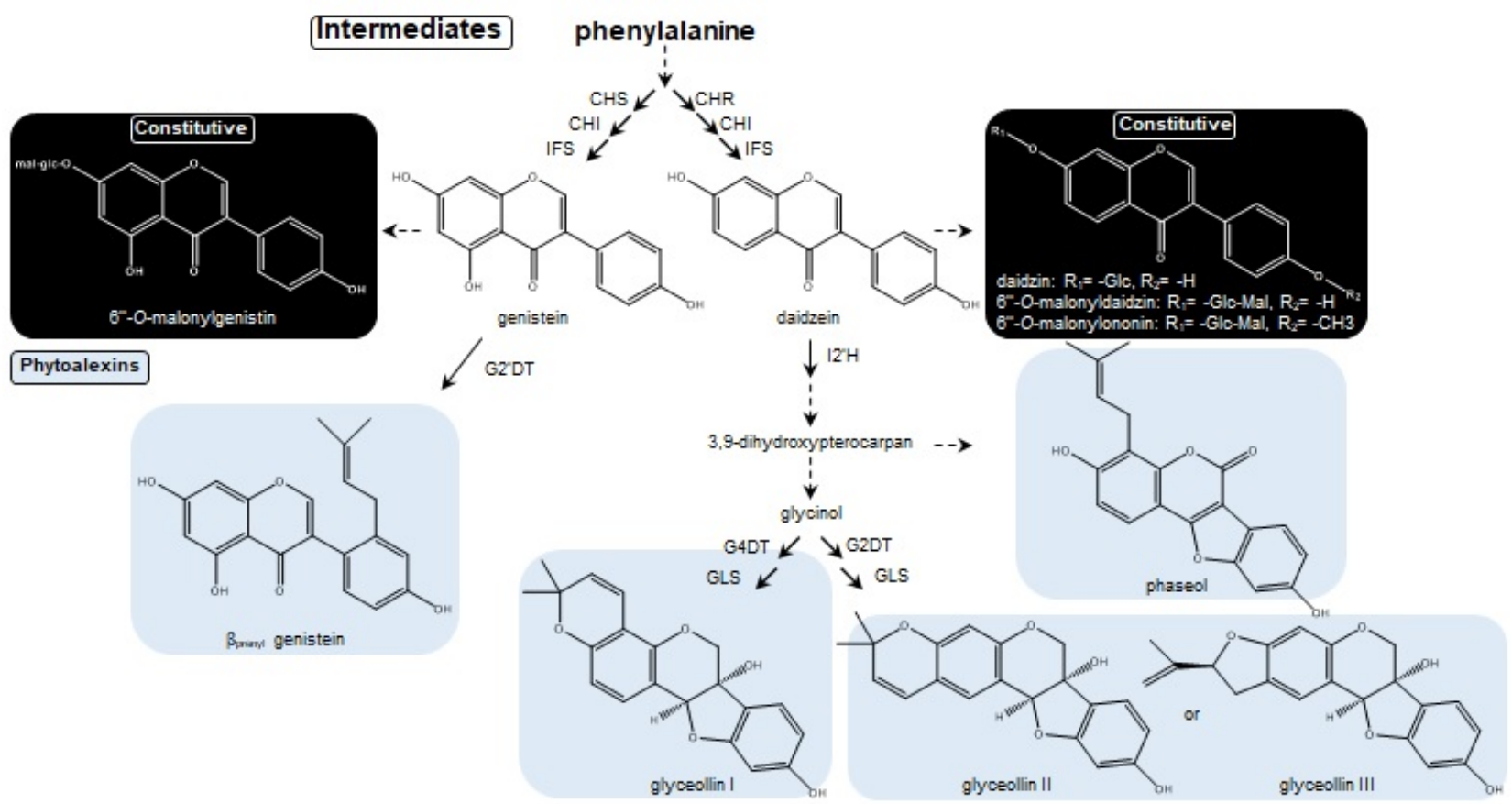

Figure 1. Soybean isoflavonoid biosynthetic pathway. Inducible phytoalexins (highlighted in blue) and constitutively biosynthesized isoflavone conjugates (highlighted in black) are derived from the isoflavone intermediates daidzein or genistein. CHS, chalcone synthase; CHR, chalcone reductase; CHI, chalcone isomerase; IFS, isoflavone synthase; G2'DT, genistein 2'dimethylallyl transferase; I2'H, isoflavone 2'-hydroxylase; G4DT, glycinol 4-dimethylallyl transferase; G2DT, glycinol 2-dimethylallyl transferase; GLS, glyceollin synthase. 

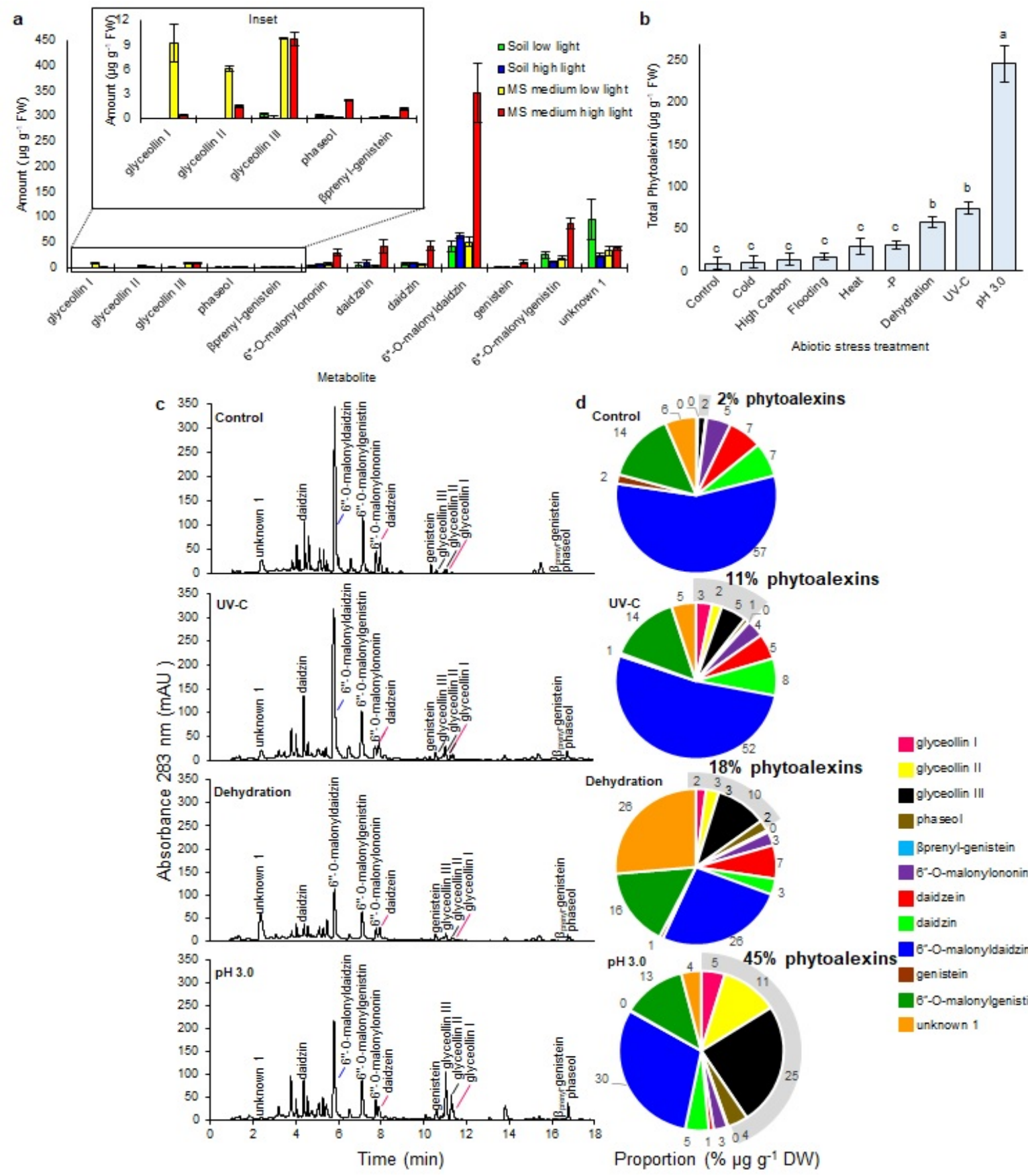

Control $6=22 \%$ phytoalexins
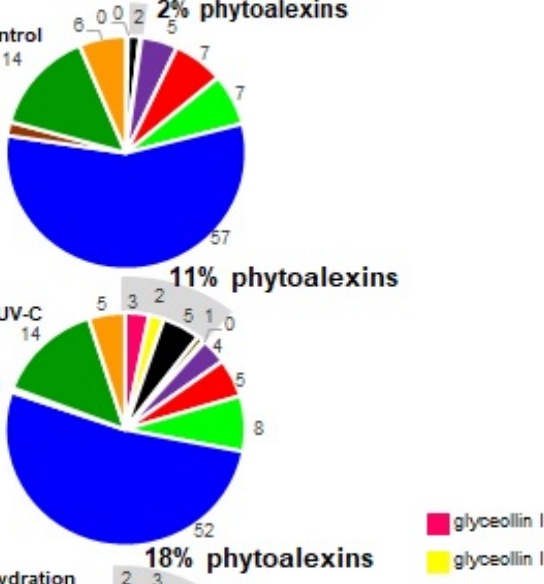

glyceollin II

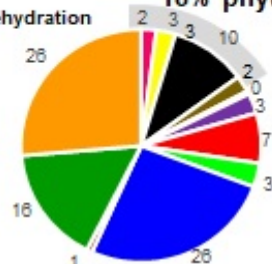

alyosollin III

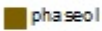

Bprenyl-genistein

6-0-malonylononin

daidze in

daidzin
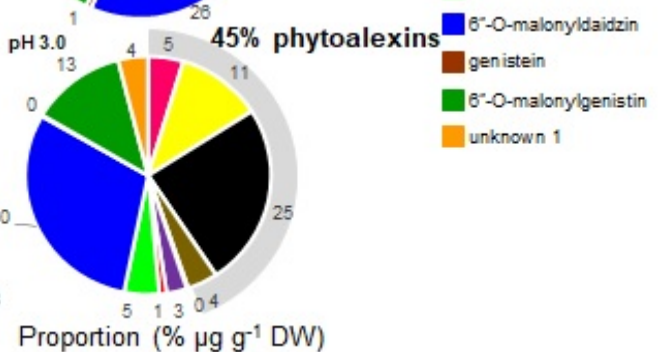

unknown 1

Fig. 2 Phytoalexin and isoflavonoid content in response to abiotic stresses. a Effects of light and growth medium on phytoalexin elicitation in Harosoy 63 seedlings. Error bars represent standard error of mean. b Effects of different abiotic stress treatments phytoalexin elicitation. Total phytoalexins represent the sum of glyceollins I-II, phaseol, and $\beta$ prenyl-genistein. Different letters show significant differences by single factor ANOVA, Tukey post hoc test, $P<0.01$. Error bars represent standard error of mean. c UPLC-PDA chromatograms of ethanolic extracts at $283 \mathrm{~nm}$. d Proportions of the metabolites labeled in $\mathrm{C}$ based on their tissue concentration $(\mu \mathrm{g}$ $\left.\mathrm{g}^{-1} \mathrm{DW}\right)$. 


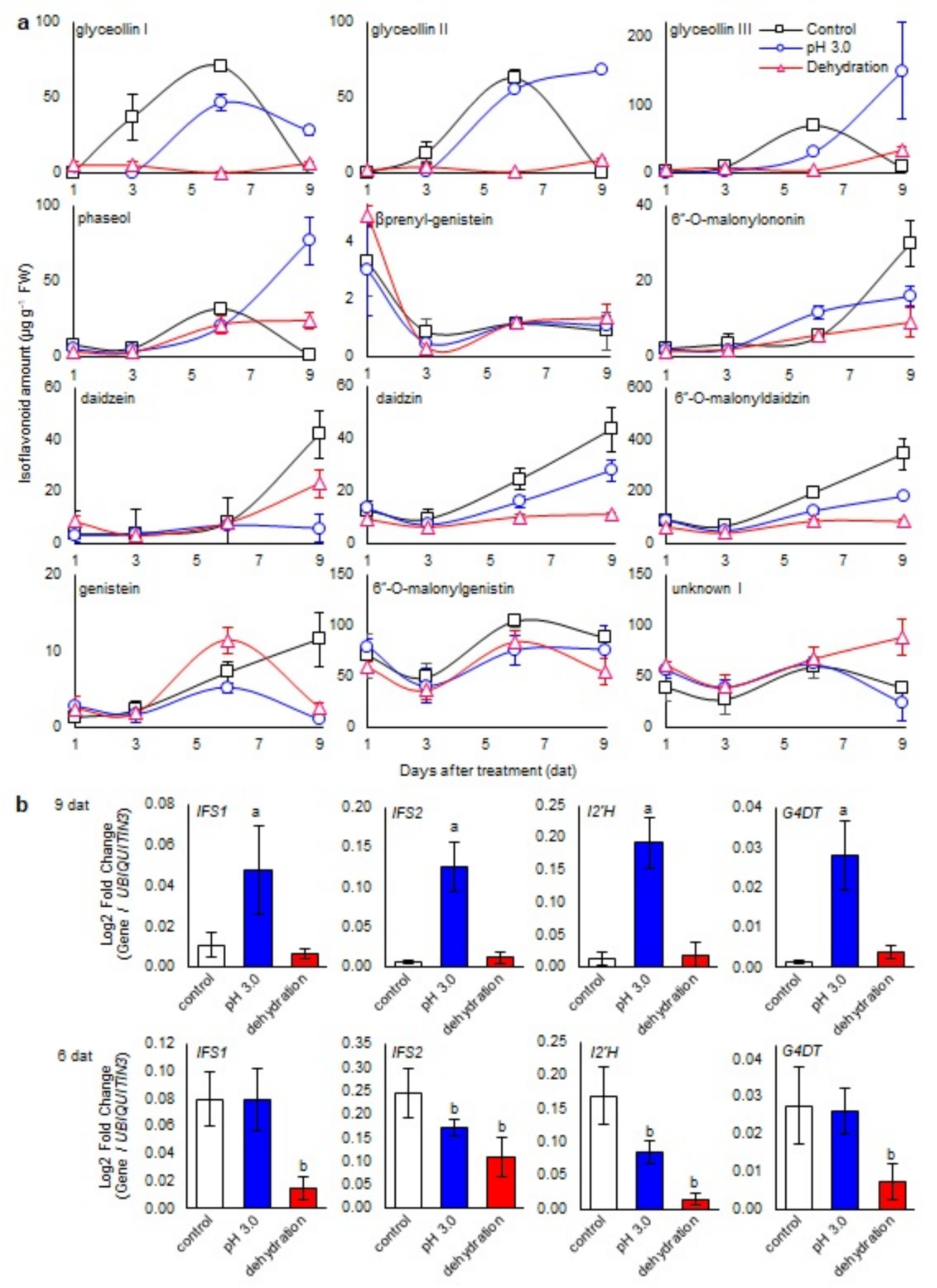

Fig. 3 Time course of phytoalexin and isoflavonoid biosynthesis during acidity and dehydration stresses. a Isoflavonoid levels by UPLC-PDA over time after transfer to the control condition, pH 3.0 medium, or dehydration stress. Error bars represent standard error of mean. b Isoflavonoid biosynthesis gene expressions at 6 and 9 dat measured by qRT-PCR. ' Significantly greater and ${ }^{\mathrm{b}}$ significantly less than control, paired students $t$-test $(P<0.01)$. Error bars represent standard error of mean. 

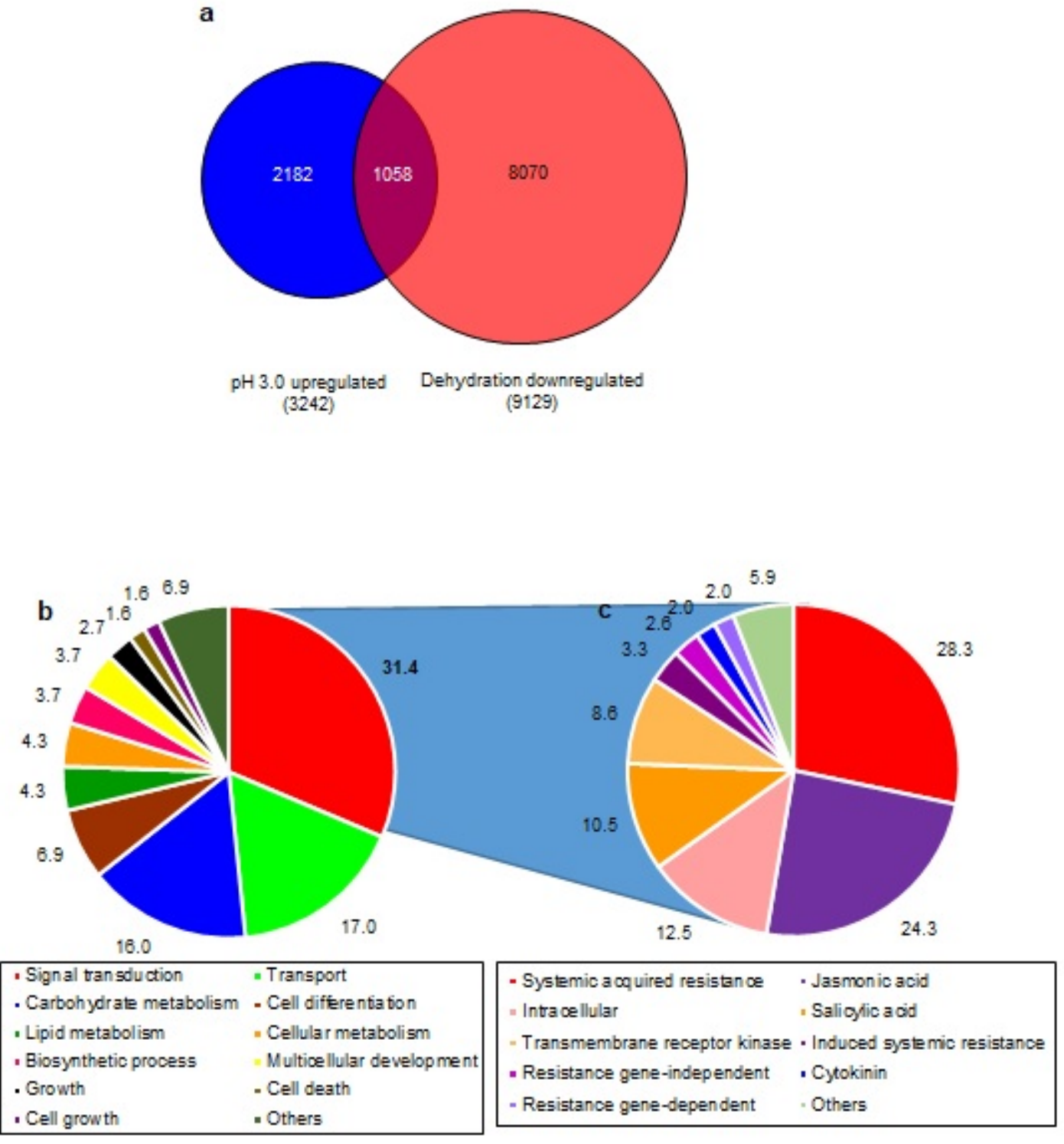

Fig. 4 Comparative transcriptomics of seedlings treated with acidity stress or dehydration. a Number of genes in Harosoy 63 seedlings that were upregulated and downregulated more than 2-fold by pH 3.0 medium and dehydration, respectively $(\mathrm{P}<0.05)$ by RNA-seq. b Percent of genes upregulated by $\mathrm{pH} 3.0$ medium and downregulated by dehydration stress assigned to a category of gene ontology. c Breakdown of the 'Signal transduction' category into gene ontologies. Ontology analysis was conducted using the SoyBase Gene Model Data Mining and Analysis tool. 


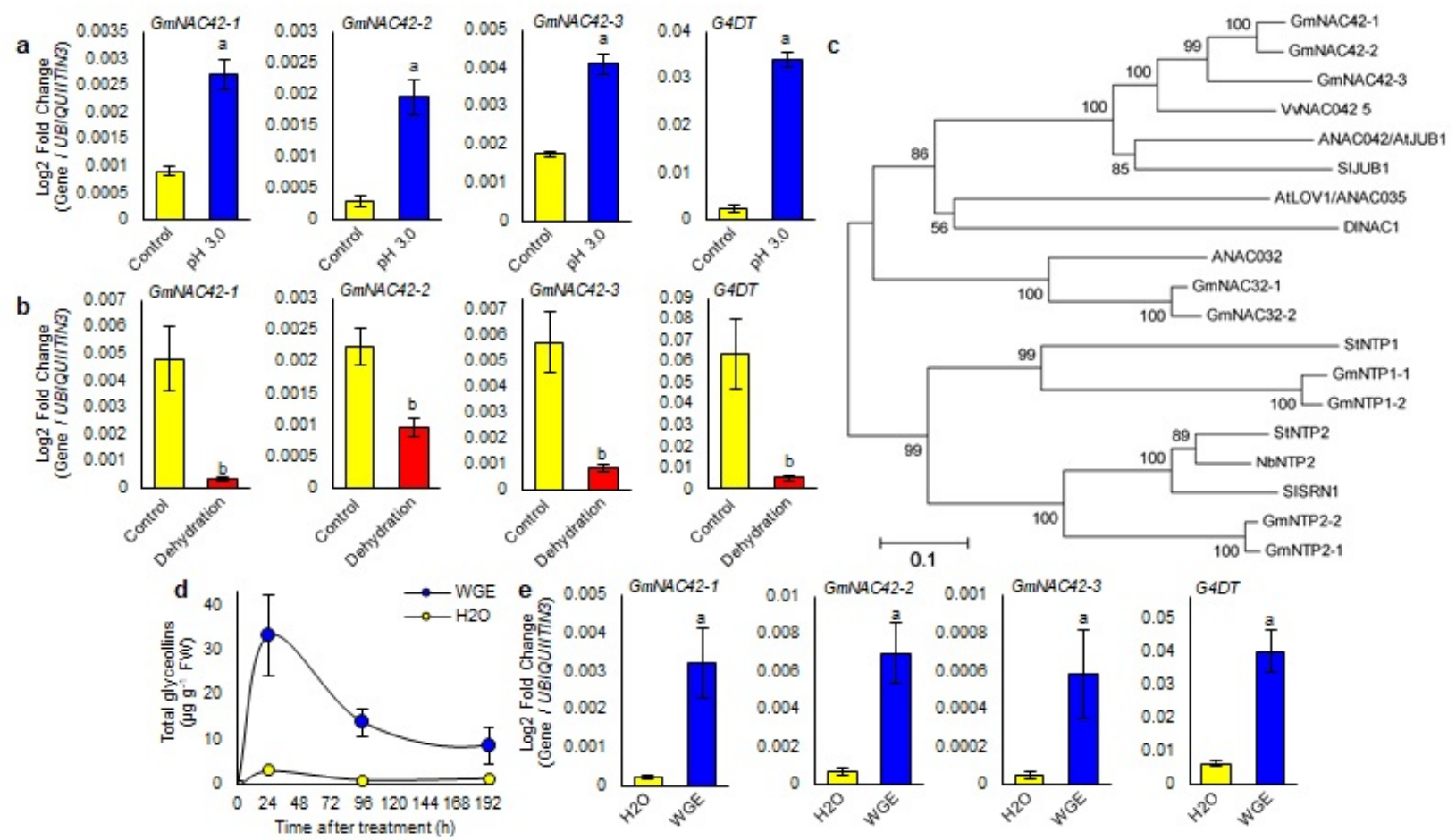

Fig. 5 GmNAC42s expressions are induced with glyceollins in response to abiotic and biotic elicitors. (a-b) Gene expressions following treatment with $\mathrm{pH} 3.0$ medium at 9 dat or dehydration at 6 dat relative to their respective controls measured by qRT-PCR. ${ }^{\text {a Significantly }}$

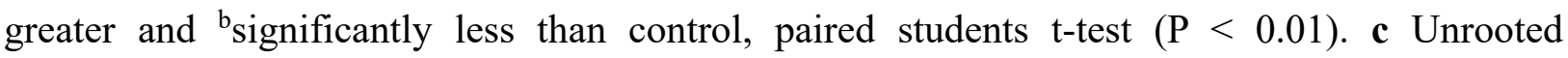
phylogenetic tree of GmNAC42 amino acid sequences and characterized NACs. GenBank Accessions and Phytozome landmarks: GmNAC42-1 (KRH73619; Glyma.02G284300), GmNAC42-2 (KRH14512; Glyma.14G030700), GmNAC42-3 (KRG98971; Glyma.18G110700), VvNAC042_5 (XP_002283251; VIT_12s0028g00860), ANAC042 (Q9SK55; AT2G43000), SlJUB1 (XP_019069297; Solyc05g021090); AtLOV1/ANAC035 (Q9ZVP8.2; AT2G02450), DINAC1 (ABQ96120; N/A), ANAC032 (AAM65083; AT1G77450), GmNAC32-1 (NP_001236871.2; Glyma.06G114000), GmNAC32-2 (NP_001240958.1; Glyma.04G249000), StNTP1 (AGY49284; PGSC0003DMT400001498), StNTP2 (AGY49285; PGSC0003DMT400079997), NbNTP2 (AGY49287; N/A), SISRN1 (NP_001304297; Solyc12g056790), GmNTP1-1 (NP_001276287; Glyma.02G222300), GmNTP1-2 (XP_006596412; Glyma.14G189300), GmNTP2-1 (XP_003556180; Glyma.20G172100), GmNTP2-2 (NP_001274375; Glyma.10G219600). The number adjacent branches indicate maximum parsimony bootstrap values for the corresponding node. The scale bar indicates the number of differences per 100 residues derived from the Muscle alignment. The phylogenetic tree was generated using MEGA v5.0 software. d Amount of total glyceollins extracted from empty-vector transformed soybean hairy roots following treatment with $\mathrm{H} 2 \mathrm{O}$ or wall glucan elicitor (WGE) from P. sojae. e Gene expressions following $24 \mathrm{~h}$ of WGE or water treatment of soybean hairy roots measured by qRT-PCR. 


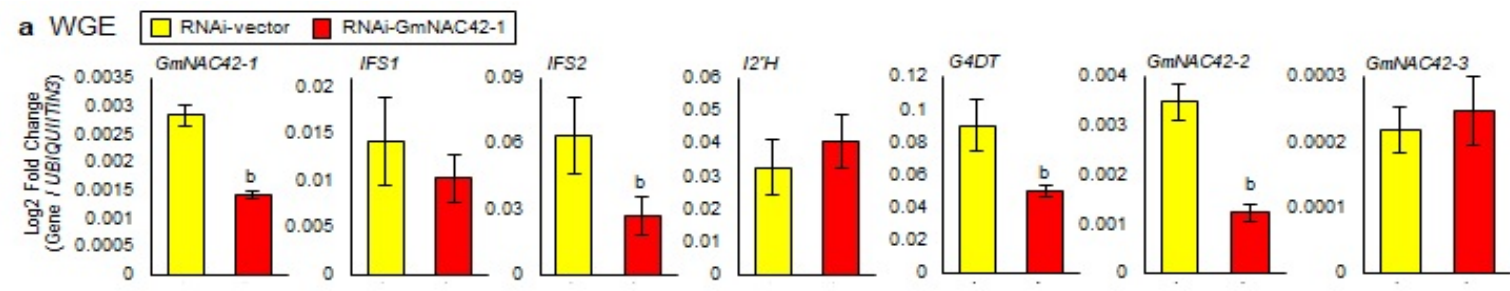

b WGE $\square$ p35S::vector $\square$ p355::GmNAC42-1

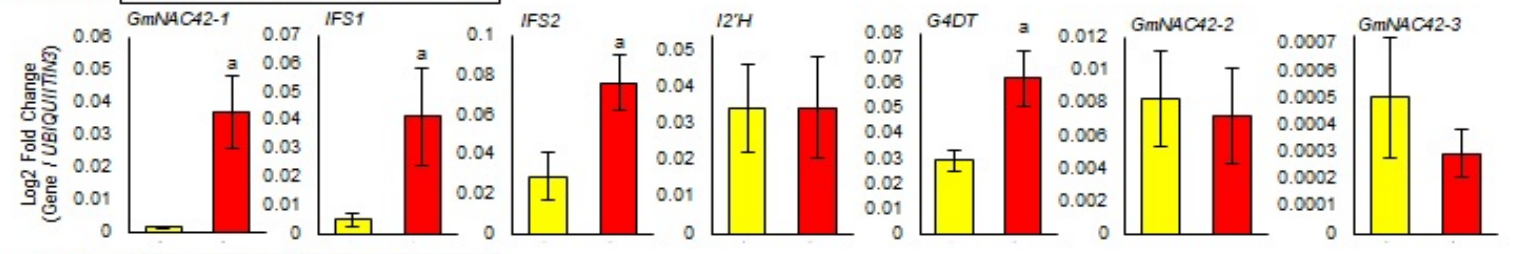

c $\mathrm{H} 2 \mathrm{O} \square$ p35S::vector $\square$ p35S::GmNAC42-1
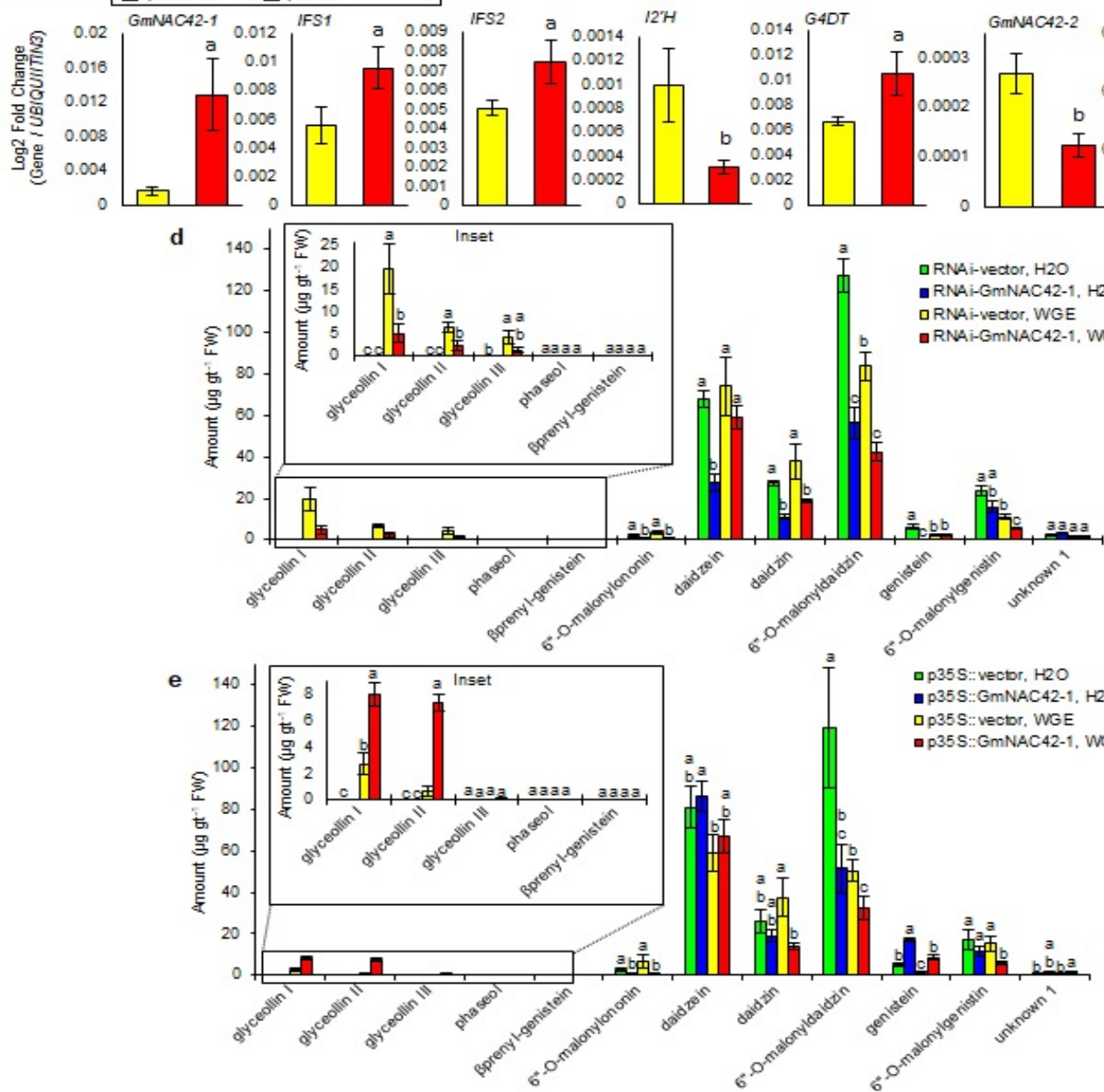

Fig. 6 Overexpression and silencing of $G m N A C 42-1$ in soybean hairy roots. a Gene expressions in WGE-treated Williams 82 hairy roots undergoing RNAi silencing of GmNAC42-1. b Gene expressions in WGE-treated hairy roots overexpressing GmNAC42-1. c Gene expressions in mock-treated hairy roots overexpressing GmNAC42-1. Measurements were $24 \mathrm{~h}$ after treatment by qRT-PCR. ${ }^{\mathrm{a}}$ Significantly greater and ${ }^{\mathrm{b}}$ significantly less than control, paired students $t$-test $(P$ $<0.01$ ). d Amounts of phytoalexins and constitutive isoflavonoids in soybean hairy roots undergoing RNAi silencing of GmNAC42-1 $24 \mathrm{~h}$ after treatment with WGE or H2O. e Metabolite amounts from hairy roots overexpressing GmNAC42-1. Different letters show significant differences by single factor ANOVA, Tukey post hoc test, $P<0.01$. 


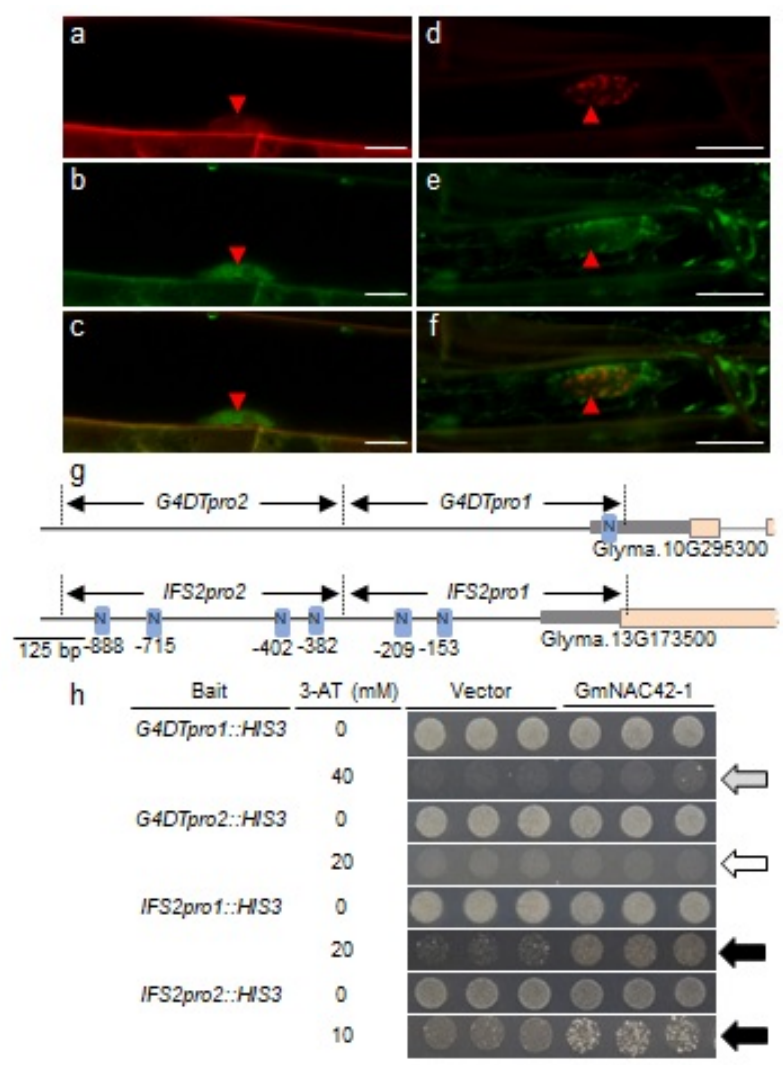

Fig. 7 Nuclear localization and DNA binding activities of GmNAC42-1. (a-f) Confocal fluorescence microscopy images of GFP-GmNAC42-1 fusion protein in transgenic soybean hairy roots. (a-c) Root cell expressing GFP-GmNAC42-1 fusion protein. (d-f) Root cell expressing GFP. a Propidium iodide $\left(10 \mu \mathrm{g} \mathrm{mL}^{-1}\right)$ staining the plasma membrane and nucleus. b GFP-GmNAC42-1 fluorescence at plasma membrane and nucleus. c Overlay of GmNAC42-1 and propidium iodide fluorescence from panels $\mathbf{a}$ and b. d Propidium iodide staining. e GFP signal in cytosol and other extranuclear compartments. f Overlay of GFP and propidium iodide fluorescence from D and E. Bars $=10 \mu \mathrm{m}$. g Schematic diagram demonstrating G4DT and IFS2 promoter fragments used for yeast one-hybrid assays and predicted NAC binding elements (blue boxes). h Yeast one-hybrid assays of YM4271 yeast transformed with GmNAC42-1 on SD/His/-Leu medium containing various concentrations of 3-AT. Arrows: gray indicates weak binding, white no binding, and black strong binding. 
Tables

Table 1 Glyceollin biosynthesis genes upregulated by $\mathrm{pH} 3.0$ medium and downregulated by dehydration.

\begin{tabular}{|c|c|c|c|c|c|c|c|}
\hline \multirow[b]{2}{*}{ Pathway } & \multirow{2}{*}{$\begin{array}{c}\text { Gene } \\
\text { symbol }\end{array}$} & \multirow[b]{2}{*}{ Enzyme } & \multirow[b]{2}{*}{ Wm82.a2 (Glyma 2.0) } & \multicolumn{2}{|c|}{ pH 3.0 medium } & \multicolumn{2}{|c|}{ Dehydration } \\
\hline & & & & $\begin{array}{c}\log 2 \\
\text { FC }\end{array}$ & $P$-value & $\begin{array}{c}\log 2 \\
\text { FC }\end{array}$ & $P$-value \\
\hline \multirow[t]{10}{*}{ Phenylpropanoid } & \multirow[t]{4}{*}{$P A L$} & \multirow{4}{*}{$\begin{array}{c}\text { phenylalanine ammonia- } \\
\text { lyase }\end{array}$} & Glyma.02G309300 & 1.49 & $2.00 \mathrm{E}-05$ & -2.15 & $1.69 \mathrm{E}-10$ \\
\hline & & & Glyma.03G181700 & 1.31 & 0.01535019 & -2.08 & 0.00169183 \\
\hline & & & Glyma.03G181600 / & 1.10 & 0.00697352 & -1.83 & 0.00121303 \\
\hline & & & Glyma.10G058200 & & & & \\
\hline & $\mathrm{C} 4 \mathrm{H}$ & $\begin{array}{l}\text { cinnamic acid 4- } \\
\text { hydroxylase }\end{array}$ & Glyma.20G114200 & 4.44 & $1.63 \mathrm{E}-170$ & -1.78 & 0.00085225 \\
\hline & $4 C L$ & $\begin{array}{c}\text { 4-coumarate: coenzyme A } \\
\text { ligase }\end{array}$ & Glyma.11G010500 & 2.17 & $2.39 \mathrm{E}-24$ & -1.08 & 0.00147188 \\
\hline & \multirow[t]{2}{*}{$\mathrm{CHR}$} & \multirow[t]{2}{*}{ chalcone reductase } & Glyma.14G005700 & 2.03 & $3.46 \mathrm{E}-10$ & -1.64 & 0.00053532 \\
\hline & & & Glyma.02G307300 & 3.78 & $6.27 \mathrm{E}-25$ & -3.25 & $1.27 \mathrm{E}-07$ \\
\hline & \multirow[t]{2}{*}{$\mathrm{CHI}$} & \multirow[t]{2}{*}{ chalcone isomerase } & Glyma.10G292200 & 1.57 & $3.94 \mathrm{E}-11$ & -4.72 & $4.19 \mathrm{E}-43$ \\
\hline & & & Glyma.20G241500 & 1.94 & 4.17E-19 & -1.32 & 0.02583103 \\
\hline \multirow[t]{10}{*}{ Isoflavonoid } & IFS1 & Isoflavone synthase & Glyma.07G202300 & 1.97 & $1.95 \mathrm{E}-13$ & -2.12 & $6.75 \mathrm{E}-15$ \\
\hline & IFS2 & Isoflavone synthase & Glyma.13G173500 & 3.23 & $2.16 \mathrm{E}-24$ & -1.11 & $3.40 \mathrm{E}-06$ \\
\hline & $H I D H$ & $\begin{array}{c}\text { 2-hydroxy-isoflavanone } \\
\text { dehydratase }\end{array}$ & Glyma.10G250300 & 1.51 & $2.00 \mathrm{E}-09$ & -1.68 & $1.30 \mathrm{E}-05$ \\
\hline & $I 2^{\prime} H$ & isoflavone 2 '-hydroxylase & Glyma.15G156100 & 4.32 & $1.43 \mathrm{E}-81$ & -4.08 & $7.32 \mathrm{E}-18$ \\
\hline & \multirow[t]{6}{*}{$I F R$} & \multirow[t]{6}{*}{ isoflavone reductase } & Glyma.11G070500 & 2.31 & $1.52 \mathrm{E}-29$ & -4.23 & $1.34 \mathrm{E}-11$ \\
\hline & & & Glyma.11G070600 & 2.67 & $1.06 \mathrm{E}-60$ & -3.28 & $4.13 \mathrm{E}-18$ \\
\hline & & & Glyma.01G172600 & 1.55 & $1.52 \mathrm{E}-11$ & -3.15 & $4.23 \mathrm{E}-13$ \\
\hline & & & Glyma.01G172700 & 1.80 & $6.88 \mathrm{E}-13$ & -2.96 & $1.54 \mathrm{E}-20$ \\
\hline & & & Glyma.01G211800 & 2.48 & $9.19 \mathrm{E}-11$ & -2.56 & $1.05 \mathrm{E}-06$ \\
\hline & & & Glyma.11G070200 & 2.64 & $1.04 \mathrm{E}-31$ & -1.43 & $9.61 \mathrm{E}-07$ \\
\hline \multirow[t]{6}{*}{ Pterocarpan } & \multirow[t]{3}{*}{ PTS1 } & \multirow[t]{3}{*}{ pterocarpan synthase } & Glyma.19G151200 & 3.67 & $1.31 \mathrm{E}-20$ & -2.84 & $4.06 \mathrm{E}-06$ \\
\hline & & & Glyma.19G151100 & 3.78 & $1.55 \mathrm{E}-32$ & -1.53 & 0.0105246 \\
\hline & & & Glyma.03G147700 & 3.75 & $1.34 \mathrm{E}-30$ & -1.70 & 0.00122376 \\
\hline & $P 6 \alpha H$ & $\begin{array}{l}\text { dihydroxypterocarpan- } 6 \alpha- \\
\text { hydroxylase }\end{array}$ & Glyma.19G144700 & 1.71 & $4.51 \mathrm{E}-16$ & -3.79 & $3.21 \mathrm{E}-16$ \\
\hline & $G 4 D T$ & $\begin{array}{l}\text { glycinol 4-dimethylallyl- } \\
\text { transferase }\end{array}$ & Glyma.10G295300 & 2.93 & $1.01 \mathrm{E}-19$ & -2.91 & $2.26 \mathrm{E}-10$ \\
\hline & $G 2 D T$ & $\begin{array}{l}\text { glycinol 2-dimethylallyl- } \\
\text { transferase }\end{array}$ & Glyma.20G245100 & 2.80 & $5.96 \mathrm{E}-45$ & -3.11 & $3.78 \mathrm{E}-10$ \\
\hline \multirow{12}{*}{$\begin{array}{l}\text { Methylerythritol } \\
\text { phosphate (MEP) }\end{array}$} & \multirow[t]{3}{*}{$D X S$} & \multirow{3}{*}{$\begin{array}{l}\text { 1-deoxy-D-xylulose 5- } \\
\text { phosphate synthase }\end{array}$} & Glyma.18G148700 & 2.73 & $2.90 \mathrm{E}-32$ & -4.63 & 4.62E-22 \\
\hline & & & Glyma.08G277000 & 3.15 & $1.45 \mathrm{E}-22$ & -3.33 & $8.88 \mathrm{E}-17$ \\
\hline & & & Glyma.08G277100 & 2.49 & $1.07 \mathrm{E}-18$ & -3.01 & $5.41 \mathrm{E}-09$ \\
\hline & \multirow[t]{3}{*}{$D X R$} & \multirow{3}{*}{$\begin{array}{l}\text { 1-deoxy-D-xylulose 5- } \\
\text { phosphate } \\
\text { reductoisomerase }\end{array}$} & Glyma.16G089000 & 1.07 & $3.73 \mathrm{E}-10$ & -2.68 & 4.07E-07 \\
\hline & & & Glyma.17G089600 & 1.49 & $6.09 \mathrm{E}-20$ & -2.34 & $2.36 \mathrm{E}-08$ \\
\hline & & & Glyma.05G037500 & 1.18 & $1.29 \mathrm{E}-23$ & -1.95 & $1.59 \mathrm{E}-07$ \\
\hline & $C M K$ & $\begin{array}{l}\text { 4-diphosphocytidyl-2-C- } \\
\text { methyl-D-erythritol kinase }\end{array}$ & Glyma.20G046800 & 1.33 & $1.09 \mathrm{E}-06$ & -2.06 & $1.27 \mathrm{E}-10$ \\
\hline & $M D S$ & $\begin{array}{l}\text { 2-C-methyl-D-erythritol } \\
\text { 2,4-cyclodiphosphate } \\
\text { synthase }\end{array}$ & Glyma.11G021400 & 1.10 & $4.90 \mathrm{E}-11$ & -1.46 & $6.26 \mathrm{E}-05$ \\
\hline & $H D S$ & $\begin{array}{l}\text { 4-hydroxy-3-methylbut-2- } \\
\text { enyl diphosphate synthase }\end{array}$ & Glyma.13G326400 & 1.82 & $9.17 \mathrm{E}-34$ & -1.19 & $1.63 \mathrm{E}-09$ \\
\hline & \multirow[t]{2}{*}{$H D R$} & 4-hydroxy-3-methylbut-2- & Glyma.11G120900 & 1.90 & $3.48 \mathrm{E}-25$ & -1.16 & $1.35 \mathrm{E}-10$ \\
\hline & & enyl diphosphate reductase & Glyma.12G046000 & 1.22 & $6.42 \mathrm{E}-15$ & -1.09 & $1.61 \mathrm{E}-05$ \\
\hline & $I D I 2$ & IPP isomerase & Glyma.18G242300 & 1.55 & $8.00 \mathrm{E}-07$ & -1.10 & $1.05 \mathrm{E}-06$ \\
\hline
\end{tabular}


Table 2 Select SAR genes upregulated by pH 3.0 medium and downregulated by dehydration.

\begin{tabular}{|c|c|c|c|c|c|c|c|c|c|}
\hline \multirow{2}{*}{$\begin{array}{l}\text { Accession } \\
\text { (Wm82.a2.v1) }\end{array}$} & \multirow{2}{*}{$\begin{array}{l}\text { Arabidopsis gene } \\
\text { symbol }\end{array}$} & \multirow[b]{2}{*}{ Annotation } & \multirow[b]{2}{*}{ Arabidopsis accession } & \multicolumn{2}{|c|}{ pH 3.0 medium } & \multicolumn{2}{|c|}{ Dehydration } & \multirow{2}{*}{$\begin{array}{l}\text { BLASTP } \\
\text { score }\end{array}$} & \multirow{2}{*}{$\begin{array}{l}\text { E-value } \\
\left(\mathrm{E}<10^{-6}\right)\end{array}$} \\
\hline & & & & $\begin{array}{c}\log 2 \\
\mathrm{FC}\end{array}$ & $\begin{array}{c}\mathrm{P}- \\
\text { value }\end{array}$ & $\begin{array}{c}\log 2 \\
\text { FC }\end{array}$ & $\begin{array}{c}\mathrm{P}- \\
\text { value }\end{array}$ & & \\
\hline Glyma.08G180600 & $A L D 1$ & $\begin{array}{l}\text { AGD2-LIKE DEFENSE } \\
\text { RESPONSE PROTEIN } 1\end{array}$ & AT2G13810 & 3.848 & 0.000 & -6.507 & 0.000 & $0.0 \mathrm{E}+00$ & 100 \\
\hline Glyma.17G046600 & FMO1 & $\begin{array}{l}\text { FLAVIN-DEPENDENT } \\
\text { MONOOXYGENASE } 1\end{array}$ & AT1G19250 & 6.575 & 0.000 & -3.981 & 0.000 & $0.0 \mathrm{E}+00$ & 100 \\
\hline Glyma.06G156300 & PAD4 & PHYTOALEXIN DEFICIENT 4 & AT3G52430 & 1.809 & 0.000 & -1.753 & 0.001 & $0.0 \mathrm{E}+00$ & 100 \\
\hline Glyma.03G249100 & SIBI & SIGMA FACTOR BINDING & AT3G56710 & 4.133 & 0.000 & -5.521 & 0.000 & $6.0 \mathrm{E}-90$ & 100 \\
\hline Glyma.04G134200 & & PROTEIN 1 & & 2.034 & 0.000 & -1.140 & 0.007 & $6.0 \mathrm{E}-89$ & 100 \\
\hline Glyma.02G284300 & $A N A C 042 / J U B 1$ & NAC DOMAIN CONTAINING & AT2G43000 & 1.178 & 0.000 & -2.568 & 0.000 & $0.0 \mathrm{E}+00$ & 100 \\
\hline Glyma.18G110700 & & PROTEIN 42 / JUNGBRUNNEN 1 & & 1.846 & 0.000 & -1.527 & 0.003 & $0.0 \mathrm{E}+00$ & 100 \\
\hline Glyma.14G030700 & & & & 3.029 & 0.000 & -1.197 & 0.011 & $0.0 \mathrm{E}+00$ & 100 \\
\hline Glyma.13G267700 & WRKY70 & WRKY DNA-BINDING PROTEIN & AT3G56400 & 4.660 & 0.000 & -3.175 & 0.005 & $0.0 \mathrm{E}+00$ & 100 \\
\hline Glyma.13G267500 & & 70 & & 3.029 & 0.000 & -5.123 & 0.000 & $0.0 \mathrm{E}+00$ & 100 \\
\hline Glyma.18G213200 & & & & 1.086 & 0.000 & -4.386 & 0.000 & $0.0 \mathrm{E}+00$ & 100 \\
\hline Glyma.04G061400 & WRKY40 & WRKY DNA-BINDING PROTEIN & AT1G80840 & 2.140 & 0.000 & -2.580 & 0.000 & $1.0 \mathrm{E}-162$ & 100 \\
\hline Glyma.14G103100 & & 40 & & 1.712 & 0.000 & -5.104 & 0.000 & $0.0 \mathrm{E}+00$ & 100 \\
\hline Glyma.11G120400 & DIRI & DEFECTIVE IN INDUCED & AT5G48485 & 1.327 & 0.000 & -4.214 & 0.000 & $2.0 \mathrm{E}-68$ & 100 \\
\hline Glyma.12G045500 & & RESISTANCE 1 & & 1.220 & 0.002 & -3.198 & 0.000 & $2.0 \mathrm{E}-67$ & 100 \\
\hline Glyma.06G137000 & DMR6 & DOWNY MILDEW RESISTANT 6 & AT5G24530 & 1.428 & 0.000 & -4.998 & 0.000 & $0.0 \mathrm{E}+00$ & 100 \\
\hline Glyma.14G048900 & $E F E$ & ETHYLENE FORMING ENZYME & AT1G05010 & 2.006 & 0.000 & -1.333 & 0.017 & $0.0 \mathrm{E}+00$ & 100 \\
\hline Glyma.08G128900 & $E F R$ & EF-TU RECEPTOR & AT5G20480 & 2.574 & 0.000 & -2.045 & 0.007 & $0.0 \mathrm{E}+00$ & 100 \\
\hline Glyma.07G103700 & YLS9 & NDR1/HIN1-LIKE 10 & AT2G35980 & 3.041 & 0.000 & -3.884 & 0.000 & $2.0 \mathrm{E}-148$ & 100 \\
\hline Glyma.07G103800 & & & & 1.466 & 0.001 & -2.917 & 0.002 & $8.0 \mathrm{E}-152$ & 100 \\
\hline Glyma.09G003100 & $R L K 1$ & RECEPTOR-LIKE PROTEIN & AT5G60900 & 2.462 & 0.000 & -2.888 & 0.000 & $0.0 \mathrm{E}+00$ & 100 \\
\hline Glyma.03G090200 & & KINASE 1 & & 2.254 & 0.000 & -1.321 & 0.000 & $0.0 \mathrm{E}+00$ & 100 \\
\hline Glyma.15G258400 & & & & 1.753 & 0.012 & -4.378 & 0.000 & $0.0 \mathrm{E}+00$ & 100 \\
\hline Glyma.16G168700 & $R L P 19$ & RECEPTOR LIKE PROTEIN 19 & AT2G15080 & 3.743 & 0.000 & -5.408 & 0.000 & $0.0 \mathrm{E}+00$ & 99.61 \\
\hline Glyma.16G169500 & $R L P 32$ & RECEPTOR LIKE PROTEIN 32 & AT3G05650 & 1.890 & 0.002 & -2.689 & 0.001 & $0.0 \mathrm{E}+00$ & 100 \\
\hline Glyma.16G170700 & & & & 2.118 & 0.023 & -3.478 & 0.001 & $0.0 \mathrm{E}+00$ & 98.59 \\
\hline Glyma.16G175100 & $R L P 33$ & RECEPTOR LIKE PROTEIN 33 & AT3G05660 & 6.601 & 0.000 & -5.803 & 0.000 & $0.0 \mathrm{E}+00$ & 100 \\
\hline Glyma.14G046000 & & & & 3.548 & 0.000 & -1.017 & 0.025 & $0.0 \mathrm{E}+00$ & 99.76 \\
\hline Glyma.16G126100 & $R L P 46$ & RECEPTOR LIKE PROTEIN 46 & AT4G04220 & 2.151 & 0.017 & -2.953 & 0.022 & $0.0 \mathrm{E}+00$ & 93.3 \\
\hline
\end{tabular}




\section{Additional File: Figure}

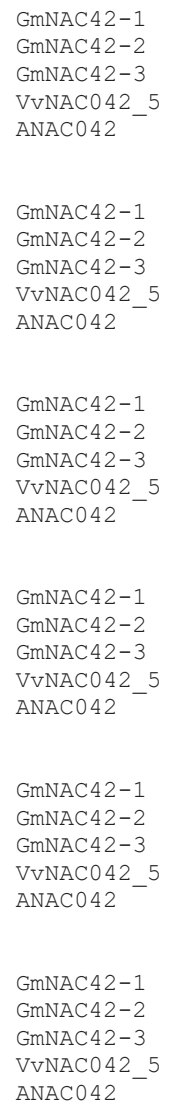

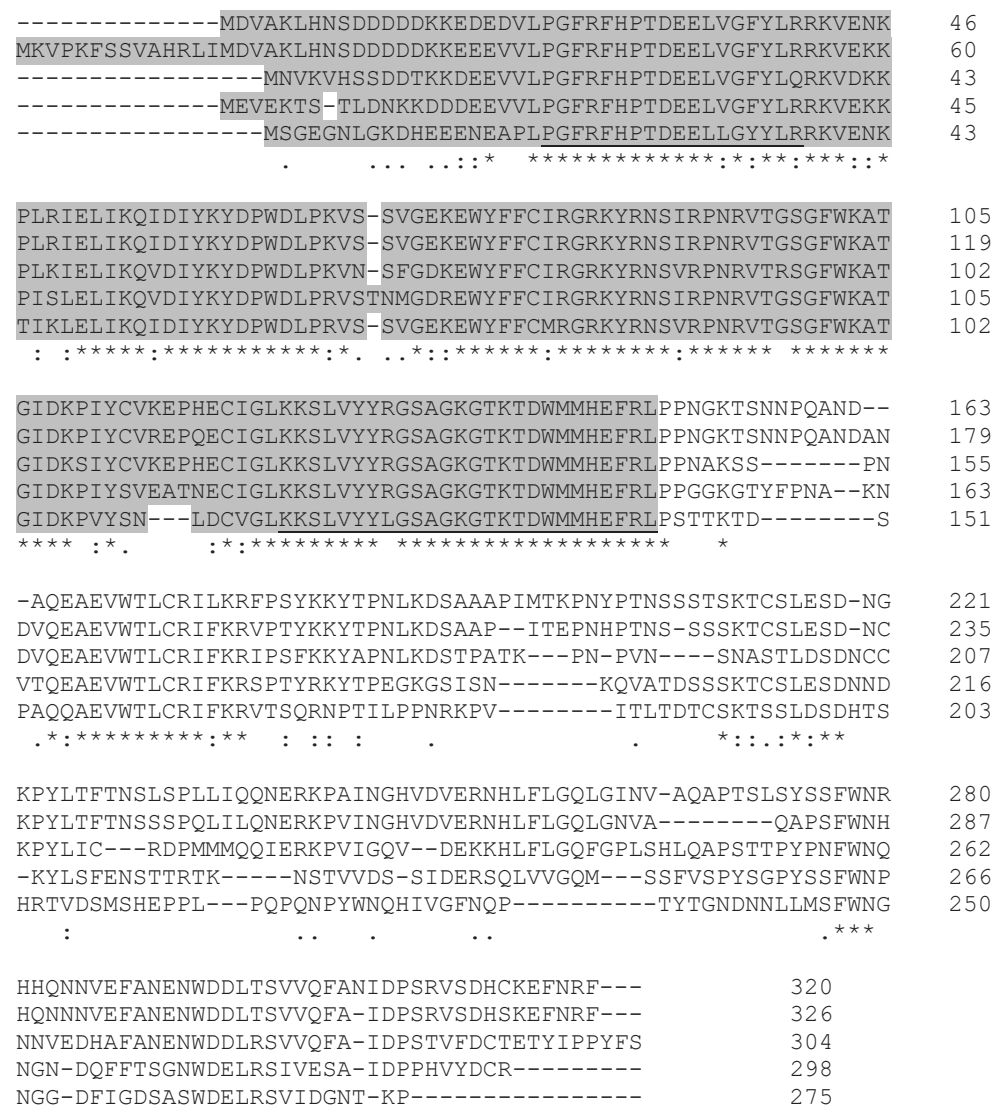

Additional file 7: Figure S1. Amino acid alignment of NAC42 proteins from soybean, Arabidopsis and grapevine. Residues that are fully conserved (*), strongly similar (:) (>0.5 in the Gonnet PAM 250 matrix), and weakly similar (.) (Gonnet PAM $\leq 0.5$ and $>0$ ). NAM domain is underlined. N-terminal half is shaded. 


\section{Additional File: Tables}

Additional file 1: Table S1. Sequences of primers used in the experiments.

\begin{tabular}{|c|c|c|c|c|}
\hline Target & & Primer & Sequence & Purpose \\
\hline UBIQUIITIN3 & Glyma.20G141600 & qUBf & GTGTAATGTTGGATGTGTTCCC & qRT-PCR \\
\hline UBIQUIITIN3 & Glyma.20G141600 & qUBr & CCGAACTTATTTTCAAGGGACAT & qRT-PCR \\
\hline G4DT & Glyma.10G295300 & $q G 4 f$ & TGGCTTTCGGAGTTGGTATC & qRT-PCR \\
\hline G4DT & Glyma.10G295300 & $q G 4 r$ & GAACAGCATTTCCCATACCC & qRT-PCR \\
\hline IFS1 & Glyma.07G202300 & qIF1f & CACTCAAACTCGGGATCACA & qRT-PCR \\
\hline IFS1 & Glyma.07G202300 & qIF1r & GACGCAAGTGCAGAAACAAA & qRT-PCR \\
\hline IFS2 & Glyma.13G173500 & qIF2f & GGAGAGGTTGTTGAGGGTGA & qRT-PCR \\
\hline IFS2 & Glyma.13G173500 & $\mathrm{qIF} 2 \mathrm{r}$ & GACCCTTGATGTGGTCCTTG & qRT-PCR \\
\hline $12^{\prime} \mathrm{H}$ & Glyma.15G156100 & $q 12 f$ & CCATGCTTTTTGGTGGAACT & qRT-PCR \\
\hline $12^{\prime} \mathrm{H}$ & Glyma.15G156100 & $q \mid 2 r$ & GCCTTCTTCAACACCTCTGG & qRT-PCR \\
\hline NAC42-1 & Glyma.02G284300 & qNACf & CTCAGCAGCAGCACCAATAA & qRT-PCR \\
\hline NAC42-1 & Glyma.02G284300 & qNACr & AAGTATGGCTTGCCGTTGTC & qRT-PCR \\
\hline NAC42-2 & Glyma.14G030700 & qNAC-2f & TTCAAACGAGTCCCAACTTACA & qRT-PCR \\
\hline NAC42-2 & Glyma.14G030700 & qNAC- $2 r$ & GGGTGATTTGGCTCAGTGAT & qRT-PCR \\
\hline NAC42-3 & Glyma.18G110700 & qNAC-3f & TTCAAACGCATCCCATCTTT & qRT-PCR \\
\hline NAC42-3 & Glyma.18G110700 & qNAC-3r & CGTTGGAATTCACAGGGTTT & qRT-PCR \\
\hline N/A & N/A & attB1 & GGGGACAAGTTTGTACAAAAAAGCAGGCT & Cloning \\
\hline N/A & N/A & attB2 & GGGGACCACTTTGTACAAGAAAGCTGGGT & Cloning \\
\hline NAC42-1 & Glyma.02G284300 & aNAC1f & AAAAAGCAGGCTtaacaATGGATGTGGCCAAGTTACA & Cloning, $\mathrm{OE}$ \\
\hline NAC42-1 & Glyma.02G284300 & aNAC1r-b & AGAAAGCTGGGTGGCATGCACCCAAGAAAAGAG & Cloning, $\mathrm{OE}$ \\
\hline NAC42-1 & Glyma.02G284300 & siNACf & AAAAAGCAGGCTTCAGTTGGGGAGAAGGAATG & $\begin{array}{l}\text { Cloning, } \\
\text { Silencing }\end{array}$ \\
\hline NAC42-1 & Glyma.02G284300 & siNACr & AGAAAGCTGGGTGTCGTGCATCATCCAATCAGT & $\begin{array}{l}\text { Cloning, } \\
\text { Silencing }\end{array}$ \\
\hline $\begin{array}{l}\text { pDEST- } \\
\text { GADT7 }\end{array}$ & N/A & $\mathrm{T7}$ & T AAT ACG ACTCAC TAT AGG GC & Sequencing \\
\hline $\begin{array}{l}\text { pMW\#2, } \\
\text { pDONR221 }\end{array}$ & N/A & M13F & GTAAAACGACGGCCAGT & Sequencing \\
\hline $\begin{array}{l}\text { YM4271 } \\
\text { HIS3 }\end{array}$ & N/A & HIS293R & GGGACCACCCTTTAAAGAGA & GIC \\
\hline IFS2pro1 & Glyma.13G173500 & clFS2pro1f & GCAGCCGATCTTAGACCAGA & C-PCR, GIC \\
\hline IFS2pro1 & Glyma.13G173500 & cIFS2pro1r & CCAAGTGCAAGTTCAAGCAA & Colony PCR \\
\hline IFS2pro2 & Glyma.13G173500 & clFS2pro2f & TTGTCAACACATTTCTTTGACTGA & C-PCR, GIC \\
\hline IFS2pro2 & Glyma.13G173500 & cIFS2pro2r & TGGAATGCTACTCGTTCGTG & Colony PCR \\
\hline G4DTpro1 & Glyma.10G295300 & cG4P1f & GCAAAGGTTACATCGAGCAAA & C-PCR, GIC \\
\hline G4DTpro1 & Glyma.10G295300 & cG4P1r & GTCTCGTCTGTGATGGCTGA & Colony PCR \\
\hline G4DTpro2 & Glyma.10G295300 & cG4P2f & TGGAGGTTACATATTGTCATCAGTT & C-PCR, GIC \\
\hline G4DTpro2 & Glyma.10G295300 & cG4P2r & AGGGCAAATGCTTCAACAAA & C-PCR \\
\hline
\end{tabular}

Abbreviations: Cl- Cloning, Si- Silencing, GIC- Genomic Integration Check, C-PCR- Colony

PCR, OE- Overexpression 


\title{
Chapter Four
}

\section{Acidity Stress for the Systemic Elicitation of Glyceollin Phytoalexins in Soybean Plants}

\author{
Md Asraful Jahan and Nik Kovinich
}

Division of Plant and Soil Sciences; West Virginia University, Morgantown, WV USA

Keywords: Bioproduction, natural products, phytoalexin, isoflavonoid

Jahan MA and Kovinich N (2019) Acidity stress for the systemic elicitation of glyceollin phytoalexins in soybean plants. Plant Signaling and Behavior.

https://doi.org/10.1080/15592324.2019.1604018 


\begin{abstract}
Glyceollins are the major pathogen- and stress-inducible natural products (phytoalexins) of soybean that possess broad-spectrum anticancer and neuroprotective properties. Yet like other phytoalexins, glyceollins are difficult to obtain because they are typically biosynthesized only transiently and in low amounts in plant tissues. We recently identified acidity stress $(\mathrm{pH} 3.0$ growth medium) as an elicitor that exerted prolonged (week-long) inductive effects on glyceollin biosynthesis and identified the NAC family TF gene GmNAC42-1 that activates glyceollin biosynthesis in response to acidity stress or WGE from the soybean pathogen Phytophthora sojae. ${ }^{1}$ GmNAC42-1 was annotated as an SAR gene and SAR genes were statistically overrepresented in the transcriptomic response to acidity stress suggesting that acidity stress triggers the systemic elicitation of glyceollin biosynthesis. Here, we demonstrate that acidity stress acts as a systemic elicitor when provided to soybean roots. Acidity stress preferentially elicited specific glyceollins in different soybean organs with exceptionally high yields of glyceollin I in root tissues.
\end{abstract}

The value of the botanical- and plant-derived drugs market worldwide was estimated to be $\sim 25$ billion in 2016 and is expected to increase to almost $\$ 42$ billion by 2023. Yet, phytoalexins represent a vast array of inducible molecules in plants that remain a mainly untapped drug resource. Phytoalexins are antimicrobial plant metabolites that are not readily accessible as drugs since they are biosynthesized only in response to pathogens or specific abiotic stresses. The chemical structures of phytoalexins vary widely among plant species and include alkaloids, terpenoids, lactones, and phenolics. With roles in plant defense, phytoalexins are naturally bioactive and have diverse activities in human cells. Mounting evidence of their value to human health and agriculture has spurred renewed interest in identifying elicitors of their biosynthesis, biosynthetic genes, and the TFs that could be used to enhance their bioproduction via bioengineering. ${ }^{2-6}$

Glyceollins are the major phytoalexins of soybean that are biosynthesized from the isoflavonoid pathway. For decades, the study of glyceollins has served as a model for understanding the molecular aspects of elicitation and the role of inducible secondary metabolites in plant defense. Biochemical and genetic evidence suggests that glyceollins are essential for providing racespecific resistance to Phytophthora sojae, one of the most devastating pathogens in soybean agriculture. $^{7-9}$ They also exhibit anticancer, antidiabetic, and neuroprotective properties that have been the subject of recent reviews. ${ }^{10-12}$ Glyceollin I, in particular, inhibits the proliferation 
and survival of a broad range of cancer types by inhibiting ER signaling and by other unclear mechanism(s). ${ }^{13-20}$ Conversely, glyceollins promote the survival of challenged neurons by stimulating the Nrf2/HO-1 signaling pathway. ${ }^{21}$

The critical barriers that limit accessibility of glyceollins is that they cannot be synthesized economically ${ }^{22-24}$ or obtained in sufficient amounts from soybean tissues. ${ }^{25-27}$ Efforts to improve accessibility have included (semi)-synthesis, ${ }^{22-24}$ fermentation of soybeans, ${ }^{28}$ combined treatments of soybean seeds with pathogens and malting, ${ }^{27}$ pathogens and environment stress, ${ }^{29}$ and pathogens and chemicals. ${ }^{26}$ A combined treatment of $P$. sojae WGE and the inorganic chemical silver nitrate had an additive effect, eliciting 1.5-fold more glyceollin I than the WGE treatment alone. ${ }^{26}$ Yet, overexpressing the isoflavonoid biosynthesis gene encoding IFR increased glyceollin amounts more than 3 -fold, ${ }^{30}$ demonstrating that bioengineering can provide greater enhancements in glyceollin yields. However, overexpressing one rate-limiting biosynthetic enzyme will indefinitely uncover another. Since upregulating the expressions of all biosynthesis genes could provide greater increases in yield, we recently set-out to identify the TF gene(s) that regulate glyceollin biosynthesis.

By screening a panel of abiotic stresses, we identified acidity ( $\mathrm{pH} 3.0$ medium) to be a potent elicitor and dehydration to be a suppressor of glyceollin biosynthesis. ${ }^{1}$ Using a comparative transcriptomics approach we found that all known glyceollin biosynthesis genes were oppositely regulated by acidity stress and dehydration, and that their expressions mirrored that of the NAC family TF gene GmNAC42-1. ${ }^{1}$ Overexpressing and suppressing GmNAC42-1 in soybean hairy roots increased and decreased, respectively, the levels of glyceollin biosynthesis gene transcripts and metabolites. ${ }^{1}$ GmNAC42-1 was annotated as an SAR gene and SAR genes were significantly overrepresented among those upregulated by acidity stress. SAR is a component of the plant immune system whereby tissues distant from a pathogen infection site become primed to more rapidly activate resistance during subsequent encounters with the pathogen. Yet, whether localized acidity stress could stimulate systemic phytoalexin biosynthesis remained untested.

Here, we grew seedlings in vermiculite to the first trifoliate leaf stage, then transferred them to $\mathrm{pH} 3.0$ growth medium as reported previously with roots in contact with the acidic medium. ${ }^{1}$ Following $9 \mathrm{~d}$ of treatment, seedlings were harvested and organs were dissected for analysis of glyceollins. 
Acidity stress elicited greater amounts of total glyceollins compared to UV-C irradiation, which is classical abiotic elicitor of phytoalexins (Fig. 1A). Transferring seedling roots to the acidic medium resulted in glyceollin accumulation in other organs with true leaves accumulating more than hypocotyls and cotyledons (Fig. 1B). Yet, the roots were the major site of glyceollin accumulation (Fig. 1B). Roots had an average of $1.7 \mathrm{mg} \mathrm{gt}^{-1}$ glyceollins, which is greater than the yield observed for the combined $\mathrm{WGE}^{-\mathrm{AgNO}_{3}}$ treatment of germinating seeds $\left(837.2 \mu \mathrm{g} \mathrm{gt}^{-}\right.$ $\left.{ }^{1}\right),{ }^{26}$ or that observed for soybean sprouts that were simultaneously malted and challenged with Rhizopus microsporus $\left(1.5 \mathrm{mg} \mathrm{gt}^{-1}\right) .{ }^{27}$ The organs preferentially accumulated specific glyceollins with glyceollin I being predominant in the roots and glyceollin III in the true leaves (Fig. 1B). Roots exhibited a browning in color after $9 \mathrm{~d}$ treatment (Fig. 1C). The phenotype was reminiscent of the localized browning observed during an incompatible interaction with $P$. sojae. $^{7,9}$ Glyceollin I represented the major isoflavonoid peak in the roots (Fig. 1D). This is uncommon, since the isoflavone-conjugates 6-O-malonyldaidzin and 6-O-malonylgenistin generally remain the major isoflavonoids in pathogen-treated Williams 82 roots.

In conclusion, acidic growth medium is a potent systemic elicitor of glyceollin biosynthesis. Whether acid mine drainage or other collected environmental contaminants (e.g. acid rain) could be exploited to economically elicit the biosynthesis of these anticancer and neuroprotective natural products, or other plant phytoalexins, remains to be investigated.

\section{Methods}

\section{Plant materials and growth conditions}

Harosoy 63 seeds were a kind gift from Elroy Cober (Agriculture and Agri-Food Canada, Ottawa, Ontario). Seeds (16-20 per batch) were surface sterilized with $70 \%$ ethanol $0.2 \%$ triton $\mathrm{X}(\mathrm{v} / \mathrm{v})$ for $5 \mathrm{~min}$ on a mixer wheel and grown in sterile vermiculite as indicated. ${ }^{1}$

\section{Acidity stress treatments}

The roots of five unblemished, uniform seedlings at their first trifoliate leaf stage ( $\sim 7$-day-old) were gently wrapped together with filter paper saturated with control $(\mathrm{pH} 5.8)$ or acidic $(\mathrm{pH} \mathrm{3.0)}$ medium that contained half-strength MS salts, MS vitamins and 1\%(w/v) sucrose and were 
placed on the medium inside sterile beakers. ${ }^{1}$ The plant organs were harvested separately and processed for metabolite analysis as indicated. ${ }^{1}$

\section{Isoflavonoid analysis}

Pulverized freeze-dried tissue powder ( $\sim 12 \mathrm{mg})$ from whole seedlings, or dissected roots, hypocotyls, cotyledons and leaves were extracted with $80 \%$ ethanol (10 $\mu \mathrm{L} \mathrm{mg}^{-1}$ dry tissue) as described. ${ }^{1}$

\section{UPLC-PDA}

UPLC-PDA measurements were performed using an Accela System (Thermo Scientific, San Jose, CA, USA) containing a 1250 pump, Open AS autosampler, and photodiode array (PDA) as described. ${ }^{26}$

Abbreviations: ER, estrogen receptor; gt $^{-1}$, per gram dry tissue; HO-heme oxygenase-1; IFR, isoflavone reductase; MS, Murashige and Skoog; NAC, NAM/ATAF1/2/CUC2 family TF; Nrf2, nuclear factor (erythroid-derived 2)-like 2; SAR, systemic acquired resistance; TF, transcription factor; UPLC-PDA, ultrahigh performance liquid chromatography-photodiode array; WGE, wall glucan elicitor.

\section{Disclosure of Potential Conflicts of Interest}

No potential conflicts of interest were disclosed.

\section{Funding}

This work was supported by WVU start-up funds to NK and is based upon work that is supported by the United States Department of Agriculture National Institute of Food and Agriculture Hatch project 1010200. 


\section{References}

1. Jahan MA, Harris B, Lowery M, Coburn K, Infante AM, Percifield RJ, et al. The NAC family transcription factor GmNAC42-1 regulates biosynthesis of the anticancer and neuroprotective glyceollins in soybean. BMC genomics 2019; 20:149.

2. Ahuja I, Kissen R, Bones AM. Phytoalexins in defense against pathogens. Trends in plant science $2012 ; 17: 73-90$.

3. Großkinsky DK, van der Graaff E, Roitsch T. Phytoalexin transgenics in crop protectionFairy tale with a happy end? Plant science 2012; 195:54-70.

4. Jeandet $\mathrm{P}$, Clément $\mathrm{C}$, Cordelier $\mathrm{S}$. Regulation of resveratrol biosynthesis in grapevine: new approaches for disease resistance? Journal of experimental botany 2019; 70:375-8.

5. Jeandet P, Hébrard C, Deville M-A, Cordelier S, Dorey S, Aziz A, et al. Deciphering the role of phytoalexins in plant-microorganism interactions and human health. Molecules 2014; 19:18033-56.

6. Jiang J, Xi H, Dai Z, Lecourieux F, Yuan L, Liu X, et al. VvWRKY8 represses stilbene synthase genes through direct interaction with VvMYB14 to control resveratrol biosynthesis in grapevine. Journal of experimental botany 2018; 70:715-29.

7. Graham TL, Graham MY, Subramanian S, Yu O. RNAi silencing of genes for elicitation or biosynthesis of 5-deoxyisoflavonoids suppresses race-specific resistance and hypersensitive cell death in Phytophthora sojae infected tissues. Plant physiology 2007; 144:728-40.

8. Hahn MG, Bonhoff A, Grisebach H. Quantitative localization of the phytoalexin glyceollin I in relation to fungal hyphae in soybean roots infected with Phytophthora megasperma f. sp. glycinea. Plant physiology 1985; 77:591-601.

9. Subramanian S, Graham MY, Yu O, Graham TL. RNA interference of soybean isoflavone synthase genes leads to silencing in tissues distal to the transformation site and to enhanced susceptibility to Phytophthora sojae. Plant physiology 2005; 137:1345-53.

10. Bamji SF, Corbitt C. Glyceollins: Soybean phytoalexins that exhibit a wide range of healthpromoting effects. Journal of Functional Foods 2017; 34:98-105.

11. Nwachukwu ID, Luciano FB, Udenigwe CC. The inducible soybean glyceollin phytoalexins with multifunctional health-promoting properties. Food Research International 2013; 54:1208-16. 
12. Pham T, Lecomte S, Efstathiou T, Ferriere F, Pakdel F. An Update on the Effects of Glyceollins on Human Health: Possible Anticancer Effects and Underlying Mechanisms. Nutrients 2019; 11:79.

13. Bratton MR, Martin EC, Elliott S, Rhodes LV, Collins-Burow BM, McLachlan JA, et al. Glyceollin, a novel regulator of $\mathrm{mTOR} / \mathrm{p} 70 \mathrm{~S} 6$ in estrogen receptor positive breast cancer. The Journal of steroid biochemistry and molecular biology 2015; 150:17-23.

14. Chimezie C, Ewing A, Schexnayder C, Bratton M, Glotser E, Skripnikova E, et al. Glyceollin Effects on MRP2 and BCRP in Caco-2 Cells, and Implications for Metabolic and Transport Interactions. Journal of pharmaceutical sciences 2015.

15. Lee SH, Jee JG, Bae JS, Liu KH, Lee YM. A Group of Novel HIF-1 $\alpha$ Inhibitors, Glyceollins, Blocks HIF-1 $\alpha$ Synthesis and Decreases Its Stability via Inhibition of the PI3K/AKT/mTOR Pathway and Hsp90 Binding. Journal of cellular physiology 2015; 230:853-62.

16. Payton-Stewart F, Schoene NW, Kim YS, Burow ME, Cleveland TE, Boue SM, et al. Molecular effects of soy phytoalexin glyceollins in human prostate cancer cells LNCaP. Molecular carcinogenesis 2009; 48:862-71.

17. Rhodes LV, Tilghman SL, Boue SM, Wang S, Khalili H, Muir SE, et al. Glyceollins as novel targeted therapeutic for the treatment of triple-negative breast cancer. Oncology letters 2012; 3:163-71.

18. Salvo VA, Boue SM, Fonseca JP, Elliott S, Corbitt C, Collins-Burow BM, et al. Antiestrogenic glyceollins suppress human breast and ovarian carcinoma tumorigenesis. Clinical cancer research : an official journal of the American Association for Cancer Research 2006; 12:7159-64.

19. Shin SH, Lee YM. Glyceollins, a novel class of soybean phytoalexins, inhibit SCF-induced melanogenesis through attenuation of SCF/c-kit downstream signaling pathways. Exp Mol Med 2013; 45.

20. Zimmermann MC, Tilghman SL, Boue SM, Salvo VA, Elliott S, Williams KY, et al. Glyceollin I, a novel antiestrogenic phytoalexin isolated from activated soy. The Journal of pharmacology and experimental therapeutics 2010; 332:35-45. 
21. Seo JY, Kim BR, Oh J, Kim J-S. Soybean-Derived Phytoalexins Improve Cognitive Function through Activation of Nrf2/HO-1 Signaling Pathway. International journal of molecular sciences 2018; 19:268.

22. Khupse RS, Sarver JG, Trendel JA, Bearss NR, Reese MD, Wiese TE, et al. Biomimetic syntheses and antiproliferative activities of racemic, natural (-), and unnnatural (+) glyceollin I. Journal of medicinal chemistry $2011 ; 54: 3506-23$.

23. Luniwal A, Khupse R, Reese M, Liu J, El-Dakdouki M, Malik N, et al. Multigram synthesis of glyceollin I. Organic Process Research \& Development 2011; 15:1149-62.

24. Malik N, Zhang Z, Erhardt P. Total synthesis of ( \pm )-glyceollin II and a dihydro derivative. Journal of natural products $2015 ; 78: 2940-7$.

25. Boue SM, Carter CH, Ehrlich KC, Cleveland TE. Induction of the soybean phytoalexins coumestrol and glyceollin by Aspergillus. Journal of agricultural and food chemistry 2000; 48:2167-72.

26. Farrell KC, Jahan MA, Kovinich N. Distinct Mechanisms of Biotic and Chemical Elicitors enable Additive Elicitation of the Anticancer Phytoalexin Glyceollin I. Molecules 2017; 22:1261-73.

27. Simons R, Vincken JP, Roidos N, Bovee TFH, van Iersel M, Verbruggen MA, et al. Increasing Soy Isoflavonoid Content and Diversity by Simultaneous Malting and Challenging by a Fungus to Modulate Estrogenicity. Journal of agricultural and food chemistry $2011 ; 59: 6748-58$.

28. Park S, Kim da S, Kim JH, Kim JS, Kim HJ. Glyceollin-containing fermented soybeans improve glucose homeostasis in diabetic mice. Nutrition 2012; 28:204-11.

29. Aisyah S, Gruppen H, Madzora B, Vincken JP. Modulation of isoflavonoid composition of Rhizopus oryzae elicited soybean (Glycine max) seedlings by light and wounding. Journal of agricultural and food chemistry 2013; 61:8657-67.

30. Cheng Q, Li N, Dong L, Zhang D, Fan S, Jiang L, et al. Overexpression of Soybean Isoflavone Reductase (GmIFR) Enhances Resistance to Phytophthora sojae in Soybean. Frontiers in plant science $2015 ; 6: 1024$. 
Figures

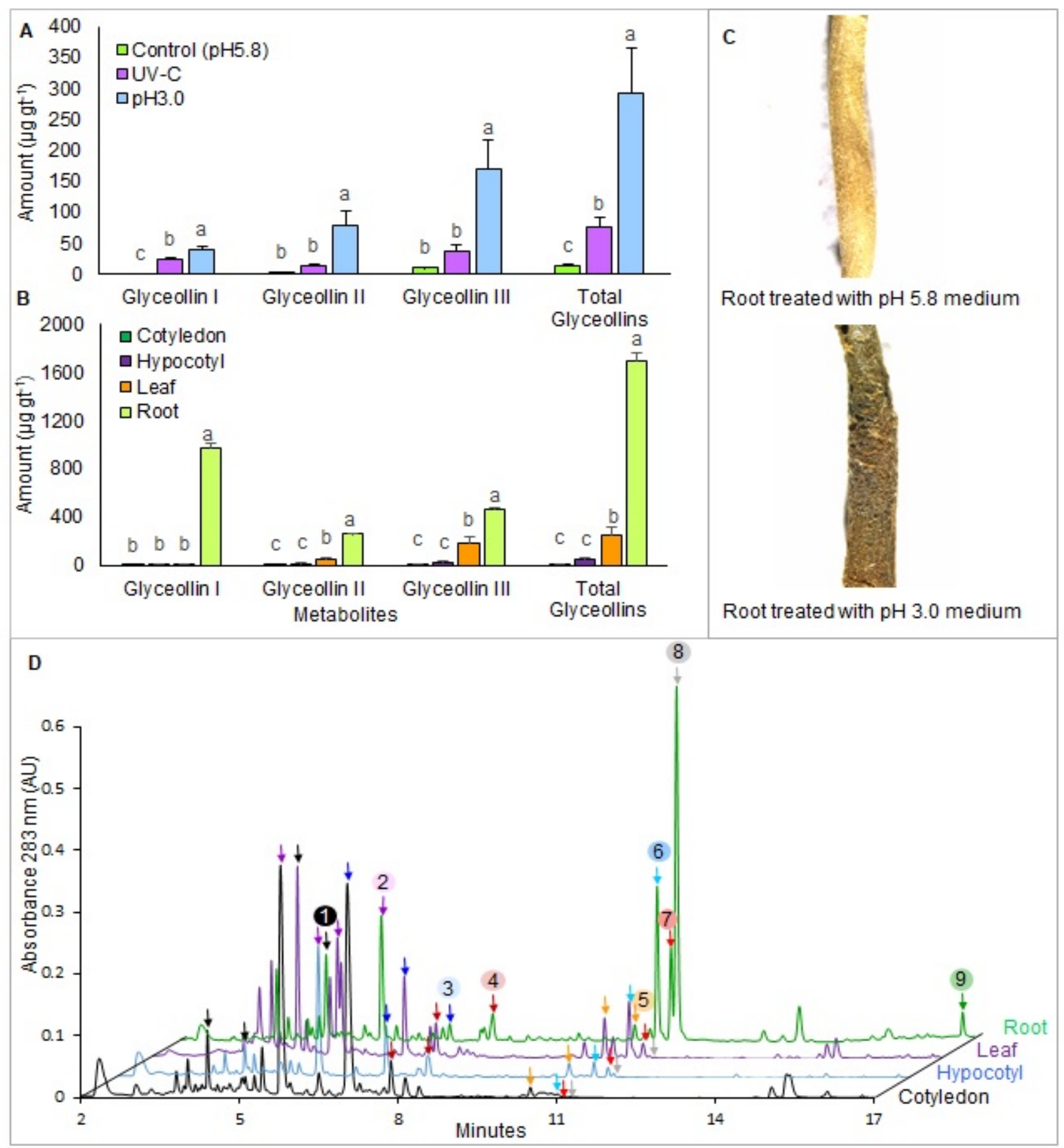

Figure 1. Elicitation of glyceollins in soybean roots by pH 3.0 medium. (A) Seven-day-old seedlings were transferred to $\mathrm{pH} 5.8$ or $\mathrm{pH} 3.0$ medium for $9 \mathrm{~d}$, or exposed to a $30 \mathrm{~W}$ UV-C lamp for $1 \mathrm{~h}$ daily. Metabolites were extracted from intact seedlings (A) or dissected organs (B) by $80 \%$ ethanol and were quantified by UPLC-PDA by comparison to purified standards. (C) Root color phenotypes following 9 days treatment with $\mathrm{pH} 5.8$ or $\mathrm{pH} 3.0$ medium. (D) UPLCPDA chromatograms of isoflavonoid extracts from cotyledons, leafs, hypocotyls and roots of Harosoy 63 seedlings elicited with $\mathrm{pH} 3.0$ medium for 9 d. Peaks: 1) daidzin, 2) 6-Omalonyldaidzin, 3) 6-O-malonylgenistin, 4) daidzein, 5) genistein, 6) glyceollin III, 7) glyceollin II, 8) glyceollin I and 9) $\beta$ prenyl-genistein. 


\section{Chapter Five}

\section{Glyceollin Transcription Factor GmMYB29A2 is a Regulator of Soybean Resistance to Phytophthora sojae}

Md Asraful Jahan ${ }^{1}$, Brianna Harris ${ }^{2}$, Matthew Lowery ${ }^{3}$, Aniello M. Infante ${ }^{4}$, Ryan J. Percifield ${ }^{2}$ \& Nik Kovinich ${ }^{1}$

${ }^{1}$ Division of Plant and Soil Sciences, ${ }^{2}$ Department of Biology, ${ }^{3}$ Department of Biochemistry, ${ }^{4}$ Department of Biostatistics, West Virginia University, Morgantown, West Virginia, 26506. 


\begin{abstract}
Glyceollins are the major pathogen-inducible secondary metabolites (phytoalexins) of soybean that provide resistance to the oomycete pathogen Phytophthora sojae but the transcription factors (TFs) that regulate their biosynthesis have remained elusive. To identify candidate TF genes, we conducted comparative transcriptomics (RNA-seq) on transgenic hairy roots of Williams 82 (W82) and imbibing seeds of Harosoy 63 (H63) following treatment with $P$. sojae wall glucan elicitor (WGE). Overexpressing and RNAi silencing the R2R3-type MYB TF gene GmMYB29A2 in elicited hairy roots increased and decreased, respectively, the amounts of glyceollin biosynthesis gene transcripts and metabolites. Overexpressing and silencing GmMYB29A2 upregulated and downregulated the glyceollin-specific biosynthesis gene G4DT in presence or absence of WGE treatment and GmMYB29A2 bound the G4DT promoter in the yeast one-hybrid (Y1H) system, demonstrating specificity for glyceollin biosynthesis. RNAi silencing of GmMYB29A2 rendered W82 hairy roots compatible with race $1 P$. sojae, whereas overexpressing GmMYB29A2 rendered Williams roots incompatible. GmMYB29A2 was essential for the full-level elicitation of glyceollin biosynthesis by WGE but was insufficient to regulate all biosynthesis genes in the absence of treatment. Overall, GmMYB29A2 is an important component of the glyceollin gene regulatory network (GRN) and could be used to enhance resistance to $P$. sojae.
\end{abstract}




\section{Introduction}

Secondary metabolites have important roles in plant-microbe interactions. These include signaling, establishment, and regulation of rhizobial endosymbiosis, and providing resistance to pathogens (Zernova et al., 2014; Cheng et al., 2015). Metabolites that provide resistance to pathogens are generally thought to have antibiotic activity. The antibiotic metabolites can be biosynthesized during plant development, independent of the perception of a pathogen (phytoanticipins) or induced by stress or pathogen attack (phytoalexins). Generally, a plant species produces only a few biosynthetically related phytoalexins that putatively provide broadspectrum activity against bacterial, fungal and oomycete pathogens. Elegant biochemical studies have provided strong correlative evidence for the potential role of phytoalexins in providing resistance to pathogens, and more recent genetics studies have supported their antibiotic roles, often narrowing down the identity of the antibiotic phytoalexin to a few molecules (Graham et al., 2007). Compelling evidence for the role of phytoalexins as important antibiotic molecules in plant defense comes from the evolution of detoxification genes in pathogens that degrade phytoalexin molecules (Lygin et al., 2010). Phytoalexin biosynthesis has been studied in numerous plant species and generally mediates incompatible interactions with pathogens by providing a lesion-limiting role (Hammerschmidt, 1999; Großkinsky et al., 2012; Jeandet et al., 2014).

One of the most highly characterized systems for understanding the molecular basis of the phytoalexin resistance to pathogens is the soybean (Glycine max)-Phytophthora sojae interaction. Most genes and enzymes for the biosynthesis of soybean's major phytoalexins, the glyceollins, have been well-elucidated (Akashi et al., 2009; Sukumaran et al., 2018) and the organization of enzymes into metabolons is beginning to be understood (Dastmalchi et al., 2016). Further, it was in this system that one of the first pathogen-associated molecular pattern (PAMP) elicitors, the cell wall glucan elicitor (WGE) from P. sojae was discovered (Ayers et al., 1976). Putative soybean receptors of WGE have been identified (Fliegmann et al., 2004) and various developmental and environmental parameters affecting the elicitation of glyceollins have been characterized (Bhattacharyya and Ward, 1986, 1986). A landmark study highlighted that it was the differential regulation of the rapidity of glyceollin elicitation that was a critical feature that distinguished resistant versus susceptible soybean genotypes (Yoshikawa et al., 1978). This work provided the foundation for later cellular studies that demonstrated that resistant soybean activated the local biosynthesis of glyceollins more rapidly than susceptible nearly-isogenic 
genotypes (Hahn et al., 1985). More recent studies found that glyceollins can be biosynthesized via two mechanisms. WGE from $P$. sojae upregulates transcripts encoding biosynthetic enzymes that span from phenylalanine ammonia lyase (PAL) to the late-stage enzymes of glyceollin biosynthesis, (Moy et al., 2004) whereas the chemical elicitor silver nitrate $\left(\mathrm{AgNO}_{3}\right)$ stimulates the specific hydrolysis of 6"-O-malonyldaidzin, (Farrell et al., 2017) the end-product of a competing branch of the isoflavonoid biosynthetic pathway to supply the intermediate daidzein (Fig. 1).

$P$. sojae is a major pathogen of soybean that causes 200 million and 1-2 billion dollars in soybean yield loss per year in the USA and worldwide, respectively. By far the most effective method for managing $P$. sojae has been resistant soybean varieties. The major source of resistance traditionally relied upon by breeders has been resistance to $P$. sojae (Rps) genes that primarily encode NB-LRR receptor proteins that recognize on a gene-for-gene basis the effector proteins encoded by P. sojae avirulence ( $A v r$ ) genes (Gao et al., 2005; Song et al., 2013). Soybean genotypes encoding Rps $1 k$ exhibit accelerated induction of glyceollin biosynthesis compared to genotypes lacking the gene when inoculated with race 1 P. sojae (Yoshikawa et al., 1978; Hahn et al., 1985). Rpsl-k has been the most widely used Rps gene in major soybeanproducing regions of the U.S. for the last two decades because it has provided resistance to several of the most commonly encountered races of $P$. sojae (Gao et al., 2005). RNAi silencing chalcone reductase $(C H R)$ in Rps1-k and Rpsl-c genotypes found that 5-deoxyisoflavonoids (spanning from daidzein to the glyceollins, Fig. 1) were required for race-specific resistance to P. sojae (Graham et al., 2007).

Phytoalexins have very diverse biosynthetic origins in plants, and until recently none of the TFs that regulate the biosynthesis of phytoalexins were found to be homologous among plant species. This lead to the notion that phytoalexin TFs were evolutionarily as diverse as the biosynthetic pathways that they regulate. The WRKY TF gene AtWRKY33 that activates camalexin biosynthesis in Arabidopsis (Qiu et al., 2008) was not the homolog of the first identified phytoalexin regulator GaWRKY1 that regulates gossypol biosynthesis in cotton (Xu et al., 2004). The R2R3-type MYB TFs MYB14 and MYB15 that regulate stilbene biosynthesis in grapevine (Höll et al., 2013) were not homologous to the AtMYB34, AtMYB51, and AtMYB122 regulators of camalexin biosynthesis, (Frerigmann et al., 2015) or to yellow seed (y1) that regulates 3-deoxyanthocyanidin biosynthesis in sorghum (Ibraheem et al., 2010). The jasmonic acid (JA)-inducible bHLH OsMYC2 that regulates sakuranetin biosynthesis in rice 
(Ogawa et al., 2017) was not homologous to the OsDPF that activates phytocassane and momilactone biosynthesis genes in the same species, (Yamamura et al., 2015) or to the JAinducible bHLHs TSAR1 and TSAR2 that regulate triterpene saponin biosynthesis in Medicago truncatula (Yamamura et al., 2015). However, using a comparative transcriptomics approach on seedlings treated with novel abiotic elicitor (acidity stress) or suppressor (dehydration), we recently identified the soybean TF gene $G m N A C 42-1$ as a regulator of glyceollin biosynthesis

(Jahan et al., 2018). GmNAC42-1 is the soybean homolog of AtANAC042/AtJUB1 that positively regulates camalexin biosynthesis in Arabidopsis (Saga et al., 2012). AtANAC042/AtJUB1 mediates ROS signaling ( $\mathrm{Wu}$ et al., 2012) by a mechanism that may be distinct from its inhibition of cell elongation (Shahnejat-Bushehri et al., 2016). Silencing the NAC TF gene GmNAC42-1 in WGE-treated soybean hairy roots found that it was essential for the full-level activation of glyceollin biosynthesis (Saga et al., 2012). However, silencing or overexpressing GmNAC42-1 did not affect the expression of all glyceollin biosynthesis genes, suggesting that at least one other TF was required to fully activate the entire glyceollin biosynthesis pathway. Here, we identified the R2R3-type MYB TF GmMYB29A2 as a positive regulator of glyceollin biosynthesis in response to WGE and demonstrate a major role in mediating Rps $1-k$ resistance to P. sojae.

\section{Results}

\section{Dynamics of glyceollin elicitation by Phytophthora sojae WGE in soybean hairy roots and seeds}

Glyceollin biosynthesis genes are upregulated transiently by WGE and the TFs that directly regulate those genes may be highly upregulated as well at the time of peak glyceollin accumulation. To identify the timing of maximum glyceollin accumulation in different soybean tissues, we studied elicitation dynamics in transgenic hairy roots of Williams 82 (W82) and germinating seeds of Harosoy 63 (H63). Following WGE treatment, W82 hairy roots accumulated glyceollins I, II, and III, whereas no glyceollins were observed from the mock control (Fig. 2A). Maximum accumulation of each was $24 \mathrm{~h}$ after treatment (Fig. 2B). The amounts of daidzin and 6"-O-malonyldaidzin dramatically decreased with increasing glyceollin accumulation in W82 hairy roots (Fig. 2B). By contrast, the maximum accumulation of 
glyceollins in germinating seeds of H63 was at $48 \mathrm{~h}$ after WGE treatment (Fig. 2C). The amounts of daidzein conjugates did not decrease with increasing glyceollin accumulation in H63 seeds. At the times of maximum glyceollin accumulation, the glyceollin TF gene GmNAC42-1 and the glyceollin-specific biosynthesis gene G4DT were upregulated 14.3- and 6.7-fold in W82 hairy roots and 7.9- and 5.7-fold in H63 seeds, respectively (Fig. 2, D and E). Taken together, the results show different mechanisms of elicitation in the different organs but both involved the upregulation of glyceollin $\mathrm{TF}$ and biosynthesis gene transcripts at the time of maximum glyceollin accumulation.

\section{Comparative transcriptomics identifies glyceollin TF gene candidates}

To identify glyceollin TF gene candidates, we searched for all TF genes that were significantly upregulated $(P<0.05)$ by RNA-seq in WGE samples compared to their respective mock-treated controls at the times of maximum glyceollin accumulation. This identified 5702 and 3852 genes in W82 hairy roots and H63 germinating seeds, respectively, with 1049 genes upregulated in both tissues (Fig. 3A, see Supplementary Tables S1, S2, and S3). The transcripts of most biosynthetic enzymes spanning from PAL to G4DT were upregulated in both tissues (Table 1). A breakdown of the 1049 upregulated genes found that 'Sequence-specific DNA binding TF activity' was the major gene ontology, comprising 14.3\% (Fig. 3B). MYB (myeloblastosis) family transcription factors were the most prevalent gene family in this ontology (14.0\%), followed by WRKY family proteins (1.3\%) (Fig. 3C). Among the ten most highly upregulated were three ETHYLENE RESPONSE FACTOR (ERF) and three MYB family genes (Table 2). Since ethylene was suggested to not be a regulator of glyceollin biosynthesis, (Paradies et al., 1980) we chose to investigate further the $M Y B$ genes.

\section{Homologs $G m M Y B 29 A 1$ and $G m M Y B 29 A 2$ are candidate regulators of WGE-elicited glyceollin biosynthesis in soybean}

The two most highly upregulated MYBs were the homologs GmMYB29A1 and GmMYB29A2 (Table 2). qRT-PCR confirmed that they were upregulated by WGE in both W82 hairy roots and H63 germinating seeds at the times of peak glyceollin accumulation (Fig. 4A). The G. $\max$ RNA-seq Atlas (SoyBased.org) demonstrated that GmMYB29A1and GmMYB29A2 were not 
developmentally regulated similar to the glyceollin biosynthesis gene G4DT and different from the isoflavone-glycoside biosynthesis and TF genes $H I D H$ and GmMYB176 (Fig. 4B). Amino acid sequence analysis found that GmMYB29A1 and GmMYB29A2 proteins encoded R2R3 DNA binding domains in their N-terminal regions (Fig. 4C). GmMYB29A1 and GmMYB29A2 proteins had 100\% identical amino acid sequences in their R2R3 DNA binding domains and were $83 \%$ identical (86\% similar) in their C-terminal regions (Fig. 4C). A phylogenetic analysis with representative proteins from each of the MYB subgroups of Arabidopsis found that GmMYB29A1 and GmMYB29A2 were most closely related to AtMYB14 (Fig. 4D). AtMYB14 regulates cold tolerance (Chen et al., 2013). They were distantly related to the stilbene biosynthesis regulators VvMYB14 and VvMYB15 from grapevine (Höll et al., 2013). Other proteins in this cluster included AtMYB34, AtMYB51, and AtMYB122 that indirectly regulate the biosynthesis of the indole alkaloid camalexin in Arabidopsis, (Frerigmann et al., 2015) AtPAP1/AtMYB75 that activates anthocyanin biosynthesis and AtPFG1/AtMYB12, AtPFG2/AtMYB11, and AtPFG3/AtMYB111 that activate flavonol glycoside biosynthesis (Stracke et al., 2001). During the course of our study, a closely related soybean MYB gene GmMYB29 was implicated by GWAS in positively regulating isoflavone glycoside biosynthesis during the development of soybean organs (Chu et al., 2017). The RNA-seq Atlas revealed that GmMYB29 had developmentally regulated expression patterns similar to HIDH and GmMYB176 and unlike the WGE-inducible genes G4DT, GmMYB29A1, and GmMYB29A2. GmMYB29A1 and GmMYB29A2 proteins were 91\% identical to GmMYB29 in their R2R3 DNA binding domains but only $49 \%$ identical (59\% similar) in their C-terminal regions (Fig. 4C). The transcription of flavonoid biosynthesis genes is typically regulated by MYB-bHLH-WDR complexes in plants (Xu et al., 2015) and MYBs such as AtPAP1/AtMYB75 must physically associate with a bHLH through their [DE]Lx2[RK]x3Lx6Lx3R motif in order to bind DNA (Zimmermann et al., 2004). Yet, GmMYB29A1 and GmMYB29A1 only retained 50\% of the residues of this domain (Fig. 4C). GmMYB29A1 and GmMYB29A2 shared two deletions relative to GmMYB29 in their C-terminal regions. Overall, we selected GmMYB29A1 and GmMYB29A2 for functional analysis since they were induced by WGE with G4DT and their proteins had DNA binding domains that were similar to the putative isoflavone glycoside regulator GmMYB29. 


\section{GmMYB29A2 is essential for the full elicitation of glyceollin I}

To evaluate whether GmMYB29A1 and/or GmMYB29A2 regulate glyceollin biosynthesis, we first silenced their gene expressions in WGE-treated W82 hairy roots. Two RNAi triggers were designed to target the 3'-UTRs of each gene (Fig. 5A). To minimize the potential for offtargeted gene silencing, care was taken to ensure that the triggers did not encode 21 consecutive nucleotides or more from other soybean genes. However, due to the high nucleotide sequence similarity of GmMYB29A1 and GmMYB29A2, each $\sim 250$ bp trigger had one segment of 21 nucleotides that was identical to both genes.

Each RNAi construct caused reduced expressions of both GmMYB29A1 and GmMYB29A2. A 2.2- to 5.2-fold silencing of the GmMYB29As decreased the expressions of the glyceollin biosynthesis genes IFS2, I2' $H$ and G4DT from 1.7- to 15.2-fold, whereas the expressions of IFS1 increased 6.1-fold (Fig. 5B). The silencing was accompanied by a 3.4-fold reduction in the amounts of glyceollin I and a 1.5- to 4.9-fold increase in the amounts of daidzein, 6-Omalonyldaidzin, and 6-O-malonylgenistin (Fig. 5C).

To distinguish the functions of GmMYB29A1 and GmMYB29A2, we overexpressed each of their coding sequences (CDSs) separately in W82 HRs using the $35 \mathrm{~S}$ viral promoter $(p 35 S)$ to drive transcription. Overexpressing GmMYB29A2 upregulated the glyceollin-specific biosynthesis genes $I 2^{\prime} H$ and G4DT in both WGE- and mock-treated roots (Fig. 5D). It upregulated all glyceollin biosynthesis genes tested in WGE-treated roots, but not IFS1 and IFS2 in mocktreated roots (Fig. 5D). The overexpression enhanced the levels of all glyceollin metabolites in WGE-treated roots, but increased only the levels of daidzein and genistein in mock-treated roots (Fig. 5E). Taken together, these results identify GmMYB29A2 as being essential for the full activation of glyceollin I biosynthesis in response to WGE, and strongly suggests that at least one other WGE-inducible factor is required for the full activation of all glyceollin biosynthesis genes.

In contrast to GmMYB29A2, overexpressing GmMYB29A1 resulted in a slight but statistically insignificant decrease in the levels of GmMYB29A2 transcripts and glyceollin I metabolites with no other changes in transcript or metabolite levels (see Supplementary Fig. S1). 


\section{$G m M Y B 29 A 2$ directly regulates the glyceollin biosynthesis genes IFS2 and G4DT}

Since GmMYB29A2 is required for the full elicitation of glyceollin biosynthesis, this raised the possibility that it may directly regulate the promoters of glyceollin biosynthesis genes. An informatics search identified several MYB recognition elements (REs) in the regions spanning 1 $\mathrm{kb}$ upstream of the transcription start sites of G4DT and IFS2 genes (Fig. 6A). Five hundred base pair segments of those regions were integrated into the genome of yeast strain YM4271 (MATa, ura3-52, his3-200, lys2-801, ade2-101, ade5, trp1-901, leu2-3, 112, tyr1-501, gal4D, gal80D, ade5::hisG) upstream of his3-200. Yeast one-hybrid (Y1H) on -HIS medium found that GmMYB29A2 could bind promoter segments from both G4DT and IFS2 genes, with greatest binding being observed for promoter segments that had the greatest number of MYB REs (Fig. 6, A and B).

To confirm direct DNA binding, we conducted electrophoretic mobility assays (EMSA) to determine whether an N-terminal HA-tagged GmMYB29A2 protein purified from E. coli could bind to two 50-bp labeled oligonucleotide probes that contained highly similar MYB elements from the promoters of IFS2 and G4DT (Fig. 6C). HA-GmMYB29A2 caused a gel shift for both probes that was abrogated by mixing with a 100-fold of unlabeled competitor oligonucleotide (Fig. 6D). Taken together with the gene overexpression and silencing experiments, these results strongly demonstrate that GmMYB29A2 is a direct regulator of glyceollin I biosynthesis.

\section{$G m M Y B 29 A 2$ mediates resistance to race $1 P$. sojae}

Since the biosynthesis of isoflavonoids is essential for providing race-specific resistance to $P$. sojae, (Subramanian et al., 2005; Graham et al., 2007) we set-out to determine whether the glyceollin TF GmMYB29A2 has a role mediating this resistance. To do this, we RNAi silenced GmMYB29A2 gene expressions in hairy roots of the variety W82 that is incompatible (resistant) to race $1 P$. sojae, and overexpressed its CDS in the roots of Williams, a variety that is universally susceptible to all races (Dorrance et al., 2004).

A 2.2-fold silencing of GmMYB29A2 in W82 resulted in a 2.4- to 2.7-fold increase in disease progression over time compared to the empty vector control, as measured by the length of watersoaked lesions that spread from the point of inoculation (Fig. 7A). Water-soaked lesions and mycelium growth out of infected tissues were highly visible in RNAi-GmMYB29A2 roots 
compared to the empty vector control (Fig. 7B). In dramatic contrast, Williams overexpressing GmMYB29A2 4.1-fold caused a 4.0- to 5.8-fold decrease in disease progression compared to the empty vector control (Fig. 7C). Water-soaked lesions and mycelium growth out of the tissues were readily visible for Williams roots transformed with the empty vector but were dramatically reduced in Williams roots overexpressing GmMYB29A2 (Fig. 7D). Taken together, these results strongly demonstrate that $G m M Y B 29 A 2$ has a role in mediating resistance to $P$. sojae.

\section{Discussion}

\section{GmMYB29A2 is essential for the elicitation of glyceollin biosynthesis}

Silencing both GmMYB29A1 and GmMYB29A2 using a single RNAi construct resulted in decreased accumulations of glyceollin I biosynthesis gene transcripts and metabolites (Fig. 5, B and C). Yet, overexpressing only GmMYB29A2 and not GmMYB29A1 in WGE-treated roots increased the levels of all glyceollin biosynthesis gene transcripts and metabolites (Fig. 5, D and E), strongly suggesting that it was specifically $G m M Y B 29 A 2$ that was responsible for the observed changes. Transcripts of the glyceollin I-specific biosynthesis gene G4DT were up- and down-regulated in GmMYB29A2 overexpressing and RNAi roots, respectively (Figs. 5, B and D). The purified HA-tagged GmMYB29A2 protein directly bound the G4DT gene promoter in $\mathrm{Y} 1 \mathrm{H}$ and EMSAs experiments (Fig. 6). Taken together, these results strongly suggest that GmMYB29A2 regulates glyceollin I biosynthesis in response to P. sojae WGE.

GmMYB29A2 is not normally expressed in the absence of WGE treatment (Fig. 4, A and B). Overexpressing GmMYB29A2 in the absence of WGE increased the levels of daidzein and genistein without the upregulation of IFSI and IFS2 genes. These ectopic overexpression results suggest that GmMYB29A2 positively regulates some gene(s) that that precede the formation of those isoflavones in the biosynthetic pathway (Fig. 1). Since overexpressing GmMYB29A2 did not result in the accumulation of glyceollin I in the absence of WGE treatment, this suggests that at least one additional WGE-induced factor is needed to regulate all genes required for glyceollin I biosynthesis. Such genes include those encoding biosynthetic enzymes for the conversion of daidzein to glyceollin I (other than $I 2^{\prime} H$ and G4DT) or genes required for metabolon formation (i.e. IFS and C4H) (Dastmalchi et al., 2016). Other possibilities include transporter genes responsible for moving biosynthetic intermediates between subcellular 
compartments where glyceollin biosynthesis enzymes have been localized, namely the endoplasmic reticulum (Dastmalchi et al., 2016), plastids (Akashi et al., 2009), and endosomes (Welle and Grisebach, 1988). Our future work will focus to identify all genes that are regulated by GmMYB29A2 in the presence and absence of WGE to better understand its role and that of the unidentified factor in regulating glyceollin biosynthesis.

\section{The role of GmMYB29A2 in regulating different biosynthetic routes to glyceollin I}

The accumulation of glyceollins in soybean tissues occurs when the rate of biosynthesis exceeds the rate of degradation. Glyceollins are constitutively being degraded and their biosynthesis can occur de novo from phenylalanine or from daidzein derived from the cleavage of daidzein glycoside conjugates (Yoshikawa, 1978; Farrell et al., 2017). The predominant biosynthetic route (i.e. from phenylalanine or from daidzein glycosides) may be organ, elicitor, and/or genotype-specific. During incompatible infections of Williams 79 cotyledons with race $1 P$. sojae, daidzein glycosides are rapidly cleaved during glyceollin biosynthesis (Graham et al., 1990). However, in the compatible infections of Williams cotyledons, the cleavage of daidzeinglycosides is delayed and glyceollins only accumulate after the infection front has passed (Graham et al., 1990). Thus, the rapid biosynthesis of glyceollins from daidzein-glycosides may be an important mechanism to provide resistance to $P$. sojae for some soybean organs. Here, we found that W82 hairy roots but not $\mathrm{H} 63$ seeds have reduced levels of daidzein-glycosides during glyceollin biosynthesis (Fig. 2B). Yet, both tissues had elevated levels of biosynthesis gene transcripts compared to the mock control, demonstrating that upregulating the transcription of biosynthesis genes is important for both biosynthesis pathways. Overexpressing the glyceollin TF gene GmNAC42-1 in W82 hairy roots reduced the amounts of daidzein-glycosides in the presence or absence of WGE (Jahan et al., 2018). By contrast, overexpressing GmMYB29A2 did not affect daidzein-glycoside levels but rather increased the levels of late-stage biosynthesis gene transcripts (i.e. I2 ' $H$ and G4DT) in the presence or absence of WGE (Fig. 5, D and E). It should be noted, that overexpressing GmMYB29A2 or GmNAC42-1 alone did not stimulate the accumulation of glyceollin metabolites in the absence of an elicitor, strongly inferring that each requires an additional WGE-elicited factor to fully elicit glyceollin biosynthesis.

Secondary metabolites have important roles in mediating plant-microbe interactions. Glyceollins are the pathogen-inducible (phytoalexin) secondary metabolites of soybean. Biochemical and 
genetics studies have provided strong evidence that the rapid activation of glyceollin biosynthesis is required to provide resistance to a wide range of microbial pathogens including Phytophthora sojae, one of the most devastating pathogens in soybean agriculture. The soybean$P$. sojae interaction has served as model system for understanding the molecular aspects of phytoalexin-based resistance to pathogens for decades. However, the TFs that regulate glyceollin biosynthesis have remained unknown until recently. Using a comparative transcriptomics approach on soybean seedlings treated with a novel abiotic elicitor (acidity stress) and suppressor (dehydration) of glyceollin biosynthesis, we recently identified the TF gene GmNAC42-1 as a regulator of their biosynthesis (Jahan et al., 2018). GmNAC42-1 was essential for full-level activation of glyceollin biosynthesis but was not sufficient to regulate all of the biosynthetic genes. Here, we provide genetic, biochemical, and physiological evidence that an R2R3-type MYB TF, GmMYB29A2, is also essential for the full activation of glyceollin biosynthesis in response to the $P$. sojae wall glucan elicitor (WGE) and is an important determinant of Rps 1k-mediated race-specific resistance to race $1 P$. sojae.

Two distinct mechanisms that elicit glyceollin biosynthesis have been identified. In imbibing seeds, WGE stimulates de novo biosynthesis by upregulating the transcripts of genes spanning from PAL to the late-stage gene G4DT, (Moy et al., 2004; Akashi et al., 2009; Farrell et al., 2017) whereas the inorganic chemical $\mathrm{AgNO}_{3}$ produces daidzein by stimulating the hydrolysis of 6"-O-malonyldaidzin (Farrell et al., 2017). Here, careful time course analyses validated that WGE elicited the de novo biosynthesis in imbibing H63 seeds, whereas both mechanisms were active in W82 hairy roots. This was evidenced by a reduction in 6"'-O-malonyldaidzin levels concomitant and the upregulation of the daidzein biosynthesis gene IFS2 by qRT-PCR (Fig. 2, B and C) and genes for most glyceollin biosynthetic enzymes by RNA-seq (Table 1). Thus, we hypothesized that the TFs that activate de novo biosynthesis would be highly upregulated by WGE in both tissue types at those time points.

Using a comparative transcriptomics approach, we identified GmMYB29A1 and GmMYB29A2 to be among the most highly WGE-upregulated TF genes in imbibing H63 seeds and W82 hairy roots during maximum glyceollin biosynthesis. RNAi silencing of GmMYB29A2 and GmMYB29A1 reduced the levels of glyceollin I biosynthesis gene transcripts and metabolites that were elicited by WGE, demonstrating that one or both GmMYB29As was essential for the full-level activation of glyceollin biosynthesis in WGE-treated roots. Yet, overexpressing only GmMYB29A2 and not GmMYB29A1 increased the levels of glyceollin metabolites and gene 
transcripts (Fig. 4, D and E). GmMYB29A2 was not developmentally regulated like the isoflavone-conjugate biosynthesis and regulatory genes, but rather was only expressed upon treatment with WGE (Fig. 3, D and E). Ectopic (constitutive) overexpression of GmMYB29A2 in mock-treated roots failed to upregulate some of the biosynthesis genes that were upregulated by GmMYB29A2 overexpression in WGE-treated roots. The genes included IFS2 (Fig. 4D), and our yeast one-hybrid $(\mathrm{Y} 1 \mathrm{H})$ results suggested that GmMYB29A2 binds the IFS2 promoter. By contrast, GmMYB29A2 also bound the G4DT promoter in $\mathrm{Y} 1 \mathrm{H}$ and its overexpression in hairy roots upregulated G4DT regardless of whether WGE treatment was applied. These results suggest that GmMYB29A2 requires some additional TF, post-translational modification, or other factor stimulated by WGE to upregulated some but not all glyceollin biosynthesis genes.

The R2R3-type MYBs that regulate flavonoid biosynthesis commonly have a conserved [DE]Lx2[RK]x3Lx6Lx3R motif in their R3 domain that interacts with bHLH proteins and the interaction is required for their MYB partners to bind DNA. However, GmMYB29A2 could bind the promoters of G4DT and IFS2 in the Y1H system in the absence of a bHLH. This was similarly observed for VvMYB15 in binding the promoter of STILBENE SYNTHASE (STS) (Höll et al., 2013). Only 50\% of the residues of this motif were conserved in GmMYB29A2 and it was $100 \%$ identical to GmMYB29A1 in the entire R2R3 domain (Fig. 3F). Since only GmMYB29A2 and not GmMYB29A1 positively regulated glyceollin biosynthesis, this suggests that the R2R3 domain and the bHLH-interacting motif are not responsible for the functional differences between GmMYB29A2 and GmMYB29A1. Yet, GmMYB29A2 was only 86\% and 59\% similar to GmMYB29A1 and GmMYB29 in the region C-terminal to the R2R3 domain, respectively. Thus, the role of this C-terminal region is clearly important for regulating glyceollin biosynthesis. We suggest that this domain interacts with a co-activator protein at some biosynthesis gene promoter that is expressed or activated by WGE treatment. We plan to screen WGE-upregulated TFs for interactors of the GmMYB29A2 C-terminal domain by yeasttwo hybrid $(\mathrm{Y} 2 \mathrm{H})$ to better understand its role in the glyceollin gene regulatory network (GRN).

Phytophthora sojae is one of the most economically devastating pathogens in soybean agriculture. By far the most effective method for managing the pathogen has been the cultivation of soybean varieties that carry resistance to $P$. sojae (Rps) genes that mediate race-specific resistance. Rps $1-k$ is the most widely used in major soybean-producing regions of the U.S for the last two decades because it has provided resistance to several of the most commonly encountered races of $P$. sojae. Here, we demonstrated that the GmMYB29A2 was essential for 
Rps 1-k-mediated resistance to race 1 P. sojae in W82 (Fig. 5, A and B). Further, overexpressing the GmMYB29A2 CDS in hairy roots of the universally susceptible variety Williams that lacks Rps 1-k provided resistance to race 1 P. sojae (Fig. 5, C and D). Previous genetic studies found that RNAi silencing IFS and CHR, the latter which is specific for biosynthesizing 5deoxyisoflavonoids, lead to a breakdown of race-specific resistance (Subramanian et al., 2005; Graham et al., 2007). Daidzein or glyceollins were suggested to be the effective defensive metabolites. Here, overexpressing GmMYB29A2 resulted in increased accumulation of glyceollins and not daidzein, suggesting the glyceollins specifically are responsible for providing an effective defense against $P$. sojae. Similarly, overexpressing G4DT resulted in increases in glyceollins and dramatically inhibited necrosis by Rhizoctonia solani AG4 in hairy roots of the soybean cultivar Spencer (Zernova et al., 2014). Thus, overexpressing GmMYB29A2 to enhance glyceollin biosynthesis may be useful to provide broad-spectrum resistance to a wide range of microbial pathogens. Our future work will aim to determine whether stably overexpressing the GmMYB29A2 CDS in soybean plants can enhance non-race-specific resistance to $P$. sojae without adversely effecting grain yields. Overall our results here suggest a novel strategy for imparting resistance to economically devastating soybean pathogens.

\section{Methods}

\section{Chemicals}

Stocks of the antibiotics kanamycin, hygromycin-B and timentin (Gold Biotechnology, St. Louis, MO, USA) were in water. Acetosyringone (Sigma-Aldrich, St. Louis, MO, USA) was $100 \mathrm{mM}$ in DMSO. (-)-Glyceollin I synthetic standard was purchased from Dr. Paul Erhardt (University of Toledo, Bancroft, MI, USA). Daidzein was from Cayman Chemical (Ann Arbor, MI, USA), daidzin, genistein, and genistein were from Indofine (Hillsborough, CA, USA). UPLC solvents were LC-MS grade from Fisher (Hampton, FL, USA). Wall glucan elicitor (WGE) was extracted from race 1 P. sojae cultured for 30 - 35 days on lima bean medium as described previously (Farrell et al., 2017). 


\section{Maintenance of Phytophthora sojae}

P. sojae race 1 isolate was a kind gift from Brett Tyler (Oregon State University). The pathogens were maintained on lima bean agar medium. In order to maintain pathogenicity, 6-7 d old (DO) culture plates were rinsed twice with sterile water, then 6-7 DO susceptible soybean seedlings were placed on the flooded culture plate. The cultures were maintained under low intensity fluorescent light for $5 \mathrm{~d}$ and infected tissue containing $P$. sojae was transferred to lima bean selection plates containing timentin $\left(500 \mathrm{mg} \mathrm{L}^{-1}\right)$. A mycelial plug (6-7 $\mathrm{mm}$ in diameter) was taken from the periphery of a 6-7 DO culture and transferred to a new plate. The cultures were incubated at room temperature for 6-7 d under low fluorescent light condition and used for the infection of hairy roots.

\section{Plant Materials and Elicitation}

Seeds of Harosoy, Harosoy 63, Williams and Williams 82 were obtained from the USDA-GRIN Soybean Germplasm Collection. Bulk seeds of Harosoy 63 were also a generous gift from Elroy Cober (Agriculture and Agri-Food Canada). For RNA-seq, large, unblemished seeds were surface sterilized and imbibed according to Farrell et. al., (Farrell et al., 2017). The seed coat was carefully removed to avoid damaging the embryo. The distal end $(\sim 2-3 \mathrm{~mm})$ of the cotyledons were excised and a longitudinal incision was made through the axis of the central vein of the cotyledons up to two thirds of the way towards the hypocotyl-radicle axis. WGE elicitor $\left(20 \mu \mathrm{g} \mu \mathrm{L}^{-1}\right.$ in water, $\left.50 \mu \mathrm{L}\right)$ or mock solvent was applied to the wound site and the treated seeds were placed upright on their distal end on sterile water soaked filter paper in a high petri dish and then incubated for $48 \mathrm{~h}$ at $24^{\circ} \mathrm{C}$ under cool white $\mathrm{T} 5$ fluorescent lights $(500 \mu \mathrm{E}$ $\mathrm{m}^{-2} \mathrm{~s}^{-1}$ ). Following selection of transgenic roots on hairy root growth (HRG) medium containing antibiotics (described below), the excised pieces of secondary roots were placed in petri dishes on HRG medium lacking antibiotics and were overlaid with $80 \mu \mathrm{L}$ of WGE or water and then incubated for $24 \mathrm{~h}$ in the conditions described above. Treated plant materials were used directly for metabolite extractions or were harvested into liquid nitrogen and lyophilized for 3-5 d (BenchTop Pro, SP Scientific) prior to storage at $-80^{\circ} \mathrm{C}$ for RNA extraction. 


\section{Isoflavonoid Analyses}

Fresh tissues of elicited seeds $(150-250 \mathrm{mg})$ or hairy roots $(100 \mathrm{mg})$ were harvested on ice and immediately extracted with $80 \%$ ethanol $\left(1 \mu \mathrm{L} \mathrm{mg}^{-1}\right.$ fresh tissue, FW) according to Farrell et. al., (Farrell et al., 2017). UPLC-PDA-MS ${ }^{\mathrm{n}}$ was carried-out using an Accela system (Thermo Scientific, San Jose, CA, USA) configured with a 1250 pump, Open AS autosampler, and photodiode array (PDA) detector connected to a Q-Exactive - Oribitral MS containing a HESI. The UPLC-PDA-MS ${ }^{\mathrm{n}}$ method and quantification of isoflavonoids by comparison to concentration curves of authentic or in-house purified standards using Xcalibur software were conducted as we've described (Farrell et al., 2017; Jahan et al., Submitted September 24, 2018). Isoflavonoid amounts were measured from two independent transformation experiments for each overexpression and RNAi silencing roots of GmMYB29A2 and GmMYB29A1, representative results are shown.

\section{RNA Extraction and qRT-PCR Analysis}

Total RNA from soybean seeds was extracted using the Spectrum Plant Total RNA Kit (SigmaAldrich, St. Louis, MO, USA) following the manufacturer's protocol with some modification as described previously (Farrell et al., 2017). DNase I (Amplification grade, Invitrogen, Carlsbad, CA, USA) treatment of the total RNA (500 ng) was done to remove genomic DNA contamination and cDNA was synthesized using SuperScript II Reverse Transcriptase (Invitrogen) following the manufacturers protocol. qRT-PCR of diluted cDNA templates were carried out using IQ SYBR Supermix as described (Farrell et al., 2017). qRT-PCR had an initial denaturation at $95^{\circ} \mathrm{C}$ for $10 \mathrm{~min}$, followed by 40 cycles of $95^{\circ} \mathrm{C}$ for 30 second; $58^{\circ} \mathrm{C}$ for $1 \mathrm{~min}$ and $72^{\circ} \mathrm{C}$ for $1 \mathrm{~min}$.

\section{RNA Sequencing and Analysis}

Total RNAs from soybean tissues were isolated the using the Spectrum Plant Total RNA Kit as mentioned above. The concentration and purity of extracted total RNA was determined using a NanoDrop 2000 spectrophotometer (Thermo Scientific, USA). The purity of RNA samples was measured by A260/A280 and A260/A230 ratios (> 2.0) which indicate lower carbohydrate carryover and protein contamination, respectively. Total RNA samples that exhibited higher quality and purity were selected and sent to the Genomics Core Facility at West Virginia 
University for library preparation. The quantity of each total RNA sample was more accurately measured using a Qubit fluorometer while RNA quality was ascertained on an Agilent 2100 Bioanalyzer using an RNA Nano 6000 chip. All of the samples used for library prep had RIN (RNA Integrity Number) values $>8.0$. The mRNA stranded library prep kit from KAPA Biosystems and $750 \mathrm{ng}$ of total RNA were used to build each library following manufacturers recommended protocol with nine cycles of PCR. The cDNA libraries were constructed and quantified via the Qubit, pooled in equimolar ratios, and sent to the Genomics Core Facility at Marshall University where eight libraries were sequenced per lane and 100 bp paired-end reads were generated with the Illumina HiSeq1500 system.

The initial QC checks were conducted upon receiving the raw data from the sequencing facility using FastQC software. Ribosomal RNA (rRNA) contamination, adapter sequences and/or low expressed genes were filtered out from the raw high-throughput RNA Sequencing data. The clean reads were mapped/aligned to soybean (Glycine max) reference genome (Gmax_275_V2.0.fa, https://phytozome.jgi.doe.gov/pz/portal.html) using STAR RNA-seq Aligner with default parameters based on the current gene annotation. Only the paired mapped reads were considered for further analyses and the number of reads per gene was calculated using Feature Counts to count only reads which mapped concordantly. Differentially expressed genes (DEGs) were identified using DESeq2 package which is based in Negative Binomial Distribution. Multiple hypothesis correction was carried out to obtain an adjusted $\mathrm{P}$ value at 0.05 with Benjamini Hochberg procedure which is a powerful tool to decrease the false discovery rate (FDR). Principle component analysis, heatmap and clustering of the samples were also conducted to check the robustness of the analysis.

\section{Cloning}

The GmMYB29A2 and GmMYB29A1 coding sequences (CDSs) were PCR amplified from the cDNA of Harosoy 63 seeds treated with WGE (24 hour) using the attB Adapter PCR protocol (Invitrogen, Carlsbad, CA), the 2X Phusion Master Mix (ThermoFisher Scientific). The PCR amplicons were cloned into the entry vector pDONR221 using BP clonase (Invitrogen, Carlsbad, CA, USA). After sequencing the CDSs, entry vectors were LR recombined downstream of the CaMV 35S promoter in the destination vector pGWB2 for overexpression in hairy roots. The GmMYB29A2 CDS was also LR recombined downstream of the GAL4 
activation domain and the HA epitome tag in the pDEST-GADT7 vector for expression in yeast for yeast one-hybrid $(\mathrm{Y} 1 \mathrm{H})$ assays and E. coli for electrophoretic mobility shift assays (EMSAs), respectively. For Y1H, G4DT and IFS2 promoter regions 1 and 2 flanked by attL4 and attR1 recombination sites were synthesized and recombined into the destination vector pMW\#2 using LR clonase (Invitrogen, Carlsbad, CA) as described (Jahan et al., 2019). For RNAi silencing, 180-bp and 253-bp regions corresponding to the 3'-UTRs of GmMYB29A1 and GmMYB29A2, respectively, were PCR amplified from cDNA and BP recombined into pDONR221, and after sequencing were LR subcloned into the RNAi destination vector pANDA35HK. Integrations that would form an RNA hairpin when transcribed were confirmed by sequencing as indicated (Kovinich et al., 2012).

\section{Hairy root transformation.}

Germinating seeds were transformed with Agrobacterium rhizogenes strain K599 according to (Jahan et al., Submitted September 24, 2018). Briefly, unblemished seeds were surface sterilized for $30 \mathrm{sec}$ with $70 \%$ isopropanol (v/v) and soaked in $10 \%$ commercial bleach [6\% sodium hypochlorite $(\mathrm{v} / \mathrm{v})]$ for $5 \mathrm{~min}$ with gentle shaking, then rinsed thrice with sterile MilliQ-filtered water. Seeds were transferred to filter paper soaked with germination and co-cultivation (GC) medium consisting of half-strength MS salts, MS vitamins (Caisson Labs, UT), $1 \%$ sucrose (pH 5.8) in a sterile petri dish, incubated in the dark for $3 \mathrm{~d}$, then transferred to growth room under $16 \mathrm{~h}$ cool white $\mathrm{T} 5$ fluorescent lights $\left(100 \mu \mathrm{E} \mathrm{s}^{-1} \mathrm{~m}^{-2}\right)$ at $24^{\circ} \mathrm{C}$ for 6-7 days.

The day before transformation, A. rhizogenes (strain K599) harboring the vector of interest was streaked onto LB plates containing kanamycin and hygromycin $\left(50 \mathrm{mg} \mathrm{L}^{-1}\right)$ and grown at $28^{\circ} \mathrm{C}$. A. rhizogenes was scraped from the plate and resuspended in phosphate buffer $(0.01 \mathrm{M}$ $\left.\mathrm{Na}_{2} \mathrm{HPO}_{4}, 0.15 \mathrm{M} \mathrm{NaCl}, \mathrm{pH} 7.5\right)$ containing acetosyringone $(100 \mu \mathrm{M})$ to an OD600 of 0.5-0.8. Unblemished cotyledons were dissected from meristem and hypocotyl tissues and several 1-mmdeep cuts were made on the adaxial surface of the cotyledon with a scalpel dipped in the $A$. rhizogenes suspension. Cotyledons were co-cultivated adaxial side down on sterile paper towel soaked with GC medium containing $100 \mu \mathrm{M}$ acetosyringone for $3 \mathrm{~d}$ a $22^{\circ} \mathrm{C}$ in $\sim 65 \mu \mathrm{E}$ light on a $16 \mathrm{~h}$ photoperiod. Cotyledons were then transferred adaxial side up onto a hairy root growth (HRG) medium containing half-strength MS salts, vitamins, 3\% sucrose (pH5.8), $2.4 \mathrm{~g} \mathrm{~L}^{-1}$ gelzan (Sigma-Aldrich, Co., MO, USA), and $500 \mathrm{mg} \mathrm{L}^{-1}$ timentin. Primary hairy roots with 2-3 
cm secondary roots were transferred to selection plates containing HRG medium supplemented with kanamycin and hygromycin $\left(50 \mathrm{mg} \mathrm{L}^{-1}\right)$ to select transgenic hairy roots. After $5-7 \mathrm{~d}$, secondary hairy roots that grew to $3-6 \mathrm{~cm}$ were harvested and cut into $1-\mathrm{cm}$ pieces for WGE treatments.

Yeast one-hybrid Bait strains of YM4271 (MATa, ura3-52, his3-200, lys2-801, ade2-101, ade5, trp1-901, leu2-3, 112, tyr1-501, gal4D, gal80D, ade5::hisG) containing G4DT and IFS2 promoter regions integrated into the yeast genome were made as described in (Jahan et al., 2019) and were transformed with pDEST-GADT7 (ABRC, Columbus, OH) or with GmMYB29A2pDEST-GADT7. Transformants were selected on media lacking histidine and leucine (SD-HisLeu) then confirmed by colony PCR. Autoactivation was tested for and positive DNA-protein interactions were determined by growth in SD-His-Leu medium that contained increasing concentrations $(5,10,20,40$ and $60 \mathrm{mM})$ of 3-amino-1,2,4-triazole (3-AT; Fisher Scientific, Hampton, NH) as described (Jahan et al., 2019). Three biological replicates are shown, results were confirmed by two independent experiments.

\section{Electrophoretic mobility shift assay}

BL21(DE3) pLysS E. coli cells (MilliporeSigma, Burlington, MA) transformed with pDESTGADT7 or GmMYB29A2-pDEST-GADT7 were grown overnight in a $37^{\circ} \mathrm{C}$ shaker at $250 \mathrm{rpm}$ in $3 \mathrm{~mL}$ of LB broth containing carbenicillin $\left(100 \mu \mathrm{g} \mathrm{mL}^{-1}\right)$. The culture was transferred into two sterile $250 \mathrm{~mL}$ conical flasks containing $30 \mathrm{~mL}$ of LB broth with carbenicillin and incubated in a $37^{\circ} \mathrm{C}$ shaker at $250 \mathrm{rpm}$ until $\mathrm{OD}_{600} \sim 0.80$. Protein expression was induced with $1 \mathrm{mM}$ IPTG at $16^{\circ} \mathrm{C}$ in a shaking incubator at $250 \mathrm{rpm}$ for 16 hours. Following centrifugation $(5000 \times \mathrm{g}$ for 10 minutes at $4^{\circ} \mathrm{C}$ ), the pellet was lysed with B-PER reagent $\left(4 \mathrm{~mL} \mathrm{~g}^{-1}\right)$ (Fisher, Hampton FL, USA) containing lysozyme (100 $\left.\mu \mathrm{g} \mathrm{mL}^{-1}\right)$ (MP Biomedicals, Solon OH, USA), Thermo Scientific $^{\mathrm{TM}}$ Pierce $^{\mathrm{TM}}$ DNase I $\left(2 \mu \mathrm{L} \mathrm{mL}^{-1}\right.$ from a $2500 \mathrm{U} \mathrm{mL}^{-1}$ stock $)$ and Thermo Scientific ${ }^{\mathrm{TM}}$ Halt ${ }^{\mathrm{TM}}$ protease and phosphatase inhibitor cocktail $\left(10 \mu \mathrm{L} \mathrm{mL}^{-1}\right)$ for $10-15$ minutes at room temperature. Lysates were centrifuged at $15,000 \mathrm{~g}$ for five minutes to remove insoluble proteins. For immunoprecipitation, $200 \mu \mathrm{L}$ lysate was mixed with $30 \mu \mathrm{L}$ of Pierce ${ }^{\mathrm{TM}}$ HA Epitope Tag Agarose Conjugate slurry and incubated overnight at $4^{\circ} \mathrm{C}$ on a rotary mixer at $40 \mathrm{rpm}$. The resin was pelleted with a $5-10 \mathrm{~s}$ pulse at $12,000 \mathrm{~g}$ and washed three times with pre-chilled TBS 
solution containing $0.05 \%$ Tween-20. The protein was eluted from resin with $30 \mu \mathrm{L}$ of $3 \mathrm{M}$ NaSCN. The NaSCN was replaced with $500 \mu \mathrm{L}$ sterile TBS buffer using an Amicon ${ }^{\circledR}$ Ultra -0.5 Centrifugal Spin Filter UFC500324 following the manufacturer's instructions. Forty microliters of $80 \%$ glycerol were mixed into the $40 \mu \mathrm{L}$ protein solution to fully resuspend. The concentration and purity of the HA-MYB29A2 protein $(32.9 \mathrm{kDa})$ was determined using a BCA kit and Mini-Protean ${ }^{\circledR}$ TGX ${ }^{\mathrm{TM}}$ Precast Gel (Bio-Rad), respectively.

For EMSAs, the oligo probe sequences were designed corresponding to predicted GmMYB29A2 binding sites in the G4DT and IFS2 gene promoters (http://plantpan2.itps.ncku.edu.tw/). The oligo probes were 5'-end-labeled with IRD700 dye by Integrated DNA Technologies (IDT), Inc (Skokie, Illinois, USA). Oligos were resuspended to $100 \mu \mathrm{M}$ in Duplex Buffer (IDT, Skokie, Illinois, USA). Probes were annealed in equimolar concentrations according to the manufacturer's instructions. Purified full-length GmMYB29A2 protein $(1 \mu \mathrm{g})$, IRD labelled oligonucleotide probes $(1 \mu \mathrm{L}$ of an annealed mixture $500 \mathrm{nM})$ were incubated with binding solution in $20^{\circ} \mathrm{C}$ incubator for 30 minutes. The binding solution was prepared with $20 \mathrm{mM}$ HEPES (pH adjusted to 7.5), $50 \mathrm{mM} \mathrm{KCl,} 5 \mathrm{mM} \mathrm{MgCl}_{2}, 3.3 \mu \mathrm{M} \mathrm{ZnSO}_{4}, 1$ $\mathrm{mM}$ dithiothreitol, $0.3 \mathrm{mg} \mathrm{mL}^{-1} \mathrm{BSA}, 0.5 \mu \mathrm{g}$ poly(dI:dC), $5 \%$ glycerol, and $0.5 \%$ triton X-100 according to (Spencer et. al., 2011). The competitors (unlabeled oligos) were added at 25X and 100X molar excess. The shifts of the DNA-protein band were resolved by running the binding reaction on $6 \%$ DNA Retardation Gel (Invitrogen) using $0.5 \%$ TBE running buffer at $200 \mathrm{~V}$ for 40 minutes at $4^{\circ} \mathrm{C}$. The gels were then imaged using an Odyssey Infrared Imager (LI-COR Biosciences).

\section{$P$. sojae infection of Hairy Roots.}

Primary hairy roots that had 3-4 $\mathrm{cm}$ branch roots were cut into apical and basal regions. To identify transgenic roots, the basal region having 4-8 branch roots was transferred to selection plates containing the antibiotics kanamycin $\left(50 \mathrm{mg} \mathrm{L}^{-1}\right)$, hygromycin $\left(50 \mathrm{mg} \mathrm{L}^{-1}\right)$ and timentin (500 $\mathrm{mg} \mathrm{L}^{-1}$ ). To measure infection by P. sojae on kanamycin- and hygromycin-free medium, the apical region was transferred to half-strength Murashige and Skoog media, $\mathrm{pH}$ 5.8, containing vitamins, $3 \%$ sucrose $(\mathrm{w} / \mathrm{v})$, gelzan $\left(2.4 \mathrm{~g} \mathrm{~L}^{-1}\right)$, and timentin. Branch roots $(2-3 \mathrm{~cm})$ were inoculated just above the elongation zone for reproducibility (Graham et al., 2007) with 2 $\mathrm{mm}$ agar plugs taken from the periphery of virulent $P$. sojae culture plates. At the site 
inoculation, a $1.5 \mathrm{~cm}$ barrier was placed between the medium and the root- $P$. sojae interface to prevent $P$. sojae growth on the medium. Plates were incubated under $16 \mathrm{~h}$ light, $8 \mathrm{~h}$ dark cycle for the time indicated.

\section{Acknowledgements}

We acknowledge the WVU Genomics Core Facility, Morgantown WV for support provided to help make this publication possible. Gustavo MacIntosh and Jessica Hohenstein (Iowa State University) for Agrobacterium rhizogenes strain K599, Wayne Parrott and Tim Chappell (University of Georgia) for the soybean hairy root transformation protocol, Brett Tyler (Oregon State University) for race $1 P$. sojae, Erich Grotewold (University of Michigan) for the yeast YM4271, Tsuyoshi Nakagawa (Shimane University) for the pGWB2 vector, the ABRC (Columbus, OH) for pDEST-GADT7, and Hiroyuki Tsuji (Yokohama City University) and the late Ko Shimamoto for pANDA35HK, and use of the WVU Shared Research Facilities' UPLCPDA-MS

\section{Additional Information}

The accession number for GmMYB29A2 is Glyma.02G005600. MYB binding sequences in the G4DT and IFS2 promoters identified by PlantPan 2.0 were: -577 ttgGAATCata, -256 aaATATCt/taaATATCtc, -207 taaATATCt/taaATATCta, -153 tatATATCt/ aaaATATCtt, -109

ggtTTAACatat/gaggttTAACAtata, $\quad-82$ taaATATCt, and +44 caAGGGCa/aatGAATCta/caGATATtga/aatGAATCta, -267 aaAATATttg, -479 ttgGAATCtt, 507 aaAATATttg, -578 aatGAATCta/tagTAGGTgaa, respectively.

Supplementary information accompanies this paper at http://www.nature.com/srep

Competing financial interests: The authors declare no competing financial interests. 


\section{References}

Akashi T, Sasaki K, Aoki T, Ayabe S-i, Yazaki K (2009) Molecular cloning and characterization of a cDNA for pterocarpan 4-dimethylallyltransferase catalyzing the key prenylation step in the biosynthesis of glyceollin, a soybean phytoalexin. Plant Physiol 149: 683693

Ayers AR, Ebel J, Valent B, Albersheim P (1976) Host-Pathogen Interactions .10. Fractionation and Biological-Activity of an Elicitor Isolated from Mycelial Walls of PhytophthoraMegasperma Var Sojae. Plant Physiol 57: 760-765

Bhattacharyya M, Ward E (1986) Expression of gene-specific and age-related resistance and the accumulation of glyceollin in soybean leaves infected with Phytophthora megasperma f. sp. glycinea. Physiological and molecular plant pathology 29: 105-113

Bhattacharyya M, Ward E (1986) Resistance, susceptibility and accumulation of glyceollins IIII in soybean organs inoculated with Phytophthora megasperma f. sp. glycinea. Physiological and molecular plant pathology 29: 227-237

Chen Y, Chen Z, Kang J, Kang D, Gu H, Qin G (2013) AtMYB14 regulates cold tolerance in Arabidopsis. Plant molecular biology reporter 31: 87-97

Cheng Q, Li N, Dong L, Zhang D, Fan S, Jiang L, Wang X, Xu P, Zhang S (2015) Overexpression of Soybean Isoflavone Reductase (GmIFR) Enhances Resistance to Phytophthora sojae in Soybean. Front Plant Sci 6: 1024

Chu S, Wang J, Zhu Y, Liu S, Zhou X, Zhang H, Wang C-e, Yang W, Tian Z, Cheng H (2017) An R2R3-type MYB transcription factor, GmMYB29, regulates isoflavone biosynthesis in soybean. PLoS Genetics 13: e1006770

Dastmalchi M, Bernards M, Dhaubhadel S (2016) Twin anchors of the soybean isoflavonoid metabolon: evidence for tethering of the complex to the endoplasmic reticulum by IFS and $\mathrm{C} 4 \mathrm{H}$. The Plant Journal

Dorrance A, Jia H, Abney T (2004) Evaluation of soybean differentials for their interaction with Phytophthora sojae. Plant Health Prog 
Farrell KC, Jahan MA, Kovinich N (2017) Distinct Mechanisms of Biotic and Chemical Elicitors enable Additive Elicitation of the Anticancer Phytoalexin Glyceollin I. Molecules 22: $1261-1273$

Fliegmann J, Mithofer A, Wanner G, Ebel J (2004) An ancient enzyme domain hidden in the putative beta-glucan elicitor receptor of soybean may play an active part in the perception of pathogen-associated molecular patterns during broad host resistance. Journal of Biological Chemistry 279: 1132-1140

Frerigmann H, Glawischnig E, Gigolashvili T (2015) The role of MYB34, MYB51 and MYB122 in the regulation of camalexin biosynthesis in Arabidopsis thaliana. Front Plant Sci 6

Gao H, Narayanan NN, Ellison L, Bhattacharyya MK (2005) Two classes of highly similar coiled coil-nucleotide binding-leucine rich repeat genes isolated from the Rps1-k locus encode Phytophthora resistance in soybean. Mol Plant Microbe Interact 18: 1035-1045

Graham T, Kim J, Graham M (1990) Role of constitutive isoflavone conjugates in the accumulation of glyceollin in soybean infected with Phytophthora megasperma. Mol Plant Microbe Interact 3: 157-166

Graham TL, Graham MY, Subramanian S, Yu O (2007) RNAi silencing of genes for elicitation or biosynthesis of 5-deoxyisoflavonoids suppresses race-specific resistance and hypersensitive cell death in Phytophthora sojae infected tissues. Plant Physiol 144: 728-740

Großkinsky DK, van der Graaff E, Roitsch T (2012) Phytoalexin transgenics in crop protection-Fairy tale with a happy end? Plant science 195: 54-70

Hahn MG, Bonhoff A, Grisebach H (1985) Quantitative localization of the phytoalexin glyceollin I in relation to fungal hyphae in soybean roots infected with Phytophthora megasperma f. sp. glycinea. Plant Physiol 77: 591-601

Hammerschmidt R (1999) Phytoalexins: what have we learned after 60 years? Annual review of phytopathology 37: 285-306

Höll J, Vannozzi A, Czemmel S, D'Onofrio C, Walker AR, Rausch T, Lucchin M, Boss PK, Dry IB, Bogs J (2013) The R2R3-MYB transcription factors MYB14 and MYB15 regulate stilbene biosynthesis in Vitis vinifera. The Plant Cell 25: 4135-4149 
Ibraheem F, Gaffoor I, Chopra S (2010) Flavonoid phytoalexin-dependent resistance to anthracnose leaf blight requires a functional yellow seed1 in Sorghum bicolor. Genetics 184: 915-926

Jahan MA, Harris B, Lowery M, Coburn K, Infante AM, Percifield RJ, Ammer AG, Kovinich N (2019) The NAC family transcription factor GmNAC42-1 regulates biosynthesis of the anticancer and neuroprotective glyceollins in soybean. BMC genomics 20: 149

Jahan MA, Harris B, Lowery M, Coburn K, Infante AM, Percifield RJ, Ammer AG, Kovinich N (Submitted September 24, 2018) The NAC Transcription Factor GmNAC42-1 Regulates Glyceollin Phytoalexin Biosynthesis in Soybean. BMC genomics

Jeandet P, Hébrard C, Deville M-A, Cordelier S, Dorey S, Aziz A, Crouzet J (2014) Deciphering the role of phytoalexins in plant-microorganism interactions and human health. Molecules 19: 18033-18056

Kovinich N, Saleem A, Rintoul TL, Brown DCW, Arnason JT, Miki B (2012) Coloring genetically modified soybean grains with anthocyanins by suppression of the proanthocyanidin genes ANR1 and ANR2. Transgenic Research 21: 757-771

Lygin AV, Hill CB, Zernova OV, Crull L, Widholm JM, Hartman GL, Lozovaya VV (2010) Response of soybean pathogens to glyceollin. Phytopathology 100: 897-903

Moy P, Qutob D, Chapman BP, Atkinson I, Gijzen M (2004) Patterns of gene expression upon infection of soybean plants by Phytophthora sojae. Molecular Plant-Microbe Interactions 17: $1051-1062$

Ogawa S, Miyamoto K, Nemoto K, Sawasaki T, Yamane H, Nojiri H, Okada K (2017) OsMYC2, an essential factor for JA-inductive sakuranetin production in rice, interacts with MYC2-like proteins that enhance its transactivation ability. Scientific Reports 7: 40175

Paradies I, Konze JR, Elstner EF, Paxton J (1980) Ethylene: indicator but not inducer of phytoalexin synthesis in soybean. Plant Physiol 66: 1106-1109

Qiu JL, Fiil BK, Petersen K, Nielsen HB, Botanga CJ, Thorgrimsen S, Palma K, Suarez-Rodriguez MC, Sandbech-Clausen S, Lichota J (2008) Arabidopsis MAP kinase 4 
regulates gene expression through transcription factor release in the nucleus. The EMBO Journal 27: $2214-2221$

Saga H, Ogawa T, Kai K, Suzuki H, Ogata Y, Sakurai N, Shibata D, Ohta D (2012) Identification and characterization of ANAC042, a transcription factor family gene involved in the regulation of camalexin biosynthesis in Arabidopsis. Molecular Plant-Microbe Interactions 25: $684-696$

Shahnejat-Bushehri S, Tarkowska D, Sakuraba Y, Balazadeh S (2016) Arabidopsis NAC transcription factor JUB1 regulates GA/BR metabolism and signalling. Nature plants 2: 16013

Song T, Kale SD, Arredondo FD, Shen D, Su L, Liu L, Wu Y, Wang Y, Dou D, Tyler BM (2013) Two RxLR avirulence genes in Phytophthora sojae determine soybean Rps1k-mediated disease resistance. Molecular plant-microbe interactions : MPMI 26: 711-720

Stracke R, Werber M, Weisshaar B (2001) The R2R3-MYB gene family in Arabidopsis thaliana. Current opinion in plant biology 4: 447-456

Subramanian S, Graham MY, Yu O, Graham TL (2005) RNA interference of soybean isoflavone synthase genes leads to silencing in tissues distal to the transformation site and to enhanced susceptibility to Phytophthora sojae. Plant Physiol 137: 1345-1353

Sukumaran A, McDowell T, Chen L, Renaud J, Dhaubhadel S (2018) Isoflavonoid-specific prenyltransferase gene family in soybean: Gm PT 01, a pterocarpan 2-dimethylallyltransferase involved in glyceollin biosynthesis. The Plant Journal

Welle R, Grisebach H (1988) Induction of phytoalexin synthesis in soybean: enzymatic cyclization of prenylated pterocarpans to glyceollin isomers. Archives of biochemistry and biophysics 263: 191-198

Wu A, Allu AD, Garapati P, Siddiqui H, Dortay H, Zanor M-I, Asensi-Fabado MA, MunnéBosch S, Antonio C, Tohge T (2012) JUNGBRUNNEN1, a reactive oxygen species-responsive NAC transcription factor, regulates longevity in Arabidopsis. The Plant Cell: tpc. 111.090894

Xu W, Dubos C, Lepiniec L (2015) Transcriptional control of flavonoid biosynthesis by MYBbHLH-WDR complexes. Trends in plant science 20: 176-185 
Xu Y-H, Wang J-W, Wang S, Wang J-Y, Chen X-Y (2004) Characterization of GaWRKY1, a cotton transcription factor that regulates the sesquiterpene synthase gene $(+)$ - $\delta$-cadinene synthase-A. Plant Physiol 135: 507-515

Yamamura C, Mizutani E, Okada K, Nakagawa H, Fukushima S, Tanaka A, Maeda S, Kamakura T, Yamane H, Takatsuji H, Mori M (2015) Diterpenoid Phytoalexin Factor, a bHLH Transcription Factor, Plays a Central Role in the Biosynthesis of Diterpenoid Phytoalexins in Rice. Plant J

Yoshikawa M (1978) Diverse modes of action of biotic and abiotic phytoalexin elicitors. Nature 275: 546-547

Yoshikawa M, Yamauchi K, Masago H (1978) Glyceollin: its role in restricting fungal growth in resistant soybean hypocotyls infected with Phytophthora megasperma var. sojae. Physiological Plant Pathology 12: 73-82

Zernova OV, Lygin AV, Pawlowski ML, Hill CB, Hartman GL, Widholm JM, Lozovaya VV (2014) Regulation of plant immunity through modulation of phytoalexin synthesis. Molecules 19: $7480-7496$

Zimmermann IM, Heim MA, Weisshaar B, Uhrig JF (2004) Comprehensive identification of Arabidopsis thaliana MYB transcription factors interacting with R/B-like BHLH proteins. The Plant Journal 40: 22-34 


\section{Figures}

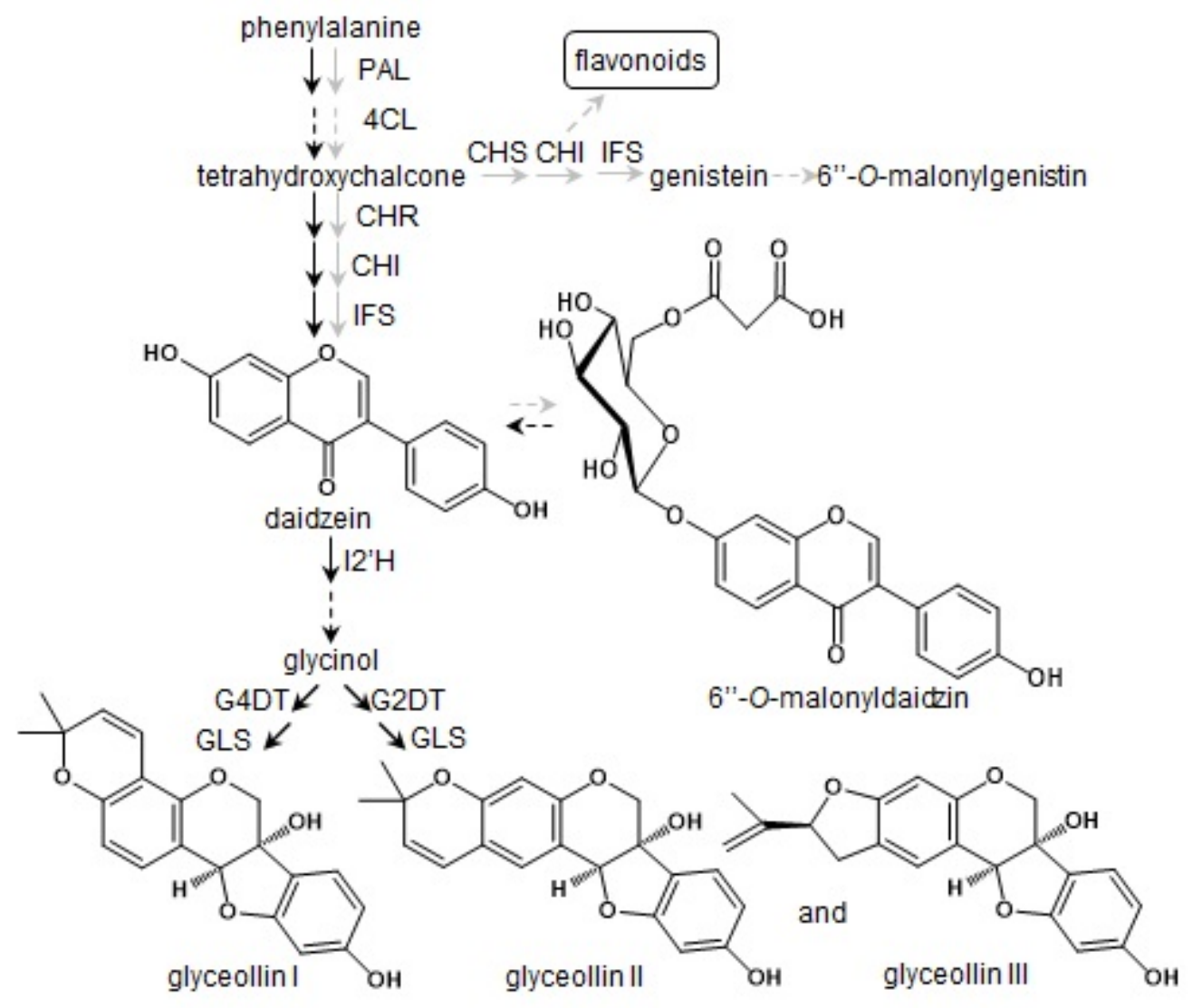

Figure 1. Pathogen inducible and constitutive isoflavonoid biosynthesis pathways. Elicitors of glyceollin biosynthesis upregulate transcripts encoding enzymes for glyceollin biosynthesis and/or the hydrolysis of 6"-O-malonyldaidzin (black arrows). Transcription factors have been identified that regulate the biosynthesis of the constitutively accumulating isoflavone conjugates 6"'-O-malonyldaidzin and 6"-O-malonylgenistin (gray arrows). PAL, phenylalanine ammonia lyase; 4CL, 4-coumaric acid: coenzyme A ligase; CHS, chalcone synthase; CHI, chalcone isomerase; CHR, chalcone reductase; IFS, isoflavone synthase; I2' $\mathrm{H}$, isoflavone 2'-hydroxylase; G4DT, glycinol 4-dimethylallyl transferase; G2DT, glycinol 2-dimethylallyl transferase; and GLS, glyceollin synthase. 


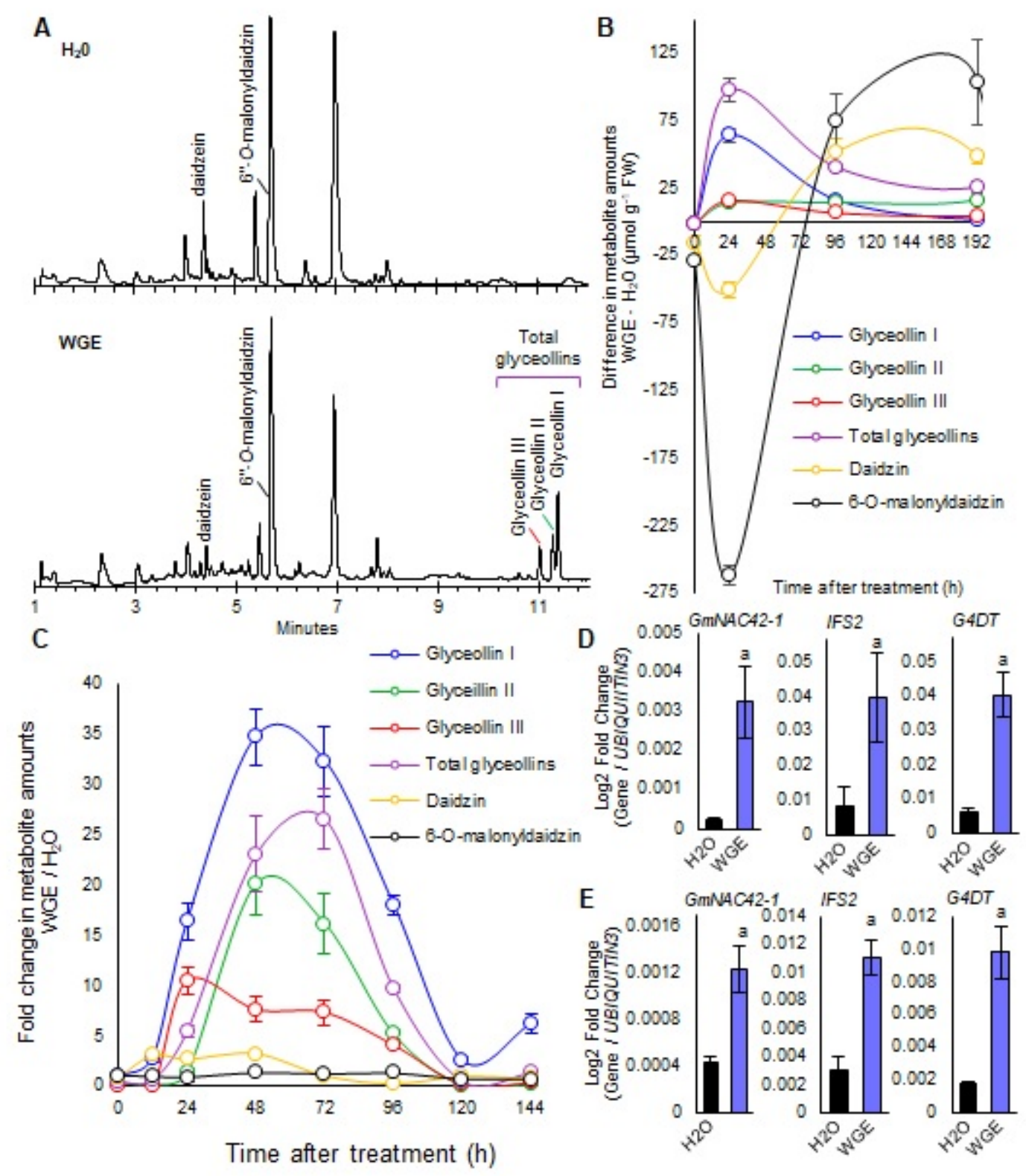

Figure 2. Glyceollin and daidzein-glycoside accumulations in W82 hairy roots and H63 seeds following treatment with $P$. sojae WGE. (A) UPLC-PDA chromatograms at A283 of aqueous ethanolic extracts from W82 hairy roots treated with $\mathrm{H}_{2} \mathrm{O}$ or WGE for $24 \mathrm{~h}$. (B) Difference in metabolite amounts from W82 hairy roots (the absence of glyceollins in the $\mathrm{H}_{2} \mathrm{O}$ control prevented calculation of the fold change). (C) Fold change of metabolite amounts from H63 seeds. (D) Relative gene expression levels in W82 hairy roots $24 \mathrm{~h}$ after treatment by qRTPCR. ${ }^{a}$ Significantly different from $\mathrm{H} 2 \mathrm{O}$ by Student $t$-test, $P<0.01$ ( $\mathrm{n}=4$ biological replicates). (E) Relative gene expression levels in $\mathrm{H} 63$ seeds $48 \mathrm{~h}$ after treatment. 


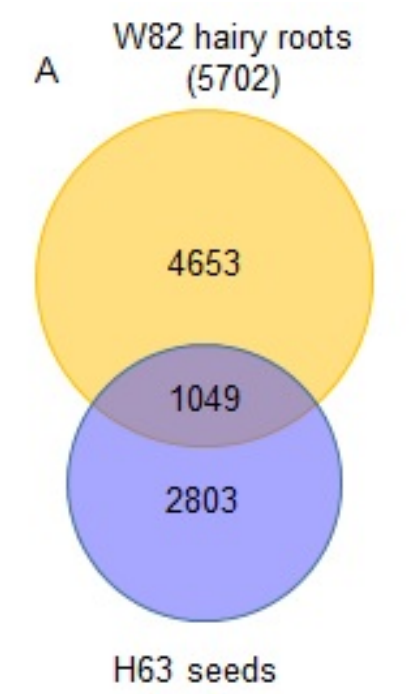

(3852)
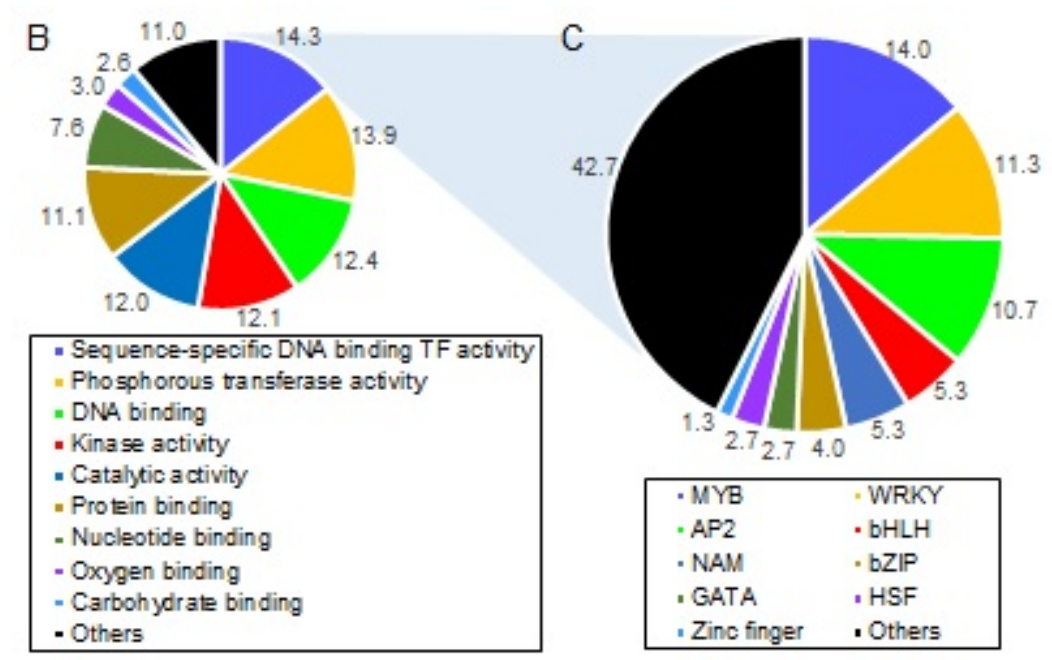

Figure 3. Ontological characterization of TF genes upregulated by WGE with glyceollins.

(A) Number of genes significantly upregulated by P. sojae WGE in H63 germinating seeds and W82 hairy roots determined by RNA-seq $(\mathrm{P}<0.05)$. (B) Percent of genes upregulated in both tissues in (a) that were assigned to a particular gene ontology category. Ontology analysis was conducted using the SoyBase.org Gene Model Data Mining and Analysis tool. (C) Breakdown of genes from the 'Sequence-specific DNA binding TF activity' ontology in (b) into TF gene families, expressed as percentages. 


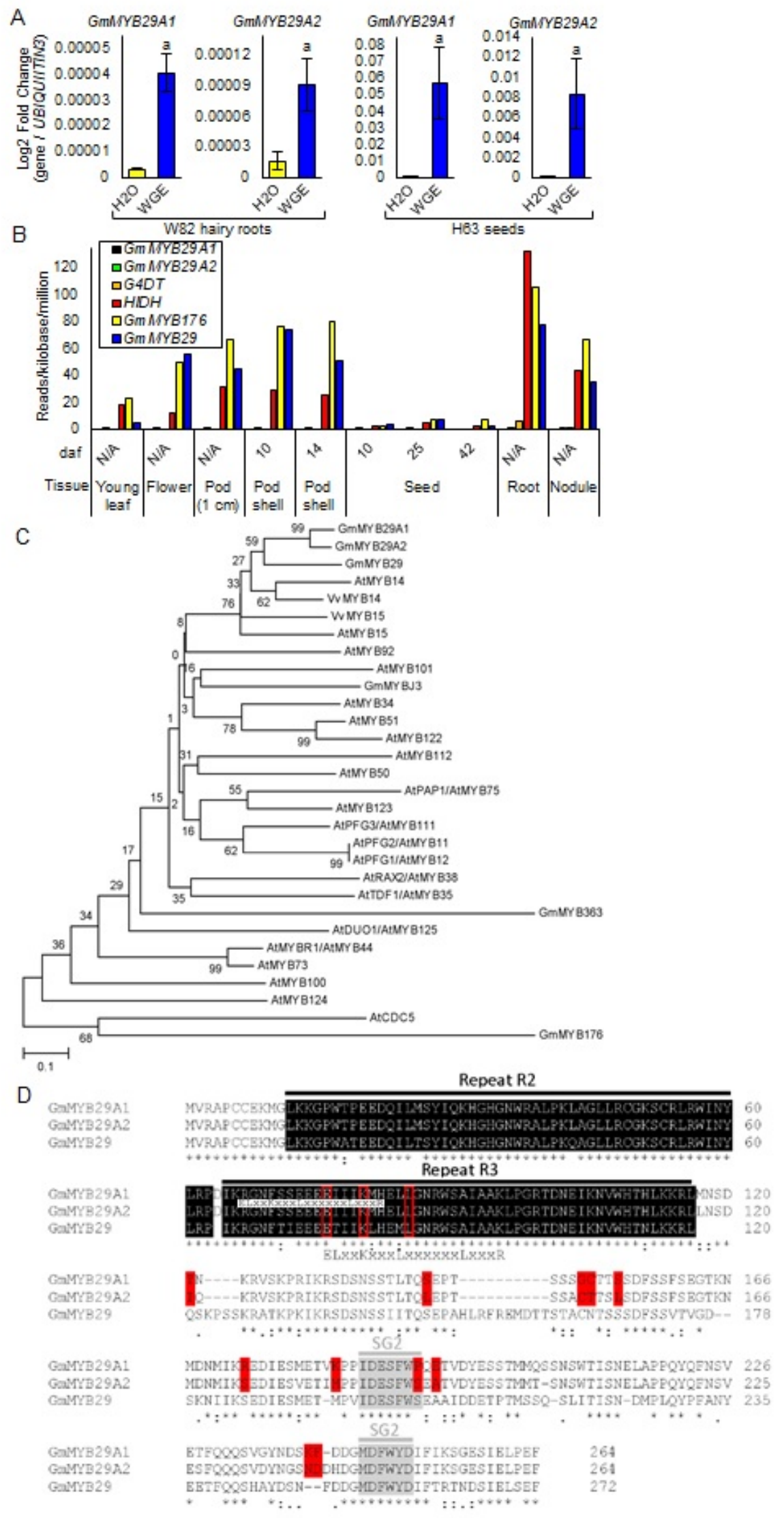


Figure 4. Expressions and phylogeny of GmMYB29 genes. (A) Gene expressions in W82

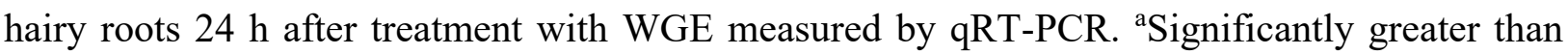
control, paired students $t$-test $(P<0.01, \mathrm{n}=4$ biological replicates). (B) Gene expressions in developing soybean organs from the RNA-Seq Atlas of G. $\max$ (Soybase.org). G4DT is a marker of stress inducible glyceollin biosynthesis, whereas $H I D H$ is a marker of developmentally regulated isoflavone glycoside biosynthesis. (C) Unrooted phylogenetic tree of GmMYB29A1 and GmMYB29A2 proteins with representative Arabidopsis and other characterized MYBs. Accession numbers are listed in Table S4. (D) Amino acid alignment of GmMYB29A1and GmMYB29A2 by Clustal Omega. R2R3 MYB repeats and SG2 stressresponsive domains are shaded in black and gray, respectively. Only $50 \%$ of the residues of the $[\mathrm{DE}] \mathrm{Lx} 2[\mathrm{RK}] \mathrm{x} 3 \mathrm{Lx} 6 \mathrm{Lx} 3 \mathrm{R}$ motif that mediates interaction with $\mathrm{bHLH}$ proteins in other MYB proteins are conserved in GmMYB29A1 and GmMYB29A2 (red boxes). Amino acids that have different charges in GmMYB29A1 compared to GmMYB29A2 are shaded in red. Residues that are fully conserved (*), strongly similar (:) (>0.5 in the Gonnet PAM 250 matrix), and weakly similar (.) (Gonnet PAM $\leq 0.5$ and $>0)$. 

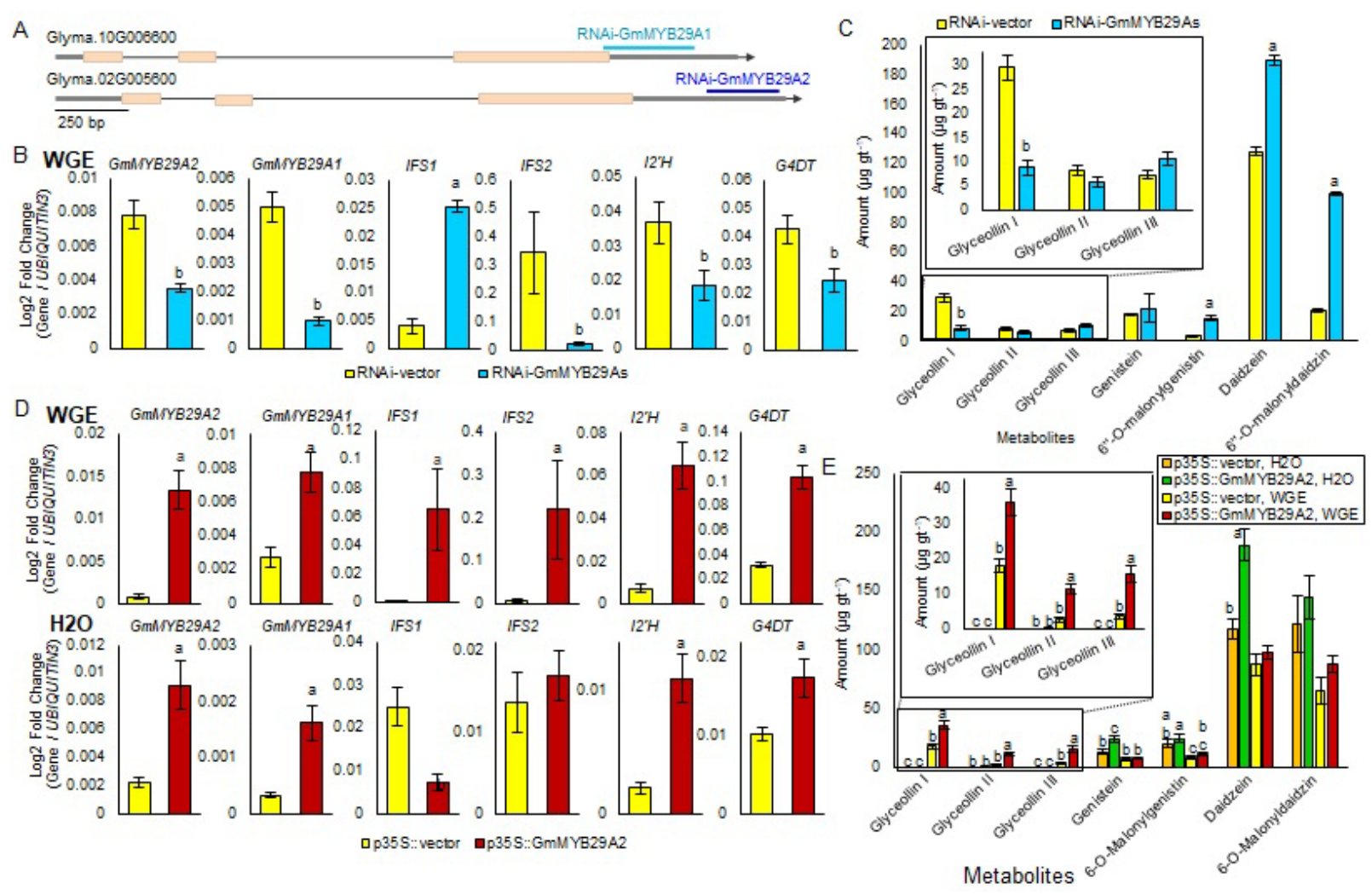

Figure 5. Functional characterization of GmMYB29A2. (A) Schematic diagram of GmMYB29A1 and GmMYB29A2 genes showing the target sites of the RNAi hairpins. (B) Gene expressions of W82 RNAi roots following treatment with P. sojae WGE by UPLC-PDA. Note: Each RNAi construct resulted in silencing of both GmMYB29A1 and GmMYB29A2, thus

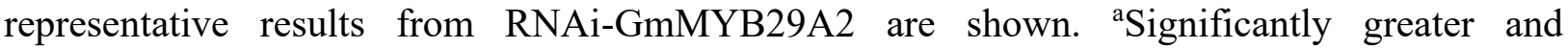
${ }^{\mathrm{b}}$ significantly less than control, paired students $t$-test $(P<0.01, \mathrm{n}=4$ biological replicates). (C) Isoflavonoid amounts from W82 RNAi roots following treatment with $P$. sojae WGE by UPLCPDA. aSignificantly greater and ${ }^{b}$ significantly less than control, paired students $t$-test $(P<0.01$, $\mathrm{n}=5$ biological replicates). (D) Gene expressions in W82 hairy roots overexpressing GmMYB29A2 by qRT-PCR $24 \mathrm{~h}$ after treatment with WGE or H20 (solvent control). (E) Isoflavonoid amounts in W82 hairy roots $24 \mathrm{~h}$ after treatment with WGE or solvent by UPLCPDA. Different letters show significant differences by single factor ANOVA, Tukey post hoc test $(P<0.05, \alpha=0.05 . \mathrm{n}=5$ biological replicates $)$. 


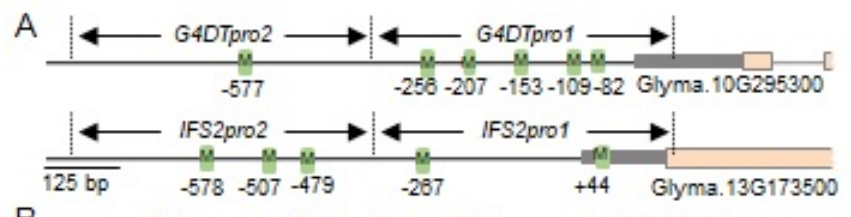

$\mathrm{B}$

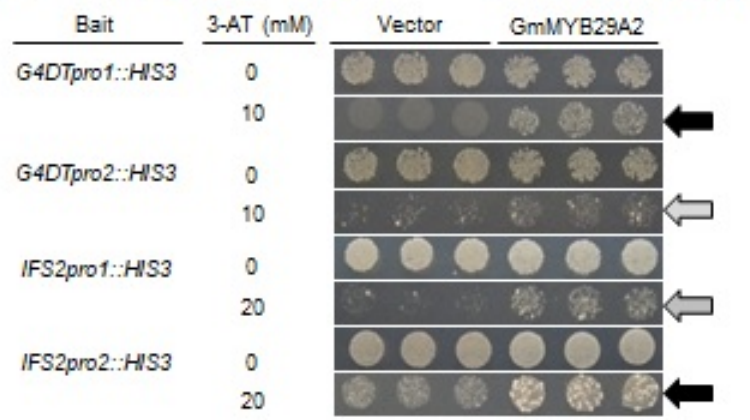

\section{c}

G4DTP $02-577$ CTATTGACAAARCARTAAATTTGGAATCATACTTAAARCATGAAARTTAC IES2pRO2-479 GTGGAGTAGATGCTTATANATTGGAATCTTAGAAGGTTGTTTCCTCAGGC
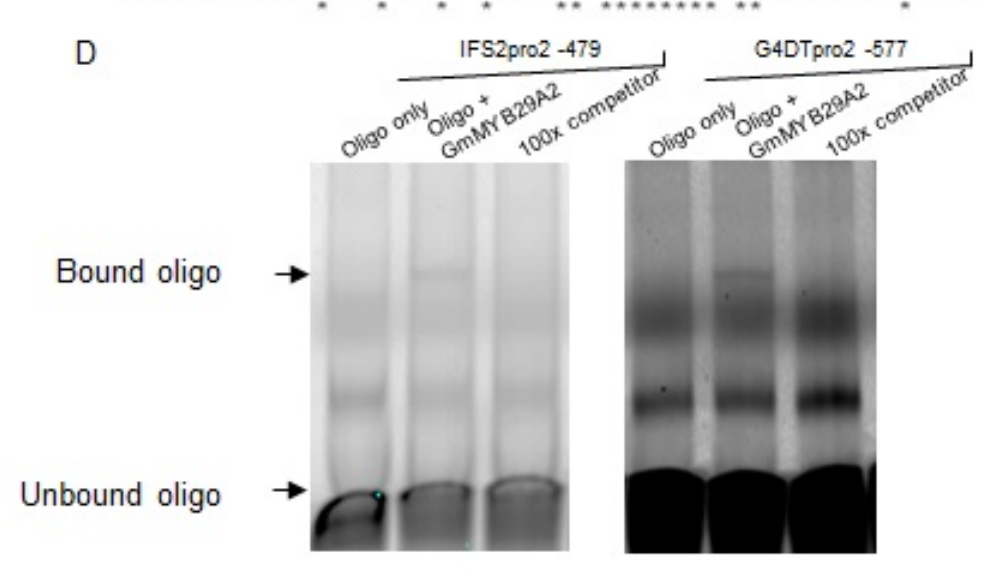

Figure 6. GmMYB29A2 binds glyceollin biosynthesis gene promoters.

(A) Schematic diagram demonstrating G4DT and IFS2 promoter fragments used for yeast onehybrid assays and predicted MYB binding elements (green boxes). See Supplemental Table S5 for the DNA sequences of MYB elements. (B) Yeast one-hybrid (Y1H) assays of YM4271 yeast transformed with GmMYB29A2 or empty vector and containing G4DT or IFS2 promoter segments integrated in the yeast genome upstream of the HIS3 gene. Assays were on $\mathrm{SD} /$-His/Leu medium containing the listed concentrations of 3-AT. Arrows: gray and black indicate moderate and strong binding, respectively. Results are representative of 2-3 independent experiments. (C) Alignment of 50-nucleotide (nt) oligo sequences that contain the predicted MYB-binding elements G4DTpro2 -577 and IFS2pro2 -479. Stars denote same nucleotide identities. Black bar indicates the predicted MYB-binding elements. (D) Electromobility shift assay (EMSA) of double-stranded G4DTpro2 -577 and IFS2pro1 -479 oligos with immunoprecipitated (IPed) hemagglutinin (HA)-tagged GmMYB29A2 protein purified from $E$. coli. Results are representative of two independent experiments. 


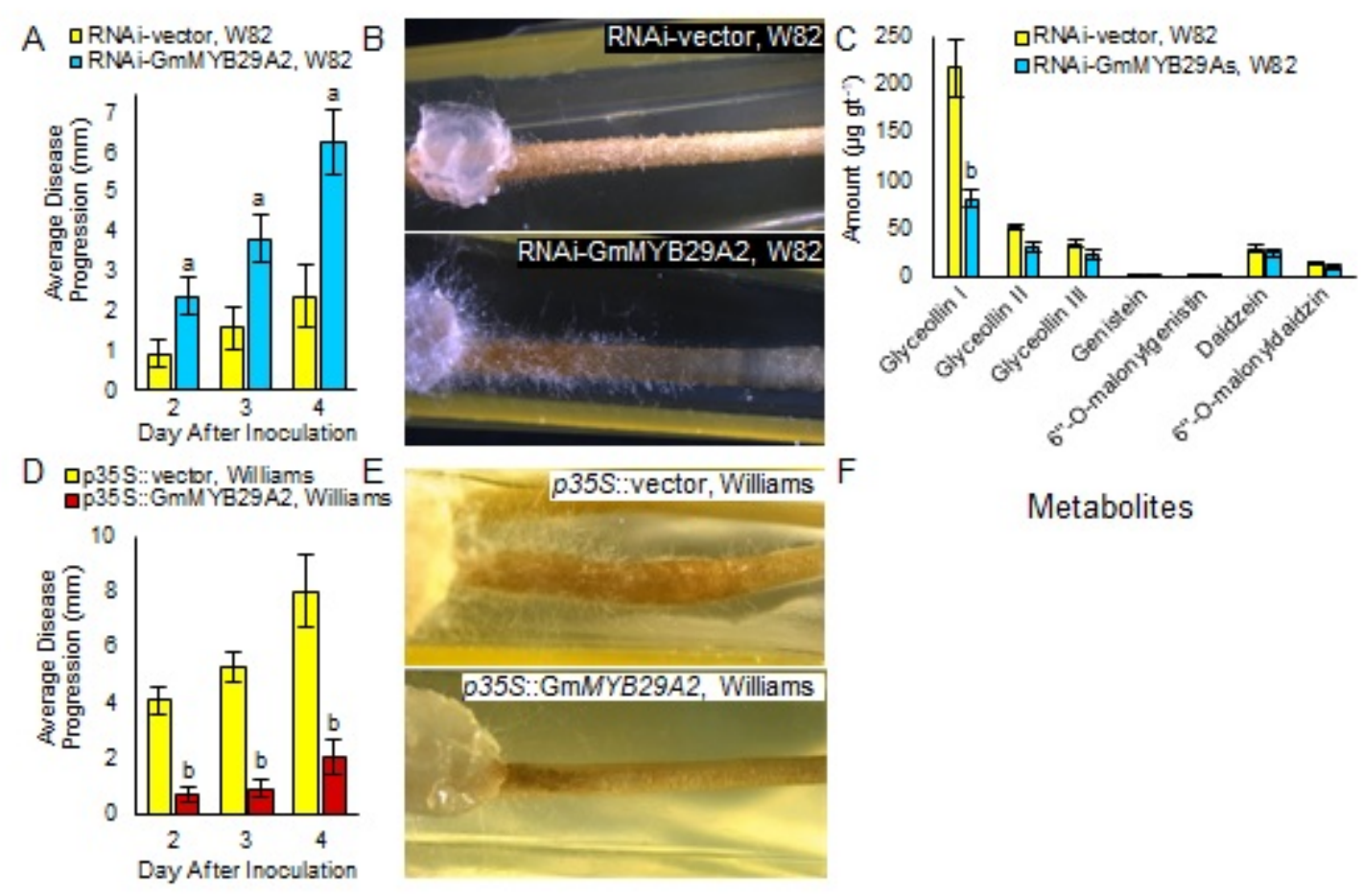

Figure 7. Effects of RNAi silencing or overexpressing GmMYB29A2 on disease progression of race $1 P$. sojae in transgenic hairy roots. (A) Average lesion length when $M Y B 29 A 2$ gene

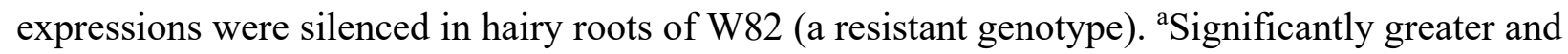
bignificantly less than control at same time point, paired students $t$-test $(P<0.01, \mathrm{n}=4-6$ biological replicates). Results are representative of two independent experiments. (B) Representative images showing disease progression phenotypes. Note the extensive watersoaked lesions and mycelium growth out of root tissues of W82 undergoing RNAi silencing of GmMYB29A2. (C) Isoflavonoid amounts from W82 RNAi roots following treatment with race 1

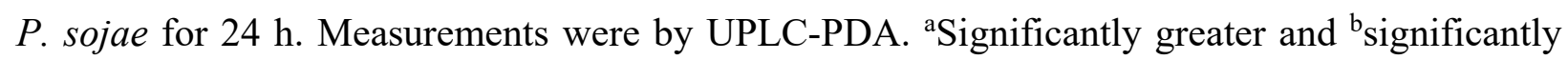
less than control, paired students $t$-test $(P<0.01, \mathrm{n}=6-7$ biological replicates). (D) Average lesion length when MYB29A2 was overexpressed in the susceptible variety Williams. Statistics are the same as in (a). Results are representative of two independent experiments. (E) Representative images of (D). Note the massive reduction in water-soaked lesions and mycelium outgrowth in Williams overexpressing GmMYB29A2. 

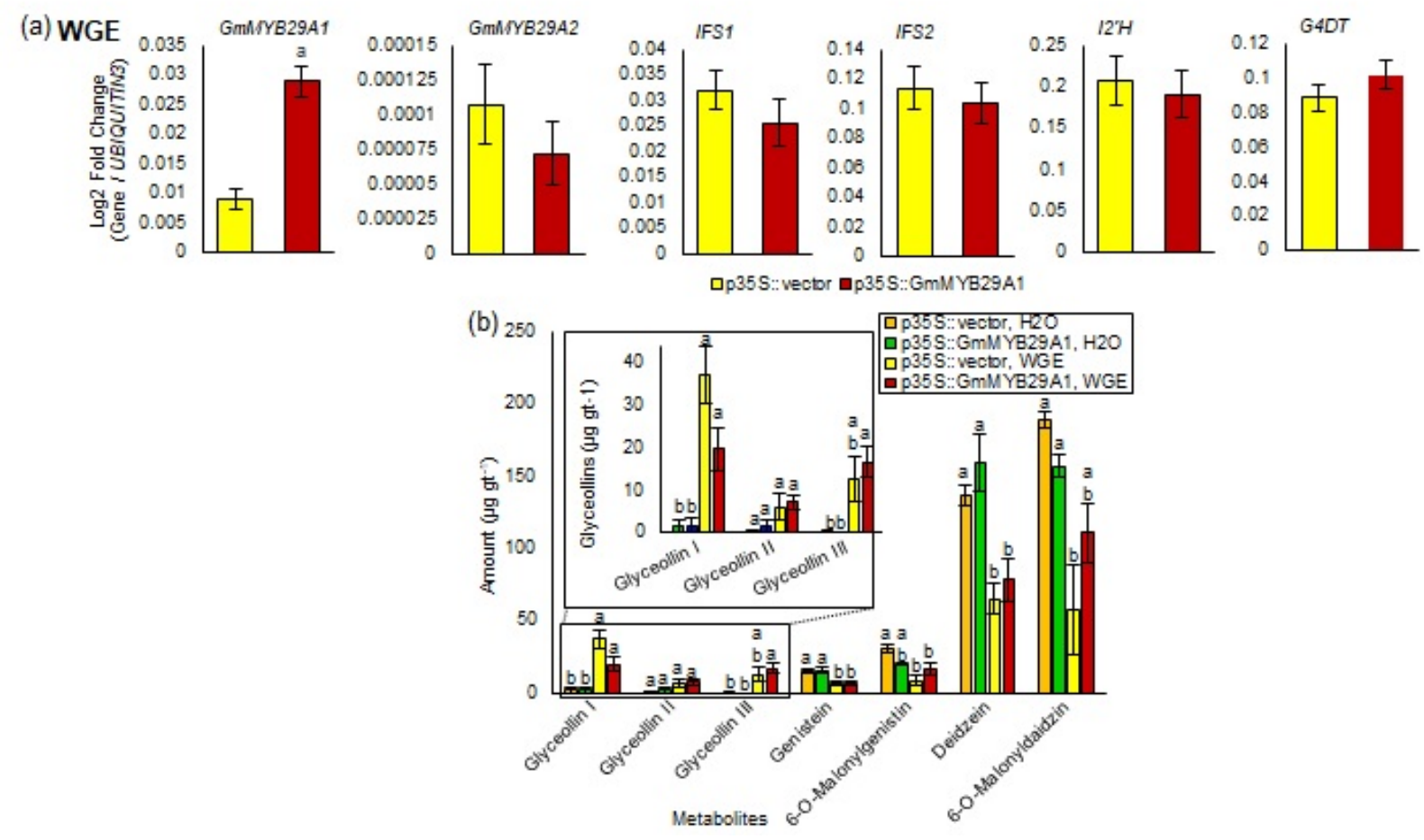

Figure S1. Overexpressing GmMYB29A1 in W82 hairy roots. (a) Gene expressions in W82 hairy roots overexpressing GmMYB29A2 by qRT-PCR $24 \mathrm{~h}$ after treatment with WGE or solvent. ${ }^{a}$ Significantly greater and ${ }^{\mathrm{b}}$ significantly less than control, paired students $t$-test $(P<$ $0.01, \mathrm{n}=4$ biological replicates). (b) Isoflavonoid amounts in W82 hairy roots $24 \mathrm{~h}$ after treatment with WGE measured by UPLC-PDA. Amounts were determined by comparison to concentration curves of purified or authentic standards. Different letters show significant differences by single factor ANOVA, Tukey post hoc test $(P<0.05, \alpha=0.05 . \mathrm{n}=5$ biological replicates). Representative results of three independent experiments are shown. 


\section{Tables}

Table 1 Glyceollin biosynthesis genes upregulated by WGE in H63 seeds and W82 hairy roots

\begin{tabular}{|c|c|c|c|c|c|c|}
\hline \multirow{2}{*}{$\begin{array}{l}\text { Gene } \\
\text { symbol }\end{array}$} & \multirow{2}{*}{ Enzyme } & \multirow{2}{*}{$\begin{array}{c}\text { Wm82.a2 } \\
\text { (Glyma 2.0) }\end{array}$} & \multicolumn{2}{|c|}{ H63 seeds } & \multicolumn{2}{|c|}{ W82 hairy roots } \\
\hline & & & $\begin{array}{c}\text { Log2 } \\
\text { FC }\end{array}$ & $P$-value & $\begin{array}{c}\text { Log2 } \\
\text { FC }\end{array}$ & $P$-value \\
\hline$P A L$ & $\begin{array}{l}\text { phenylalanine ammonia- } \\
\text { lyase }\end{array}$ & Glyma.03G181600 & 1.43 & 5.78E-05 & 1.44 & 1.10E-08 \\
\hline $\mathrm{C} 4 \mathrm{H}$ & $\begin{array}{l}\text { cinnamic acid 4- } \\
\text { hydroxylase }\end{array}$ & Glyma.20G114200 & 2.66 & $1.20 \mathrm{E}-07$ & 1.17 & 1.00E-22 \\
\hline $4 C L$ & $\begin{array}{c}\text { 4-coumarate: coenzyme A } \\
\text { ligase }\end{array}$ & Glyma.11G010500 & 1.38 & 2.76E-02 & 0.86 & 1.08E-08 \\
\hline $\mathrm{CHR}$ & chalcone reductase & Glyma.02G307300 & 1.56 & 3.05E-02 & 1.81 & $3.00 \mathrm{E}-23$ \\
\hline $\mathrm{CHI}$ & chalcone isomerase & Glyma.04G222400 & 0.81 & $1.45 \mathrm{E}-06$ & 0.32 & 1.99E-02 \\
\hline IFS1 & isoflavone synthase & Glyma.07G202300 & 3.78 & 7.06E-45 & 0.30 & 1.75E-03 \\
\hline IFS2 & isoflavone synthase & Glyma.13G173500 & 2.75 & $1.54 \mathrm{E}-22$ & 1.62 & $2.32 \mathrm{E}-25$ \\
\hline$H I D H$ & $\begin{array}{c}\text { 2-hydroxy-isoflavanone } \\
\text { dehydratase }\end{array}$ & Glyma.01G239600 & 1.44 & 1.89E-04 & 0.62 & 1.09E-05 \\
\hline $12^{\prime} H$ & isoflavone 2'-hydroxylase & Glyma.15G156100 & 1.67 & $2.16 \mathrm{E}-02$ & 2.31 & $1.31 \mathrm{E}-12$ \\
\hline \multirow[t]{2}{*}{ IFR } & isoflavone reductase & Glyma.01G211800 & 1.74 & 4.13E-03 & 2.49 & $2.83 \mathrm{E}-21$ \\
\hline & & Glyma.11G070200 & 1.78 & $6.42 \mathrm{E}-03$ & 1.80 & 1.18E-26 \\
\hline$P 6 \alpha H$ & $\begin{array}{c}\text { dihydroxypterocarpan- 6a- } \\
\text { hydroxylase }\end{array}$ & Glyma.19G144700 & 1.69 & $1.32 \mathrm{E}-04$ & 0.72 & 8.57E-05 \\
\hline G4DT & $\begin{array}{c}\text { glycinol 4-dimethylallyl- } \\
\text { transferase }\end{array}$ & Glyma.10G295300 & 1.78 & $1.29 \mathrm{E}-02$ & 2.51 & 2.29E-99 \\
\hline
\end{tabular}


Table 2. The most highly upregulated TF genes by $P$. sojae WGE in H63 germinating seeds and in W82 hairy roots

\begin{tabular}{|c|c|c|c|c|c|c|}
\hline Gene symbol & Gene family & $\begin{array}{l}\text { Wm82.a2 } \\
\text { (Glyma 2.0) }\end{array}$ & $\begin{array}{c}\text { log2 fold } \\
\text { change H63 } \\
\text { seeds }\end{array}$ & $\begin{array}{l}\text { p-value } \\
\text { H63 } \\
\text { seeds }\end{array}$ & $\begin{array}{c}\text { log2 fold } \\
\text { change W82 } \\
\text { hairy roots }\end{array}$ & $\begin{array}{l}\text { p-value } \\
\text { W82 hairy } \\
\text { roots }\end{array}$ \\
\hline GmERF15 & $\begin{array}{c}\text { ETHYLENE } \\
\text { RESPONSE } \\
\text { FACTOR }\end{array}$ & Glyma.11G036500 & 3.523 & $\begin{array}{l}2.18 \mathrm{E}- \\
10\end{array}$ & 0.648 & $4.91 \mathrm{E}-03$ \\
\hline GmMYB29A1 & $M Y B$ & Glyma.10G006600 & 3.329 & $\begin{array}{c}2.77 \mathrm{E}- \\
10\end{array}$ & 2.483 & $1.66 \mathrm{E}-17$ \\
\hline $\begin{array}{l}\text { GmCRF1- } \\
\text { like1 }\end{array}$ & $\begin{array}{c}\text { ETHYLENE } \\
\text { RESPONSE } \\
\text { FACTOR }\end{array}$ & Glyma.02G016100 & 3.260 & $\begin{array}{l}2.22 \mathrm{E}- \\
33\end{array}$ & 0.723 & $9.25 \mathrm{E}-05$ \\
\hline GmGBF1-like & $\begin{array}{c}\text { G-BOX } \\
\text { BINDING } \\
\text { FACTOR }\end{array}$ & Glyma.01G177400 & 3.178 & $\begin{array}{l}5.36 \mathrm{E}- \\
10\end{array}$ & 1.385 & 3.06E-05 \\
\hline GmHBP1b & $\begin{array}{c}\text { CAMP- } \\
\text { RESPONSE } \\
\text { FACTOR }\end{array}$ & Glyma.05G195200 & 3.163 & $\begin{array}{l}3.18 \mathrm{E}- \\
09\end{array}$ & 1.177 & $6.58 \mathrm{E}-03$ \\
\hline GmHSF2A & $\begin{array}{l}\text { HEAT SHOCK } \\
\text { FACTOR }\end{array}$ & Glyma.01G143500 & 2.891 & $\begin{array}{l}2.22 \mathrm{E}- \\
09\end{array}$ & 1.410 & $4.82 \mathrm{E}-08$ \\
\hline GmMYB29A2 & MYB & Glyma.02G005600 & 2.806 & $\begin{array}{c}6.43 \mathrm{E}- \\
07\end{array}$ & 0.873 & 5.27E-10 \\
\hline GmMYB363 & $M Y B$ & Glyma.01G224900 & 2.760 & $\begin{array}{l}3.20 \mathrm{E}- \\
09\end{array}$ & 3.008 & 1.67E-30 \\
\hline $\begin{array}{l}\text { GmCRF1- } \\
\text { like2 }\end{array}$ & $\begin{array}{c}\text { ETHYLENE } \\
\text { RESPONSE } \\
\text { FACTOR }\end{array}$ & Glyma.19G213100 & 2.701 & $\begin{array}{l}8.60 \mathrm{E}- \\
12\end{array}$ & 1.200 & $5.18 \mathrm{E}-04$ \\
\hline GmWRKY72 & WRKY & Glyma.17G097900 & 2.516 & $\begin{array}{l}5.13 \mathrm{E}- \\
07\end{array}$ & 0.389 & 5.86E-03 \\
\hline
\end{tabular}




\section{Supplemental Tables}

Table S4 - Protein accession numbers from Phytozome

\begin{tabular}{lcc}
\hline Species & Protein accession & Gene symbol \\
\hline Arabidopsis thaliana & AT1G14350 & AtMYB124 \\
Arabidopsis thaliana & AT5G60890 & AtMYB34 \\
Arabidopsis thaliana & AT2G36890 & AtRAX2/AtMYB38 \\
Arabidopsis thaliana & AT3G62610 & AtPFG2/AtMYB11 \\
Arabidopsis thaliana & AT2G47460 & AtPFG1/AtMYB12 \\
Arabidopsis thaliana & AT1G56650 & AtPAP1/AtMYB75 \\
Arabidopsis thaliana & AT5G67300 & AtMYBR1/AtMYB44 \\
Arabidopsis thaliana & AT3g60460 & AtDUO1/AtMYB125 \\
Arabidopsis thaliana & AT1G09770 & AtCDC5 \\
Arabidopsis thaliana & AT3G28470 & AtTDF1/AtMYB35 \\
Arabidopsis thaliana & AT5G49330 & AtPFG3/AtMYB111 \\
Arabidopsis thaliana & AT1G18570 & AtMYB51 \\
Arabidopsis thaliana & At1g74080 & AtMYB122 \\
Arabidopsis thaliana & AT2G25230 & AtMYB100 \\
Arabidopsis thaliana & AT4G37260 & AtMYB73 \\
Arabidopsis thaliana & AT2G32460 & AtMYB101 \\
Arabidopsis thaliana & AT1G48000 & AtMYB112 \\
Arabidopsis thaliana & AT1G57560 & AtMYB50 \\
Arabidopsis thaliana & AT5G35550 & AtMYB123 \\
Arabidopsis thaliana & AT2G31180 & AtMYB14 \\
Arabidopsis thaliana & AT3G23250 & AtMYB15 \\
Arabidopsis thaliana & AT5G10280 & AtMYB92 \\
Vitis vinifera & GSVIVT01028328001 & VVMYB14 \\
Vitis vinifera & GSVIVT01027811001 & VvMYB15 \\
Glycine max & Glyma.10G006600 & GmMYB29A1 \\
Glycine max & Glyma.02G005600 & GmMYB29A2 \\
Glycine max & Glyma.01G224900 & GmMYB363 \\
Glycine max & Glyma.20G209700 & GmMYB29 \\
Glycine max & Glyma.06g193600 & GmMYBJ3 \\
Glycine max & Glyma.05G032200 & GmMYB176 \\
\hline & &
\end{tabular}


Supplemental Table S5: Predicted MYB recognition elements.

\begin{tabular}{lcc}
\hline $\begin{array}{l}\text { Promoter } \\
\text { segment }\end{array}$ & Position $^{\text {a }}$ & Predicted MYB recognition elements \\
\hline G4DTpro1 & -82 & taaATATCt \\
& -109 & ggtTTAACatat, gaggttTAACAtata \\
& -153 & tatATATCt, aaaATATCtt \\
& -207 & taAATATCt, taaATATCta \\
& -256 & aaaATATCt, taATATCtc \\
G4DTpro2 & -577 & ttgGAATCata $^{\text {b }}$ \\
IFS2pro1 & +44 & aatGAATCta, caAGGGCa, caGATATtga, aatGAATCta \\
& -267 & aaAATATttg \\
IFS2pro2 & -479 & ttgGAATCtt \\
& -507 & aaAATATttg \\
& -578 & aatGAATCta, tagTAGGTgaa
\end{tabular}

${ }^{\text {aP }}$ osition relative to transcription start site.

${ }^{b}$ Element included in EMSA oliggonucleotide probe. 


\section{Chapter Six}

\section{DISCUSSION}

Phytoalexin biosynthesis can be elicited by the transcriptional activation of the biosynthetic genes involved in response to biotic and abiotic elicitors (Weisshaar et al., 1998, Zhao et al., 1998). Understanding the transcriptional regulation of the biosynthetic genes is important in the manipulation of plants for metabolic engineering to develop plants with expected characteristics. Extensive research has been done to provide further insight of genetic regulation of phytoalexin biosynthesis in different plant species. However, no conserved TFs have been identified and little is known about the transcriptional regulation of the elicitation of glyceollin phytoalexins biosynthesis in soybean.

In chapter 2, to address aim 1, we tested the hypothesis that elicitation mechanisms were different for biotic and chemical elicitors. We found that WGE elicited glyceollin I by inducing the accumulation of biosynthesis gene transcripts whereas, silver nitrate stimulated the hydrolysis of isoflavone conjugate, 6"-O-malonyldaidzin and inhibited the degradation of glyceollin I. These results strongly supported the hypothesis that biotic and chemical elicitors regulate the elicitation mechanisms by distinct mechanisms.

In chapter 3, to address aim 2, we hypothesized that "there is a TF, that will regulate phytoalexin biosynthesis in response to abiotic stress." We found that low $\mathrm{pH}$ medium elicited the highest accumulation of glyceollins and dehydration suppressed glyceollin biosynthesis. Using comparative transcriptomics approach to identify the TF candidates, we identified the NAC family transcription factor $G m N A C 42-1$ and by functional analysis we confirmed that GmNAC42-1 is a direct positive regulator of glyceollin biosynthesis. GmNAC42-1 is the soybean homolog of ANC042 from Arabidopsis. These results strongly support our hypothesis that the GmNAC42-1 TF is a conserved regulator of both glyceollins and camalexin in plants. This is the first identification of a conserved component for phytoalexin GRNs in plants.

In chapter 5, to address aim 3, we conducted a comparative transcriptomics approach of soybean seeds and hairy roots elicited with WGE. Overexpression and RNAi silencing of GmMYB29A2 in WGE-treated soybean hairy roots resulted in increased and reduced accumulation of glyceollins I metabolite with the biosynthesis gene transcripts indicating that GmMYB29A2 was responsible for regulating glyceollin biosynthesis in response to WGE. GmMYB29A2 is the 
soybean homolog of $V v M Y B 14$ that directly regulates STS (stilbene synthase) and stilbene phytoalexin biosynthesis in grapevine (Holl et al., 2013). Yeast one-hybrid (Y1H) and electrophoretic mobility assay (EMSA) results indicated that GmMYB29A2 could bind with promoter segments containing of G4DT and IFS2 glyceollin biosynthesis genes. The results strongly indicated that $G m M Y B 29 A 2$ and $V v M Y B 14$ are conserved regulators of different phytoalexin biosynthesis pathways in different plant species.

We also found that GmMYB29A2 provides Rspl-k-mediated resistance against race 1 P. sojae. We found that the overexpression of $G m M Y B 29 A 2$ enhance resistance in susceptible variety Williams and RNAi silencing broke-down resistance in the resistant variety Willilams 82 following infection with race $1 P$. sojae. Similar studies found that RNAi silencing of isoflavonoids gene IFS (isoflavone synthase) and CHR (chalcone reductase) led to breakdown race-specific resistance in soybean (Subramanian et al., 2005, Graham et al., 2007). However, overexpression of $G m M Y B 29 A 2$ in hairy roots increased the accumulation of glyceollins rather than daidzein indicating that glyceollins are conferring resistance $P$. sojae. A similar report showed that overexpression of glyceollins specific gene G4DT induce glyceollins accumulation and provide resistance against Rhyzoctonia solany in hairy roots (Zernova et al., 2014). Therefore, enhancing glyceollins accumulation in soybean plants by overexpressing their regulator GmMYB29A2 could be a useful to provide resistance to a wide range of pathogenic fungi. So, our results strongly agreed with the hypothesis that TF is involved in the regulation of glyceollins that could enhance resistance in soybean against $P$. sojae.

The overall findings opened a window for developing new approaches for economic bioproduction of glyceollins and enhance resistance in soybean. Overexpressing GmNAC42-1 in soybean could be a promising approach for economical bioproduction of glyceollins. Future research should be conducted to study the protein:protein interactions to determine how glyceollin TFs are interconnected. Also field trials are needed to determine the usefulness of GmMYB29A2 transgenic plants. We hypothesize that understanding the gene regulatory network that regulates glyceollin biosynthesis will help to engineer soybeans for economic bioproduction of glyceollins for medical research and to develop disease resistant crops. 


\section{References}

Graham T.L., Graham M.Y., Subramanian S., Yu O. (2007) RNAi silencing of genes for elicitation or biosynthesis of 5-deoxyisoflavonoids suppresses race-specific resistance and hypersensitive cell death in Phytophthora sojae infected tissues. Plant physiology, 144(2):728740.

Höll J., Vannozzi A., Czemmel S., D'Onofrio C., Walker A.R., Rausch T., Lucchin M., Boss P.K., Dry I.B., Bogs J. (2013) The R2R3-MYB transcription factors MYB14 and MYB15 regulate stilbene biosynthesis in Vitis vinifera. Plant Cell. 25(10):4135-49.

Subramanian S., Graham M.Y., Yu O., Graham T.L., (2005) RNA interference of soybean isoflavone synthase genes leads to silencing in tissues distal to the transformation site and to enhanced susceptibility to Phytophthora sojae. Plant Physiol, 137(4):1345-1353.

Weisshaar, B., and Jenkins, G. I. (1998) Phenylpropanoid biosynthesis and its regulation. Curr Opin Plant Biol 1, 251-257

Zernova O.V., Lygin A.V., Pawlowski M.L., Hill C.B., Hartman G.L., Widholm J.M., Lozovaya V.V., (2014) Regulation of plant immunity through modulation of phytoalexin synthesis. Molecules 19: 7480-7496

Zhao, J.M. et al. (1998) Induction of Arabidopsis tryptophan pathway enzymes and camalexin by amino acid starvation, oxidative stress, and an abiotic elicitor. Plant Cell 10, 359-370 